FORSCHUNGSERGEBNISSE DER WIRTSCHAFTSUNIVERSITÄT WIEN

Aida Numic

\title{
Multinational Teams in European and American Companies
}




\section{Aida Numic}

\section{Multinational Teams in European and American Companies}

Incorporating team context into research and practice concerning team effectiveness in multinational organizations still remains an ongoing challenge. This book aims at drawing the attention of researchers and practitioners towards the importance of various 'layers' of context on multinational teams and developing an empirically derived framework for multinational team functioning in business organisations. It shows how companies make use of these teams and how these teams contribute to competitive advantage. The study has been conducted in an Austrian, a German, and an American company. It reveals that if managed appropriately, these teams reduce the complexity of operations by facilitating the creation and transfer of explicit and tacit knowledge and by transferring appropriate dimensions of headquarter corporate culture between geographically dispersed business units.

Aida Numic is a lecturer at Brunel University in London and external lecturer at the Vienna University of Economics and Business Administration. She earned her PhD from the Vienna University of Economics and Business Administration in 2007. Her research focuses on cross-border mergers and acquisitions, multinational teams, knowledge transfer, and team learning. She published several articles in academic journals. 
Multinational Teams in European and American Companies 


\section{Forschungsergebnisse der Wirtschaftsuniversität Wien}

Band 26

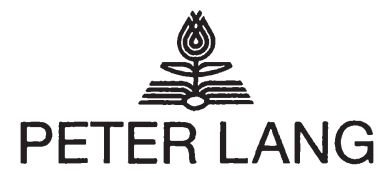

Frankfurt am Main · Berlin · Bern · Bruxelles · New York · Oxford · Wien 
Aida Numic

\section{Multinational Teams in European and American Companies}

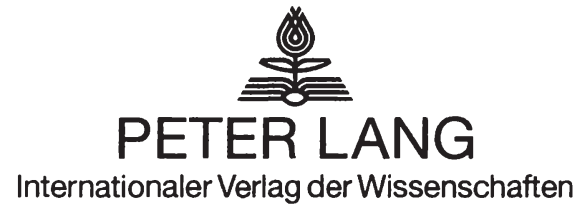

Aida Hajro - 978-3-631-75438-2

Downloaded from PubFactory at 01/11/2019 04:52:54AM

via free access 


\title{
Bibliographic Information published by the Deutsche Nationalbibliothek
}

The Deutsche Nationalbibliothek lists this publication in the Deutsche Nationalbibliografie; detailed bibliographic data is available in the internet at <http://www.d-nb.de>.

Open Access: The online version of this publication is published on www.peterlang.com and www.econstor.eu under the international Creative Commons License CC-BY 4.0. Learn more on how you can use and share this work: http://creativecommons. org/licenses/by/4.0.

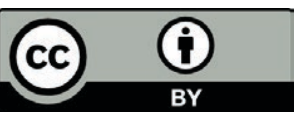

This book is available Open Access thanks to the kind support of ZBW - Leibniz-Informationszentrum Wirtschaft.

Cover design:

Atelier Platen according to a design of the advertising agency Publique.

University logo of the Vienna University of Economics and Business Administration.

Printed with kindly permission of the University.

Sponsored by the Vienna University of Economics and Busines Administration.

\author{
ISSN 1613-3056 \\ ISBN 978-3-631-57767-7 \\ ISBN 978-3-631-75438-2 (eBook) \\ (C) Peter Lang GmbH \\ Internationaler Verlag der Wissenschaften \\ Frankfurt am Main 2008 \\ All rights reserved.
}

All parts of this publication are protected by copyright. Any utilisation outside the strict limits of the copyright law, without the permission of the publisher, is forbidden and liable to prosecution. This applies in particular to reproductions, translations, microfilming, and storage and processing in electronic retrieval systems.

Printed in Germany 123457

www.peterlang.de 
Diese Arbeit ist meinen Eltern gewidmet, die mich immer bedingungslos auf meinem Lebensweg unterstützt haben.

Ohne ihr Verständnis, moralische Unterstützung und vor allem Liebe hätte ich diese Herausforderung ganz sicher nicht so gut gemeistert.

Bei meinem Vater möchte ich mich auch für die langen Diskussionen, die dieser Arbeit wesentliche Impulse gegen haben, bedanken.

Vielen Dank!

Mein besonderer Dank gilt Herrn Univ. Prof. Dr. Gerhard Fink für die großartige fachliche Betreuung und Unterstützung, das Wecken meiner Freude am wissenschaftlichen Arbeiten und die zahlreichen herausfordernden Diskussionen, die zum Gelingen dieser Arbeit wesentlich beigetragen haben. Durch ihn habe ich gelernt, was Wissenschaft eigentlich bedeutet und wie spannend es sein kann, wissenschaftlich $\mathrm{zu}$ arbeiten.

Vielen Dank!

Ich danke auch meinem Bruder Mirza für seine Unterstützung, sein Verständnis und vieles mehr. 
Aida Hajro - 978-3-631-75438-2

Downloaded from PubFactory at 01/11/2019 04:52:54AM

via free access 


\title{
Multinational Teams (MNTs) in European and American Companies
}

\begin{abstract}
Incorporating team context into research and practice concerning team effectiveness in multinational organizations still remains an ongoing challenge. The purpose of this dissertation is to explore the influence of industry, corporate culture, structure, strategy and task characteristics on MNTs in business organisations and to develop a more comprehensive framework connecting the internal dynamics with contextual aspects of MNTs functioning in companies in Europe and the USA. The study has been conducted in an Austrian (VA TECH), a German (Henkel) and an American company (K\&M International). Forty-two problem-centred interviews have been conducted with 22 team members and 20 team leaders. Levels of uncertainty, stress and turbulence influence organisations and MNTs since teams and organisations have to reshape their strategies. Multinational strategy has a positive impact on MNTs while companies with a global strategy assign low value to diversity. MNT norms in companies with a strong corporate culture are reflective of the organizational culture. MNTs at companies with a weak corporate culture develop their own unique cultures and deviate from the values and norms set by the organization. Team composition, size and length of cooperation have a moderating effect on MNTs. We could identify several team leader competences that contribute to team success. The results show how teams reduce the complexity of operations by facilitating the creation and transfer of explicit and tacit knowledge and by transferring appropriate dimensions of the HQ corporate culture between geographically dispersed business units.
\end{abstract}

\section{Abstract (German)}

Das Ziel dieser Arbeit bestand darin Einflussfaktoren auf multinationale Teamzusammenarbeit im organisatorischen Kontext zu erheben und ein Model, das den Zusammenhang dieser Variablen mit internen Teamprozessen in Verbindung setzt, zu entwickeln. Es wurden 42 problem-zentrierte Interviews mit Teammitgliedern und Teamführern in einem österreichischen (VA TECH), einem deutschen (Henkel) und einem amerikanischen Unternehmen (K\&M International) geführt. Die Branche, Unternehmenskultur, -strategie und -struktur sowie Art der Aufgabe haben als kontextuelle Faktoren einen starken Einfluss auf multinationale Teamzusammenarbeit. Der Grad an Unsicherheit, der Stressfaktor und die aktuelle Situation in der Brache beeinflussen das Unternehmen und die Teams, da diese auf solche Einflüsse reagieren, indem sie Strategien entwickeln und gezielt einsetzen. Multinationale Strategie hat einen positiven Einfluss auf multinationale 
Teams, währen Unternehmen mit einer globalen Strategie einen geringen Wert der Diversität ihrer Belegschaft beimessen. Teams in Unternehmen mit einer starken Organisationskultur übernehmen die Werte und Normen der Organisation. In Unternehmen, deren Organisationskultur schwach ausgeprägt ist, entwickeln sie ihre eigenen Werte und Normen und bilden Subsysteme innerhalb des Unternehmens. Teamzusammensetzung, die Größe und die Dauer der Kooperation haben ebenfalls einen Einfluss auf multinationale Teams. Diese Teams tragen auch zur Reduktion der Komplexität in großen Unternehmen bei. Sie entwickeln und transferieren neues, implizites Wissen vom HQ zu den Tochtergesellschaften und umgekehrt. Darüber hinaus tragen sie auch zur Bildung einer einheitlichen Organisationskultur bei. 


\section{Table of contents}

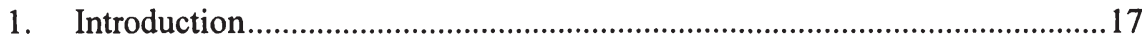

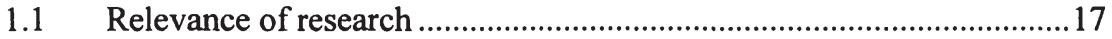

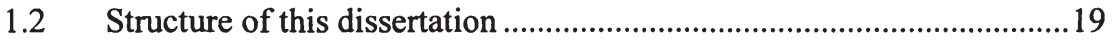

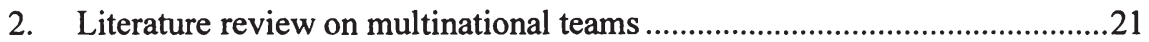

2.1 Contextual aspects: society as a set of contextual aspects.....................23

2.2 Contextual aspects: global industry context and its impact on teams....24

2.3 Contextual aspects: organisation as a set of contextual factors .............26

2.3.1 Organisation as a set of contextual factors: organisational

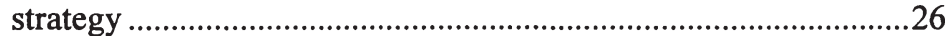

2.3.2 Organisation as a set of contextual factors: organisational

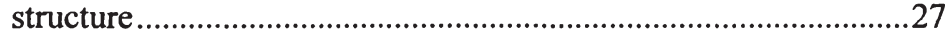

2.3.3 Organisation as a set of contextual factors: organisational culture ..27

2.3.4 Organisation as a set of contextual factors: social integration of culturally diverse employees........................................................29

2.3.5 Team task and its impact on multinational project teams ...............30

2.4 Multidimensional-diversity within a team.............................................33

2.4.1 Cultural dimensions and cultural standards of MNT members.........33

2.4.2 Personality traits of MNT members and their impact on team

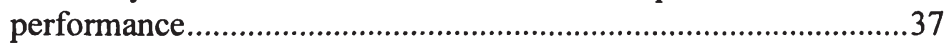

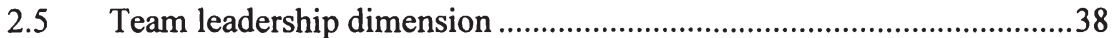

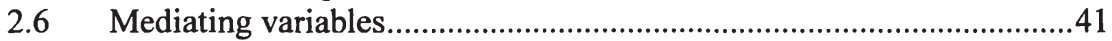

2.6.1 Team norms ..............................................................................42

2.6.2 Technology used by team members, MNT size and composition....43

$2.7 \quad$ Future research implications and research aim.....................................44

3. A purposeful approach to the interview and data analysis method in studying MNTs in European and American companies .................................47

3.1 Rationale for choosing a qualitative research design...........................47

3.2 Grounded theory in organizational research ........................................49

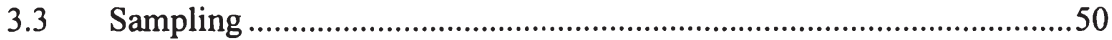

3.4 Method of data collection and data analysis ......................................56

3.4.1 Problem-centred interviews.............................................................56

3.4.2 Observations and other sources of data collection ...........................58

3.4.3 Qualitative content analysis........................................................59

3.4.4 Approach to the constant comparative method in the analysis of problem-centred interviews...........................................................60

4. Empirical findings from VA TECH...........................................................65

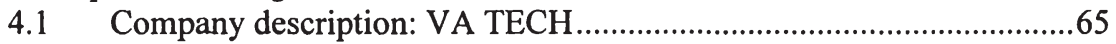

4.2 Major empirical findings from VA TECH ........................................66

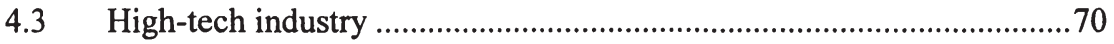

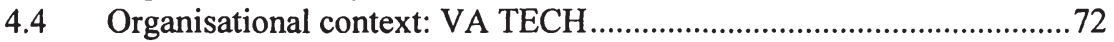




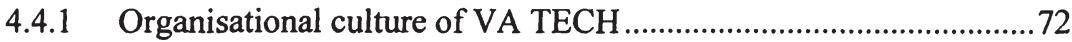

4.4.2 Organisational structure of VA TECH .............................................74

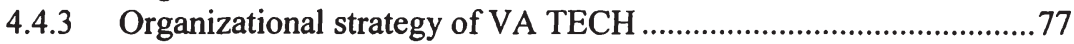

4.5 Team task and task interdependence ..................................................8 80

4.6 Multinational team composition and functioning at VA TECH............81

4.6.1 Team size and composition at VA TECH ......................................81

4.6.2 Different cultural standards of team members and their impact on MNT performance......................................................................82

4.6.3 Learning processes within the team and the effect of time on cultural standards of MNT members.............................................84

4.6.4 Degree of cultural diversity within MNTs and subgroup

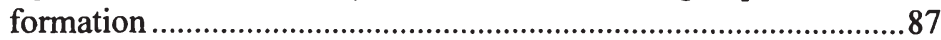

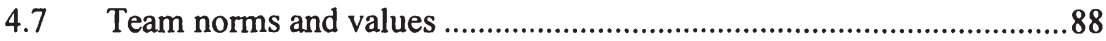

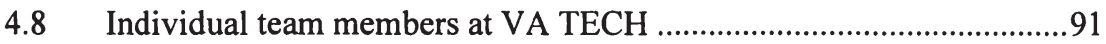

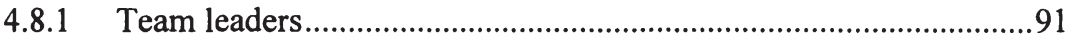

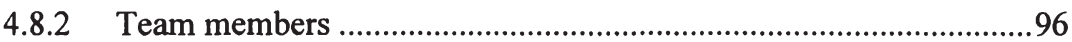

4.9 Summary of empirical findings from VA TECH ................................98

5. Empirical findings from Henkel Central Eastern Europe (CEE).................103

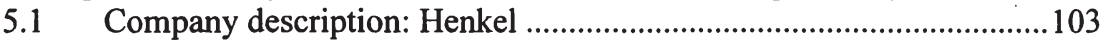

5.2 Major empirical findings from Henkel CEE......................................104

5.3 Organizational context: Henkel CEE...............................................110

5.3.1 Organisational culture of Henkel CEE and its impact on MNTs ...110

5.3.2 Organisational strategy of Henkel CEE........................................115

5.4 Multinational team composition and functioning at Henkel CEE .......116

5.4.1 Teams size, structure and composition at Henkel CEE..................116

5.4.2 Diversity within MNTs at Henkel CEE and cultural characteristics of team members from CEE

5.4.3 Learning processes within the team and the moderating effect of time on cultural standards of MNT members ..........................124

5.4.4 Transfer of knowledge between organisational units through

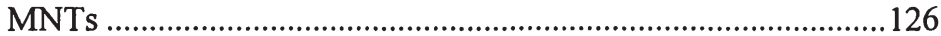

5.4.5 Transfer of the appropriate dimensions of the home organization's culture between organizational units through MNTs

5.5 Individual team members at Henkel CEE..........................................131

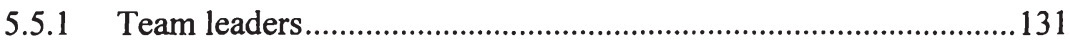

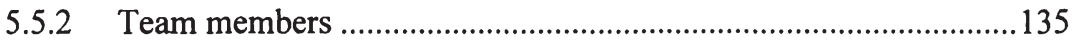

5.6 Summary of empirical findings from Henkel CEE ............................137

6. Empirical findings from K\&M International...............................................141

6.1 Company description: K\&M International ..........................................141

6.2 Major findings from K\&M International .......................................142

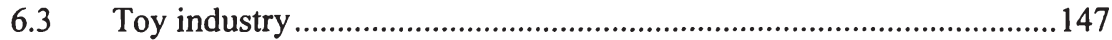

6.4 Organisational context: K\&M International ......................................148 
6.4.1 Organisational culture of K\&M International .................................148

6.4.2 Organisational strategy of K\&M International...............................155

6.5 Different team tasks and their impact on MNTs at K\&M

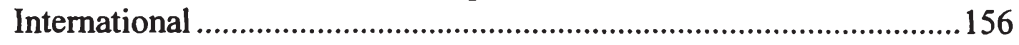

6.6 Multinational team composition and functioning at $\mathrm{K} \& \mathrm{M}$

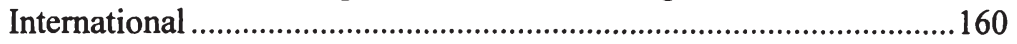

6.6.1 Team composition at K\&M International and occurrence of bilateral conflicts ........................................................................160

6.6.2 Team identification and subgroup formation ..............................175

6.6.3 Knowledge exploitation and exploration through MNTs...............178

6.7 Individual team members at K\&M International................................181

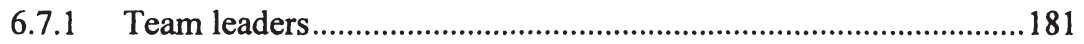

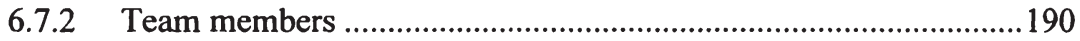

6.8 Summary of empirical findings from K\&M International...................192

7. Summary and the conceptual framework for MNTs in business

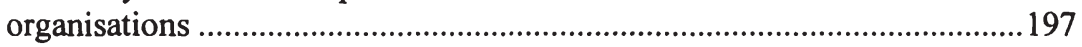

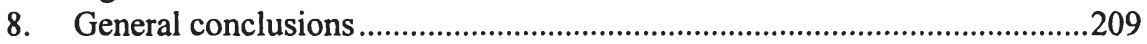

8.1 Discussion: limitations and future research implications ..................209

8.1.1 Limitations of this dissertation ....................................................209

8.1.2 Implications for future research...................................................210

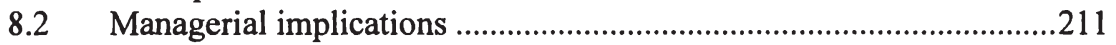

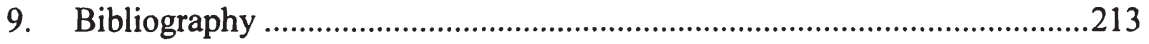


Aida Hajro - 978-3-631-75438-2

Downloaded from PubFactory at 01/11/2019 04:52:54AM

via free access 


\section{List of tables and figures}

Table 1: Research Design (Source: Author).......................................................... 48

Table 2: Demographic and statistical information of the interview partners (Source: Author).................................................................. 52

Table 3: Interview guide (Source: Author)...................................................... 57

Table 4: Ten year summary of VA TECH's financial performance from 1995 to 2004 (Source: VA TECH, 2007b)................................................ 65

Table 5: Categories and codes derived from the analysis of interviews conducted at. VATECH (Source: Author)..................................................66

Table 6: Major empirical findings from VA TECH (Source: Author).................. 69

Table 7: Team leader functions and characteristics at VA TECH (Source: Author)......................................................................................... 92

Table 8: Sales of Henkel CEE from 1996 to 2005 (Source: Henkel,

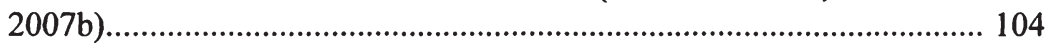

Table 9: Ten year summary of Henkel's financial performance from 1996

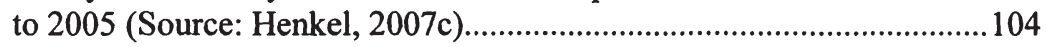

Table 10: Categories and codes derived from the analysis of interviews conducted at Henkel CEE (Source: Author).......................................... 105

Table 11: Major empirical findings from Henkel CEE (Source: Author)......... 107

Table 12: Corporate norms at Henkel (Source: Author).................................... 112

Table 13: MNT leader functions and characteristics at Henkel CEE

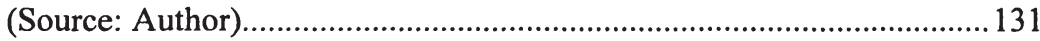

Table 14: Categories and codes derived from the analysis of interviews conducted at K\&M International (Source: Author)................................. 143

Table 15: Major empirical findings from K\&M International (Source: Author).

Table 16: Cultural dimensions of India and USA (Source: Hofstede and Bond, 1998)

Table 17: Scores for Societal Cultural Practices and Values Scales in India and the USA (Source: House et al., 2004)..............................................161

Table 18: MNT leader functions at K\&M International (Source: Author).......... 186

Table 19: Categories and sub-categories derived from data analysis

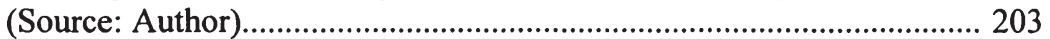

Figure 1: Conceptual framework for MNTs in business organisations (Source: Author) 
Aida Hajro - 978-3-631-75438-2

Downloaded from PubFactory at 01/11/2019 04:52:54AM

via free access 


\section{List of abbreviations}

CEE

Central and Eastern Europe: The term Central and Eastern Europe is taken here to also include Central Europe, Russia and the newly independent states (NIS) derived from the former Soviet Union.

D

Dimension

$\mathrm{HQ}$

Headquarter

HR

Human Resources

HRD

Human Resource Department

HRM

Human Resource Management

KNM

Knowledge Management

$\mathrm{MNC}$

Multinational Corporation

MNT

Multinational Team

MNTL

Multinational Team Leader

MNTM

Multinational Team Member

TN

Team Norm

USA

United States of America 
Aida Hajro - 978-3-631-75438-2

Downloaded from PubFactory at 01/11/2019 04:52:54AM

via free access 


\section{Introduction}

\subsection{Relevance of research}

Given the increasing complexity and intensity of work and increasing workforce diversity, MNT based work has been implemented within many organizations (Earley and Gibson, 2002). With the success of Japanese manufacturers, western organizations sought to identify keys to team success and strove to imitate these features in their own organizations. As a consequence, teamwork has been frequently adopted also in Western companies (Erez and Earley, 1993; Butler and Earley, 2001). Globalization has increased pressure on these teams by requiring them not only to perform at a high level, but also to do so simultaneously across geographically dispersed business units of the company. This trend suggests that an increased understanding of how best to make use of MNTs contributes to competitive advantage (Butler and Earley, 2001).

MNTs, though, only recently have been the subject of intensive empirical study (Jelinek and Wilson, 2005; Joshi and Lazarova, 2005; Earley and Gibson, 2002; Jackson et al., 2003; Mendez, 2003; Matveev and Nelson, 2004; Neyer, 2004; Canney Davison, 1995; Earley and Mosakowski, 2000; Gibson, 1999; Snow et al., 1996) and they still remain a relatively understudied field of research. Most of the MNT research has been carried out in a laboratory setting using students as subjects (Vallaster, 2005). Yet these settings do not account for the interplay between organizational and group context (Maznevski and Chudoba, 2000). To take proper advantage of MNTs requires a good understanding of the impact of environmental and organisational context on such groups. Gibson et al. (2003) argue that a more explicit consideration of team context is critical. The general context in which teams are embedded is very important.

Many hypotheses tested in studies of the relationships between contexts and teams concern unidirectional relationships between variables. This has led to a pattern of mixed results in studies of international diversity. Some studies have found its effects on performance positive by making it easier for teams to behave more cooperatively, to be more innovative and to derive higher quality solutions (Earley and Mosakowski, 2000; Elron, 1997; Ely and Thomas, 2001, Cox et al. 1991; O'Reilly et al., 1997; Kirchmeyer and Cohen, 1992). Others have found that international diversity is detrimental to performance in the long run, showing that homogeneous teams are more innovative and perform better (Watson et al., 1998; Watson et al., 1993) while MNTs are more likely to experience ineffective team processes that result in lower levels of team performance (Thomas, 1999). As common in most regression models, other variables not included in the study 
might have moderated the relationships discovered. International studies tend to be contextual and demand approaches that incorporate high levels of external validity. To ignore or to minimize external validity is to assume that theories apply irrespective of context, that is, that they apply under any political, economic, cultural, legal, or historical situation (Adler and Boyacigiller, 1991).

Incorporating team context into research and practice concerning team effectiveness in multinational organizations still remains an ongoing challenge (Gibson et al., 2003). Neyer (2004) has provided a useful framework for understanding the relevance of the complexity inherent in MNTs in bureaucratic organisations. In her study she has clarified the influence of various categories on MNT performance and their interrelations by conducting empirical research in the European Parliament and the European Commission. In addition, Jelinek and Wilson (2005) have identified the macro influences on MNTs and approached such teams from a multi-level perspective, focusing on global business culture, industry situation, and national political context as forces affecting MNTs. They have explained how these factors affect team functioning through the centripetal and centrifugal forces that they exert on individuals.

However, a more comprehensive framework connecting the internal dynamics with contextual aspects of MNTs' functioning in business organizations is still missing. Developing and testing the validity of such a framework would substantially aid in the extension of MNT research. Without such a framework, researchers will continue ignoring the fact that non-causal relationship between variables can be produced to be causal due to existence of other, unexplored variables.

Consequently, the aim of this dissertation is to develop a framework for MNT effectiveness in business organisations by showing the impact that industry and organisational context have on MNTs and the complex interplay between different sets of variables that influence team performance.

The study has been conducted at VA TECH, an Austrian multinational company that used to operate in the high-tech industry and is now part of Siemens; Henkel, one of the most internationally aligned of German consumer goods companies; and $\mathrm{K} \& \mathrm{M}$ International, the American world-leader in the production of nature related toys.

The main contribution of this dissertation is to explore the influence of industry, corporate culture, structure and strategy, and task characteristics on MNTs in business organisations and to develop a more comprehensive framework connecting the internal dynamics with contextual aspects of MNTs' functioning in 
companies operating in the high-tech and consumer good industries in Europe and the USA. The results show the impact of industry and organisational context on teams and the interplay between team members and leaders, team size, task and norms. The study contains many issues that can help managers to understand the value of MNTs and the factors that influence their performance in business organisations. In addition, it shows how MNTs reduce the complexity of operations by facilitating the creation and transfer of explicit and tacit knowledge and the transfer of appropriate dimensions of the home organisation's culture between geographically dispersed business units.

\subsection{Structure of this dissertation}

This dissertation is structured as follows: (I) After this introduction, this thesis will present the major findings of an extensive literature review on MNTs that shows how society as a set of contextual factors, industry and organisational culture, structure and strategy influence team performance. Team task is aspect of team context. We will explain how task characteristics impact MNTs. A brief review of exemplary work on how multinational companies utilize multinational project teams in order to bring together individuals from different countries to work on complex projects and to reduce the complexity inherent in big corporations will be included. The literature review continues with a description of the complexity inherent in MNTs. It also provides a review on the role of MNT leadership. One factor that enables effective functioning of MNTs is leadership. This section will also include a brief review of the current research related to leadership. Team norms have a strong moderating effect on team performance. The type of team norms identified in prior studies will be presented. (III) The rationale for choosing a qualitative research approach will be given and the method of data collection and analysis discussed in more detail. (IV-VI) Section four to six of this thesis will present the empirical findings from the three companies under study, VA TECH, Henkel and K\&M International. The three cases will be presented independently from each other. (VII) In section seven, we will summarize the major empirical findings and compare the categories resulting from the interviews conducted in different organisational settings. This section will also include the conceptual framework developed that connects the internal dynamics with external contextual aspects of MNT functioning in business organisations. (VIII) Finally, we will present general conclusions by focusing on limitations of this dissertation, implications for future research and managerial implications. 
Aida Hajro - 978-3-631-75438-2

Downloaded from PubFactory at 01/11/2019 04:52:54AM

via free access 


\section{Literature review on multinational teams}

The extant literature on MNTs suffers from a notable and major limitation. Most researchers have tended to focus almost exclusively on the internal dynamics of MNTs. They have overlooked the team embeddedness within a particular country, industry context and organizational culture.

Very little information has been provided about the context in which a study has been conducted. Lack of information about the context in which research has been conducted impedes our ability to understand the reasons for conflicting results found across studies (Jackson et al., 2003). Basic team information that should be relayed in order to understand the study results includes the type of company, team structure and composition, type of tasks performed, and the technology and equipment used. These details, which are essential for the development of an understanding of the team literature by providing a context for the study's results, are very often missing.

Many researchers moved into the field in order to administer questionnaires to anonymous respondents. Such research often entails sending packets of questionnaires to company representatives for distribution to respondents, who return them by mail. Consequently, MNTs were often studied without going near the organization and without talking to any of its members. Yet removing researchers from the context has costs in terms of the depth of understanding researchers can achieve.

MNT members are subject to numerous exogenous forces that profoundly affect how these teams' members relate, how they communicate, what their strengths and weaknesses are, and how they interact with other team members, tasks, and the larger organizations around them. Past research has usually tried to measure the impact of single independent variables on MNT performance. In his study, Thomas (1999), e.g., used collectivism as a single cultural dimension in order to determine group effectiveness. Yet MNTs are composed of individuals and the specific cultures represented in work groups influence group processes and outcomes. His findings show that individual's degree of collectivism and his or her relative difference from other group members has an effect on the functioning of work groups. But how can we measure the relative difference of one team member from the others? What if the preference for dependency and hierarchy of one individual from a high power distance and collectivist society limits his ability to complement group or participation-based decision making? 
Can power distance mediate the effect of group collectivism and negatively impact team functioning? These questions remain unanswered.

We can gain a deeper understanding of the factors that influence MNT members to perform effectively only if we keep in mind that organization members do not think, feel, or behave in isolation (Pfeffer, 1991). A person's location in the social context influences his/her contacts and experiences within the organization. We agree with Cappelli and Sherer (1991:97) who claim that "What is unique about behavior in organizations is presumably that being in the organization - the context of the organization - somehow shapes behavior, and it is impossible to explore that uniqueness without an explicit consideration of the context."

By participating in the organizations under study and interacting with employees, researchers may achieve a deeper understanding and explore new areas of inquiry. Consequently, progress in MNT research is unlikely if research is conducted in laboratory settings or through short visits to companies during which questionnaires are distributed to convenience samples. Instead, Adler and Boyacigiller (1991) advocate more qualitative and idiographic research that can only be accomplished when scholars invest considerable time within the cultural, organizational and societal context they wish to understand. We agree with Jelinek and Wilson (2005:210) who argue that MNT researchers "cannot afford to continue to ignore factors beyond the organizational level of analysis such as the effects of political or economic events or strategic conditions that are local, national, or international in scope, if they want to explain and predict the behavior of multicultural teams and their members".

Research on MNTs captures complex interactions of individuals from different cultures and it is a very formidable undertaking because variables of interest must often be monitored over lengthy periods. Longitudinal investigations are honored in theory, yet they are less often pursued in practice. In future, more longitudinal studies need to be done. They are difficult to do and time-consuming, but often the best way to assess causality. For example, a study conducted by Early and Mosakowski (2000) shows that time may change the effects of international diversity on MNTs. According to the results obtained, heterogeneity has a detrimental impact on team functioning at the beginning. This disadvantage is not a monotonically decreasing function; rather, the impact is consistent, with both split and heterogeneous teams inferior to a homogeneous team. Over time, how- 
ever, the impact of heterogeneity on team performance and other team outcome variables becomes curvilinear. After forming ways to interact and communicate, highly heterogeneous teams create a common identity. If this could be generalized, then outcome of research into MNTs would also be influenced by the time path.

In this chapter we will review the research on MNTs. The literature review starts with studies that explore the effect of societal and organizational context on MNT functioning. MNTs are the units of investigation in this study. Consequently, team task is aspect of team context. We will explain how task characteristics impact MNTs. The literature review continues with a description of the complexity inherent in MNTs. It also provides a review on the role of MNT leadership. Team norms, team size and technology may mediate MNT performance. These mediating variables and studies that incorporated them in their research design are also summarized in this chapter.

\subsection{Contextual aspects: society as a set of contextual aspects}

Context is where teams, departments and organizations live (Hackman, 1999) and it is inescapable - regardless of whether or not researchers pay attention to it (Jackson et al., 2003). Consequently, it is important to know the contextual factors when conducting research in field settings. Examples of societal factors include labour laws and a country's education system (Friel, 2005; Jackson et al., 2003).

Labour laws that engender the retention of employees and facilitate their integration into the decision-making process contribute to employment security and commitment of workers to a company. They also provide the best environment for the successful implementation of cross-functional work teams (Friel, 2005). In his study, Friel (2005) has found an explanation for the failure to implement crossfunctional work teams in the American facility of a German multinational. In Germany labour laws provide employment security and improve the commitment of workers. Consequently, fewer managers are required and the organisational structure is characterised by flat hierarchies. Power can be transferred to relatively autonomous teams of workers. This facilitates the successful implementation of cross-functional teams. The American facility has relied on temporary workers with low levels of skills. The county's labour laws do not engender the retention of employees. In addition, the fact that employers have to pay $50 \%$ of any unemployment compensation for all workers creates an incentive for the company to 
dismiss those employees with the highest level of skills. The introduction of cross-functional teams has failed.

In accordance with this, Adler (1986) claims that American employment practices are short-term. Managers who do not perform well during their first year are fired or, at best, not promoted. Companies do not give them ten years to demonstrate their worth, nor do new employees, especially new MBAs, give the organization a decade to recognize their contribution. By contrast, major Japanese companies use a more long-term, future-oriented time horizon. This creates trust and commitment of workers to a company and facilitates the implementation of autonomous teams that do their best for the success of the company.

The nature of the country's education system plays an important role as well. For a self-managed team to be successful it is important to have members who possess broad-based skills in order to perform a variety of managerial tasks. The impact of teams may be enormous. In a study conducted by Francesco and Gold (1998) selfmanaged teams have raised productivity by $30 \%$ and have substantially raised quality in organizations. In addition, their introduction changes how work is organized and eliminates managerial levels, thereby creating a flatter organization (Francesco and Gold, 1998). According to the results obtained from a study conducted by Kirkman and Shapiro (2001), the highest employee resistance to selfmanaged work teams has been observed in the USA, where many work team implementation initiatives end in failure. One reason may be the lack of relevant skills of team members. A survey by the National Association of Manufacturers (1998) indicates that manufacturers view the lack of skills among job applicants as one of the largest problems facing U.S. manufacturers today. The same phenomenon has been observed by Friel (2005) who describes the failure of the German multinational to implement a lean production program in its U.S. facility. Many workers have lacked the necessary skills to efficiently meet the requirements of the job. Consequently, levels of management could not be eliminated nor could such workers be empowered, since they don't possess basic literacy skills. The implementation initiatives of cross-functional teams in the American facility of the German multinational have not been successful.

\subsection{Contextual aspects: global industry context and its impact on teams}

Firms react to industry context in order to shape their strategies. Those strategies in turn clearly affect MNTs. The pressures of employer demands, resource scarcity and the levels of uncertainty and stress will differ in various industries. 
Strategy will necessary respond and this will impact MNTs (Jelinek and Wilson, 2005).

In their theoretical work Jelinek and Wilson (2005) describe the impact of automotive and airlines industry on organisations and teams. According to them beyond the auto-motive industry, global economics create many opportunities and demands for alliances, which often translate into strategies that entail MNTs. In the airline industry, these strategies include operating alliances. The Star Alliance was the first global airline alliance. Such alliances can be limited to sharing codes and coordinating flight timings and there may be little interaction. Or, they can extend to something much closer to a joint venture with joint product development and even sharing of aircrafts and crews in a single operating company. The closer the bonds between the organisations are the more extensive is the use of MNTs. These examples show how the stress of competitive pressures in the automotive and airlines industry forces companies to shape their strategies and consequently increase the use of MNTs. The more extensive is the multicultural teaming, thus more evident is the heterogeneity in cultural norms and expectations. Yet, if the stress of competitive pressures looms large it may exacerbate cognitive differences. It will have an impact on MNT members and their performance (Jelinek and Wilson, 2005). None of the studies reviewed has managed to empirically assess the impact of industry turbulence on MNTs.

According to Hofstede et al. (1990) organisational cultures reflect among many variables also industry and market. They are related to organization structure and control systems and have a strong impact on the type of organisational culture. We assume that through the corporate culture industry context also impacts MNTs.

Researchers studying MNTs have ignored factors beyond the usual individual and organizational levels of analysis. Many studies do not provide any information about the type of company, the type of industry or the situation in the particular industry at the time when data was collected. This prevents us from developing a clear understanding for study results. In future, there will be more MNTs. They will either arise from multicultural workforces within the same company or country or through global economic activities, e.g. cooperative alliances between companies. They represent an interesting object for research and in future studies must not ignore the impact of a particular industry on MNT functioning. 


\subsection{Contextual aspects: organisation as a set of contextual factors}

A big weakness of MNT studies is that researchers have often ignored the organisational context and its impact on team performance. According to Jackson et al. (2003), the context of an organization includes its competitive strategy, patterns of social integration (vs. segregation), organizational climate and culture, diversity history (e.g., exposure to discrimination lawsuits), and the presence of specific practices for managing diversity (e.g., affirmative action policies, diversity training programs). These factors may support MNT performance or in the worst case contradict, abandon, and undermine its functioning.

\subsubsection{Organisation as a set of contextual factors: organisational strategy}

The strategy of an organisation is one important factor. According to Richard's findings (2000), the relationship between cultural diversity and a firm's performance will be moderated by a business strategy. Consequently, higher cultural diversity will be positively related to firm performance when the firm pursues a growth strategy and negatively related to firm performance when the firm pursues a downsizing strategy. The results have shown that downsizing firms with high cultural diversity have the lowest productivity gains. Companies that are involved in expansion and focus more on 'business to consumer marketing' can benefit from market-related advantages obtained from cultural diversity. Diversity will bring cultural sensitivity that is very important if the company enters new markets and tries to reach different market segments (Cox, 1993). However, diversity can become a disturbing factor in simply structured organizations that focus on cost saving (Richard, 2000). One could assume that MNTs are more successful in companies with a growth and multidomestic strategy, while task forces are used for the solution of specific problems in firms with a downsizing and global strategy. This assumption creates an interesting and new avenue for future research. In addition, a socio-cognitive perspective suggests that team diversity will be more beneficial under conditions of greater strategic complexity, because diversity helps the team deal with the demands of greater complexity (see e.g. Jehn and Bezrukova, 2003, Richard, 2000; in Jackson et al., 2003). In contrast, the behavioural perspective suggests that team diversity will be more detrimental under conditions of greater strategic complexity, because diversity makes the necessary coordination among team members more difficult (e.g., see Carpenter, 2002; in Jackson et al., 2003). 


\subsubsection{Organisation as a set of contextual factors: organisational structure}

The consequences of diversity will also depend on the degree of structure present in an organization (Cox and Tung, 1997). Some research even suggests that an adaptive, technologically advanced, and non-hierarchical organization is more likely to succeed with MNTs than a highly structured, control-oriented organization (Apgar, 1998).

In the USA efficient management requires a division of labour and the use of employees according to their abilities. Consequently, inequality in power and status is inevitable in U.S. organizations and this fact has been accepted by the Americans to a higher degree than by other cultures. The national culture of the USA may be characterised by individualism, independence and free will. Yet, organizations in the USA are more structured than German companies. American companies usually find it difficult to switch to new, innovative organizational structures and therefore mainly remain at more conventional Fordist arrangements (Weinstein et al., 1995; in Friel, 2005). As already mentioned, the consequences of diversity will depend on the degree of organizational structure present in the company (Cox and Tung, 1997). Consequently, it will be interesting to explore if a more structured and control-oriented company will succeed with the implementation and management of MNTs.

None of the studies reviewed has explored the impact of matrix structure on MNT effectiveness. It still remains unanswered if and how the matrix structure and the repeated withdrawal of team members impact MNT functioning.

\subsubsection{Organisation as a set of contextual factors: organisational culture}

Culture at the national level and culture at the organizational level or corporate culture are two very different phenomena and the use of a common term for both is confusing (Meyer and De Wit, 2004). According to Hofstede et al. (1990) national culture consists of a set of orientations that arise from basic values developed early in life while organizational culture is based more on specific work practices that are acquired within the organization. In a study conducted in twenty units from ten different organisations in Denmark and the Netherlands in 1990 Hofstede and his team could identify six different dimensions (D) that characterise different organisational cultures: process-oriented vs. results-oriented (D1), employee-oriented vs. job-oriented (D2), parochial vs. professional (D3), opensystem vs. closed system (D4), loose vs. tight control (D5), normative vs. prag- 
matic (D6). D1 opposes a concern with means (process-oriented) to a concern with goals (results-oriented). D2 opposes a concern for people (employeeoriented) to a concern for getting the job done (job-oriented). D3 opposes units whose employees derive their identity largely from the organisation (parochial) to units in which people identify with their type of job (professional). D4 opposes open systems to closed systems. It describes the communication climate, a focus of attention for both human resources and public relations experts. D5 refers to the amount of internal structuring in the organisation. A tight control system may be associated with strict codes in terms of dress and dignified behaviour. D6 deals with the popular notion of customer orientation. Pragmatic units are marketdriven while normative units perceive their task toward the outside world as the implementation of inviolable rules. These six dimensions can be seen as a checklist for practical culture differences between organisations. There is no "one best corporate culture type". Hofstede et al. (1990) claim that what is good or bad depends in each case on where one wants the organisation to go. None of the studies on MNTs has tried to assess the impact of these dimensions of corporate cultures on MNT performance. This could be an interesting avenue or future research.

Several authors have argued that organizational cultures shape diversity dynamics (Jackson et al., 2003). Many American companies have strong, well-developed corporate cultures. The term strong culture implies that most managers and employees share a set of values and methods of doing business (Francesco and Gold, 1998). Collins and Porras (1994) claim that strong cultures are an important characteristic of organizations with outstanding performance records since they 'permit a standardized response that minimizes complexity, thereby holding the promise of efficient administration and common mindset' (Bergley and Boyd, 2003; p. 357) an observation, which may be valid for U.S. firms but not necessarily for European or Asian firms. Unfortunately, none research has been done in order to explore the relationship between strength of corporate culture and its influence on MNTs.

Corporate culture has an impact on the implementation process of MNTs which sets the stage for the creation of team norms. These team norms regulate communication and decision-making procedures in a team and they have a strong influence on team performance (Fink et al., 2004). Today, many teams are almost entirely self-managing. These teams often have the authority to determine their work strategies and manage their internal processes. Given such freedom, teams have more opportunity to develop their own unique cultures, which have the potential to reinforce the overall firm culture, but also to deviate from the values and norms set by the organization, ultimately influencing the organizational culture (Mannix et al., 2001). To what extent MNTs serve as catalysts for organizational change and how far these teams can help transfer the appropriate dimensions of the home organisation's culture between geographically dispersed busi- 
ness units in multinational companies creating a strong, unified corporate culture still remains an interesting area for future research. A key research question also remains how such teams may facilitate the knowledge transfer across geographic and organisational boundaries (Gibson et al., 2003).

\subsubsection{Organisation as a set of contextual factors: social integration of culturally diverse employees}

The context of an organization also includes the patterns of social integration of culturally diverse employees. The consequences of diversity depend on the degree of informal integration (e.g. the inclusion of minority-culture members in activities outside normal working hours and in informal networks) (Cox and Tung, 1997) and on specific practices for managing diversity present in the organization (Jackson et al., 2003). The organizational capability for effective integration of culturally diverse employees will impact the emergence and development of shared team norms in MNTs. Many companies in the United States have found it necessary to use diversity programs in order to develop initiatives to promote mutual understanding and cooperation among employees (Francesco and Gold, 1998). However, it usually happens that instead of integrating culturally diverse people these companies try to impose their own values (Begley and Boyd, 2003). They tend to accept diversity nominally, but not organizationally. American companies do not provide much room for people unwilling or unsuited to their demanding standards. Employees have to adapt and accept a company's values and norms (Collins and Porras, 1994). None of the studies reviewed has investigated the question if companies that tend to accept diversity nominally but not organizationally face a higher employee resistance in MNTs than companies that successfully integrate culturally diverse people. These companies may enable team members to influence and develop their own norms of communication and decision making.

Given this increased need for focus on organization and cultural context, in future MNTs must not be regarded as socially isolated entities. Both internal and external processes have important implications for MNTs. Organisational strategy, culture, structure and the patterns of social integration of culturally diverse employees across geographically dispersed national facilities of the multinational company are important aspects of external team context. 


\subsubsection{Team task and its impact on multinational project teams}

Some aspects of context describe the larger social system, e.g. the organization under investigation within which the MNT is embedded. Other aspects of context may describe the unit under investigation, e.g. the team. If teams are the unit, team task will be aspect of context. The type of task to be accomplished by a MNT does matter. It determines the type of team and different types of teams shape different strategies. These strategies influence internal team processes.

According to Turner et al. (1994), situational features have a powerful impact on the salience of interpersonal differences and on an individual team member's behaviour. These views imply that individual team members may differ in their reactions depending on how they perceive their work context. For team members working under congruent conditions of low task and low goal interdependence, little interaction is required. They pursue their personal interests with low potential for conflict (Saavedra et al., 1993). A different picture may emerge when individual team members work under incongruent conditions of low task interdependence and high goal interdependence. Van Der Vegt et al. (2003) have conducted a study in order to examine how the educational and functional dissimilarity of multidisciplinary team members is related to team identification and how task and goal moderate these relations. Questionnaire data have been collected from 129 members of 20 multidisciplinary teams who work in a telecommunications company in the Netherlands. The results reveal that congruent task and goal interdependence create a positive climate in which dissimilar team members not only identify with their team, and behave in a loyal and cooperative way, but are also stimulated to explore and exchange their different perspectives and opinion and to manifest creativity and innovative behaviour. Task interdependence is defined as the extent to which an individual team member needs information, materials, and support from other team members to be able to carry out his or her job (Brass, 1981; Van der Vegt et al., 2001; in Van der Vegt et al., 2003). Goal interdependence is defined as the degree to which group members believe that they are assigned group goals or provided with group feedback (e.g., Saavedra et al., 1993; in Van der Vegt et al., 2003). Cohen and Bailey (1997) distinguish individual work settings from team settings by the increased interaction facilitated in interdependent conditions. Interdependence, whether based on task inputs and processes or on shared goals and rewards, establishes connections and increases the need for cooperation between team members (Saavedra et al., 1993; Thompson, 1967). Members must interact to diagnose, analyze, and complete a task. The task interdependence requires and results in more cooperative behaviour and information sharing than does individual-based work (see Campion et al., 1993; Campion et al., 1996; Janz et al., 1997). Strong ties between members 
should therefore develop in interdependent work environments (Kozlowski and Klein, 2000). This cohesion may facilitate the exchange of information among team members by providing the opportunity for all members to discuss organizational policies and practices and to jointly interpret the team's experiences (Roberson and Colquitt, 2005). The type of task will have an impact on individual team member performance as well. According to Schweiger et al. (2003), people are more motivated to work when a project offers them the opportunity to learn and develop new skills, to be associated with high priority and visible international projects, and to expand their personal networks. It appears that people are focused on developmental opportunities rather than on short term payoffs (Schweiger et al., 2003). The generally accepted assumption is that the potential benefits of diversity for performance are greater when the task requires creativity and innovation. When the task is routine, or when speed is the goal, diversity may interfere with performance (e.g., see Jackson, 1992a, 1992b; Williams and O'Reilly, 1998; Jackson et al., 2003). The importance of task characteristic as a moderator of diversity effects in MNTs still remains unexplored. More research is needed to resolve the question of whether the effects of diversity differ for different types of tasks. According to Thomas (1999), additional research on the influence of cultural diversity on intellective tasks is required.

By distinguishing among types of teams, the review clearly indicates that the variables that are studied and the findings that are captured vary for different types of teams. Consequently, task and type of team matter for the determinants of effectiveness. In the following, we will provide a short literature review on one innovative type of team, the multinational project team since its role has increasingly become an important organizational mechanism for facilitating cooperation in multinational organizations (Schweiger et al., 2003). It shows how task impacts team processes and why certain tasks can only be accomplished by multinational project teams. The functioning of this type of team has also been explored in section 4 of this dissertation.

The literature review shows that despite the fact that there is growing awareness of the importance of multinational project teams, there has been little theory and research that has explicitly addressed them. Little is known about how they effectively function. Goodall and Roberts (2003) draw on two case studies of multinational project teams to analyse the use of local staff versus expatriates to help mitigate what has been called the 'liability of foreignness'. This is a set of costs associated with unfamiliar operating environments, economic, administrative and cultural differences, and with the challenges of coordination over geographic distance. Both teams are operating in highly uncertain environments. Such contexts 
are interesting since they affect MNT performance. The results show that the value of the local knowledge of local staff is not utilized due to a highly socialized network of expatriates who work together and make it difficult for locals to penetrate their network. Schweiger et al. (2003) explores the impact that context has on transnational project teams, how such teams function and the role that leadership plays in their effectiveness. According to their findings, the senior management represents a key ingredient in the effective functioning of transnational project teams by creating an instrumental environment where horizontal cooperation and teamwork are either encouraged or not. The team leader may have a significant influence on team effectiveness and it is important that he is able to secure the cooperation and resources needed to accomplish the projects. The paper presents a practical set of observations and it shows the impact of different contextual factors on transnational project teams. Mendez (2003) examines how global R\&D activities are managed through the use of project teams. She identifies the factors that lead to the particular project management design and discusses important organizational contextual factors that shape the project. Lagerstroem and Andersson (2003) provide managers with information how to manage and organize multinational project teams to support creation and sharing of knowledge. In order to study how knowledge is created and shared in multinational companies through the use of multinational project teams, a case study approach is chosen, as is appropriate when explorative questions are asked and when a contemporary phenomenon is in focus (Yin, 1993). This study shows how by means of this type of teams, local knowledge of business units can be leveraged to a global level for the development of common global business solutions in the multinational corporation. Lunnan and Barth (2003) explore the dilemma between exploitation and exploration in dispersed teams, i.e., teams in a firm working closely with an external partner. They aim at exploring what type of learning is generated in these teams and to what extent this learning is captured by the team. They present four cases from two firms. They argue that teams that are located at different locations and involving many nationalities have a higher exposure to a variety of rich knowledge, but that the process of integrating this learning into the firm is more difficult.

Only recently multinational project teams have become the subject of intensive empirical study. Yet researchers have only touched on the topic of multinational project teams and there are still many questions that remain concerning context, functioning, leadership, and more importantly their effectiveness. 


\subsection{Multidimensional-diversity within a team}

MNTs are a very complex phenomenon, since there are various effects and influences observed in them. It is very challenging to identify the various principles that drive these teams. There are many reasons and motives for why they operate as they do. They are too complex to be reduced to single explanations, as this has usually be done by many researchers in previous studies.

Factors that exist within MNTs must be attended to by managers who hope to manage effectively these teams. Individual team members act "as carriers of exogeneous factors into the team through individuals' sense perceptions, cognitive filters, interpretations, assumptions, and beliefs; the team's shared perceptions, interpretations, interactions and, ultimately, its performance, are all affected" (Jelinek and Wilson, 2005: 211).

\subsubsection{Cultural dimensions and cultural standards of MNT members}

We distinguish between 'cultural dimensions' and 'cultural standards'. 'Cultural dimensions' are the characteristics of national cultures and they measure values. That is "a conception, distinctive of an individual.... of the desirable which influences the selection from available modes, means and ends of action" (Kluckhohn, 1951: 395; in Fink et al., 2006). Whereas by 'cultural standards' we understand "all kinds of perceiving, thinking, judging, and acting that in a given culture by the vast majority of individuals are considered for themselves and others as normal, self-evident, typical and obligatory" (Thomas, 1993: 381, translation by Fink et al., 2004: 17). Different cultural standards of individual team members will influence what patterns of behaviour and what group and individual outcomes will be desirable (Thomas, 1999). Team members from different countries act as 'carriers' of exogenous factors into the team (Jelinek and Wilson, 2005). They have different cultural standards. They are based on the values in their national culture and on traditional modes and rules of behaviour that comply with these values (Fink et al., 2004). The socio-cultural context influences the functioning of MNTs and the existence of this variable must be taken seriously when studying MNTs (Schoonhoven and Woolley, 2005).

Cross-cultural social scientists have been mapping culture for many decades. They have researched the cultural values that most influence important international practices and they have given estimates about the social distance between two cultures. The most frequently encountered study that provides this sort of information is Hofstede's analysis of 53 nations and regions based on a survey done with IBM. The survey relies on questions about work goals and preferences 
for how work should be organized. He studied the data on four dimensions: individualism versus collectivism, power distance, uncertainty avoidance, and masculinity/femininity (Hofstede, 2001). Trompenaars and Hampden-Turner (1998) have developed a taxonomy of cultural values that has been used extensively in management consulting and training. They discuss a series of dimensions for which they found cross-country differences based on a survey distributed to 15,000 employees from a variety of industries in over fifty countries and describe five dimensions: universalism/particularism, individualism/ communitarianism, achievement/ascription, neutral/emotional, and specific/diffuse. Most of these dimensions stress distinctive aspects of individualism and collectivism. The most recent cultural values project is Project GLOBE (Gupta et al., 2002). This project is based on a value survey of over sixty nations and identifies nine societal values: performance versus human orientation, group and family collectivism, institutional collectivism, power distance, gender egalitarianism, assertiveness, future orientation and uncertainty avoidance. The project also provides evidence for ten clusters of countries that are similar in their value orientation. It has the benefit of providing managers with scores on specific value dimensions for a large number of nations. These scores can be used for preliminary business planning and they can help team leaders anticipate what to expect from members from a particular country. Many studies on MNTs have assessed only one cultural dimension and have failed to capture the full spectrum of diversity found in MNTs. For example, $43 \%$ of the studies reviewed by Jackson et al. (2003) focus on one diversity attribute only. Very few studies (less than 5\%) address the question of whether the effect of a particular dimension of diversity depends on the present or absence of other dimensions of diversity. MNT researchers have not yet succeeded in tackling the challenge of empirically assessing multi-dimensional diversity in teams. In the following section, we would like to give several examples of studies on MNTs that focus on few diversity attributes.

For example, Thomas (1999) studies 24 MNTs using collectivism as the only cultural dimension. His findings show that culturally homogeneous groups perform better than heterogeneous groups across all five cases and that on individual's degree of collectivism and his or her relative difference from other group members has an effect on the functioning of work groups.

Kirkman et al. (2001) aim at giving guidance as to how to maximize the success of self-managing work teams in a variety of distinct cultures. The exploratory variables used in this study are Individualism/Collectivism, Power Distance, Doing versus Being Orientation, and Determinism versus Free Will. It is found that employee acceptance of teams and self-management is related to deeply held cultural values. Employees who are high in collectivism more readily accept the team aspect of self-management work teams (SMWTs) than do employees who are more individualistic. Employees who are low in power distance, more doing- 
oriented, and less deterministic accept the self-management aspect of SMWTs more than do employees who hold opposite values. The highest employee resistance is observed in the USA where many work team implementation initiatives end in failure. The authors claim that the major limitation of this study is the fact that other variables probably influencing the implementation and effectiveness of work teams in the USA are not exploited.

The study conducted by Gomez et al. (2000), using Mexican and U.S. samples, shows that when a team member is perceived to be an in-group rather than an outgroup member, collectivists evaluate that member significantly more generously than do individualists. Further, collectivists value maintenance contributions more and individualists value task contribution more than collectivists do. Again, the study focuses on one diversity attribute only. Country differences other than collectivism, such as masculinity/femininity and societal preferences for assertiveness versus nurturing, are proposed as important to research in future studies on MNTs.

The findings of a study by Earley and Mosakowski (2000) show that most effective teams are either highly heterogeneous or highly homogeneous and that performance of heterogeneous teams improves over time, but that of the homogeneous or moderately heterogeneous teams stays relatively constant. The major limitation of this study is again that the approach does not fully capture the richness of nationality and the cultural distance among the nations represented.

Gibson and Zellmer-Bruhn (2001) found that people around the globe hold different definitions of teamwork. The variance turns out to be systematic across nations and organisations. However, the research has been conducted in only four countries and a limited number of exploratory variables has been used.

The main goal of a study by Kirkman and Shapiro (2001) is to prove that cultural values create resistance to management initiatives such as self-managing work teams that, in turn, leads to negative organizational outcomes and to provide a theoretical explanation for why cultural values are related to satisfaction and commitment. They find that a tendency for higher levels of collectivism is associated with greater organizational commitment and that a tendency for lower levels of power distance is associated with higher levels of organizational commitment. Although they find that cultural values do influence employee resistance to self-managing work teams, the resistance to the self-management-related and team-related aspects of such teams differs by country. Ironically, the influence of cultural values on employees' teams-related resistance is apparently greater for employees in the United States than for those in Finland or the Philippines. They claim that future research should continue to examine the role of other potential mediators affecting the relationships between cultural values and employee work 
attitudes. Such research promises to capture more fully why cultural values affect job satisfaction and organizational commitment worldwide.

Schlegelmilch and Ambos (2004) analyse the influence of cultural distance on teams. A distance measure between the home country's cultural profile and that of the host culture is used. According to their findings, the possibility that cultural distance is more related to team performance as opposed to team formation has to be more seriously considered. A more complex and in-depth study design is needed to fully capture the role cultural diversity plays before team conclusions can be drawn.

Kirkman and Shapiro (2005) illuminate and test a theory regarding how both cultural as well as demographic diversity influence the performance of MNTs. They examine how diversity of four cultural values (collectivism, power distance, doing orientation and cooperation orientation) affect MNT performance. The findings lead the researchers to make three conclusions. First, relative to demographic diversity in MNTs, cultural value diversity explains significantly greater variance in MNT performance with regard to the team's cooperation and productivity as rated by members and leaders. Second, relative to the mean level of cultural values in MNTs, cultural value diversity explains significantly greater variance in MNT performance with regard to all MNT performance outcomes. Third, the strength and direction of cultural value diversity effects in MNTs depend on which country and which type of team-outcome is under study. The findings suggest that team researchers interested in "diversity effects" ought to broaden their conceptualization of "team diversity" to include cultural values. They ought to broaden the cultural values they study in country-comparison research, so that they include more than "collectivism" and "power distance". This is rarely done in cross-cultural research. Team researchers must broaden their conceptualization of "team outcomes" to include several, such as the many performance outcomes examined in their study.

These examples show that MNT researchers so far have not succeeded in tackling the challenge of empirically assessing multi-dimensional diversity in teams. We agree with Schlegelmilch and Ambos (2004) that a more in-depth study design is needed to fully capture the role cultural diversity plays before MNT conclusions can be drawn. It is obvious that numerous forces and contextual aspects will impact MNT performance. The literature review shows that different cultural values and practices of team members have a strong influence on MNT performance. 


\subsubsection{Personality traits of MNT members and their impact on team performance}

According to Caligiuri (2000: 71) "personality characteristics predispose humans to behave in certain ways, given particular situations, to accomplish goals and so forth." Psychologists have long used the idea of personality to talk about the more stable internal characteristics that distinguish one individual from another (Allport, 1937). They have identified hundreds of personality traits. In order to introduce some order, researchers have recently sorted through this complexity and identified five major personality factors known as the "Big Fives". They are: extroversion, agreeableness, conscientiousness, neuroticism, and openness to experience (McCrae and Costa, 1997).

Extroversion reflects an individual's comfort level with new relationships. Extroverts tend to be sociable, talkative, assertive, aggressive and active. In contrast, introverts are more shy and reversed, and prefer to work alone. Agreeableness refers to an individual's ability to deal with others. High agreeableness refers to the degree to which someone is trusting, good-natured, compliant, modest, gentle, and cooperative. People with low levels of agreeableness tend to act aggressively and competitively and are inflexible towards others. They might not be the perfect team players. Conscientiousness refers to the series of goals aims at. Individuals high in conscientiousness focus on a small number of goals at one time. They tend to be careful, organized and responsible. Neuroticism refers to a person's level of emotional stability. Individuals with high levels of neuroticism tend to be anxious, depressed, angry, and insecure, while those low in neuroticism tend to be calm, poised, secure, and emotionally stable. Openness to experience is likely to be related to openness to new cultures. Individuals with high levels of this are likely to be interested in learning and gaining professional knowledge and tend to adjust well to new tasks and requirements. They may contribute to MNT effectiveness more then individuals with low levels of openness.

Some findings of this field have already served as an input to team research: Beerma et al. (2003; in Fink et al., 2004a) use the 'Big Five'. They find that independently 'agreeableness' and 'extroversion' have no direct positive effect on team performance. However, in combination with cooperative reward structures a positive influence on both variables on performance is found. Neumann et al. (1999 in Fink et al., 2004a) investigate the effectiveness of different strategies for using the 'Big Five' to select members for work teams. They find that high levels of agreeableness, consciousness and openness to experience are valid predictors of team performance. 
Hofstede and McCrae (2004: 57) reanalyse the data from the Five-Factor Model of personality and the IBM study dimensions of culture. Mean personality scores from 33 countries are significantly correlated with culture dimension scores. Hofstede relates dimensions of culture to personality factors. He claims that trait levels are completely determined by cultural influences. Yet, according to McCrae cultural values are merely a reflection of personality. They shape the expression of traits but not their level. McCrae illustrates this by providing the following example: Higher neuroticism and lower agreeableness predict higher uncertainty avoidance. Each new discussion is a potential source of distressing conflict. Such people may find that they coexist only if they adopt a rigid set of rules and screen out new situations that would require new decisions. They would develop the values and institutions that typify high uncertainty avoidance countries. This publication illustrates that the study of personality and culture is no longer a matter of documenting how culture shapes personality. It asks how personality traits and culture interact to shape the behaviour of individuals and social groups. Consequently, it is not enough to assess the cultural distance between team members and to correlate it with MNT effectiveness. We must be aware of personality traits of individual team members in order to understand their impact on team performance.

\subsection{Team leadership dimension}

The literature review suggests that only few team performance models have specified leadership as central driver of team processes (e.g., Hirokawa, 1980; McGrath, 1991; Zaccaro et al., 2001; Fink et al., 2004). Researchers have endeavoured to understand the factors that enable the effective functioning of MNTs but with few exceptions (e.g., Joshi and Lazarova, 2005) they have ignored to explore the competences that team leaders must possess in order to effectively lead such MNTs. The literature on leadership in MNTs is still in the early stage of development. The research is theoretical, anecdotal, or based on domestic samples (Kirkman et al., 2004; Yoo and Alavi, 2004; in Joshi and Lazarova, 2005). In addition, it is limited in scope and characterised by many inconsistencies. The literature on MNTs focuses primarily on team processes and ignores the role of leadership. Many studies rely on student samples to understand factors predicting MNT success (e.g., Maznevski and Chudoba, 2000) or represent theoretical conceptualizations (Fink et al., 2004). There is very little empirical work on leadership in MNTs.

According to Zaccaro et al. (2001) most teams contain certain individuals who are primarily responsible for defining team goals and for supporting the team to accomplish its mission. They define team directions and organize the team to maximize its performance. They also influence team norms by the selection, dele- 
gation and implementation of people. Experienced managers who are aware of team norms, which proved successful in the past, can positively influence the development of team norms and contribute to the success of teams (Fink et al., 2004). Team leaders also play an important role in the implementation stage of an MNT (Fink et al., 2004). New team members will have their own expectations of appropriate interaction rules, group efficacy beliefs, and group identity. Their personal characteristics will affect team member's expectations of how other members should act within the team (Earley and Mosakowski, 2000). During this interaction process of the implementation of MNTs, the experienced team leader should influence the perceptions and expectations of team members and stress shared objectives and mutual interests. Wrong perceptions of individual team members can have a detrimental impact on future team performance (Fink et al., 2004). Maznevski and DiStefano (2000) suggest that leaders need to be able to successfully map, bridge, and integrate the different perspectives of culturally dissimilar team members. In a similar vein, Matveev and Nelson (2004) explore the relationship between cross cultural communication competence and multicultural performance. Their goal is to find out if a high degree of cross-cultural communication competence among team members affects the performance of MNTs. Cross-cultural communication competence entails knowledge of the culture and language, affective and behavioural skills such as empathy, human warmth, charisma, and the ability to manage anxiety and uncertainty (Gudykunst, 1998; Spiess, 1996, 1998; in Matveev, 2004). In the interpersonal skills dimension, a team member acknowledges differences in the communicative and interactional styles of people from different cultures and feels comfortable when communicating with foreign nationals. The team effectiveness dimension includes such critical skills as the ability of a team member to understand and clearly communicate team goals and norms to other members of an MNT. The cultural uncertainty dimension reflects the ability of a team member to be patient in intercultural situations, to be tolerant and accept cultural differences, and to work in a flexible manner with others on an MNT. Finally, in the cultural empathy dimension, a culturally empathetic team member behaves as though he or she understands the world as team members from other cultures do, is familiar with the communication patterns in these cultures, shows an appreciation for a variety of working styles, and an ability to view the ways things are done in other cultures not as bad but simply as different. The results of the study show that there is a positive relationship between the level of cross-cultural communication competence of an MNT member and the performance of an MNT. The authors claim that team leaders leading MNTs must be competent cross-cultural communicators in order to work effectively with people with different cultural backgrounds. According to Schwer (2004), incorporating team leaders with international experience will contribute to MNT effectiveness. Their cultural awareness and empathy will make such team members stand out from the other colleagues and will help them reframe conflicts and misunderstandings, change wrong perceptions of 
others in the team, break stereotypes and establish commonly shared and accepted team norms. Such individuals will contribute to the overall success of diverse teams. Cummings (in press) have studied 129 teams working across different units in a multinational company. Although the study focuses on the role of communication for the effective team performance, rather than on leadership, results suggest that leader communication with team members mitigates the negative impact of high geographical dispersion. Cummings concludes that leaders should communicate more frequently than they may typically do with team members who are dispersed across different units of a multinational company, and that for such teams, they should create norms that encourage team members to communicate among themselves frequently and openly. Although cross-cultural research emphasizes that different cultural groups have different conceptions of what leadership should entail, a recent study has shown that attributes associated with charismatic/transformational leadership will be universally endorsed as contributing to outstanding leadership. This hypothesis was tested in 60 cultures as part of the Global Leadership and Organizational Behaviour Effectiveness (GLOBE) Research Program. The results support the hypothesis that specific aspects of charismatic/transformational leadership are strongly and universally endorsed across cultures (Den Hartog, 2005). Consequently, charismatic and transformational leaders create and handle effective teams and are helpful in transferring and implementing successfully applied team norms. According to Schweiger et al. (2003), team leadership is critical. Many of the successful leaders are able to succeed because of their ability to manage the many complex team functioning issues and navigate the team context. A number of the personal capabilities and characteristics that help them to do so are identified. These are the ability to understand skills needed on a team, to have a solid relationship with subsidiaries, to be multilingual, to have project management skills, to have a high need for achievement and to demonstrate open-mindedness for learning. Joshi and Lazarova (2005) have conducted a qualitative phone-interview based study involving 89 MNT members and 50 MNT leaders from a Fortune 500 software and hardware company. They have been asked to describe their current jobs and related responsibilities, to identify challenges that they face in their work context and to describe the role of the leader in their specific work context. They identify four competencies that are considered as important by MNT leaders and members across multiple locations: Communication, Direction and goal setting, Facilitating teamwork, and Motivating and inspiring. Direction and goal setting and communication are identified as important MNT leader competencies by a clear majority ( $65 \%$ or more) of the MNT members in each country; the latter two competencies thus seem to be generally viewed - regardless of geographic location - as key skills for MNT leaders. Perhaps the next strongest area of agreement among MNT members in all geographic locations regards the importance of motivating and inspiring as an MNT leader competency. None of the MNT members in any of the countries represented in the study have identified 
Empowering as an important MNT leader competency. Similarly, only a minority of the MNT members in this study have identified managing cultural diversity as an important MNT leader skill. Team members in the corporate HQ have identified boundary spanning as an important leader competency. Given the universal appeal of these competencies among the respondents, it has been proposed that these may be viewed as "core" competencies or minimum requirements of effective MNT leadership. It should be mentioned that some leadership competencies have been identified as important primarily by team members in some locations rather than in others. Specifically, a majority of team members in China, Russia, and Eastern Europe have identified Mentoring and coaching and Staffing/resource acquisition as important leader competencies. These location-specific demands regarding MNT leadership might point to specific needs of these geographic locations. MNT leadership competences also differ depending on whether MNT members are collocated or distant from their leaders. This indicates that additional research is needed that tests the role of cultural values, nationality, location, and subsidiary - HQ relationship in predicting the effectiveness of leadership styles in MNTs.

Future research should continue to explore the unique leadership requirements in an MNT context. These requirements will vary in different countries and in different organisations. In order to enhance our understanding of MNT leadership, we should devote greater attention to the links between team leadership and the organisational context. Exploring the factors that influence MNT leadership success presents an interesting avenue for future research. Moreover, the core competences of multinational project team leaders may differ from the skills and abilities of multinational product development team leaders. We assume that the type of team will matter for the determinants of MNT leader competences and requirements. Therefore, research on MNT leadership should distinguish among different types of MNTs.

\subsection{Mediating variables}

In this chapter we will present control variables that have a mediating impact on MNT functioning in business organisations. We could identify three mediating variables: MNT norms, team size and technology used to facilitate members' interaction. Team norms influence how team members interact and communicate with one another, make decisions, solve problems and give feedback. The literature review shows, that basic work group information such as technology and equipment has often not been relayed. Studies on MNTs often do not provide 
information about team composition and size. Yet, this information is essential in order to understand studies' results.

\subsubsection{Team norms}

Norms are informal rules that groups adopt to regulate group members' behaviour; they are among the least visible and most powerful forms of social control over human action (Hackman, 1976; Flynn and Chatman, 2001). They influence how team members interact and communicate with one another, make decisions, solve problems and give feedback. Despite the fact that studies on team norms have been conducted, researchers know relatively little about factors that influence the emergence of team norms in business organisations. Yet to understand MNTs in organisational setting, more insights may be derived by exploring the factors leading team members to develop and accept certain norms. Most of the research on group norms has focused on identifying the types of norms that increase team performance.

For instance, teams that emphasise norms that support innovation, will promote creativity and encourage organisational members to develop original and useful products (Peters and Waterman, 1982; in Flynn and Chatman, 2001). Norms that require organizational members to build upon others' ideas rather than limit their attention to their own ideas are vital to creativity (Sutton and Hargadon, 1996). Without a combination of diverse perspectives, groups charged with generating creative ideas may adopt the best individual idea rather than utilize their combined potential (Chatman et al., 1998). Certain strong norms may facilitate the implementation of creative ideas. In particular, emphasizing task-oriented norms that focus on members' cooperation may determine the success of the implementation process (Abbey and Dickson, 1983). Team members emphasising collectivistic norms will be willing to give priority to the goals of the team over their personal goals. This may be a key to team success in product development teams. A collectivistic orientation emphasising innovation as a collective goal over varying individual goals will increase the likelihood that such teams will produce innovative outcomes (Chatman et al., 1998). Two types of norms that are crucial for team performance are a conflict openness norm and open communication norms. Norms within the group affect the degree to which individuals with value diversity will accept and engage in task conflict. Discussions about conflict are often avoided within groups but recent research has suggested that open discussions about task-related conflict can be helpful within groups. Jehn (1997) has found that open communication norms around task-related differences increase performance. When a team fosters norms that task differences are accepted, the discussions are well managed and produce positive results (Jehn, 1997). Team norms 
also vary within different contexts. Successful norms in R\&D teams will value innovation and longer time frames while promising norms in sales teams will value aggressiveness and shorter time frames (Nadler and Tushman, 1988). According to Thomas (1999), different cultural norms of individual team members will influence what patterns of behaviour and what group and individual outcomes will be desirable. Individuals from collectivist cultures will exhibit more concern for the needs of others. They will be more willing to contribute their ideas and information and place more importance on common interests and shared objectives. They will use an equality norm when dealing with members of their ingroup, whereas individualists will use an equity norm for dealing with others, regardless of group membership (Leung and Bond, 1984; in Thomas, 1999). These values and norms of behaviour of individuals from collectivistic cultures will have a positive impact on the development of cooperative team norms. The review shows that only few studies (e.g. Thomas, 1999; Chatman et al., 1998; Chatman and Flynn, 2001) have considered the effect of demographic heterogeneity among group members on the emergence of certain team norms.

Future research should address the relative influence of contextual factors on the development and enforcement of norms in teams consisting of culturally heterogeneous members with different perceptions of norms and values.

\subsubsection{Technology used by team members, MNT size and composition}

The literature review has shown that basic work group information such as technology and equipment used by team members are often not relayed. MNTs interact using a variety of electronic means. Researchers so far have not succeeded in assessing the impact of e-mail, video or teleconferencing, telephones etc. on the dynamics of a MNT. It would be interesting to determine how the various combinations of technology are used and how they impact team norms. For members from a high context culture, what is unsaid is more central than what is actually said and without direct contact they may miss the right interpretation of interactions (Hall, 1959). As a result, they will prefer a face-to-face conversation. The question is how critical technology is to MNT success (Earley and Gibson, 2002) and the establishment of cooperative team norms.

In order to fulfil a certain task it is very important that the team members have the capabilities, the knowledge and the time they need. According to Hackman (1987; in Fink et al., 2004), large MNTs might not be as efficient as smaller teams, since it seems harder to reach an agreement among a larger group than a smaller one. Yet the likelihood to succeed with the establishment of new team norms increases 
with diversity among team members and the importance of bilateral cultural conflicts decreases (Fink et al, 2004), creating more room for the adaptation of new team norms. Demographic diversity in teams consisting of two nationalities may create faultlines, since demographic characteristics divide the network into subgroups or result in attitudinal diversity within the team (Harrison et al., 1998; in Roberson and Colquitt, 2005). Just few of the studies reviewed provide information about the average size of the MNTs under investigation. The lack of this information impedes our ability to understand many empirical findings and the conclusions drawn from them.

Basic team information that should be relayed includes team size, team composition, and the technology and equipment used. These details are essential for the development of an understanding of the team literature by providing an understanding for study's results. Yet, as the literature review shows, this information is often missing. The importance of team size and composition as moderators of diversity effects in MNTs still remains unexplored. Past research has not succeeded in assessing the impact of technology on MNT performance.

\subsection{Future research implications and research aim}

From the literature review we can draw the following conclusions:

1. Organizational context is to be taken more seriously. Numerous exogeneous forces and contextual aspects that impact MNT performance have not been assessed. The complex interplay between the context, MNTs and the individuals is typically not evident in research on MNTs, as studies on MNTs do not include reciprocal relationships. Most of the hypotheses tested in studies on the relationship between contexts and individuals or MNTs concern unidirectional relationships between variables. This has important implications. MNTs must not be regarded as socially isolated entities. Organisational strategy, culture, structure and the patterns of social integration of culturally diverse employees across geographically dispersed national facilities of the multinational company should be incorporated into research designs and should be considered as important aspects of team context.

2. Unique leadership requirements in MNT context vary in different countries and in different organisations. In order to enhance our understanding of 
MNT leadership, we should devote greater attention to the links between team leadership and the organisational context. Factors that influence MNT leadership may depend on task. The core competences of multinational project team leaders may be different from the skills and abilities of multinational product development team leaders.

3. Basic team information that should be relayed also includes team size, and the technology and equipment used. These details are essential for the development of an understanding of the team literature by providing a context for a study's results. Yet, as the literature review shows, this information is often missing. The importance of task characteristic as moderator of diversity effects in MNTs is worth deeper exploration.

4. MNTs, though, only recently have been the subject of intensive empirical study and they still remain a relatively understudied field of research. Some studies on MNTs find a positive impact of international diversity on team performance (Earley and Mosakowski, 2000; Elron, 1997; Ely and Thomas, 2001, Cox et al. 1991; O'Reilly et al., 1997; Kirchmeyer and Cohen, 1992). Others find that international diversity is detrimental to performance in the long run, showing that homogeneous teams are more innovative and perform better (Watson et al., 1998; Watson et al., 1993) while MNTs are more likely to experience ineffective team processes that result in lower levels of team performance (Thomas, 1999).

The aim of this dissertation is to explore the influence of various categories on MNTs in business organisations and to develop a more comprehensive framework connecting the internal dynamics with contextual aspects of MNTs' functioning in companies operating in the high-tech and consumer good industry in Europe and the USA. 
Aida Hajro - 978-3-631-75438-2

Downloaded from PubFactory at 01/11/2019 04:52:54AM

via free access 


\section{A purposeful approach to the interview and data analysis method in studying MNTs in European and American companies}

\subsection{Rationale for choosing a qualitative research design}

Empirical studies on MNTs have predominantly used quantitative methods to obtain and analyse data. Quantitative research generally tests theoretical propositions derived from theory (Ongwuegbuzie, 2003) and the focus is on testing variables and categories that can be measured and treated as interval and ordinal data in statistical analysis (Patton, 1997). Precise problems, well defined in scale and scope, can easily be investigated with rigorous scientific methods. Quantitative methods should be applied if expertise is available and prior research has been carried out that points to the underlying problem and ambiguities.

To identify causal relationships and phenomena in a specific field which before has not been studied in detail (Bortz and Döring, 2002) qualitative research methods might be more appropriate. Qualitative research aims to explain social reality by describing the complexity of the social setting under study from people's experiences (Flick et al., 2000). MNTs are a very complex social phenomenon. Studies based on quantitative methods have usually ignored the larger external context for MNTs and, consequently, a pattern of mixed results has been found for studies on MNTs. Some studies on MNTs have found a positive impact of international diversity on team performance, while other studies have found that international diversity is detrimental to team performance in the long run. Usually, researchers have not provided any information about industry and organisation in which teams are embedded, such as the mission, structure or competitive challenges. The lack of this information prevents us from understanding the context and interpreting study results. The aim of this dissertation is to explore the influence of various categories on MNTs in business organisations and to develop a more comprehensive framework connecting the internal dynamics with contextual aspects of MNTs' functioning. It is a theory building and not theory testing study. Rich descriptions and explanations of processes are needed and therefore we have decided on qualitative data collection and data analysis as the appropriate method.

A number of scholars call for adaptation of qualitative methods in order to gain a better understanding of the complexity inherent in MNTs and the context in which they operate (e.g., Jackson et al., 2003; Gibson et al., 2003; Vallaster, 2005; Pauleen, 2003). Yet qualitative research involves the use of unstructured explora- 
tory techniques. In contrast to quantitative techniques it is more difficult to precisely capture phenomena with qualitative research. As a result qualitative research design has often been treated as an oxymoron (Maxwell, 1997). However, if we want to understand the particular context within which the participants act and the influence which this context has on their actions (Maxwell, 1997), if we intend to develop causal explanations (Maxwell, 1997) and to identify unanticipated phenomena and influences and to generate new grounded theories about the latter (Strauss and Corbin, 1998) qualitative approach is the most appropriate:

"Qualitative data are attractive (.....) they are rich, full, earthy, holistic, real and their face validity seems unimpeachable (....) (Miles, 1979:590)"

In keeping with the complexity of the research aim of this dissertation, the research has been designed to be exploratory. A grounded theory approach is used (Strauss and Corbin, 1998) with the aim to investigate the related group dynamics within their real organisational context. This section introduces a purposeful approach to the interview and data analysis method in studying MNTs in business organisations. First, it provides a short review of the application of grounded theory in organisational research and continues with sampling. The technique of problem-centred interviews is used in order to collect the data that is analysed applying qualitative content analysis (Mayring, 2000) and using Atlas.ti software. The process of data reduction consists of three main operations: coding (labelling data), memoing (theorizing about codes and their relationships), and developing propositions. Finally, the constant comparative method is applied in order to develop the conceptual framework connecting external aspects with internal dynamics of MNTs. Table 1 shows the four stages of the research design:

\begin{tabular}{|l|l|}
\hline Desk research & $\begin{array}{l}\text { literature review, identification of important issues } \\
\text { and development of interview questions }\end{array}$ \\
\hline Field-research & $\begin{array}{l}\text { problem-centred interviews and extensive } \\
\text { observations of the phenomenon under study }\end{array}$ \\
\hline Data analysis & $\begin{array}{l}\text { qualitative content analysis and constant comparative } \\
\text { method }\end{array}$ \\
\hline Empirical findings & $\begin{array}{l}\text { propositions and conceptual framework for MNTs in a } \\
\text { business context }\end{array}$ \\
\hline
\end{tabular}

Table 1: Research Design (Source: Author) 


\subsection{Grounded theory in organizational research}

The constant comparative method together with theoretical sampling constitutes the core of qualitative analysis in the grounded theory approach developed by Glaser and Strauss (Boeije, 2002). Grounded theory was developed by Glaser and Strauss (1967) when they observed that in sociological research studies focusing on verifying existing classic theories flourished, while research on generating new theories hardly existed (Lansisalmi et al., 2004). The aim is to discover what kinds of concept and hypotheses are relevant to the area one wishes to understand. Grounded theory, therefore, provides new insights into the understanding of social processes emerging from the context in which they occur, without forcing and adjusting the data to previous theoretical frameworks (Glaser, 1995, 1998; in Lansisalmi et al., 2004).

Qualitative studies in which researchers adopted grounded theory's logic and its basic operational practices began to appear in the newly established discipline of management and organizational behaviour in the early 1970s. Studies have been published in prominent journals, e.g. in the 'Journal of Management Studies in Europe' and 'Administrative Science Quarterly' in the United States. The full adaptation of the logic and practices of grounded theory continued through the 80s and 90s (Wagner, 2004).

During the last ten years the application of grounded theory has gained even more popularity among organizational researchers (Lansisalmi et al., 2004). It has been applied in, for example, studies focusing on organizational culture (Lansisalmi et al., 2000), organizational growth (Brytting, 1995), organizational change and innovation (Carrero et al., 2000), work teams (Gersick, 1988) and company survival (Lowe, 1995, in Lansisalmi et al., 2004).

Researchers have started using the grounded theory method more often, since they need a method that will enable them to understand, react and improve the processes of individual and group behaviour in all its complexity (Locke, 2001) and to link well into the gap of research and practice (Locke, 2001).

Pauleen's (2003) research on leadership in virtual teams is a good example of how this link can be achieved. His target was to connect two research fields, virtual team-leadership and the relationship-building process, and to generate a theory that fills the gap that currently exists between researchers and practitioners. $\mathrm{He}$ used the grounded theory approach for data collection and analysis. The researcher was guided by a research question prior to the study: 'what are the issues facing virtual team leaders and how do they manage them?' During data analysis, Pauleen (2003) followed the constant comparative method with simulta- 
neous data collection and analysis. The most important outcome of his study was the need of leaders to first build personal relations with their team members. According to Pauleen (2003), organizations will increase their performance by supporting relationship building in virtual teams and organizational trust among employees. This study is a good example of a successful application of the grounded theory method. It shows why grounded theory is highly recommended in organizational research. In a similar vein, Vallaster (2005) used the grounded theory approach in order to explore the social interactive processes on multicultural groups observed in their organisational settings. The aim was to explore the dynamics of cognitive, affective and communication aspects during the development of a shared understanding. The results show that for a successful cooperation among culturally diverse group members, they need to facilitate social interactive processes by balancing perceived differences. According to Vallaster (2005), the grounded theory approach was the only way to investigate the related group dynamics within their real organizational context.

In the grounded theory model, researchers make the move from empirical observation to composing conceptual categories and to delineating the ways in which the categories relate to each other. They have to invent some aspects of the social world through their conceptualization. In hypothetic-deductive models of research, the line of investigative action begins with theory; it moves from the definition of concepts and their proposed relations out to the 'real world' where they ought to be observed and where they are tested (Locke, 2001). Both, Pauleen (2003) and Vallaster (2005) were guided by a research question prior to the study. This dissertation also starts with some prior specification of existing theory in order to narrow down and direct the analysis and to limit the possibility of being overwhelmed by the sheer volume of unstructured data. The identification of important issues and the development of interview questions are aimed at helping the researcher to remain more sensitive to relevant data. Our goal is to close the knowledge gap with interviews and application of grounded theory.

This method adapts well to capturing complexities of the context in which MNTs operate. In this context it is also powerful as it gives room for the interpretation of real experiences of the participants. Past research on MNTs has often emphasized divorcing context from the topic under investigation. The strength of this research design consists in exploring the interactions of phenomenon and context.

\subsection{Sampling}

Sampling in the grounded theory approach is described as being theoretically driven. The logic of the theoretical sampling comes from researcher's commit- 
ment to develop a theory about a topic. As a consequence, the theory sets the terms for sampling through the study (Locke, 2001). This means that the researcher decides what data will be gathered next and where to find them on the basis of his theoretical ideas (Boeije, 2002). According to Glaser and Strauss (1967), the rationale of the theoretical sampling is to direct all data collection efforts towards gathering information that will best support the development of the theoretical framework. This means that the data collection will be an open ended and flexible process. Researchers should flexibly pursue data collection to support category development to the point of theoretical saturation and the development of the conceptual framework until it stabilizes (Locke, 2001).

This study has been conducted at three different companies in Austria and the USA. VA TECH, now owned by Siemens, was a focused technology and service provider. It held leading international market positions in the segments Metallurgy, Power Generation, Transmission and Distribution as well as Infrastructure and employed around 16,600 people worldwide. The HQ was located in Vienna and the company used to have an international workforce. Due to the high degree of multinationality it has been decided to analyse the complexity inherent in working in MNTs in the context of this business organisation. Siemens AG Austria completed the acquisition on August 15, 2005 and has initiated integration activities. Twelve interviews were conducted with team leaders and team members at VA TECH in July, 2005.

Henkel is one of the most internationally aligned of German consumer goods companies. It is the leading supplier of home care and personal care products as well as adhesives, sealants and products for surface treatment. It has a total of around 50,000 employees with $77 \%$ of them working outside Germany and it is represented in 75 countries. This business organisation pursues a multinational strategy. Its regional HQ in Vienna is responsible for the company's activities in Central and Eastern Europe (CEE). Fifteen interviews were conducted at its HQ in the period between July and September, 2005.

The third informant company is K\&M International, the world leader in the production of nature-related toys, located in Ohio, USA. An additional fifteen interviews were conducted with team members and team leaders at its HQ in August, 2005. This company operates in the USA, Canada, Australia, Singapore, Hong Kong, Japan, U.K., Denmark, France, Austria, Holland, Italy and Germany and has production facilities in China and India. Around 120 people work in the HQ in Ohio (approximately 30\% Indians and 70\% Americans). The company emphasizes teamwork and the employees from different departments have significant opportunities to interact and contribute with their ideas to new product development and the overall success of the company. The product development team develops approximately 800 to 1000 toys every year. 
All data collection efforts have been directed towards gathering information that best support the development of the conceptual framework. In total, forty-two interviews have been conducted and considerable time has been given to writing up notes of observation. Data collection has been aimed at supporting category development to the point of theoretical saturation and the development of the conceptual framework. A situation where no new categories or properties emerged from the gathering of further data has been attained after conducting six to seven interviews with team members or team leaders in each of the companies under study. In all three cases we have conducted additional interviews in order to ensure that the point of theoretical saturation is attained. Table 2 presents the demographic and statistical information on the interview partners at Henkel CEE, VA TECH and K\&M international. Interviews have been conducted with $22 \mathrm{MNT}$ members and 20 MNT leaders:

\begin{tabular}{|c|c|c|c|c|c|c|}
\hline Company & Interview & Country & Sex & Age & $\begin{array}{l}\text { Educational } \\
\text { Background }\end{array}$ & Function \\
\hline $\begin{array}{l}\text { Henkel } \\
\text { CEE }\end{array}$ & $\mathrm{P} 1$ & Austria & $\bar{M}$ & 45 & Master & $\begin{array}{l}\text { Team } \\
\text { leader/ } \\
\text { Department } \\
\text { Head }\end{array}$ \\
\hline $\begin{array}{l}\text { Henkel } \\
\text { CEE }\end{array}$ & P2 & Ukraine & $\bar{F}$ & 26 & Master & $\begin{array}{l}\text { Team } \\
\text { member/ } \\
\text { Marketing } \\
\text { Department }\end{array}$ \\
\hline $\begin{array}{l}\text { Henkel } \\
\text { CEE }\end{array}$ & P3 & Poland & $\bar{M}$ & 29 & Master & $\begin{array}{l}\text { Team } \\
\text { member/ } \\
\text { Marketing } \\
\text { Department/ } \\
\text { Inpatriate }\end{array}$ \\
\hline $\begin{array}{l}\text { Henkel } \\
\text { CEE }\end{array}$ & P4 & Austria & $\bar{F}$ & 36 & Master & $\begin{array}{l}\text { Team } \\
\text { leader/ } \\
\text { Department } \\
\text { Head }\end{array}$ \\
\hline $\begin{array}{l}\text { Henkel } \\
\text { CEE }\end{array}$ & P5 & Austria & $\bar{M}$ & 42 & Master & $\begin{array}{l}\text { Team } \\
\text { leader/ } \\
\text { Regional } \\
\text { Manager/ } \\
\text { Expatriate }\end{array}$ \\
\hline $\begin{array}{l}\text { Henkel } \\
\text { CEE }\end{array}$ & P6 & Poland & $\mathrm{F}$ & 26 & Master & $\begin{array}{l}\text { Team } \\
\text { member/ } \\
\text { Marketing } \\
\text { Department/ } \\
\text { Inpatriate }\end{array}$ \\
\hline
\end{tabular}




\begin{tabular}{|c|c|c|c|c|c|c|}
\hline $\begin{array}{l}\text { Henkel } \\
\text { CEE }\end{array}$ & P7 & Austria & $\overline{\mathrm{M}}$ & 36 & Master & $\begin{array}{l}\text { Team } \\
\text { leader/ } \\
\text { Marketing } \\
\text { Department }\end{array}$ \\
\hline $\begin{array}{l}\text { Henkel } \\
\text { CEE }\end{array}$ & P8 & Austria & $\bar{M}$ & 27 & Master & $\begin{array}{l}\text { Team } \\
\text { member/ } \\
\text { Marketing } \\
\text { Department }\end{array}$ \\
\hline $\begin{array}{l}\text { Henkel } \\
\text { CEE }\end{array}$ & P9 & Austria & $\bar{F}$ & 36 & Master & $\begin{array}{l}\text { Team } \\
\text { leader/ } \\
\text { Department } \\
\text { Head } \\
\end{array}$ \\
\hline $\begin{array}{l}\text { Henkel } \\
\text { CEE }\end{array}$ & $\mathrm{P} 10$ & Austria & $\bar{M}$ & 39 & Master & $\begin{array}{l}\text { Team } \\
\text { leader/ } \\
\text { Department } \\
\text { Head } \\
\end{array}$ \\
\hline $\begin{array}{l}\text { Henkel } \\
\text { CEE }\end{array}$ & P11 & Austria & $M$ & 39 & Master & $\begin{array}{l}\text { Team } \\
\text { leader/ } \\
\text { Business } \\
\text { Operations }\end{array}$ \\
\hline $\begin{array}{l}\text { Henkel } \\
\text { CEE }\end{array}$ & P12 & Bosnia & $\mathrm{F}$ & 26 & Bachelor & $\begin{array}{l}\text { Team } \\
\text { member/ } \\
\text { Marketing } \\
\text { Department }\end{array}$ \\
\hline $\begin{array}{l}\text { Henkel } \\
\text { CEE }\end{array}$ & P13 & Austria & $\bar{F}$ & 30 & Master & $\begin{array}{l}\text { Team } \\
\text { leader/ } \\
\text { Marketing } \\
\text { Department }\end{array}$ \\
\hline $\begin{array}{l}\text { Henkel } \\
\text { CEE }\end{array}$ & P14 & Ukraine & $\bar{F}$ & 27 & Master & $\begin{array}{l}\text { Team } \\
\text { member/ } \\
\text { Marketing } \\
\text { Department/ } \\
\text { Inpatriate }\end{array}$ \\
\hline $\begin{array}{l}\text { Henkel } \\
\text { CEE }\end{array}$ & P15 & Hungary & $\bar{F}$ & 28 & Master & $\begin{array}{l}\text { Team } \\
\text { member/ } \\
\text { Business } \\
\text { Operations }\end{array}$ \\
\hline VA TECH & P16 & Austria & $\bar{M}$ & 31 & Master & $\begin{array}{l}\text { Team } \\
\text { member/ } \\
\text { Project } \\
\text { Member }\end{array}$ \\
\hline
\end{tabular}




\begin{tabular}{|c|c|c|c|c|c|c|}
\hline VA TECH & P17 & Spain & $\bar{M}$ & 30 & Master & $\begin{array}{l}\text { Team } \\
\text { leader/ } \\
\text { Project } \\
\text { Manager }\end{array}$ \\
\hline VA TECH & P18 & Austria & $\mathrm{M}$ & 43 & Master & $\begin{array}{l}\text { Team } \\
\text { leader/ } \\
\text { Project } \\
\text { Manager }\end{array}$ \\
\hline VA TECH & P19 & Slovakia & $\mathrm{M}$ & 55 & Master & $\begin{array}{l}\text { Team } \\
\text { leader/ } \\
\text { Project } \\
\text { Manager }\end{array}$ \\
\hline VA TECH & P20 & Austria & $\mathrm{M}$ & 32 & Master & $\begin{array}{l}\text { Team } \\
\text { member/ } \\
\text { Project } \\
\text { Member }\end{array}$ \\
\hline VA TECH & P21 & USA & $M$ & 39 & Master & $\begin{array}{l}\text { Team } \\
\text { leader/ } \\
\text { Project } \\
\text { Manager }\end{array}$ \\
\hline VA TECH & P22 & $\begin{array}{l}\text { South } \\
\text { Africa }\end{array}$ & $\mathrm{M}$ & 45 & Master & $\begin{array}{l}\text { Team } \\
\text { leader/ } \\
\text { Project } \\
\text { Manager }\end{array}$ \\
\hline VA TECH & P23 & Bosnia & $F$ & 35 & Master & $\begin{array}{l}\text { Team } \\
\text { member/ } \\
\text { Project } \\
\text { Member } \\
\end{array}$ \\
\hline VA TECH & P24 & $\begin{array}{l}\text { Rumani } \\
\text { a }\end{array}$ & F & 36 & Bachelor & $\begin{array}{l}\text { Team } \\
\text { member/ } \\
\text { Project } \\
\text { Member }\end{array}$ \\
\hline VA TECH & P25 & Austria & $\mathrm{M}$ & 46 & Bachelor & $\begin{array}{l}\text { Team } \\
\text { member/ } \\
\text { Project } \\
\text { Member }\end{array}$ \\
\hline VA TECH & P26 & Austria & $M$ & 34 & Bachelor & $\begin{array}{l}\text { Team } \\
\text { member/ } \\
\text { Project } \\
\text { Member }\end{array}$ \\
\hline
\end{tabular}




\begin{tabular}{|c|c|c|c|c|c|c|}
\hline VA TECH & P27 & Austria & $\bar{F}$ & 31 & Master & $\begin{array}{l}\text { Team } \\
\text { member/ } \\
\text { Project } \\
\text { Member }\end{array}$ \\
\hline$\overline{K \& M}$ & P28 & India & $\bar{M}$ & 43 & Master & $\begin{array}{l}\text { Team } \\
\text { leader/ } \\
\text { Director }\end{array}$ \\
\hline$\overline{\mathrm{K} \& \mathrm{M}}$ & P29 & $\overline{\text { USA }}$ & $\mathrm{M}$ & 27 & Bachelor & $\begin{array}{l}\text { Team } \\
\text { member }\end{array}$ \\
\hline $\mathrm{K} \& \mathrm{M}$ & P30 & $\overline{\text { USA }}$ & $\bar{M}$ & 55 & Bachelor & $\begin{array}{l}\text { Team } \\
\text { leader/ } \\
\text { Director }\end{array}$ \\
\hline $\mathrm{K} \& \mathrm{M}$ & P31 & India & $\bar{M}$ & 34 & Master & $\begin{array}{l}\text { Team } \\
\text { leader/ } \\
\text { Director }\end{array}$ \\
\hline $\mathrm{K} \& \mathrm{M}$ & P32 & India & $\bar{F}$ & 37 & Master & $\begin{array}{l}\text { Team } \\
\text { leader/ } \\
\text { Director }\end{array}$ \\
\hline$\overline{\mathrm{K} \& \mathrm{M}}$ & P33 & $\overline{\text { USA }}$ & $\bar{F}$ & 44 & Bachelor & $\begin{array}{l}\text { Team } \\
\text { member }\end{array}$ \\
\hline K\&M & P34 & India & $\bar{M}$ & 70 & Bachelor & $\begin{array}{l}\text { Team } \\
\text { leader/ } \\
\text { President }\end{array}$ \\
\hline $\mathrm{K} \& \mathrm{M}$ & P35 & USA & $\bar{M}$ & 35 & Bachelor & $\begin{array}{l}\text { Team } \\
\text { leader/ } \\
\text { Director }\end{array}$ \\
\hline $\mathrm{K} \& \mathrm{M}$ & P36 & India & $\bar{F}$ & 27 & Bachelor & $\begin{array}{l}\text { Team } \\
\text { member }\end{array}$ \\
\hline $\mathrm{K} \& \mathrm{M}$ & P37 & USA & $\bar{M}$ & 37 & Bachelor & $\begin{array}{l}\text { Team } \\
\text { member }\end{array}$ \\
\hline $\mathrm{K} \& \mathrm{M}$ & P38 & $\overline{U S A}$ & $\bar{F}$ & 48 & Bachelor & $\begin{array}{l}\text { Team } \\
\text { leader/ } \\
\text { Director } \\
\end{array}$ \\
\hline $\mathrm{K} \& \mathrm{M}$ & P39 & $\overline{\text { USA }}$ & $\bar{M}$ & 26 & Bachelor & $\begin{array}{l}\text { Team } \\
\text { member }\end{array}$ \\
\hline $\mathrm{K} \& \mathrm{M}$ & $\mathrm{P} 40$ & USA & $\bar{M}$ & 41 & Bachelor & $\begin{array}{l}\text { Team } \\
\text { member }\end{array}$ \\
\hline$\overline{\mathrm{K} \& \mathrm{M}}$ & P41 & $\overline{\text { USA }}$ & $\bar{M}$ & 40 & Bachelor & $\begin{array}{l}\text { Team } \\
\text { member }\end{array}$ \\
\hline
\end{tabular}




\begin{tabular}{|l|l|l|l|l|l|l|}
\hline K\&M & P42 & India & $\mathrm{M}$ & 43 & Bachelor & $\begin{array}{l}\text { Team } \\
\text { member }\end{array}$ \\
\hline
\end{tabular}

Table 2: Demographic and statistical information on the interview partners (Source: Author)

\subsection{Method of data collection and data analysis}

\subsubsection{Problem-centred interviews}

The impact on and the gathering of social situations in the interview depend on whether the interview concept is open, i.e. less structured, or if a structured questionnaire is used. The degree of structure is defined by the aim of research: The less structured the interview is, the more qualitative-oriented it is. In contrast, the higher the degree of structure of the interview is, the more it allows for the collection of quantitative aspects (Atteslander, 2000; in Neyer, 2004).

The non-standardized interview is the data collection method applied in order to provide a thematical framework for the interview. This type of interview is open, i.e. the interviewer has to stimulate a conversation. It is most notably used in explorative studies to get a first impression and opinions about a certain topic and about complex patterns of behaviours and motives. Selected types of nonstandardized interviews are the problem-centred and the narrative interview as well as group discussions. In the narrative interview the interviewed person is encouraged to openly talk about his/her experiences (Mayring, 1999). This enables the collection of subjective opinions of the interviewee. Consequently, new and pervasive cognitions about the research topic can be gathered, which might be limited in the framework of a systematic standardized questioning. Forty-two problem-centred interviews with narrative questions have been conducted in three different companies with MNT members and leaders.

This technique allows collecting information/data without restricting data collection by presuppositions (prejudices, previous restrictive assumptions) (Fink et al., 2004b). It is a hermeneutic method to be applied whenever we have inadequately detailed information insufficient for theory building or when we have doubts about the assumptions made in already existing theories (Bewley, 2002; in Fink et al., 2004b). According to the results obtained from linguistic studies, one of the advantages of this type of interview is that narrations possess a firm, similar structure and a universal grammar (Wiedemann, 1986; in Mayring, 2002). Consequently, short series of interviews can be more easily compared and the most important types of incidents identified. 
Only 'what' or 'how' questions have been asked. This has resulted in a sufficiently rich picture of what is occurring in the three different organizations. Interviews have been conducted with a group of people who share common experience of working in teams in the same organization. Team members have been encouraged to tell their own stories and experience. Collecting workplace stories about what challenges team members face in their team, how they get things done, what they expect from their colleagues and what their colleagues expect from them has enabled a rich picture to emerge. Such a picture reflects the reality of the complexity of organizational and team life.

Table 3 shows the questions asked in the course of the interview:

\section{Interview questions}

1. Could you tell us a little about what you do and the teams you work with?

2. Who is on the team? How are these members selected? How are responsibilities divided?

3. Do the team members come from the same business unit or from different business units of the same company?

\section{Could you tell me something about the work style of your team?}

5. What works very well in your team? Are there any remarkable issues you could tell me something about?

6. Could you give me any piece of advice how a team leader could improve the effectiveness of his/her team?

Table 3: Interview guide (Source: Author)

On average, the interviews have lasted for one hour. All conversations have been captured with recording equipment and the interviews have been taped and a 565 pages transcript has been produced. The interviews have been conducted in German, English and partly Bosnian. Since the Bosnian interview partners have been fluent in German, they have been asked if they would prefer to speak in German or Bosnian. According to their wish we have started the interviews in German and continued in Bosnian language. Quotations from the first part of the interviews have been included in this dissertation. 
Age, gender, personality, appearance, and expectations of interviewers and interviewed persons can easily lead to unnoticed problems during the interview (Fink et al., 2004b). In addition, interviewer bias is also quite often linked with interviews in foreign languages and can have a strong impact on trust building, the current flow of the interview and on the content of the interview (Fink et al., 2004b). Therefore, it is strongly recommended that interviews are undertaken by members from the same culture as the interviewed person (Fink et al., 2004b). Forty interviews have been conducted by one researcher in three different languages: German, English and Bosnian. The researcher has lived for 7 years in Bosnia, 13 years in Austria, 5 years in Mexico and one year in the USA. The experience of living abroad has enhanced her cross-cultural understanding of different cultures and at the same time deepened the cultural self-awareness improving her cross-cultural competence. The international experience and the knowledge of all three languages has enabled the researcher to collect rich data and gain the trust of interview partners.

\subsubsection{Observations and other sources of data collection}

Considerable time has been given to writing up notes of observations. The researcher has been willing to immerse herself in the context by spending considerable time in the company and observing MNTs. It should be mentioned that she has worked for VA TECH during summer months as internee. She has also spent three years working as marketing assistant for $\mathrm{K} \& \mathrm{M}$ International in Vienna. This has made it possible to get access to internal data and to develop an understanding for the corporate culture and climate of these two companies. By spending time at the HQ of VA TECH in Vienna and K\&M International HQ in Ohio she could gain a deeper understanding for the dynamics of the social setting, MNT processes and its functioning. At K\&M International she could participate at directors' meetings and take notes of observation. Through this actual participation in the organisations being studied, an ongoing extensive interaction between researcher and subject could take place. The interviews at Henkel CEE were conducted from July to September 2005. In addition to the data obtained from interview partners the researcher has spent considerable time observing team members' interactions and meetings with representatives from subsidiaries. Valuable information could be obtained during lunch time or numerous coffee breaks with company's employees. The method has particularly been suited to research questions which require a detailed understanding of organizational processes because of the rich data collected in the context. The context has been part of the design and research issues have been examined by setting them in a contextual and causal relationship. 
Moreover, ten groups consisting of four to five students have been asked to complete individual studies dealing either with VA TECH or Henkel CEE financial performance, core competences, corporate strategy, structure and culture and company's foreign direct investment activities. Students have been asked to conduct interviews and provide the supervisor with transcripts and a written report. This data has been used to compare diverse perspectives. In order to consider triangulation a young researcher conducted interviews with 12 team members and team leaders using exactly the same questions at VA TECH in year 2006 (Repitz, 2006). Same results could be obtained with these diverse method approaches.

\subsubsection{Qualitative content analysis}

The qualitative content analysis consists of a bundle of techniques for systematic text analysis (Mayring, 2000) which were developed in a longitudinal study about psycho-social consequences of unemployment (Ulich et al., 1995). The basic idea of qualitative content analysis is to preserve the advantages of quantitative content analysis for a more qualitative text interpretation (Mayring, 2000).

According to Mayring, content analysis is based on 3 steps: summarizing, explication, and structurization (Lamnek, 1995). Inductive category development and deductive category application are two central approaches of the first step of analysis. The goal is to develop the categories as near as possible to the material and to formulate them in terms of the material. The material is worked through and categories are then deduced step by step (Mayring, 2000).

Deductive category application works with prior formulated, theory derived aspects of analysis. The goal is to bring these aspects of analysis in connection with the text. The categories are assigned to a passage of the text. The main idea here is to give definitions, examples and coding rules for each category and to determine exactly under what circumstances a text passage can be coded with a category (Mayring, 2000).

In order to avoid the risk of being overwhelmed by the sheer volume of unstructured data, both approaches have been followed. First of all, inductive categories have been formulated out of the material regarding category definitions and levels of abstraction. Then in a second step, main categories and sub-categories based on the theoretical derived aspects of analysis have been created.

Within the last few years several computer programs have been developed within the framework of qualitative analysis to support steps of text interpretation. The computer supports the steps of text analysis on screen by e.g. working through the 
material and defining category definitions and coding rules. In addition, it offers links to quantitative analysis by comparing frequencies of categories etc. (Mayring, 2000). In order to analyse the interviews, ATLAS.ti software has been used. The methodological approach of this empirical study is based on the grounded theory. This theory has exerted a particularly strong influence on the qualitative analysis program ATLAS.ti, which can be seen in the structure of the program, the developers' publication. This is also accounted for by the contacts the developers had with Anselm Strauss (Kelle, 1995). The clearest impact of ATLAS.ti can be found in the program's support for the researcher in generating a theory from empirical data (Kelle, 1995). Since this data analysis method is based on the grounded theory, ATLAS.ti has been the right program for conducting an analysis in line with this methodology. In addition, the program provides many features. By enabling the researcher to document the method, it makes the collection and analysis of data as comprehensible and transparent as possible. The researcher is aware of every single analysis step in the analysis model and this helps increase the validity of the measurement.

\subsubsection{Approach to the constant comparative method in the analysis of problem-centred interviews}

In the work of Glaser and Strauss (1967) constant comparison is very important in developing a theory that is grounded in the data (Boeije, 2002). Comparison is the main activity and, according to Glaser and Strauss (1967), it consists of the following four stages:

1. Comparing incidents applicable to each category

2. Integrating categories and their properties

3. Delimiting the theory

4. Writing the theory

Despite the fact that the aim and the different stages of the constant comparative method are clear, the application of the method and technique remains rather unclear (Boeije, 2002). A guide for a purposeful procedure has been missing in the work of the two founders of the grounded theory. Recently, Boeije (2002) has developed a five-step analysis procedure from his empirical study of couples coping with the effects of multiple sclerosis.

For the purpose of this empirical study, Boeije's five-step analysis has been adopted to a four-step analysis. According to Boeije the number of steps as such is not important, because that always depends on the kind of material that is in- 
volved. In the following we will describe the four-step analysis developed for this empirical study.

First of all, we have examined the consistency of the interview as a whole by comparing different parts of the interview. In the process of open coding, every passage of the interview has been studied to determine what exactly has been said and to label each passage with an adequate code. Quotations have been labelled with the most appropriate codes.

As soon as more than one interview has been conducted, the interviews have been compared. In this step the comparison has been between interviews within the same Austrian/German or American company, which means persons who share the same experience of working in a team in the same industry, same company and country. It is important to compare fragments from different interviews that the researcher has interpreted as dealing with the same theme and that have been given the same code. At this stage, the various conceptual categories are compared and arranged in relation to each other.

At a third step, the interviews from team managers and team members working in the same company have been compared. The aim of comparing the interviews of team members with a specific experience of working in a team with the interviews of managers has been to complete the picture already obtained and to enrich the information on the first group, namely team members. This comparison is used in order to validate the stories of team members and leaders either by confirming them or casting doubts on them.

Research has been conducted in three different companies and integration and organization has been brought to the conceptual categories. In a next step, the data obtained in each company separately has been conceptualised into an individual framework and then the step to compare the categories resulting from the interviews conducted in different settings has been undertaken. By thinking about the data incidents more in terms of the whole set of categories, the researcher has noted relationships between the categories. It has been necessary to perform a conceptual reduction and to make the commitment to tell a particular kind of story. When analysts integrate their theoretical categories and make a commitment to tell a particular story from their data, this reduction helps them to focus on the more relevant and robust categories (Locke, 2001). As soon as all the interviews conducted in the three different companies have been analysed together the theory has been presented and propositions for future research have been formulated. Finally, we have developed the conceptual framework connecting the internal dynamics with contextual aspects of MNTs' functioning in companies operating in different industries and different countries. 
This method is particularly suited to research questions which require detailed understanding of organizational processes because of the rich data collected in the context. The context is part of the design and the research study examines research questions and issues by setting these in a contextual and often causal context. In order to meet the criterion of generalization, the theory has been developed on the basis of a three-case research design. This approach has increased confidence in the findings, by enabling cross checking and comparison. A clear link between theory and data collection has been created. The researcher has worked closely with a variety of informants in their organizational settings.

As in quantitative research, the validity of a measurement is the most important quality factor in qualitative research (Bortz and Döring, 2002). This section makes the decision for a particular qualitative analysis tool and the collection and analysis of data as comprehensible and transparent as possible. It describes every single analysis step in the analysis model. The interpretation of the empirical findings is coherent. The researcher has spent considerable time writing up notes of observations and conducting interviews in the three companies under study. She has been very close to the every day life of team members and leaders. Parts of this dissertation have been published in e.g. European Management Journal, European Journal of International Management, Journal of Cross-cultural Competence and Management etc. and the reviewers have provided the researcher with valuable feedback. The results and their interpretation have been discussed with $\mathrm{PhD}$ students in doctoral students consortiums at international conferences (Academy of Management Annual Meeting, Southern Management Association Annual Meeting), at international workshops (InterKnow and the $4^{\text {th }}$ and $5^{\text {th }}$ Workshop on International Strategy and Cross-cultural Management) and with the supervisors. This has ensured validity in the qualitative research process. Mayring (2002) identified 6 general quality factors in qualitative research. These are documentation of the method, argumentative coverage of the interpretation, observation of method rules, closeness to the subject, communicative validity and triangulation. Triangulation is concerned with diverse solution strategies for a given problem. However, the aim is not to achieve exactly the same results with the diverse method approaches but to compare the diverse perspectives. In order to consider triangulation a young researcher conducted interviews with 12 team members and team leaders using exactly the same questions at VA TECH in year 2006 (Repitz, 2006). She has analysed the data using ATLAS.ti software and applying the qualitative content analysis. In her study she could identify the same categories of influence on MNTs as will be described in section 4 of this dissertation. Ten groups of students have been asked to conduct, record, transcribe and analyse interviews with representatives from VA TECH and Henkel CEE. The same results concerning the corporate strategy, structure and culture have been obtained with this method approach. 
Consequently, the present study considers all quality factors mentioned by Mayring (2002) and ensures validity of the measurement tool.

The next three sections of the dissertation will illustrate the empirical findings from the three companies under study: VA TECH, Henkel CEE and K\&M International. 
Aida Hajro - 978-3-631-75438-2

Downloaded from PubFactory at 01/11/2019 04:52:54AM

via free access 


\section{Empirical findings from VA TECH}

\subsection{Company description: $V A$ TECH}

VA TECH has been a focused Technology and Service Company headquartered in Austria, Vienna. The company has offered products and services in the following four divisions: metallurgy, power generation, power transmission and distribution and infrastructure. It has employed 16,562 people worldwide in more than 50 countries worldwide (VA TECH, 2007a). VA TECH has pursued a global strategy.

In 1900 Gesellschaft für elektrische Industrie, or ELIN, was founded in Vienna. The company changed its name to ELIN Aktiengesellschaft für elektrische Industrie as it became a limited liability in 1921.25 years later it was nationalized by government of newly formed Austrian Republic. In 1959 ELIN was merged with another government-owned company, AEG Union, to form Elin Union AG. It became part of government-owned Oesterreichische Industrieholding AG (OIAG) in 1970 and it was split into Elin Energieversorgung and Elin Energieanwendung, the latter of which took over services and electromechanical infrastructure operations. In 1993 Elin Energieanwendung was placed under newly created VA Technologie formed by OIAG. One year later VA Technologie was privatized and became a publicly listed company. Later its name was changed to VA TECH (Source: VA TECH, 2007a). Table 4 provides a ten year summary of VA TECH's financial performance from 1995 to 2004.

\begin{tabular}{|l|l|l|l|l|l|l|l|l|}
\hline \multicolumn{7}{|c|}{ Ten year summary of VA TECH's financial performance from 1995 to 2004} \\
In million euros \\
\hline Years & 1995 & 1997 & 1999 & 2000 & 2001 & 2002 & 2003 & 2004 \\
\hline Sales & 1,896 & 2,792 & 3,447 & 3,985 & 3,999 & 3,872 & 3,923 & 4,073 \\
\hline $\begin{array}{l}\text { Operating } \\
\text { profit } \\
\text { (EBIT) }\end{array}$ & --- & - & 130 & 93 & 83 & 83 & 101 & -44 \\
\hline Profit/loss & 97 & 110 & -95 & 30 & 32 & -93 & -15 & -68 \\
\hline $\begin{array}{l}\text { Number } \\
\text { of } \\
\text { employees }\end{array}$ & 15,46 & 17,92 & 21,71 & 21,34 & 18,85 & 17,73 & 17,48 & 16,56 \\
\hline
\end{tabular}

Table 4: Ten year summary of VA TECH's financial performance from 1995 to 2004 (Source: VA TECH, 2007b) 
In 2005 the division metallurgy, power transmission and distribution and infrastructure were overtaken by Siemens. VA TECH Hydro has been the power generation division. It has been a global supplier of electromechanical equipment and services for hydropower plants and one of the world's largest players in the hydropower generation market. This division has been acquired by Andritz. Interviews have been conducted at VA TECH Hydro and VA TECH Transmission and Distribution.

\subsection{Major empirical findings from VA TECH}

Data analysis of forty-two interview transcripts and interpretation are based on the findings of the literature analysis and interview transcripts. On 565 pages of interview transcript we could identify 205 codes. In the text we quote typical arguments and refer to relevant codes of each category.

In table 5 we show seven categories of influence on MNT performance at VA $\mathrm{TECH}$. It also includes the number of quotations for each code and the percentage of interviews per most frequently coded variables. This enables the researcher to indicate the perceived salience of matters and to preserve the advantages of quantitative content analysis for a more qualitative text interpretation. The most frequently mentioned categories are team norms (mentioned by $92 \%$ of interview partners), followed by industry turbulence and team member characteristics (mentioned by $83 \%$ of interview partners), team leader characteristics and the impact of corporate structure on team performance (mentioned by $75 \%$ of interview partners). We could also obtain 68 quotations by $58 \%$ of interview partners that refer to cultural differences between team members from different countries.

\begin{tabular}{|l|l|l|l|}
\hline Category & Codes & $\begin{array}{l}\text { Number of } \\
\text { quotations }\end{array}$ & $\begin{array}{l}\text { Percentage of } \\
\text { interviews } \\
(100 \%=12 \\
\text { interviews })\end{array}$ \\
\hline $\begin{array}{l}\text { Cultural } \\
\text { differences } \\
\text { between team } \\
\text { members }\end{array}$ & $\begin{array}{l}\text { Reference to cultural } \\
\text { differences between } \\
\text { team members from } \\
\text { different countries: }\end{array}$ & 68 & $58 \%$ \\
\cline { 2 - 4 } & $\begin{array}{l}\text { Austria and Central } \\
\text { Eastern Europe }\end{array}$ & 9 & $25 \%$ \\
\cline { 2 - 4 } & Austria and Italy & 10 & $17 \%$ \\
\cline { 2 - 4 } & Austria and U.K. & 6 & $17 \%$ \\
\cline { 2 - 4 } & $\begin{array}{l}\text { Austria and } \\
\text { Malaysia }\end{array}$ & 4 & \\
\hline
\end{tabular}




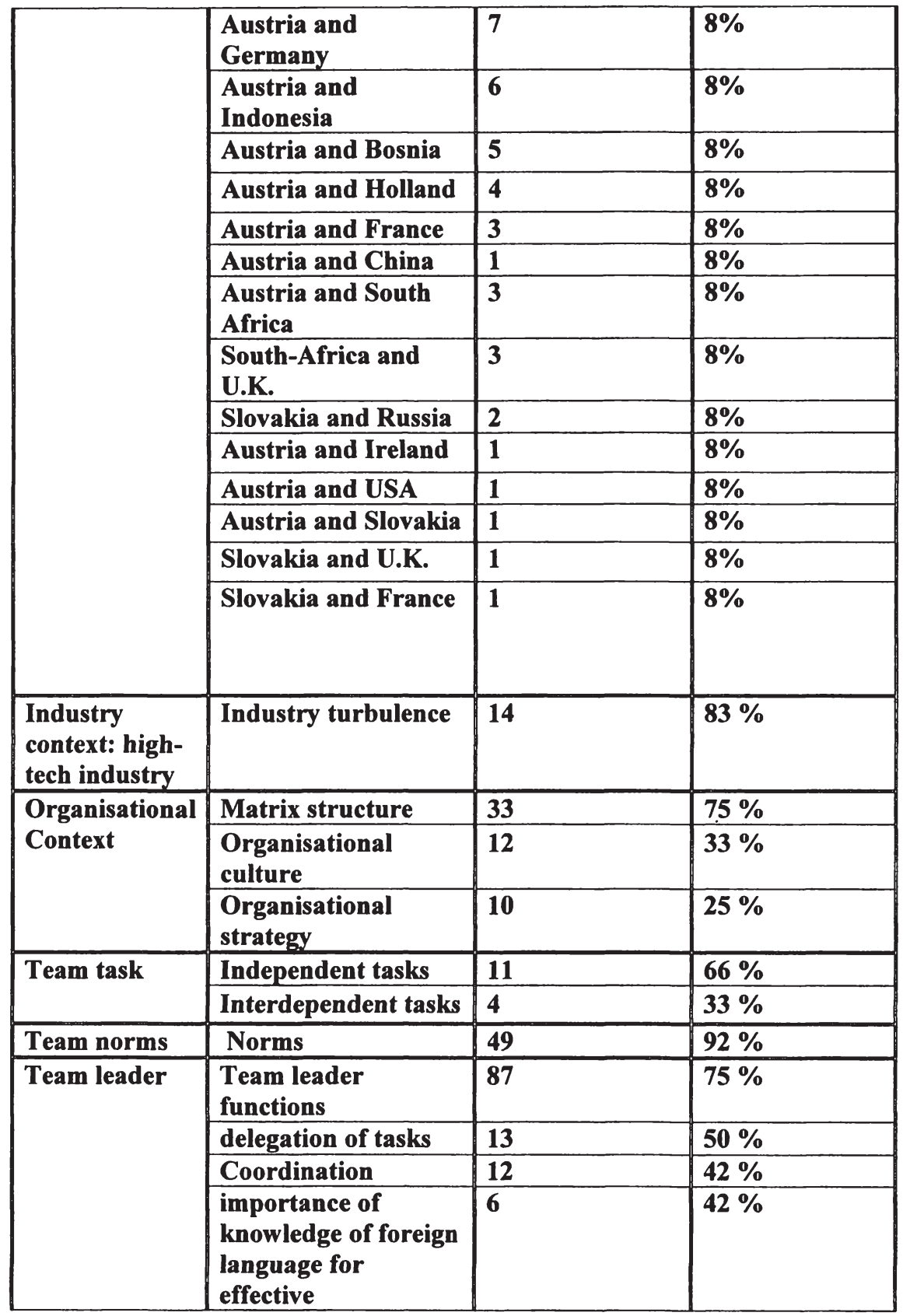




\begin{tabular}{|c|c|c|c|}
\hline & $\begin{array}{l}\text { communication with } \\
\text { subsidiaries }\end{array}$ & & \\
\hline & $\begin{array}{l}\text { Communication with } \\
\text { team members }\end{array}$ & 10 & $25 \%$ \\
\hline & $\begin{array}{l}\text { selection of team } \\
\text { members }\end{array}$ & 9 & $25 \%$ \\
\hline & Providing leadership & 7 & $25 \%$ \\
\hline & conflict management & 5 & $25 \%$ \\
\hline & decision making & 4 & $25 \%$ \\
\hline & goal setting & 4 & $25 \%$ \\
\hline & Monitoring & 7 & $17 \%$ \\
\hline & motivation & 7 & $17 \%$ \\
\hline & $\begin{array}{l}\text { creation of collective } \\
\text { team identification }\end{array}$ & 3 & $17 \%$ \\
\hline \multirow[t]{9}{*}{ Team member } & $\begin{array}{l}\text { Team member: } \\
\text { characteristics, } \\
\text { competences and } \\
\text { functions }\end{array}$ & 56 & $83 \%$ \\
\hline & Work experience & 15 & $42 \%$ \\
\hline & social competence & 12 & $42 \%$ \\
\hline & Personality & 7 & $42 \%$ \\
\hline & Open-mindedness & 7 & $33 \%$ \\
\hline & $\begin{array}{l}\text { Coordination } \\
\text { function }\end{array}$ & 5 & $25 \%$ \\
\hline & national background & 4 & $25 \%$ \\
\hline & $\begin{array}{l}\text { Adaptability and } \\
\text { flexibility }\end{array}$ & 4 & $25 \%$ \\
\hline & Freelancer & 2 & $17 \%$ \\
\hline
\end{tabular}

Table 5: Categories and codes derived from the analysis of interviews conducted at VA TECH (Souce: Author)

For the presentation of the categories we start with contextual influences on MNT performance (industry and organization). Next, we will provide information about team size, team composition and structure at VA TECH and stress the importance of task interdependence and identified MNT norms and values. We will conclude this part of the empirical analysis with a presentation of the role of MNT leaders and members. Table 6 presents a short summary of major empirical findings from VA TECH. 


\begin{tabular}{|c|c|}
\hline \multicolumn{2}{|r|}{ Major empirical findings } \\
\hline Industry & $\begin{array}{l}\text { Unexpected fluctuations in order-intake, which are caused by } \\
\text { industry turbulence, result in uncertainty and stress. They } \\
\text { have an impact on MNTs since teams react to them in order } \\
\text { to adjust their strategies. }\end{array}$ \\
\hline $\begin{array}{l}\text { Organisational } \\
\text { culture }\end{array}$ & $\begin{array}{l}\text { VA TECH does not have a strong task/achievement culture } \\
\text { since the company has been highly decentralized and has } \\
\text { undergone several mergers. However, the corporate culture is } \\
\text { strong enough to create an environment that stimulates } \\
\text { MNTs to perform and contribute to the reduction of com- } \\
\text { plexity inherent in multinational companies. }\end{array}$ \\
\hline $\begin{array}{l}\text { Organisational } \\
\text { structure }\end{array}$ & $\begin{array}{l}\text { The strength and performance of HRM has a positive impact } \\
\text { on MNT performance in companies with a matrix structure, } \\
\text { where human resource managers are responsible for dele- } \\
\text { gating the right people to projects where their skills and } \\
\text { abilities are immediately needed. Yet the withdrawal of team } \\
\text { members due to the need to apply specialised expertise to } \\
\text { other projects may harm MNT performance. }\end{array}$ \\
\hline $\begin{array}{l}\text { Organisational } \\
\text { strategy }\end{array}$ & $\begin{array}{l}\text { Despite the fact that the company focuses on cost savings and } \\
\text { pursues a global strategy, diversity in MNTs is very benefi- } \\
\text { cial. Important knowledge about different markets, custom- } \\
\text { ers, distribution partners, local competitors etc. is shared } \\
\text { within the team and then applied in order to successfully } \\
\text { enter new markets. }\end{array}$ \\
\hline Team task & $\begin{array}{l}\text { Task interdependence increases the need for cooperation } \\
\text { between MNT members and facilitates the exploration and } \\
\text { exploitation of tacit knowledge. }\end{array}$ \\
\hline $\begin{array}{l}\text { MNT } \\
\text { composition }\end{array}$ & $\begin{array}{l}\text { MNTs at VA TECH consist of three or more individuals who } \\
\text { interact directly or indirectly for the accomplishment of a } \\
\text { common goal and who come from two or more different } \\
\text { cultural or national backgrounds. } \\
\text { The category "norms and values of behaviour of team mem- } \\
\text { bers" consists of } 68 \text { quotations and has been reported by } 58 \% \\
\text { of interview partners. Several cultural standards have been } \\
\text { identified indicating that team leaders and team members } \\
\text { should be aware of different kinds of perceiving, thinking, } \\
\text { judging, and acting that regulate behaviour of people from } \\
\text { other societies. They should use this knowledge for prelimi- } \\
\text { nary business planning. Especially in the initial stage of team } \\
\text { building, this knowledge can be helpful for understanding } \\
\text { differences, avoiding stereotyping and creating cohesion and } \\
\text { solidarity in the team. In addition, learning acculturation has }\end{array}$ \\
\hline
\end{tabular}




\begin{tabular}{|l|l|}
\hline & $\begin{array}{l}\text { a strong moderating effect on team members. Mutual inter- } \\
\text { actions of team members over a certain period of time have a } \\
\text { strong impact on their identities, societal values and norms of } \\
\text { behaviour, creating hybrid cultures. } \\
\text { Fraction into three or more subgroups facilitates the creation } \\
\text { of a positive motivational climate in MNTs through greater } \\
\text { information sharing about personal traits, backgrounds, and } \\
\text { interests, while in MNTs consisting of two major partners } \\
\text { demographic diversity creates faultlines, since demographic } \\
\text { characteristics divide the network into two subgroups. }\end{array}$ \\
\hline MNT norms & $\begin{array}{l}\text { The impact of a norm on effectiveness has been shown to } \\
\text { depend both on its content and its context. The context of the } \\
\text { corporate culture is not so strong in the case of VA TECH. } \\
\text { Team norms are more dependent on team context. }\end{array}$ \\
\hline MNT leader & $\begin{array}{l}\text { We could identify several competencies that are considered } \\
\text { as important by MNT leaders and members. The most } \\
\text { frequently mentioned competencies are setting and commu- } \\
\text { nicating common goals, coordinating, making the right deci- } \\
\text { sions on time, delegating tasks and providing team leader- } \\
\text { ship. Moreover, successful team leaders turn out to be } \\
\text { socially and cross-culturally competent, multilingual and to } \\
\text { have project-management skills, long working experience } \\
\text { and the knowledge required to manage the challenging tasks. }\end{array}$ \\
\hline MNT member & $\begin{array}{l}\text { To demonstrate open-mindedness, to have the ability to ad- } \\
\text { just well to new situations, tasks and requirements and to } \\
\text { show cross-cultural competence are the characteristics of } \\
\text { team members of successful teams. }\end{array}$ \\
\hline
\end{tabular}

Table 6: Major empirical findings from VA TECH (Source: Author)

\subsection{High-tech industry}

Unexpected fluctuations in order-intake, which are caused by industry turbulence (e.g., high competition, high corruption rates in foreign markets, different legal systems and legal requirements in different countries, cartel formation in the industry etc.), result in uncertainty and stress. They have an impact on MNTs since teams react to them in order to adjust their strategies. The company under study operates in the high-tech industry that is characterised by intense competition and constant need for innovation and speed. Project teams have been part of the organizational landscape in the high-tech industry for quite a while. Their capacity to do multiple activities simultaneously, rather than sequentially, saves 
time and consequently, companies are expanding their use of project teams as a response to time-based competition (Stalk and Hout, 1990).

Multinational project teams are time limited. When a project is completed, the members either return to their functional units or move on to the next project. Members are drawn from different disciplines and functional units, so that specialized expertise can be applied to the project at hand. In some cases, they even involve external alliance partners, since they may lack the resources, know-how and time necessary to complete the project without external support. The following quotations from team members illustrate how stress, unexpected external factors and industry situation influence multinational project teams' performance:

"However, these people will then quickly be replaced. After all, there's a lot of money involved in our projects. The order value is $200 \mathrm{~m}$ to $300 \mathrm{~m}$ euros. And nobody wants to know whether it can be done or not. It has to. A new team member is appointed who has to show performance fast, or else... There is an immense pressure to deliver (P23: VA TECH 22; 156:156). "

"Well, more likely someone gives the wrong answer, wrong answer, well for him the right answer and for the rest the wrong answer, because of overload or stress or something, and then he calms down again and you can talk about it again. But there's no special event, it just happens, happens periodically, where each of us goes "I don't want anymore, I can't go on" or something like that (P24: VA TECH 11; 93:93)."

"The project I mentioned in Zambia, it was such an intensive project, it was such a short timeframe, and there was so much stress involved that many people lost the view where they were headed (P21: VA TECH 32; 119:119)."

"Well. When some people were under pressure, they accused others. But that's normal. That's not a problem. When people are under pressure, they react differently than when they're not. People, who normally get along, suddenly don't get along. This can lead to short-term quarrelling. But in this team there's a good atmosphere. Probably because everything works according to plan and nothing goes wrong. In many other projects many things go wrong and then people start blaming each other. This immediately poisons the atmosphere. We are lucky in that everything works, everything according to plan. Deliveries arrive. We are just lucky everything works fine (P23: VA TECH 11; 96:96).

In our opinion, MNT information that should be relayed should also include the type of company and the local and global situation in the industry at the time when the research study was conducted. This information is essential for the development of an understanding of the results obtained by providing a context 
for them. Companies in different industries will implement different kinds of MNTs (e.g., multinational task forces, multinational project teams, multinational marketing teams etc.) and team composition, team members' requirements, team tasks and team climate will depend on the industry and the situation at the time when the study was conducted. According to Jelinek and Wilson (2005), researchers studying MNTs have tended to focus on factors at the organizational or group level of analysis. However, MNT researchers cannot afford to continue to ignore factors beyond the organizational level of analysis, if they want to explain and predict the behaviour of MNTs and their members (Jelinek and Wilson, 2005).

\subsection{Organisational context: $V A$ TECH}

\subsubsection{Organisational culture of VA TECH}

According to Harrison $(1972,1987,1990)$, there are four different types of organisational culture. These are power culture, role cultures, task/achievement cultures and person/support cultures. The data shows that VA TECH has a task/achievement culture. In such corporate cultures it is more important to know what has to be achieved and not to focus too much on how to achieve particular goals. Consequently, skills and abilities of individual employees are more important than their individual position in the company or the acceptance of rigidly defined rules and norms of behaviour. Hofstede et al. (1990) who measured organisational culture on six different dimensions would characterise this type of corporate culture as "results-oriented". Task/achievement cultures are characterised by a high degree of flexibility and individual responsibility. This creates a motivational climate that encourages creativity and gives employees more freedom to make their own decisions. In difficult situations, task/achievement cultures turn into role cultures since they lack a formal authority. VA TECH is more employeeoriented. The company shows more concern for people than for getting the job done. Team members identify more with their type of job than the organization. The communication climate is very open.

Employees from VA TECH have described the company's corporate culture as follows (It should be mentioned that these interviews were conducted in July 2005. This same year VA TECH was taken over by Siemens.):

"Well, here with this business-oriented thinking, this typical entrepreneurship people keep talking about, here you are not subject to so many rules and structures, you have a lot of freedom, you can think outside the box, make 
decisions beyond the core business, which is not that easy to do at Siemens I think (P18: VA TECH 35; 170:170). “

"I.e. many of these lateral thinkers sometimes, how shall I put it, these free spirits that are difficult to control, but which were a great asset to our company, you will find few of these, or significantly fewer than here, at Siemens (P18: VA TECH 37; 178:178). “

VA TECH does not have a strong, culture. The company has been highly decentralized and has undergone several mergers before the takeover by Siemens last year. This can be seen from the following quotation:

"We have this common spirit that has only developed now during the takeover, when defending ourselves that is, which has forged us together. We now have a $V A$ TECH awareness that didn't exist to this extent at all 18 months ago and this is really my answer, we have something, yes that depends on the situation, that wasn't created by VA TECH internally, without this I would say we have no uniform culture, no common vision, no common mission, we have written this down, we have, we are also getting better at this, I fully admit this, but we are far away from having something like this because we are living it (P18: VA TECH 112; 479:479)."

The organization supports team work. This type of corporate culture contributes to team success, since teams have enough freedom to develop their own cultures and they act in accordance with newly developed rules and norms of behaviour. They are responsible for doing the planning, decision making, and implementation of the work. This way they can more easily adopt and enhance their ability to meet the needs of changing external circumstances. Teams form their own cultures and they perform more effectively with their own types of culture.

This dissertation is part of a comprehensive empirical study on MNTs in business organisations in a cross-cultural context which has been conducted in fourteen different companies (e.g., Siemens, IBM, VA TECH, Henkel, K\&M International, Pöyry, OMV, Bombardier etc.) with different types of corporate culture. Due to the limited scope of the dissertation it is not possible and also not required to present all these findings. Yet we would like to mention that companies with task/achievement cultures are more successful in creating an environment and a motivational climate where MNTs perform successfully and contribute to the reduction of the complexity inherent in the organisation. This is not the case for companies with a role culture characterised by logic, rationality and highest effectiveness. This type of culture turns out to be detrimental for the implementation of MNTs. 


\subsubsection{Organisational structure of VA TECH}

\section{Matrix structure and the role of Human Resource Management (HRM)}

The project teams at VA TECH are embedded in a matrix structure. The findings indicate that an effective matrix structure is one of the organisational conditions under which such teamwork flourishes in multinational companies. An organisation must be able to quickly mobilize employees with diverse capabilities into well functioning teams to respond to new challenges and contribute to a company's success. Project teams are time limited and they come from different disciplines and organisational units. They save time by doing multiple activities simultaneously. HRM is one important component that can help an organisation with a matrix structure to improve team effectiveness by delegating the right employees to projects were their skills are immediately needed and by developing their skills, knowledge and motivation. Central here is the resource based perspective (Barney, 1991). According to Barney (1991), a firm's human resources are believed to have implications for firm performance and provide a unique source of competitive advantage that is difficult to replicate. The results show that the effectiveness of the HRM system could have contributed to multinational project team success at VA TECH, but this has not been the case. The HRD has not been aware of the qualifications of its employees and consequently people with wrong qualifications have been delegated to projects were members with different skills have been needed. This is probably one of the biggest weaknesses of VA TECH. Due to the downsizing strategy qualified people have usually been fired. Consequently, there has been a lack of qualified team members for the different tasks that have to be fulfilled in project teams. In 1999 the company had 21,711 employees, while in 2004 this number decreased to 16,562 (see Table 4). The following quotations describe how important it is to have the right people with right qualifications on the right positions in a matrix structure in order to be effective. Due to the lack of people with required skills and the inability of the HRD to delegate the right employees to right position VA TECH has been facing many difficulties:

"Well, I've had to deal with structures and organisation systems so much. I don't even know where I am right now or where I should start with my answer. I've thought about this so much, for years, about vertical, horizontal, business units, divisional, structures, matrix structures, basically I would say each structure works if the players within the structure are good, that is, good in this case also means they fit the requirements of the structure, of this particular structure. Well I think, to discuss this rather superficially, the question whether a matrix structure works for me is totally irrelevant, as long as I can make sure that the players in the matrix, particularly at the interfaces of course, that's the main 
issue to make sure these are capable to function properly, i.e. to find solutions and work with the others and handle conflicts, then every matrix works fine for me. And no matter how well-structured they are, what the guidelines for decisionmaking are, if there are people in the matrix, and the crucial interfaces, who cannot handle this, they will fail, in this case you can have hundreds of pages of process descriptions and rules, you need someone to live and communicate this all (P18: VA TECH 104; 419:419). “

"Well, regarding these structures, I'm still convinced there is no way you can work without a real matrix because we simply are too multidimensional. .... The main point for me is simply to have the right people at the really critical interfacing positions, and then everything works. Well, really, I am a great advocate of the statement that with the right people you can achieve anything (P18: VA TECH 105; 425:25). “

Past research has ignored the link between HRM practices, team effectiveness and firm performance. The following statement by the general secretary of VA TECH indicates one big weakness of the company under study. This is again the inability of the HRM to delegate the right people to the projects were their skills are immediately needed:

"And this is exactly why in so many companies I'm missing the appreciation or also maybe the importance of HR, which in my opinion is a blatant show of incompetence.... Naturally every head of personnel will tell you, well I cannot know what personnel requirements the divisional head exactly has. Returned the answer to you straight away, well for heaven's sake, you will have to talk to him, that's part of your task. And then, as the person responsible for personnel you and no-one else simply have to create the right environment to first, determine what requirements there are in our company, generally, regarding people, human resources. ..... what type of training systems do we need, which incentive systems do we need, how do we get that into our company structure and company culture? .... Again and again I'm totally frustrated when I see companies really tumble on their way to success and totally neglect the most important thing they need, and that's the human resources, by leaving that to some HR manager who doesn't do his job properly ... And this leads us to managing projects, understanding project objectives, establishing requirements, defining the path towards achieving objectives and then distribute the respective tasks and modules. If an $H R$ project leader did this here, I think we would be massively successful (P18: VA TECH 106; 425:425).

"And again we're talking about HR. And this is not top management or divisional management; it could be managing a team of 5 to 8 , maybe up to 10 people. If this team leader has been the wrong person for the job in the first 
place, and there are maybe three or four difficult people in the team, you can forget the team's performance, this will cost money, this reduces performance, here the offers will be made, there the projects will be managed and all that in such an environment, terrible (P18: VA TECH 109; 458:458). “"

Research on MNTs has ignored to measure or evaluate the impact of HRM systems on MNT climate and performance. Future research should consider its role more explicitly and explore the interplay between HRM and project teams in a matrix structure. The performance of HRM will have a positive impact on MNT performance in companies with a matrix structure where human resource managers are responsible for delegating the right people to projects where their skills and abilities are immediately needed.

\section{The withdrawal of team members and collective team identification}

The rules for how team members relate to one another and interact socially are important in creating a healthy social environment within a team. Given team members' diversity of values and assumptions about appropriate interaction, developing clear rules can be highly complex and time consuming in MNTs. Members from different cultures will have their own values and norms of behaviour. Through intense interaction with other employees they may change their perspectives and adopt new working styles. Yet this process takes time. But what happens if team members are repeatedly being withdrawn from the team? Withdrawal has turned out to be a key concern in MNTs, since the disruption caused by withdrawal of team members can harm team functioning and the motivational climate within a team. This positive motivational climate can be achieved if team members have considerable time to develop a sense of identification with the team and identify with their group members. Such teams are also more likely to behave in a cooperative way showing the willingness to share information and ideas in order to meet team goals (Gerben et al., 2005). It is important to have one core team consisting of employees who are involved in pursuing team goals from the beginning of the project until its end. Otherwise, it is impossible to develop a sense of identification in a team as reported by several team members:

"And this is mainly about information exchange, to establish a team and when people are on the 1st, 2nd, $3^{\text {rd }}, 4^{\text {th }}$ floors, they won't be a team and they won't feel part of a whole. Well, this really is a central topic cropping up again and again, no matter whether you work in a national or international context. It is important to have a location, a core team everything else centres around. Whether person number 45 is an ardent supporter of this idea and totally loyal, that's a different matter. But the core has to be there. And if the core's fine, the whole team spirit is fine. This can be supported by simple logistical things, like sitting next to each other (P27: VA TECH 20; 34:34). 
"As I said, that's not always the same people. On average, that's twenty to thirty people that always change. Especially the technicians are here first and then the work in the head office decreases. Some shifts to the construction site.... People come and go all the time. It's not like there's a group that's emerging that sees itself as a homogenous group. The whole team gets mixed up all the time, construction site and here, so that they see themselves as one big project team rather than have their own group identity (P20: VA TECH 20; 95:95). "

"You have to be careful. These group-specific phenomena that appear when you have a group of twenty people together. Naturally we haven't got that here, but a team that's constantly changing (P20: VA TECH 21; 105:105).

Obviously, the matrix structure and the need to withdraw team members from a team at any time harm team functioning and team climate. The empirical findings show that learning to accept the standards shared by members of an MNT always presents a challenge for a new member. It takes time to learn new ways to interact and communicate in an MNT, to get familiar with new role expectations and the values about appropriate interaction in the team.

According to Gerben et al. (2005), managers need to consider the motivational climate that exists within the group and, more specifically, the extent to which members emotionally identify with their group in order to understand whether a given level of expertise diversity in a group will have positive or negative implications for group performance. Gerben et al. (2005) have found that under conditions of low collective team identification, the relationship between expertise diversity and performance is not significant, whereas under conditions of high collective team identification, the relationship between expertise diversity and performance is positive. The focus of this study is on diversity in task-related expertise rather than on diversity in cultural characteristics of team members. Our study shows that withdrawal is a key concern in MNTs because of high interdependence between team members and the need to develop trust and emotionally identify with the team. Withdrawing of competent members may harm team functioning and the creation of a collective team identification.

\subsubsection{Organizational strategy of VA TECH}

The context of an organization also includes its competitive strategy (Jackson et al., 2003). VA TECH has operated in the high-tech industry and has pursued a global strategy by offering standardised products to its customers. The diversity of its workforce has brought cultural sensitivity that is very important when the company enters new markets and tries to reach different market segments. The 
demographic diversity has increased the available pool of perspectives, styles, knowledge, and insights that employees bring to bear on complex problems. Team members share and apply their knowledge. Individual team member's knowledge of the local language and the culture of the markets where the company operates and builds its facilities help maintain communication richness and the effective information flow with customers and local suppliers. This can be seen from the following quotation by a team member:

"Well. I think.... Austrians get along well with each other much faster than with other nationalities. In this particular team it was no problem for different nationalities to work together. It certainly had advantages. And people, for instance, who have English as their mother tongue understand all these terms of the contract much better. So they can formulate things much better if there are critical points to the contract. If, for instance, Italians from our team delivered the steam turbines they got along great with the Greeks, who placed the order. Somehow it seems to work better with them. They get along much faster. In this particular case it certainly has many advantages (P23: VA TECH 12; 106:106).

Team members share, apply and create new knowledge. The knowledge exploitation and exploration are indispensable and they increase the company's competitive advantage. Individuals acquire, process, and disseminate their knowledge about their home market, products, technologies, business processes etc. that is based on their personal experience of conducting business in the local market and the information from local customers, suppliers, competitors, and other sources. Through the intensity of interpersonal interaction based on mutual trust and respect, team members secure vital tacit knowledge about different niche markets. Knowledge exploitation takes place when existing knowledge is shared by team members in the team. On the other hand, knowledge exploration is triggered by the exhaustive discussions during meetings and leads to the creation of new knowledge and determination of new strategies. The intense interaction between individual team members and the motivational team climate support these knowledge sharing activities. This observation is consistent with the need for a positive interactive atmosphere not merely at the beginning of interactions but also throughout their duration (Holden, 2004) and with the central role of socialisation for knowledge creation and sharing (Nonaka and Takeuchi, 1995). By getting to know individual team members on a personal level, employees create trust and this facilitates the information exchange. Fifty percent of my respondents have stressed the importance of socialisation for team effectiveness:

"Very good! It was so good we even had breakfast together every day at the construction site and discussed the schedule for the day. In fact, added a real social component with the project manager. We sat together in his room, he had a nice big table. There were all these topics we had to do with, regarding the manage- 
ment of the site, commissioning engineers, systems engineers. These 6 people sat together in the morning having coffee and they were going through what was to be done, where are the objectives, where is there room for improvement, which strategy should we select, new ideas were exchanged, new strategies were fixed (P26: VA TECH 19; 98:98). “

"And we live it with the good teams, by getting together after work and playing pool, or occasionally the English can excel at their national sports, then we invite them bowling and show them how to keep the ball rolling. This is where you make, which then make the differences insignificant, here you realize it is all the same and you exchange important information and think about new strategies how to work the market better ... (P25: VA TECH 39; 121:121). “

"There's a large number of kick-offs, there are sub-kick-offs, whatever, and then there's the official start, where the team members are to introduce themselves to each other, make clear who's on the team, who is part of the team. Ideally this takes place somewhere else, not really within a company setting in some meeting room, but maybe even a day or two at a seminar hotel at a nice location, where there's a chance to talk to people on a different level, not just project-related. ....You get to know each other and it's an official start and things start off differently, psychologically even, than when someone just starts to work here or there. This already provides a structure of a team. Not unimportant in projectoriented companies (P27: VA TECH 25; 47:47).

The teams at VA TECH have existed in harmony with the rest of the organization and their behaviour has been congruent with the strategic goals of the organization. The knowledge has been shared and created through intense interaction between individual team members with different cultural backgrounds. This knowledge has existed within the teams. The company has never made the effort to codify this knowledge and to enable employees from other divisions of the organisation to take advantage of it. This has remained probably one big weakness of VA TECH. Yet teams have benefited from the knowledge about different markets, customer attitudes and preferences, different negotiation styles etc. that has been shared within the group and then applied in order to successfully enter new markets and negotiate with customers from different countries.

Despite the fact that the company has focused on cost saving and has pursued a global strategy, diversity has turned out to be very beneficial. According to Richard's findings (2000) the relationship between cultural diversity and a firm's performance will be moderated by a business strategy. Consequently, higher cultural diversity is positively related to firm performance when the firm pursues a growth strategy and negatively related to firm performance when the firm pursues a downsizing strategy (see Table 4). The results of the study conducted by 
Richard (2000) have shown that downsizing firms with high diversity have the lowest productivity gains. Yet this is not in accordance with our study. By facilitating knowledge exploitation and knowledge exploration multinational project teams increase company's competitive advantage.

\subsection{Team task and task interdependence}

The type of task that has to be accomplished by team members has an impact on team processes. Interdependence, whether based in task inputs or in shared goals and rewards, increases the need for cooperation between team members and facilitates the exploration and exploitation of tacit knowledge. Members must interact in order to complete a task. The findings show that task interdependence results in more cooperative behaviour and information sharing and strengthens team cohesion that motivates team members to jointly discuss organizational policies and practices and to interpret the team's experiences:

"As the systems cannot function independently from each other, there is a lot of interaction between these people. Those responsible for their own area also have to take the interfaces to the other systems into consideration. And this is why there's such an active information exchange between these people (P26: VA TECH 6; 68:68).

“...... as a central contact point possibly provides support with some specific problems, where we get together in a Jour Fix and discuss this problem, farther reaching effects, that you say, for instance, this team member has already experienced this, so you have to put him together with the other team members currently having this problem and they look at it together. This results in this unified process (P27: VA TECH 10; 26:26). “

"We work with each other and not independently from one another. And this has indeed resulted in something positive, some team spirit. I think, when there is a party on finishing the project, they'll pat each others' backs, and the negative aspects will be seen as almost irrelevant and less important (P25: VA TECH 26; 103:103)."

A different picture may emerge when individual team members' tasks are not interdependent.

"That's a good question. Well I'd say you've hit the point there. Well, I wouldn't dare say that I've succeeded in getting good cooperation there, it is more a well functioning working next to each other, in rare cases where some matters 
concern more than one team also with each other, but not generally working with each other. Simply speaking, the tasks are clearly defined and so the tasks are handled in the individual groups (P18: VA TECH 19; 126:126).'

The literature supports the findings and says that task interdependence requires and results in more cooperative behaviour and information sharing than does individual-based work (Campion et al., 1993; Campion et al., 1996; Janz et al., 1997). Strong ties between members should therefore develop in interdependent work environments (Kozlowski and Klein, 2000). The results of a study on intrateam interdependence and team identification show that for team members working under congruent conditions of low task and low goal interdependence, little interaction is required. They pursue their personal interests with low potential for conflict (Saavedra et al., 1993). A different picture may emerge when individual team members work under conditions of high task interdependence and high goal interdependence. They have to work together and need each other to achieve common goals. Congruent task and goal interdependence create a positive climate in which dissimilar team members are stimulated to explore and exchange their different perspectives and opinions and to manifest creativity and innovative behaviour (Van Der Vegt at al., 2005).

\subsection{Multinational team composition and functioning at VA TECH}

\subsubsection{Team size and composition at VA TECH}

MNTs at VA TECH consist of individuals from different countries, functions and divisions of the corporation. Sometimes, they also involve external alliance partners. Specialized expertise can be applied to the project at hand. When a project is completed, the members either return to their functional units or move on to the next project. Their ability to draw the best expertise regardless of where it resides and the capability of the interaction medium to capture a large portion of team processes and products is probably their biggest advantage. Multinational project teams are semi-virtual networks. The core team has one location and there is not a high fluctuation within this team. Many different nationalities are involved in such projects as can be seen from the following quotation from a team member:

"The people coming from $V A T E C H$, the original company, are definitely not all Austrians. There are Brits, Finns, Germans, from all sorts of countries, then especially in Northern Ireland there are people who know the market much better. They are mainly British or Irish. They are then involved in the project as team members. In Vienna it is 20 people working closely together. But that's not 
always the same. There are 20 to 30 people taking turns. Sometimes they're here, sometimes in Ireland. They are sent abroad for a couple of months and then they return (P20: VA TECH 3; 32:32). “

Project teams have been part of the organizational landscape for quite a while. Their capacity to do multiple activities simultaneously, rather than sequentially, saves time. Consequently, companies are expanding their use of project teams as a response to time-based competition (Stalk and Hout, 1990). In order to better understand study results, we recommend that in future researchers should provide more detailed information concerning the functions represented on the team, the percentage of time that members are dedicated to the team, the degree of cultural heterogeneity and the geographic location of individual team members.

\subsubsection{Different cultural standards of team members and their impact on MNT performance}

Norms and values of behaviour of individual team members influence MNT performance. Team members from different countries bring different exogenous societal factors into the team. Different norms of communicating, making decisions or resolving conflicts sometimes result in lower levels of team performance and team member satisfaction. By asking the interview partners if they could remember any critical incidents that emerged through interaction with employees from different countries in the team, we could collect cultural standards that are based on the values in members' national culture.

Austrian team members have reported that the different ways of Chinese, Indonesian and Malaysian colleagues to interpret their environment, think, feel and act create barriers that hamper smooth cooperation. Harmony in their relationship is very important and they hesitate to criticise other team members. Austrians have to adopt a new communication style and to learn new ways how to indirectly criticize Chinese, Indonesian and Malaysian employees in order to avoid critical incidents. This can be seen from the following quotations:

"Oh yes, it's possible you're ignored and if you criticised someone in a negative and specific manner and maybe did that impolitely, then it's possible that you have to suffer the consequences for a long time. So offending people is a big issue, generally with the Chinese, and I think that comes from a Chinese context, to lose face. You should give others the chance, in the Asian region, even if they were talking rubbish, to keep face and to wrangle out of this situation, without them losing face. Lose face is, to get to feel this version and also to learn it in the Asian region (P27: VA TECH 31; 62:62). “ 
"Especially when criticising, with Indonesians, criticising people is a terrible issue. ...... In Indonesia, I'd say generally in South East Asia you'll very rarely find that. You have to wrap up any criticism in nice words, in such a way that if it can't be avoided that someone is to blame, you have to look for someone, or if it can't be helped, you have to invent someone to blame, someone seems to have made a terrible mistake, knowing it was the person you are talking to, but you mustn't say so. You have to let him keep face and that has obviously been the greatest challenge for me in all I did in project organization, to keep together this teambuilding and also team management (P18: VA TECH 63; 258:258).

"You'll mainly see this in Malaysia. Well, in Malaysia you have all these different peoples and there's the Chinese, the Indians and the Malays. And what they probably have in common is that nobody wants to admit when they've made a mistake. This goes as far as people giving you the wrong information rather than none at all. With clearly expressed criticisms, which are perceived as criticism, you won't achieve anything anywhere in the Asian region. And if you make it personal, that's the end. You need to develop the right feeling for this, how to handle people, how to put it, how he could do that a little bit better and it really depends on how you communicate this, how you present yourself and treat others, in other words it's all about the interpersonal level (P27: VA TECH 44; 85:85). "

These findings are in accordance with the results obtained in a study conducted by Vallaster (2005), who reports results from three longitudinal studies carried out to understand the social interactive processes on multicultural groups observed in their organizational settings. The studies show how Chinese members tend to adopt an acceptance-based attitude that is characterised by only minor and careful questioning of issues and situations and why they tend to avoid any direct criticism. Shen-Wei Hwong (2001) identifies the desire and need for harmony and respect as important Chinese cultural standards. Our data supports these findings.

Critical incidents caused through interactions with Italian team members have also been reported. Through their synchronic perception of time and the tendency to do several things at once they are late with deliveries of important documents. Moreover, their negotiation style is very confusing and this creates additional challenges for Austrian team members:

"With the Italians, agreement rather leads to the talks coming to an end and then the real negotiating tactics start. In the beginning this was strange, to finish talks and then, when processing and finalising the documents, notes, plans to really start the discussions. Now, the dialogue took place on various levels and very differently than we had expected. .......We had thought that Central European project management would be similar, but that isn't really so. 
We fell for that trap. We could have prepared for that ..... (P25: VA TECH 14; 55:55). “

"If you raise a topic to early, they won't listen to you at all in Italy. They'll only start the dialogue once it becomes terribly urgent. And then there's the question whether you trust the Italians' talent for improvisation. And we just didn't have the time anymore to put much trust in anything. We had to bear it. Yes, bearing it is probably the right word. Although some of the deadlines were actually met .... Therefore afterwards it's much less dramatic than during the phase where this gap appears, where we say: Now it's really about time and the Italians say: We'll start not before the day after tomorrow. This last minute speed-up, they're really cutting it close, much more than we do. They improvise more (P25: VA TECH 18; 76:76). “

"Something we can't do, this instant switching. The Italians also discuss things hotly, hot-blooded we say, but they switch back, once the discussion is over, and you're back to the starting phase. This is different where we are from, this always has an effect and that's the biggest difference .... (P25: VA TECH 28; 112:112).

Valtingojer (2005), who has studied Italian cultural standards, call this negotiation style "Diskursive Kultur". According to his findings, Austrians tend to be confused when they discuss important issues with business partners from Italy, since they are not used to speak extensively and simultaneously about multiple topics not previously mentioned in the agenda. They can not follow all the details of the discussion.

In MNTs, individual team members serve as entry points for the influences of societal factors. The findings show that different cultural standards of team members have a strong impact on MNT processes and its performance.

\subsubsection{Learning processes within the team and the effect of time on cultural standards of MNT members}

An MNT entails differences among members in language, interpersonal styles, and a host of other factors. Yet over time team members reconstruct their identities and adopt new perspectives, new sets of rules and norms of behaviour, expectations and perceptions. Time has a moderating effect on MNT members. Learning processes within the team help to overcome insufficiencies in the performance of individuals. These learning processes also change MNT members' prior rules, procedures, norms of behaviour and communication. Team members' 
cultural standards are subject to change over time due to an intense interaction with employees from different countries. They accept the practices of team members with different cultural backgrounds and different working and managerial styles as they are, and then they actively integrate them into their working culture. In this way they improve their performance through an on-going integration of different cultural values and norms of behaviour that they find useful and appropriate. After intense mutual interactions with Italian and English team members in a multinational project team, Austrians have reported how they adopt certain practices to fit Italian and English culture and improve the overall effectiveness of the team, as can be seen from the following three quotations from Austrian employees:

"What worked perfectly was that we benefited from the Italians' experience, because we could copy that for our work. With these positive effects, they regained our respect, which had been pretty much lost .... In Austria this wouldn't have happened like this, in a non-multinational project we would have taken all sorts of other steps to avoid this. That hasn't happened there (P25: VA TECH 22; 89:90).

"In general, in these international teams.... the main decision-makers are English or British and they were more or less pushing things and the people actually responsible for it, they naturally were rather the Austrians and that of course resulted in a clash. Because if the one side pushes and sees it as their responsibility ..... On the other hand, the Austrians, who come from their bureaucratic system, they have to follow their reporting standards, follow the internal structures, another pair of eyes should see more, that's what makes everything even more complex. And you're moving between these forces. I'd say there is a lot of potential of banging your heads. Basically there's always some form of alignment process. We get a little more flexible, depends on the area, in case of multimillion problem cases the whole thing's difficult and not so flexible, and with the smaller things, that aren't that important, we more readily make decisions. And then there's this alignment process, where the others see how the Austrians work and we see how the English work. And occasionally there will be nice synergy effects (P27: VA TECH 34; 55:55)."

"The way our colleagues reacted to us. But also the formalisms of the English. Well we had certain problems to adapt, both with the English-language project leaders, because we didn't meet their expectations regarding work procedures, from our point of view as I said a little bit too bureaucratic the way they acted. ... Later we adapted. Then people began to reflect, that is, to show the same behaviour with withheld information, or to go for the greater formalism by squeezing particular questions in particular forms and creating a bureaucracy, 
which now after the event helps us with claim management, because everything is documented in writing, but back then it hampered the project's progress a little bit. We simply had expected to proceed faster and ended up with a fairly bureaucratic process (P25: VA TECH 7; 43:43)."

Through the free flow of information and new ideas and through intense mutual interactions team members adopt new sets of rules and actions and they change their working practices. This observation is in accordance with the results of a study conducted by Early and Mosakowski (2001). They have found that heterogeneity has a detrimental impact on team functioning in the beginning. Over time, the teams form new ways of interaction and communication and the impact of heterogeneity on team performance becomes curvilinear. The findings and the results of this study show that cultural values and norms are subject to change and team members may adopt new perspectives and working styles through constant interaction with employees with different cultural backgrounds. Consequently, their predominantly held cultural identities should not be seen in fixed and unchanged national terms. Temporal factors impact MNT members. The fact that longitudinal investigations are less pursued in practice leads to the pattern of mixed results for studies of international diversity. The predominately held cultural values of members from one society have an impact on team performance, since individuals can be regarded as carriers of societal factors into the team (Jelinek and Wilson, 2005). Yet through the interaction with individuals from other societies these values are affected and team members tend to co-create their culturally determined frames of reference. Prior studies that have used such measures as collectivism or individualism or have tried to assess the influence of the relative cultural distance between team members on team effectiveness have ignored the effect that over a certain period of time mutual and intense interaction of team members may have on their identities, societal values and norms of behaviour.

MNT members' values and norms of behaviour are affected by what they find in the team, by the negotiated team culture and by the interactions in which they take part. Based on the data at hand we support Larkey's (1996; in Vallaster, 2005) suggestion that before being able to work together efficiently, culturally diverse group members need to share their perceptions, definitions and frames of reference so that they can later predict how, and explain why, other members react in a certain way. Through learning processes in the team, the sharing and application of tacit knowledge and an intensive interaction with team members from different cultures individuals change their norms of behaviour and adopt new standards, values and working practices. 


\subsubsection{Degree of cultural diversity within MNTs and subgroup formation}

By forming new ways of interaction and communication and bringing different perspectives and information to the team, MNT members increase team performance. This is the case in teams consisting of at least three different nationalities. Splitting into three or more subgroups facilitates the creation of a positive motivational climate in the team through greater information sharing about personality traits, backgrounds, and interests. The likelihood to succeed with the establishment of new norms increases with diversity among team members. These findings are in accordance with the assumption made by Fink et al. (2004) that the larger the team and the more culturally different the members in the team are, the more easily the cause and emergence of conflicts will be reduced. In teams consisting of two major partners, demographic diversity creates faultlines, since demographic characteristics divide the network into subgroups. This phenomenon has also been observed by Lau and Murnighan (1998) and Harrison et al. (1998; in Roberson and Colquitt, 2005). Team members at VA TECH have reported how teams run into problems because of strong subgroup identification:

"There are always some of these. No question. In particular at the construction site, where regional workers, who also live there, have adapted to the environment much better. In the region of Northern Ireland, and they know their way there. And people sent there from here for a year still have some kind of temporary residence and no family around them and for this reason they are guests, who meet like-minded people in this kind of field-trip atmosphere. But outside the family, not like locals do. Naturally there's a tendency to have separate groups amongst the locals and the international people, which is occasionally overcome. Of course, due to personal sympathies, but in certain crisis situations this can cause certain problems. This can be an issue relevant for everyone. (P20: VA TECH 12; 83:83).

"Of course you get larger sub-groups that develop. That's all very fine. Not everyone will be included. I've encountered this only once that this was completely mixed. But then people got together every day. Such group dynamics are possible, but this is not quite the standard, as some of the people live there and the others are only guests. (P20: VA TECH 45; 157:157). "

In MNTs consisting of two major partners demographic diversity will create faultlines, since demographic characteristics will divide the network into two subgroups. These findings are in accordance with the literature. 


\subsection{Team norms and values}

Project teams at VA TECH have the freedom to develop their divergent subcultures and define their own norms. These norms regulate group members' behaviour and they vary within different contexts. Successful norms in R\&D project teams value longer time frames, while norms in other multinational project teams value aggressiveness and shorter time frames. Consequently, we could identify different types of norms that increase team performance. They influence how team members interact and communicate with one another, make decisions, solve problems and give feedback. Team norms are one of the most influential forms of social control over team members' actions. We expected the organisational culture to have a strong impact on the emergence of norms we see operating in multinational project teams. Yet this has not been the case. VA TECH is a company with a weak corporate culture and its teams have the freedom to develop divergent subcultures. They define their own norms and are not forced to pursue the norms set by the organisation. The team leaders have the strongest influence on team members and they define the norms that are agreed upon by team members and permit the teams to regulate members' behaviour. They are responsible for setting the goals and delegating the tasks. Team leaders who manage to define the tasks together with team members, to decide on standards that are shared by all and stress the importance of shared goals can create a motivational climate that motivates all members to contribute to a team's overall success. 'Formulating common goals in the team' is identified as a type of norm that increases team performance at VA TECH.

To have a unified sense of purpose is very important, since the project team at VA TECH work on complex tasks, have frequently changing membership, and work remotely from one another. Under such circumstances, creating shared goals is not a straightforward task. It is the main responsibility of the team leader. This finding is in accordance with the results of other studies. For instance, Early and Mosakowski (2000) have found that team members with a unified sense of purpose and direction are more effective than those with inconsistent and fractionated goals.

One type of norm that is crucial in ensuring team performance is a 'cooperative norm'. Cooperative team norms reflect the degree of importance members place on shared objectives and mutual interests. The emphasis in teams pursuing this norm is on satisfying members' needs and objectives and maintaining harmonious relations. Consequently, members are more willing to share their ideas and knowledge because their rewards are derived from meeting team goals. Team leaders stress the importance of cooperation norms and mutual trust: 
"The biggest challenges ... Yes. The project started really in the tender phase. In the tender phase we had to make an offer to the customer to supply this project, prepare the specifications and the price as well. This was very challenging for me because I have not done this before. The customer is an electricity utility like Wienstrom. So, I did not have much experience in selling projects. So this was very challenging. To execute the project is also very challenging. And sure, it is also very challenging interfacing with all these cultures. At the end of the day it is contract, it is programs, it is certification but behind all of this it is just cultures. So, this is....... This will give you some background. This is the contact. And this contract is based on law of contract. They wrote all of these things in such detail with such specific clauses, if you have any damage, any failure you can claim. But after they wrote all of this they realized that if you are too taught in contract management than the project can fail as well. So the first clause here says.....that the customer and the contractor, which is me, should act under the spirit of mutual trust and cooperation. Spirit of mutual trust and cooperation. It is very important despite you have a contract and you know exactly what you need to do you still should have the ability to act within the spirit of mutual trust and cooperation. So, I really found that between these two companies there was not the spirit of trust and cooperation. Without trust and cooperation sharing of ideas and information was perceived risky and turned to be detrimental to our performance (P20: VA TECH 43; 145:145)."

This finding is in accordance with Chatman and Flynn's (2001) theoretical contribution to MNTs. Their results support a model in which cooperative norms mediate the effects of demographic heterogeneity on work processes and outcomes. It suggests that, in past investigations of teams, researchers have overemphasized the direct influence of demographic composition and failed to appreciate the influence of norms. By pursuing cooperative norms team members stress the importance of shared objectives, mutual interests, and commonalties (Chatman and Flynn, 2001).

A collaborative and diplomatic approach influences how a group's members perceive and interact with one another, approach decisions, and solve problems. Project managers expect their employees to engage problems on a professional level by, first of all, understanding the details that lead to the emergence of the particular problem and then by implementing the right solutions how to solve the problem. Pointing the finger at somebody is not tolerated, since this way people just follow the team leader but they are not encouraged to share their ideas and perspectives with the team. To the extent that a team member is treated fairly, he/she feels satisfied belonging to it and remains attached and committed to it. Moreover, following a diplomatic approach turns out to be crucial in culturally heterogeneous teams: 
"My approach is always a collaborative approach, more or less a democratic approach. I do not like to point a finger. I have not pointed the finger yet. You did that and you did this wrong. It is always to engage the problem on the professional level. Understand the details of the problem and to than implement solutions. So, away from this blaming culture. The second thing is that.... This can be a flow as well. I prefer the democratic way or the diplomatic way. It is always a little bit better. On this level you need to be diplomatic because you are working with people from different cultures that also cause this kind of problems (P22: VA TECH 21; 112:112)."

"The first thing you have to do if you are exposed to a serious problem is to laugh about it and then solve it. And this is also not an Austrian way. How can you laugh if the delivery is too late? Don't point with the finger! Have a diplomatic approach! Stay away from stamping with the fist on the table! You do not get a cooperative approach this way. You just get the people following you (P22: Varech 22; 112:112)."

Mutual trust, respect and tolerance were the most frequently mentioned values by team leaders and team members of different teams in the company:

"And this makes life so easy, to talk to people in their respective languages is easy, it also shows you respect them, I think it's so easy, it's not just skills and competence, it is simply also a matter of respect. This is, by the way, also an integral part of when I say keeping an open mind, this includes respect, no matter what's in store for you (P18: VA TECH 75; 298:298). “

"Tolerance and acceptance for these people's traits and habits (P27: VA TECH 47; 93:93). “

"To be able to trust people in your team is very important (P17: VA TECH 15; 54:54)."

Teams at VA TECH form their norms early. Teams have the freedom to define different norms and are not forced to pursue the norms set by the organisation. Consequently, numerous types of norms that increase team performance have been identified. The impact of a norm on effectiveness has shown to depend both on its content and its context. At VA TECH, the context of the corporate culture is not so strong. Team norms depend on the team context. Our findings show that in companies with a weak corporate culture, MNTs form divergent subcultures and define their own socially shared standards against which the appropriateness of behaviour is evaluated in the team. 


\subsection{Individual team members at VA TECH}

\subsubsection{Team leaders}

Effective team leadership turns out to be one of the most important factors that enable the effective functioning of multinational project teams at VA TECH. We could identify several competencies that are considered as important by MNT leaders and members. In this chapter we will present these MNT leader competences. We report findings that incorporate the perspectives of MNT leaders as well as members on MNT leadership together. Identifying and presenting dual perspectives is not the aim of this dissertation and consequently does not play an important role in this context. Constructive monitoring is one important team leader function. Project managers have to make sure that the team invests time at the beginning of a new project to scope out the key deadlines and responsibilities. This helps also team members to understand who is doing what in the team. Leaders are expected to facilitate MNTs' shared goals by helping team members understand how their mission contributes to the overall business strategy. Consequently, they are responsible for setting and communicating common goals to team members. Communication is considered to be an important MNT leader competency. Project managers who are multilingual are able to bridge the gap between the foreign customer and the company by acting as boundary spanners. Without a leader who can help translate, virtual cooperation is sometimes impossible. Language turns out to be an even higher potential problem than functional or cultural differences in the team. The knowledge of different languages helps team leaders to maintain communication richness and the effective information flow. By knowing the local language of their customers, they can gain more trust and respect and are more likely to get the contract. In order to facilitate the sharing and application of knowledge in the team, successful project managers create norms that encourage team members to communicate among themselves frequently, openly creating a positive motivational climate. Under these circumstances team members identify with their team and they become emotionally attached to their membership in the team. Leaders who can foster a level of collective team identification within the team by increasing the contact among team members through informal events, regular meetings or outdoor activities and supporting and recognising the team are perceived as a good leader by their members. One strong area of agreement among MNT members regards the importance of motivating and inspiring as an MNT leader competency. Team members are coming from different countries, functions and divisions of the company. In a hierarchical set up they have a different boss. Consequently, the project manager doesn't have priority but only consensus-based control over his employees. He has to keep the personal level, the commitment, the interest and the dedication of 
each individual member very strong and to motivate them to spend more time working on his project. Coordination has also been identified as an important MNT leader task. Project managers spend most of their time coordinating the activities of their sub-teams and ensuring a constant information flow between the various parties. Under a high level of uncertainty, intense competition, stress and turbulence in the industry it is important to make quick decisions and give clear directions to team members. To make the right decisions on time and lead the team has been identified as an important function of the project manager. Developing relationships with a variety of people from different countries in MNTs can be a very challenging task. This ability to build relationships is essential in the modern age of team-based organizations. For a leader, it is necessary to be socially competent and to have the required interpersonal abilities. Moreover, he should be a competent cross cultural communicator in order to work effectively with people with different cultural backgrounds. This entails not only the knowledge of the language but also the knowledge of different cultures and different values and norms of behaviour. He should acknowledge differences in behavioural styles of people from different countries, demonstrate flexibility in resolving conflicts between team members and show patience in intercultural situations. Finally, he should have project-management skills, long working experience and the knowledge required to manage the challenging tasks. The functions and characteristics of a MNT leader are summarised and illustrated by quotations in table 7:

\begin{tabular}{|l|l|}
\hline \multicolumn{2}{|c|}{ Team leaders' functions and characteristics } \\
\hline $\begin{array}{l}\text { Delegation of } \\
\text { tasks }\end{array}$ & $\begin{array}{l}\text { "What worked really well was that people at some stage } \\
\text { realised what the expectations were, what was expected of } \\
\text { them. That was an adaptation process, the expectations } \\
\text { were adapted to the player's skills, that also happened, the } \\
\text { players in the process or team weren't just trained until they } \\
\text { knew something, which we wanted, sometimes you have to } \\
\text { accept, OK we have a very valuable employee who is } \\
\text { excellent in negotiating with salespeople, but I would still } \\
\text { handle the legal stuff in this contract with someone else. } \\
\text { That's of course the mutual understanding of all team } \\
\text { members regarding the respective A areas of respon- } \\
\text { sibility, B skills and C areas of operation, and once you've } \\
\text { found a match, where everyone is where he knows what to } \\
\text { do best, then you have the option of turning around and } \\
\text { just let the process go on. And I have to admit that at the } \\
\text { end for me as a project leader, that was where I said that } \\
\text { this worked best, simply putting the people where they } \\
\text { belong (P18: VA TECH 69; 277:277). " }\end{array}$ \\
\hline
\end{tabular}




\begin{tabular}{|c|c|}
\hline Coordination & $\begin{array}{l}\text { "The last thing is do not spend too much time on the details. } \\
\text { Somebody has to have the big picture. If I had to do in } \\
\text { detail I would have to drop the detail work whenever it is } \\
\text { necessarily for somebody to have the big picture. Other- } \\
\text { wise nobody knows what is going on. And the more projects } \\
\text { I was involved in the most I have seen that the person with } \\
\text { the big picture does the least work. O.k. produces the least } \\
\text { amount of paper work. It looks like he is doing the least } \\
\text { work. But if this person is not going around and coordi- } \\
\text { nating and talking to people and keeping them motivated } \\
\text { than the coordination fails. And that I think, keeping the } \\
\text { big picture, keeping the people communicating with each } \\
\text { other these are the most important things (P21:VATECH } \\
36 ; 134: 134) \text {." }\end{array}$ \\
\hline $\begin{array}{l}\text { Knowledge of } \\
\text { foreign language } \\
\text { for effective } \\
\text { communication } \\
\text { with subsidiaries }\end{array}$ & $\begin{array}{l}\text { "No, it might be possible but really the knowledge of Rus- } \\
\text { sian is essential. Without knowledge of Russian it could be } \\
\text { very difficult because there is a lot of call correspondence } \\
\text { written in Russian only. Certain specifications are written } \\
\text { in Russian so it takes some time so I can read it and I can } \\
\text { respond very quickly (P19: VA TECH 4; 47:47)." }\end{array}$ \\
\hline $\begin{array}{l}\text { Ensuring } \\
\text { communication } \\
\text { within the team }\end{array}$ & $\begin{array}{l}\text { "Communication. I know that I mentioned that before. To } \\
\text { make sure that people don't only pass text or data but share } \\
\text { information and work together. He has to make sure that } \\
\text { the environment is fitting to support a real communication } \\
(P 21: V A T E C H \text { 34; } 134: 134) . "\end{array}$ \\
\hline $\begin{array}{l}\text { Providing } \\
\text { leadership }\end{array}$ & $\begin{array}{l}\text { "Of course, I mean, a great lot of people are involved here, } \\
\text { each with his own interests and tasks, and if they don't have } \\
\text { these under control, and now I'm coming back to this, that } \\
\text { is the rigid management, if you can't keep them under } \\
\text { control, a lot can go wrong in such a project. This can lead } \\
\text { to damage costing millions, there's no room for unre- } \\
\text { strained democracy, that's not possible. And to return to } \\
\text { your question now, if you move in an environment that is } \\
\text { like that, because of national structures or cultures, or } \\
\text { because of corporate cultures, so that you have a certain } \\
\text { hierarchical or acceptance regarding hierarchies, then you } \\
\text { will find it much easier to work in such an environment } \\
\text { (P18: VA TECH 120; 503:503)." }\end{array}$ \\
\hline Decision making & $\begin{array}{l}\text { "Basically ... I, and that's simple, that's for instance the } \\
\text { militarist approach, that's not very popular, but you need } \\
\text { leadership somewhere and at the moment I do not let go of } \\
\text { this leadership and so decisions are made, although on a }\end{array}$ \\
\hline
\end{tabular}




\begin{tabular}{|c|c|}
\hline & $\begin{array}{l}\text { bilateral discussion basis information is gathered, but at } \\
\text { some stage it's simply that I exert my power and say, OK, } \\
\text { from the VA TECH point of view I now make a decision } \\
\text { and inform everybody of this decision or guideline. Of } \\
\text { course, once again, they have all been involved in the } \\
\text { run-up to the decision, in the discussions and the } \\
\text { information-gathering process, I do not make completely } \\
\text { isolated decisions just by myself, I naturally try to consider } \\
\text { all the inputs I got from the discussions, but you do get to } \\
\text { a point where you say, democracy in a group that's been } \\
\text { put together at short notice is an ideal, but not what's pos- } \\
\text { sible from an operational and feasible point of view at this } \\
\text { moment, and so there has to be a certain, I don't want to } \\
\text { call it dictatorial way of making decisions, but as we like } \\
\text { to call it democratorship. I simply have to make decisions, } \\
\text { or they don't make it, we could discuss everything end- } \\
\text { lessly and then I just communicate my decisions into the } \\
\text { individual groups, and I think at the end of the day the } \\
\text { people accept that (P18: VA TECH 20; 132:132)." }\end{array}$ \\
\hline Monitoring & $\begin{array}{l}\text { "The diversification of the different types of people. This } \\
\text { was probably the biggest individual challenge. That there } \\
\text { are many different disciplines and everybody thinks that } \\
\text { what he is doing is right and everybody wants to do a good } \\
\text { job. But one person, when he does a good job and does } \\
\text { every single step in the best engineering detail, this means } \\
\text { that he is running into many individual hours of work, he is } \\
\text { going into the direction that every single solution he needs } \\
\text { for that... And on the other side, I am responsible for cost. } \\
\text { Many of these people do not understand the cost factor. And } \\
\text { they do not understand when they do an excellent job for a } \\
\text { project that the next time somebody else has to do it again. } \\
\text { And the cost factor of personnel that runs up some of the } \\
\text { costs and makes us less competitive. In order to continue } \\
\text { being very successful on the market we have to look at this } \\
\text { commercial factor as well. Many of these engineers do not } \\
\text { have an understanding for ideas as liability, guarantee, } \\
\text { costs, framework contracts, standards. So, my task is to } \\
\text { monitor what they are doing (P21: VA TECH 3; 25:25)." }\end{array}$ \\
\hline Motivation & $\begin{array}{l}\text { "Again it comes down how do you motivate these people to } \\
\text { do the work. If they do not work for you most project } \\
\text { managers in this house do not have priority but only } \\
\text { consensus-based control over the people. You have to keep }\end{array}$ \\
\hline
\end{tabular}




\begin{tabular}{|c|c|}
\hline & $\begin{array}{l}\text { this personal level very strong, to keep the commitment, to } \\
\text { keep the interest, to keep the dedication...because you can } \\
\text { not tell them: "I am the boss and do what I say. When I } \\
\text { say jump than jump." Because they do not work for you. } \\
\text { In a hierarchical set up they have a different boss. So the } \\
\text { expectations are based on what they have to do, and how } \\
\text { close they work, and how much you can check... an } \\
\text { inserted corporate influence (P21: VA TECH 38; } \\
140: 140) . "\end{array}$ \\
\hline $\begin{array}{l}\text { Creation of } \\
\text { collective team } \\
\text { identification }\end{array}$ & $\begin{array}{l}\text { "In this case, the groups exchange certain prejudices with } \\
\text { each other. This normally does not go very deep. Real full } \\
\text { integration in and identification with the team on the part } \\
\text { of the team members doesn't necessarily just happen by } \\
\text { itself. It can happen, but it takes the boss's assistance, so } \\
\text { that there can be some interaction and that people spend } \\
\text { some private time together, too (P20:VA TECH 15; } \\
83: 83) \text {." }\end{array}$ \\
\hline $\begin{array}{l}\text { Project- } \\
\text { management } \\
\text { skills }\end{array}$ & $\begin{array}{l}\text { "...well, that you help people with this inter basis, that is } \\
\text { this basic knowledge about project processing, project } \\
\text { management, project execution and then social competence } \\
\text { and I think then you've achieved a major step, then later of } \\
\text { course also the expertise, and I would even go as far, if a } \\
\text { project leader is good enough in handling a project and } \\
\text { with his social skills, to put together a project team that is } \\
\text { easily managed and works together well, then he also has } \\
\text { the ability to bring in his procedural experts and general } \\
\text { experts at the right place, where they simply cover the } \\
\text { knowledge which he has as a process leader but not as the } \\
\text { owner of the process, no, wrong, not the owner, as the } \\
\text { engineer of the process (P18:VATECH 52; 229:229)." }\end{array}$ \\
\hline $\begin{array}{l}\text { Social } \\
\text { competence }\end{array}$ & $\begin{array}{l}\text { "And I'm back at what I said at the very beginning, I think, } \\
\text { and again a lot comes from the topic of competence, from } \\
\text { our rational mind, from our brain it goes down straight to } \\
\text { our gut, our feeling, well I have a lot of feeling in my gut, } \\
\text { that's why it's so big. That's not written anywhere, you } \\
\text { don't learn that anywhere, you can fall terribly for people, } \\
\text { if you do not realise, if you can't read their faces or if you } \\
\text { can't look behind the mask, well, I'd say here social skills } \\
\text { are at least as important as expert skills, I would even go } \\
\text { as far as to say even a bit more important, because we had } \\
\text { a lot of people with a lot of expert know-how, but failed } \\
\text { totally in these tasks. And that includes people with more }\end{array}$ \\
\hline
\end{tabular}




\begin{tabular}{|l|l|llll}
\hline & $\begin{array}{l}\text { technical knowledge than me (P18: VA TECH 62; } \\
252: 252) . "\end{array}$ & \\
\hline
\end{tabular}

Table 7: Team leader functions and characteristics at VA TECH (Source: Author)

These functions and characteristics of MNT leaders have been identified as necessary requirement by other researchers too. Yet we would like to point out that the current literature on leadership in teams in multinational settings is still in the early stages of development. Maznevski and DiStefano (2000) suggest that leaders need to be able to successfully map, bridge, and integrate the different perspectives of culturally dissimilar team members. However, empirical work, especially studies that are not based on student data, is still rare. One notable exception is a study by Cummings (in press) based on data gathered from 129 teams working across different units in a multinational company. Cummings concludes that leaders should create norms that encourage team members to communicate among themselves frequently and openly. The empirical study conducted by Joshi and Lazarova (2005) has identified four competencies that are considered as important by MNT leaders and members across multiple locations: communication, direction and goal setting, facilitating teamwork, and motivating and inspiring. Given the universal appeal of these competencies among the respondents, it has been proposed that these may be viewed as "core" competencies or minimum requirements of effective MNT leadership. The study has involved 89 MNT members and 50 MNT leaders from a Fortune 500 software and hardware company. According to Schweiger et al. (2003), many of the successful leaders are able to succeed because of their ability to manage the many complex team functioning issues and navigate the team context. Understanding skills needed on the team, having solid relationship with subsidiaries, being multilingual, having project management skills and a high need for achievement, demonstrating openmindedness for learning and exhibiting humility are the personal capabilities and characteristics that help leaders to do so.

Researchers should continue identifying core competencies of effective MNT leadership. However, they should be aware that the type of team matters. By distinguishing among types of teams they may find out that the personal capabilities, skills and abilities of MNT leaders will vary for different types of teams.

\subsubsection{Team members}

Team members are individuals and they react to socialization attempts in MNTs in different ways. We could identify several personal characteristics and requirements that team members should have in order to contribute to effective team functioning. For a team member of an MNT it is important to be socially and 
culturally competent and to have the required interpersonal abilities. He/she should have the ability to deal with people from different cultures, to be trusting and cooperative:

"That's the main point. It takes place on all levels, in verbal and in general behaviour. Some people are better at this, handle people more diplomatically, in all sorts of contexts and some are not so good, but this also depends on the communication and the meaning, and whether you have the antennae for this and the sensitivity... Simply being sensitive regarding other nations and cultures ... (P27: VA TECH 48; 93:93).

To demonstrate open-mindedness has also been identified as a critical ability for MNT members. There are many perspectives that are represented in such teams and team members should be able to appreciate the value of these different cultural views. They should be interested in learning from such perspectives. The ability to adjust well to new situations, tasks and requirements by showing openness for experience has been mentioned to be an important requirement. McCrae and Costa (1997) have identified five major personality factors. These are extroversion, agreeableness, conscientiousness, neuroticism, and openness to experience. The last factor 'openness to experience' is related to openness to new cultures. People with high levels of this are likely to be interested in learning and gaining professional knowledge. They adjust well to new tasks and requirements. These findings are in accordance with our data.

Cultural distance between team members has also an impact on MNT functioning. Yet members from very distinct cultures don't necessarily have more difficulties finding the right ways of interaction and showing understanding for different cultural values and norms of behaviour as can be seen from the following quotation:

"With the Italians the difference was too small, that's why it affected us like a grain of sand in our shoe... If there's a big pebble in your shoe, you remove it, straight away. If you have a grain of sand there, you think, this will go away, and at the end your foot is completely sore. That's an anagram for, what is it like when .... (P18: VA TECH 41; 215:215).

Having team members with extensive work experience is a benefit for the team. The experience helps individual members to understand the value that each party brings to the table and to face the challenges of melding these perspectives. Successful teams have the right mix of professionals:

"Well I'd say the success criteria are the professionalism of the player, the process does not allow for, it is too complex, how should I put it, too unique, you 
cannot repeat it, we now have our in-house process and it must work (P18: VA TECH 42; 210:210)......And that brings me back to your question, the secret of success is simply the professionalism of the players... (P18: VA TECH 43; 210:210).

Multinational project teams may also involve external alliance partners. In this case it is necessary to introduce coordination and control functions between these two parties. Coordinating the activities of the two parties creates additional challenges for individual team members.

As can been seen it is very challenging to decide on the right mix of people in the team. This will depend on the situation, the task that has to be accomplished, the time frame and the type of team. The results show that having team members who are socially and culturally competent, open-minded and able to adjust to new situations, tasks and requirements does contribute to team effectiveness. These findings are in accordance with the literature. For example, Matveev et al. (2001) have identified four dimensions of cross-cultural competence that represent a necessary requirement for MNT members. These are interpersonal skills, team effectiveness, cultural uncertainty, and cultural empathy. According to Gudykunst (1998; in Matveev et al., 2001), cross cultural communication competence of individuals affects multinational team performance. McCrae and Costa (1997) claim that individuals with high levels of openness to experience will tend to adjust well to new situations and different cultures.

\subsection{Summary of empirical findings from VA TECH}

This study has been conducted at VA TECH. Twelve problem-centred interviews have been conducted with team members and team leaders and considerable time has been given to writing up notes of observation. All conversations have been captured with recording equipment and the interviews have been taped and a transcript has been produced.

The findings indicate that unexpected fluctuations in order-intake, which are caused by industry turbulence (e.g., high competition, high corruption rates in foreign markets, different legal systems and legal requirements in different countries, cartel formation in the industry etc.), result in uncertainty and stress. They have an impact on MNTs since teams react to them in order to adjust their strategies.

Corporate culture has a strong impact on team effectiveness. VA TECH doesn't have a strong task/achievement culture since the company has been highly decen- 
tralized and has undergone several mergers. However, the corporate culture is strong enough to create an environment that stimulates MNTs to perform and contribute to the reduction of complexity inherent in multinational companies.

Past research has ignored the link between HRM practices, team effectiveness and firm performance. Future research should consider its role more explicitly and explore the interplay between HRM and project teams in a matrix structure. According to the empirical findings, the strength and performance of HRM will have a positive impact on MNT performance in companies with a matrix structure, where human resource managers are responsible for delegating the right people to projects where their skills and abilities are immediately needed.

According to Van der Vegt and Bunderson (2005), researchers need to consider the motivational climate that exists within the group and, more specifically, the extent to which members emotionally identify with their group in order to understand whether a given level of expertise diversity in a group will have positive or negative implications for group performance. However, the repeated withdrawal of team members from MNTs due to the need to apply specialized expertise to the next projects has a negative impact on the creation of collective team identification and may harm team performance.

Despite the fact that the company focuses on cost saving and pursues a global strategy, diversity turns out to be very beneficial. The teams at VA TECH have the freedom to develop their divergent subcultures. They exist in harmony with the rest of the organization and their behaviours are congruent with the strategic goals of the organization. The knowledge is shared and created through intense interaction between individual team members with different cultural backgrounds. This knowledge about different markets, customer attitudes and preferences exist within the teams. It is shared within the group and then applied in order to successfully enter new markets and negotiate with customers from different countries.

The type of task that has to be accomplished by team members has an impact on team processes. Interdependence, whether based in task inputs or in shared goals and rewards, increases the need for cooperation between team members and facilitates the exploration and exploitation of tacit knowledge. The findings show that task interdependence results in more cooperative behaviour and information sharing and strengthens team cohesion that motivates team members to jointly discuss organizational policies and practices and to interpret the team's experiences.

MNTs at VA TECH consist of three or more individuals who interact directly or indirectly for the accomplishment of a common goal and who come from two or 
more different cultural or national backgrounds. They come from different functions and divisions of the corporation. Sometimes, they also involve external alliance partners. Specialized expertise is applied to the project at hand. When a project is completed, the members either return to their functional units or move on to the next project. Team members from different countries bring different norms of communicating, making decisions or resolving conflicts to the team. By asking the interview partners if they could remember any critical incidents that emerged through interaction with employees from different countries in the team we could collect cultural standards that are based on the values in members' national culture. Leaders and team members should be aware of different kinds of perceiving, thinking, judging, and acting that regulate behaviour of people from other societies. They should use this knowledge for preliminary business planning. Especially in the initial stage of team building this knowledge could be helpful for understanding differences, avoiding stereotyping and creating cohesion and solidarity in the team.

Time has a moderating effect on cultural standards of team members. For example, after intense mutual interactions with Italian and English team members in a multinational project team, Austrians have reported how they adopt certain practices to fit Italian or English culture and improve the overall effectiveness of the team. Through the interaction with individuals from other societies their values are affected and they co-create their culturally determined frames of reference. Prior studies that have used such measures as collectivism or individualism or tried to assess the influence of the relative cultural distance between team members on team effectiveness have ignored the effect that mutual and intense interaction of team members over a certain period of time may have on their identities, societal values and norms of behaviour.

Splitting into three or more subgroups facilitates the creation of a positive motivational climate in MNTs through greater information sharing about personality traits, backgrounds, and interests, while in MNTs consisting of two major partners demographic diversity creates faultlines, since demographic characteristics divide the network into two subgroups.

We could identify numerous types of norms that increase team performance. The impact of a norm on effectiveness is shown to depend both on its content and its context. At VA TECH, the context of the corporate culture is not so strong. Team norms are more dependent on team context.

Effective team leadership turns out to be one of the most important factors that enable the effective functioning of multinational project teams. We could identify several competencies that are considered as important by MNT leaders and members. These are constructive monitoring, setting and communicating common 
goals, motivating and inspiring, coordinating, making the right decisions on time and leading the team. Moreover, successful team leaders turn out to be socially and cross-culturally competent, multilingual and to have project-management skills, long working experience and the knowledge required to manage the challenging tasks. To demonstrate open-mindedness, to have the ability to adjust well to new situations, tasks and requirements and to show social competence are the characteristics of team members of successful teams. 
Aida Hajro - 978-3-631-75438-2

Downloaded from PubFactory at 01/11/2019 04:52:54AM

via free access 


\section{Empirical findings from Henkel Central Eastern Europe (CEE)}

\subsection{Company description: Henkel}

Henkel, headquartered in Düsseldorf/Germany, has about 52,000 employees worldwide and counts among the most internationally aligned German-based companies in the global marketplace. It has subsidiaries in more than 75 different countries and it operates in three strategic business areas: Home Care, Personal Care, and Adhesives, Sealants and Surface Treatment. These strategic business areas are organized into four globally operating business sectors within Henkel. These are Laundry and Home Care, Cosmetics/Toiletries, Consumer and Craftsmen Adhesives and Technologies (Henkel, 2007a). Henkel pursues a multinational strategy.

The company Henkel was founded in 1876 in Aachen by a 28 year-old merchant who was interested in science - Fritz Henkel. Its first product was a washing powder based on water-glass. In 1893 the 17-year-old Fritz Henkel junior joined the firm as an apprentice. After receiving commercial training he became his father's right-hand man in commercial matters. He put Henkel's brand-name product business on a sound footing and developed its already advertising still further. Dr. Hugo Henkel, the youngest son of Fritz Henkel, joined the company as chemist. He was in charge of chemical products and technology, laid the foundations of systematic research and introduced advanced technologies for new materials. At that time the company was already operating in Germany, Austria, USA, France and England. In 1907 the word's first self-acting detergent "Persil" was introduced by Henkel. In 1927 the Henkel \& Voit company was founded in Vienna. Later it changed its name to Henkel Austria Group. In 1985 Henkel went public, with Henkel preferred shares being traded on the stock exchange. Henkel Austria Group started exporting its products to the countries of CEE in 1984 and three years later it changed its name to Henkel Central Eastern Europe (CEE). Henkel Budapest, its first subsidiary in the region, was established in 1987. Henkel Central Eastern Europe has been growing steadily since then. This dynamic expansion drive aimed at opening up new markets is still continuing, and serves as the guarantee of a successful future. Today Henkel CEE is responsible for managing business operations in 30 countries. Besides Austria, these are Albania, Armenia, Azerbaijan, Belarus, Bosnia and Herzegovina, Bulgaria, Croatia, the Czech Republic, Estonia, Georgia, Hungary, Kazakhstan, Kyrgyzstan, Latvia, Lithuania, Macedonia, Moldova, Poland, Rumania, Russia, Serbia and Montenegro, Slovakia, Slovenia, Tajikistan, Turkey, Turkmenistan, Ukraine, Uzbekistan and Yugoslavia. This region covers a market of almost 490 million 
people and Henkel CEE employs 7,700 people. Henkel CEE has been very successful in the last ten years. Its sales have been steadily increasing from 1996 as can been seen in table 8 (Henkel, 2007a).

\begin{tabular}{|l|c|c|c|c|c|c|}
\hline \multicolumn{7}{|c|}{ Sales of Henkel CEE from 1996 to 2005 in million euros } \\
\hline Years & 1996 & 1998 & 2000 & 2002 & 2004 & 2005 \\
\hline Sales & 422 & 611 & 688 & 818 & 1144 & 1346 \\
\hline
\end{tabular}

Table 8: Sales of Henkel CEE from 1996 to 2005 (Source: Henkel, 2007b)

Table 9 provides important financial data from the annual reports of the last ten years of Henkel. It shows that the sales increased by $13 \%$, the operating profit by $16.7 \%$, net earnings by $2.9 \%$ and the number of employees by $3.6 \%$ from 2004 to 2005.

\begin{tabular}{|l|c|c|c|c|c|c|c|c|}
\hline \multicolumn{7}{|c|}{ Ten year summary of Henkel's financial performance from 1996 to 2005} \\
in million euros \\
\hline Years & 1996 & 1998 & 2000 & 2001 & 2002 & 2003 & 2004 & 2005 \\
\hline Sales & 8,34 & 10,91 & 12,78 & 9,41 & 9,66 & 9,44 & 10,59 & 11,97 \\
\hline $\begin{array}{l}\text { Operating } \\
\text { profit } \\
\text { (EBIT) }\end{array}$ & 517 & 791 & 950 & 602 & 666 & 706 & 996 & 1,162 \\
\hline $\begin{array}{l}\text { Net } \\
\text { earnings }\end{array}$ & 284 & 372 & 505 & 476 & 431 & 551 & 748 & 770 \\
\hline $\begin{array}{l}\text { Number of } \\
\text { employees }\end{array}$ & 46,4 & 56,3 & 60,5 & 47,4 & 47,2 & 48,3 & 45 & 51,7 \\
\hline
\end{tabular}

Table 9: Ten year summary of Henkel's financial performance from 1996 to 2005 (Source: Henkel, 2007c)

The success of the company is primarily rooted in its employees' commitment and performance. The human resources policy of Henkel CEE is based on the principle of providing salaries commensurate with performance and a reasonable level of social security. In addition, the company promotes teamwork as well as establishing international and interdisciplinary networks at all levels (Henkel, 2007c)

\subsection{Major empirical findings from Henkel CEE}

In this chapter we will present the findings from the study conducted at Henkel CEE in Vienna. Data analysis and interpretation are based on the findings of the interview transcripts and the notes of observations. As already mentioned, 15 interviews have been conducted. The interviews lasted for approximately one hour. 
The researcher has spent considerable time in the company observing the phenomenon under study, leading informal talks with Henkel employees and socialising with them during lunch time and coffee breaks. Table 10 shows the categories of influence on MNT performance at Henkel CEE and focuses on the relevant codes of each category. It also includes the number of quotations for each code and the percentage of interviews per most frequently coded variables. The most frequently mentioned categories are team norms (mentioned by $100 \%$ of interview partners), followed by transfer of knowledge between organisational units by MNTs (mentioned by $93 \%$ of interview partners), team leader characteristics and reference to cultural differences between team members from different countries (mentioned by $60 \%$ of interview partners). We could also obtain 9 quotations by $47 \%$ of interview partners that refer to the transfer of the appropriate dimensions of the home organisation's culture between organisational units by MNTs at Henkel CEE.

\begin{tabular}{|c|c|c|c|}
\hline Category & Codes & $\begin{array}{l}\text { Number of } \\
\text { quotations }\end{array}$ & $\begin{array}{l}\text { Percentage of } \\
\text { interviews } \\
(100 \%=15 \\
\text { interviews })\end{array}$ \\
\hline \multirow[t]{9}{*}{$\begin{array}{l}\text { Cultural } \\
\text { differences } \\
\text { between team } \\
\text { members }\end{array}$} & $\begin{array}{l}\text { Reference to } \\
\text { cultural } \\
\text { differences } \\
\text { between team } \\
\text { members from } \\
\text { different } \\
\text { countries: } \\
\end{array}$ & 58 & $60 \%$ \\
\hline & $\begin{array}{l}\text { Austria and } \\
\text { Central Eastern } \\
\text { Europe } \\
\end{array}$ & 32 & $60 \%$ \\
\hline & \begin{tabular}{|l|} 
Austria and \\
Poland
\end{tabular} & 8 & $27 \%$ \\
\hline & \begin{tabular}{|l} 
Austria and \\
Serbia \\
\end{tabular} & 6 & $20 \%$ \\
\hline & $\begin{array}{l}\text { Austria and } \\
\text { Germany } \\
\end{array}$ & 4 & $20 \%$ \\
\hline & $\begin{array}{l}\text { Austria and } \\
\text { Hungary } \\
\end{array}$ & 2 & $7 \%$ \\
\hline & Poland and India & 2 & $7 \%$ \\
\hline & \begin{tabular}{|l|} 
Austria and \\
Russia \\
\end{tabular} & 1 & $7 \%$ \\
\hline & Austria and & 1 & $7 \%$ \\
\hline
\end{tabular}




\begin{tabular}{|c|c|c|c|}
\hline & Slovenia & & \\
\hline & $\begin{array}{l}\text { Austria and } \\
\text { Croatia }\end{array}$ & 1 & $7 \%$ \\
\hline & \begin{tabular}{|l|}
$\begin{array}{l}\text { Austria and } \\
\text { Turkey }\end{array}$ \\
\end{tabular} & 1 & $7 \%$ \\
\hline & $\begin{array}{l}\text { Cultural } \\
\text { differences } \\
\text { between Austria } \\
\text { and Central } \\
\text { Eastern Europe }\end{array}$ & 32 & $60 \%$ \\
\hline & $\begin{array}{l}\text { Individualism in } \\
\text { CEE }\end{array}$ & 9 & $33 \%$ \\
\hline & $\begin{array}{l}\text { Power Distance in } \\
\text { CEE } \\
\end{array}$ & 7 & $33 \%$ \\
\hline & $\begin{array}{l}\text { Relationship } \\
\text { management in } \\
\text { CEE }\end{array}$ & 4 & $33 \%$ \\
\hline & $\begin{array}{l}\text { Degree of honesty } \\
\text { in CEE }\end{array}$ & 4 & $13 \%$ \\
\hline & $\begin{array}{l}\text { Criticising } \\
\text { behaviour in CEE }\end{array}$ & 2 & $13 \%$ \\
\hline & Mentality in CEE & 2 & $13 \%$ \\
\hline & $\begin{array}{l}\text { Gender } \\
\text { egalitarianism in } \\
\text { CEE } \\
\end{array}$ & 2 & $7 \%$ \\
\hline & $\begin{array}{l}\text { Time perception } \\
\text { in CEE }\end{array}$ & 2 & $7 \%$ \\
\hline $\begin{array}{l}\text { Organisational } \\
\text { context }\end{array}$ & $\begin{array}{l}\text { Organisational } \\
\text { strategy }\end{array}$ & 13 & $47 \%$ \\
\hline & $\begin{array}{l}\text { Organisational } \\
\text { culture }\end{array}$ & 19 & $40 \%$ \\
\hline Corporate norms & Norms & 63 & $100 \%$ \\
\hline $\begin{array}{l}\text { MNT external } \\
\text { dynamics }\end{array}$ & $\begin{array}{l}\text { Transfer of } \\
\text { knowledge } \\
\text { between } \\
\text { organisational } \\
\text { units by MNTs } \\
\end{array}$ & 18 & $93 \%$ \\
\hline
\end{tabular}




\begin{tabular}{|c|c|c|c|}
\hline & $\begin{array}{l}\text { Transfer of the } \\
\text { appropriate } \\
\text { dimensions of the } \\
\text { home } \\
\text { organisation's } \\
\text { culture between } \\
\text { organisational } \\
\text { units by MNTs }\end{array}$ & 9 & $47 \%$ \\
\hline \multirow[t]{8}{*}{ Team leader } & $\begin{array}{l}\text { Team leader } \\
\text { functions }\end{array}$ & 22 & $60 \%$ \\
\hline & \begin{tabular}{|l|} 
Goal \\
Determination
\end{tabular} & 4 & $27 \%$ \\
\hline & Motivation & 4 & $27 \%$ \\
\hline & \begin{tabular}{|l|} 
Selection of team \\
members
\end{tabular} & 5 & $20 \%$ \\
\hline & Communication & 3 & $20 \%$ \\
\hline & Monitoring & 2 & $13 \%$ \\
\hline & Coaching & 2 & $13 \%$ \\
\hline & $\begin{array}{l}\text { Virtual team } \\
\text { leadership }\end{array}$ & 2 & $13 \%$ \\
\hline \multirow[t]{4}{*}{ Team member } & Personality & 12 & $47 \%$ \\
\hline & Work experience & 11 & $47 \%$ \\
\hline & Open-mindedness & 11 & $47 \%$ \\
\hline & Social competence & 7 & $47 \%$ \\
\hline
\end{tabular}

Table 10: Categories and codes derived from the analysis of interviews conducted at Henkel CEE (Source: Author)

We start this chapter with a presentation of contextual influences on MNT performance (organisational culture and strategy) and continue with information about team size, team composition and structure at Henkel CEE. The findings also show how MNTs reduce the complexity of operations in multinational companies by facilitating the creation and transfer of explicit and tacit knowledge and of appropriate dimensions of the home organisation's culture between geographically dispersed business units. This section ends with a presentation of MNT leader and member competences and characteristics. Table 11 presents a short summary of major empirical findings from Henkel CEE.

\section{Major empirical findings}

\begin{tabular}{|l|l|}
\hline Organisational & Henkel CEE has a family-like corporate culture that supports
\end{tabular} culture team work. The management philosophy is one of involvement. The organization is built on the principle that people 


\begin{tabular}{|c|c|}
\hline & $\begin{array}{l}\text { have the right to be involved in matters that affect them. } \\
\text { Team members make decisions in the best interest of the } \\
\text { organisation and the organisational culture motivates them to } \\
\text { do their best in order to achieve the company's goals. }\end{array}$ \\
\hline $\begin{array}{l}\text { Organisational } \\
\text { strategy }\end{array}$ & $\begin{array}{l}\text { MNTs at Henkel CEE add a multicultural perspective to the } \\
\text { multinational strategy development. They enable the com- } \\
\text { pany to act as locally as necessary and as globally as possi- } \\
\text { ble. }\end{array}$ \\
\hline $\begin{array}{l}\text { Corporate } \\
\text { values and } \\
\text { norms and } \\
\text { their impact } \\
\text { on MNTs }\end{array}$ & $\begin{array}{l}\text { Values (that define what is important) and norms that define } \\
\text { appropriate attitudes and behaviours for MNT members (how } \\
\text { to feel and behave) are consistent with the organisational } \\
\text { culture. The organizational level culture is solidaristic and } \\
\text { teams develop parallel solidaristic cultures. Certain strong } \\
\text { norms such as a cooperative approach, constructive and } \\
\text { instant feedback, open communication and innovation } \\
\text { enhancing norms facilitate the generation and expression of } \\
\text { creative ideas. }\end{array}$ \\
\hline $\begin{array}{l}\text { MNT } \\
\text { composition at } \\
\text { Henkel CEE } \\
\text { and cultural } \\
\text { characteristics } \\
\text { of Central } \\
\text { Eastern } \\
\text { Europeans }\end{array}$ & $\begin{array}{l}\text { MNTs at Henkel CEE consist mainly of Austrians, Germans } \\
\text { and members from Central and Eastern Europe. The societal } \\
\text { culture of CEE with focus on low collectivism, high power } \\
\text { distance, high-level of uncertainty avoidance, a preference } \\
\text { for a direct approach of criticising team members and subor- } \\
\text { dinates and a tendency to withhold relevant information } \\
\text { creates critical incidents in MNTs. A strong preference for } \\
\text { individual rather than shared responsibilities of members } \\
\text { from CEE is reported by Austrians and team members from } \\
\text { this region are busier using personal contacts with superiors } \\
\text { to promote their own interests and strengthen their position in } \\
\text { the organizational hierarchy than pursuing common goals } \\
\text { and giving support to their team members. Compared to } \\
\text { Austrian team members, who are expected to react in con- } \\
\text { sistent ways in different situations, reactions of employees } \\
\text { from CEE depend more on the place, time, and person. } \\
\text { Behaviour that is judged appropriate for a given place, time, } \\
\text { and person is not appropriate for other times, places and } \\
\text { persons. They change the self to meet environmental } \\
\text { demands and can become highly competitive and individual- } \\
\text { istic in a business context. It has been reported that they } \\
\text { hesitate to share important business related information with } \\
\text { other team members. For Austrian team leaders it is very } \\
\text { challenging to complement group or participation-based } \\
\text { decision making and to introduce the concept of team work }\end{array}$ \\
\hline
\end{tabular}




\begin{tabular}{|l|l|}
\hline $\begin{array}{l}\text { Transfer of } \\
\text { knowledge } \\
\text { between } \\
\text { organisational } \\
\text { units by MNTs }\end{array}$ & $\begin{array}{l}\text { MNTs facilitate the creation and transfer of explicit and tacit } \\
\text { knowledge between geographically dispersed business units. } \\
\text { CE\% of their members are rotating members from different } \\
\text { supporting the generation and implementation of creative } \\
\text { ideas and building upon the ideas of members from CEE they } \\
\text { contribute to new product development, branding and adver- } \\
\text { tising. Inpatriates from CEE promote the effective transfer of } \\
\text { knowledge about products, markets, customers, competitors } \\
\text { in their home country to the HQ and from the HQ back to the } \\
\text { subsidiaries and eventually throughout the entire multina- } \\
\text { tional organization. The principle behind creating its system } \\
\text { of knowledge exploitation and transfer is job rotation. } \\
\text { Employees work together in MNTs over a sufficiently long } \\
\text { period of time to consolidate close relationships. This way, } \\
\text { MNTs contribute to the creation and transfer of tacit know- } \\
\text { ledge that is very important in today's global knowledge- } \\
\text { based economy and that contributes to the company's com- } \\
\text { petitive advantage. }\end{array}$ \\
\hline $\begin{array}{l}\text { Transfer of the } \\
\text { appropriate } \\
\text { dimensions of } \\
\text { the home } \\
\text { organisation's } \\
\text { culture } \\
\text { between } \\
\text { organisational } \\
\text { units by MNTs }\end{array}$ & $\begin{array}{l}\text { By employing inpatriates in MNTs on semi-permanent } \\
\text { rotational assignments the company maintains its cultural } \\
\text { consistency between geographically dispersed business units } \\
\text { and creates a strong corporate culture characterised by com- } \\
\text { mon values and business methods. MNTs reduce the com- } \\
\text { plexity of operations of the German multinational company } \\
\text { by facilitating the transfer of appropriate dimensions of the } \\
\text { home organisation's culture between its business units. }\end{array}$ \\
\hline $\begin{array}{l}\text { MNT leader } \\
\text { Melection of team members, goal determination, motivation, } \\
\text { communication and monitoring are the most frequently men- } \\
\text { tioned MNT leader competences. In addition, social compe- } \\
\text { tence and the ability to provide virtual MNT leadership are } \\
\text { identified as important factors that enable the effective func- } \\
\text { tioning of MNTs. }\end{array}$ \\
\hline $\begin{array}{l}\text { The category team member comprises personality, work ex- } \\
\text { perience, social competence and open-mindedness. }\end{array}$ \\
\hline
\end{tabular}

Table 11: Major empirical findings from Henkel CEE (Source: Author) 


\subsection{Organizational context: Henkel CEE}

This study has been conducted at the regional HQ of the German multinational company located in Vienna. The HQ in Vienna is responsible for operations in $\mathrm{CEE}$ and it pursues a multinational strategy. MNTs consist of members from this region who are mainly on rotational assignment for a period of one to two years at the HQ in Vienna and who work in MNTs. Eighty percent of the staff at the junior level are inpatriates from the countries where the company operates. They add a multicultural perspective to the global strategy development of the organisation and they enable the company to act as locally as necessary and as globally as possible. By developing a deeper understanding of its customers and different business environments, the company stays ahead of the global competition and creates a competitive advantage. This chapter illustrates how the organisational culture and strategy impact MNT performance at Henkel CEE.

\subsubsection{Organisational culture of Henkel CEE and its impact on MNTs}

The regional HQ has a non-blaming, family-like corporate culture. It is successful because of its people and dedicated to sustainability and corporate social responsibility. Employees communicate openly and actively and they preserve the tradition of an open family company. The organization is designed to support team work. In order to be customer driven and to develop superior brands and technologies it uses a variety of team types (e.g. product development teams, marketing team etc.). Its corporate culture contributes to its team success. Teams are responsible for planning, decision making, and implementation. The adaptability of team members enhances the organization's ability to meet the needs of changing external circumstances. The management philosophy is one of involvement. People have a right to be involved in matters that affect them. In return, people make decisions in the best interest of the organization because of the awareness of mutual benefit. Management development is built around the team concept, focusing on a collaborative, facilitative, development role. Consequently, the corporate culture contributes to the successful implementation of MNTs in its different business units:

"We work in teams. In small ones regarding the individual brands and also in a large team and we try to handle both. Yes, that's the way it works at Henkel. Team spirit and co-operation are very important and necessary for a successful performance. On a personal level, they are important for me too. (P14: Henkel $25 ; 158: 158)$. 
"I think that is, thank goodness, part of our corporate culture, an open culture and therefore, so is the communication. It means that each new employee at Henkel learns how to communicate and deal with each other openly from the very beginning. That is the reason why team members fit together so perfectly and there is a continuous rotation. ... Thus, frankness is a very important topic, procedures are important, what else (P7:Henkel 50; 206:206)?“

"Not in the sense that you are being left alone but for having personal responsibility for a project, and there is always somebody you can ask, there is always a senior manager you can consult, but you are still personally responsible for your project until it is finalized. You are not left alone when something goes wrong, we are in this together, i. e. the culture is extremely strong, we win and we lose together, nobody is left out in the rain and still you are responsible for your project; This, I think, results in a lot of motivation (P7: Henkel 12; 103:103). “

The company builds on the principle of involvement and participation and it is successful with the implementation of MNTs. Team members describe Henkel $\mathrm{CEE}$ as employee-oriented, professional type of corporate culture with an open organisational communication climate and looser control. The managers have a higher average education level. According to Hofstede et al. (1990) the education level of the management team impacts organisational culture. More educated teams correspond with a more employee-oriented culture. Team leaders claim to spend a relatively large share of their time in meetings and person-to-person discussions. Employees at Henkel CEE have a higher average education level and the organisation fosters a more professional culture. To communicate openly and to share information is regarded as very important for company's success. Managers and team leaders delegate responsibilities and tasks to their subordinates who are responsible for writing reports and memos from inside the organisation.

\section{The types of norms and values identified at Henkel CEE and their impact on MNTs}

Corporate values (that define what is important) and norms that define appropriate attitudes and behaviours for employees (how to feel and behave) are consistent with team norms and values. The organizational level culture is solidaristic and teams develop parallel solidaristic cultures. Certain strong norms such as a cooperative approach, constructive and instant feedback, open communication and innovation enhancing norms facilitate the generation and expression of creative ideas. Strong norms, that reward information sharing, particularly unique pieces of information and emphasize greater tolerance for intellectual debate, reduce inhibitions and encourage divergent thinking. Employees are also expected to utilize their combined potential by building upon their members' ideas and by sharing important information. The agreement on these norms leads to more inno- 
vation and creativity. Members from different departments have consensus on work values and they tend to agree on norms regarding work in the company. Organisational values such as trust, mutual respect, loyalty and tolerance have a strong impact on team processes. MNTs at Henkel are characterised by a high level of value consensus. Members are more likely to trust and respect one another and feel that they are working toward a cooperative rather than competitive goal by emphasising common goals. Employees with high value consensus are more likely to develop positive relationships and attitudes towards one another. Respect and trust are critical for building an environment of constructive conflict. Corporate values and norms have a strong impact on team functioning. MNTs that emphasize a cooperative approach, constructive feedback, common goals, conflict openness and open communication norms and willingness to share information with team members are effective and their members are more satisfied.

Corporate norms that were most frequently mentioned at Henkel are listed in table 12 and illustrated by sample quotations:

\section{Corporate Norms}

Cooperative approach:

"Basically, well, something that works out just fine is the team spirit. There is, you help each other, you are willing to take over somebody else's work when you realize tasks and topics clash. It just happens that sometimes you have to work on two or three projects at the same time while somebody else has only one project. There is a strong team spirit and support, I consider that extremely positive, and there is a large amount to loyalty which I consider a positive aspect and that people actually try to help each other. And this goes beyond team membership, you try to help out people from other countries as well, if they have problems, and that's why, in this regard, I think working as a team is quite positive (P4: Henkel 26; 115:115). “

"Basically, we are a team that works on an operational level, more or less. And here, I have to add the level of co-operation is a little bit higher, we cooperate more because we have to put ideas into practice. We also encourage people, in other words, experiments are carried out in our plants and new machinery is adjusted, and there people can apply their expertise. It is always a matter of give and take, therefore it is easier than in other areas (P1: Henkel 11; 73:73)".

Constructive and instant feedback:

"To give an honest feedback, positive as well as negative, I consider very important. To address certain topics properly, in a constructive manner, even 
if you are concerned yourself, that is an advantage sometimes. And when you let the matter rest for two or three days, so that it doesn't get too emotional or so you don't get insulting or something like that, well, you say something if you feel offended by a co-worker or you are annoyed at something, that can happen, too. After all it's not like your boss is in a good mood all the time or, what might not be so pleasant for an employee, and this works both ways of course and, therefore, it is important that you don't react offended but make clear that there is something wrong, in quite a constructive and, by all means, direct way (P4: Henkel 30; 127:127).

"It is important that everybody, I mean feedback in general, what I want to say is, I think it is important that everybody states his point of view for once and not only, for example, that I present a point of view and everybody else accepts it, just like that, the most important thing about team work is that everybody has a chance to participate, takes over an active role and therefore, bears responsibility ...(P13: Henkel 38; 184:184). “

"I had instant feedback on any matter that I had and this was crucial to my establishment here. This was the key factor I would say (P3: Henkel 18; 97:97)."

Conflict openness norms:

"All conflicts are addressed directly and brought to a point (P2: Henkel 31). "

Common Goals:

"We have common goals that we want to achieve. It is always working together. If somebody only aims for personal goals this is seen rather negatively. This should not happen (P2: Henkel 18; 104:104). “

Justice in teams:

"Equal rights, the partner has to be able to feel he is on the same level with you, then, I will get something in return, otherwise he will just look at me expectantly, what I tell him and what I tell him to do, and that's not what we want, right (P1: Henkel 33; 159:159)."

"O.K., the biggest challenge in human resources is to find a balance between treating everybody in the same fair way and meeting the special needs of each individual. I think that large companies tend to make no differences and we at Henkel, too, we have very complex structures, certain hierarchies, that means, a product manager who has been working for us for a long time is eligible for a certain salary, certain employee benefits, for example, has a company phone or 
not, has a company car, if he has to travel a lot or not and employees talk to each other, naturally, and soon enough this can result in questions such as "why does he have that" or "why don't I". Here, to find the balance between treating everybody in a fair way and meeting individual needs is basically the biggest challenge (P10: Henkel 27; 113:113).

Open communication:

"By no means. Anyway, we at Henkel have an open communications culture, we address problems. Open communication is very important and that is true for the company as a whole and followed internationally (P5: Henkel 15; 56:56).

"I think that is, thank goodness, part of our corporate culture, an open culture and therefore, so is the communication. It means that each new employee at Henkel learns how to communicate and deal with each other openly from the very beginning (P7: Henkel 32; 206:206).

"Number 1 is continuous communication, what we have here, if you have gone through the hallways, maybe it's still a little bit too early at 8 a. m., but if you have a look you will realize that the office doors are open, not closed, therefore a lot of business takes place just by walking by and talking, exchange of information, a short question here, some information there, all of this continuous and open communication, ... P11: Henkel 15; 111:111)“

Willingness to share knowledge:

"This is one of Henkel's rules which I think is very well established in reality as well. You do not hide the information you have. You are ready to share it with others (P5: Henkel 15; 56:56)."

Table 12: Corporate norms at Henkel (Source: Author)

The impact of societal-level culture on corporate norms and values

Despite the fact that studies on norms have been conducted, researchers know relatively little about factors that influence the emergence of norms in business organisations. In the following section, we would like to illustrate how the societal-level culture of CEE countries influences the type of norms and values enacted by employees of Henkel CEE.

Loyalty and trust are identified as key values infused into the corporate culture of Henkel CEE by employees from CEE. The societal-level culture of CEE has a strong impact on the organizations and its teams. The match between the societal culture of CEE and the organizational culture of Henkel is positively related to its 
success. Usually, HQs of foreign corporations try to transfer management techniques or management know-how to the subsidiaries in CEE. The manoeuvrings of the acquiring corporation often induce culture shock at the local end, which usually leads to resistance and passivity at all organisational levels (Fink and Feichtinger 1998, Fink and Holden 2002, Fink and Holden 2005a, Fink and Holden 2005b, Hurt and Hurt 2005, Napier 2005, Javidan et al. 2005, Lunnan et al. 2005, May et al.2005; in Fink et al., in press). This is not the case at Henkel. By enacting the values and norms of behaviour of CEE countries that shape shared managerial assumptions about the nature of employees and how the organization needs to be structured for such employees, Henkel creates an environment of trust and friendship among the work teams. The organisational practices are created to be in line with the prevailing social-cultural context of CEE. This includes the development of relationships between employees through their intense interaction in MNTs and the numerous family-like practices, e.g. assistance in helping employees from CEE countries with accommodation when they move to Vienna for rotational assignment. As a consequence, employees are ready to make sacrifices for the company. These findings are in accordance with the literature. For example, Lincoln et al. (1981) found that matching organizational culture with societal culture results in high job satisfaction. Ferris and Wagner (1985) found that a congruence of Japanese organizational structure with Japanese values was positively related to the effectiveness of quality cycles. Great emphasis is put on personal relations, trust and loyalty. Members display a high level of personal involvement with other employees extending even into their personal lives and they are involved in their personal and family matters creating and enforcing a family like corporate culture at the HQ and its subsidiaries. CEE members have very good, instrumental relationships with individuals at the workplace with whom they are interdependent and form vital relationship for trust building and for exchanging of important information. According to Fink et al. (in press), loyalty was more important than efficiency in state owned enterprises in CEE. The imperative was to be friend with immediate colleagues and superiors. An atmosphere of trust and lasting friendship was to be generated among the primary work team. This same phenomenon has been observed at Henkel CEE.

\subsubsection{Organisational strategy of Henkel CEE}

The company under study is involved in expansion and focuses more on 'business to consumer marketing'. By implementing MNTs it benefits from market-related advantages obtained from cultural diversity. The cultural diversity of its workforce brings cultural sensitivity that is very important when the company enters new markets and tries to reach different market segments. The MNTs add a multicultural perspective to the strategy development of the company and they enable the company to act as locally as necessary and as globally as possible. The team 
members usually come from the subsidiaries located in CEE and they spend one or two years working in different teams at the regional HQ in Vienna. Coming from a host country enables them to understand how people in the host country think in terms of their relationship with the HQ and to improve the acceptance of host country ideas by bringing in the feedback of other people. These team members promote the effective transfer of knowledge about products, markets, customers, and competitors in their home country to the HQ and from the HQ back to the subsidiaries and, this way, throughout the entire multinational organization. Their knowledge of the host country language increases the level of trust with the subsidiaries and it contributes to a favourable motivational disposition. This enables the company to successfully pursue a multinational strategy and it contributes to its competitive advantage. The aim is to act "as locally as necessary and as globally as possible":

"In general, of course, if you have 18 countries, countries as different as Poland or Hungary and Kazakhstan in just one region, then it is difficult, the biggest challenge is to obey the rule of "as global as possible, as local as necessary". That means authorizing as many local processes, variations and exceptions as necessary for the local market because the markets are really different from each other, at the same time you have to say enough in order to harmonize and to save money and not to reinvent the wheel and to secure knowledge transfer etc. The balance between these two aspects is the biggest challenge, for sure, in such a diverse region as we face it in Eastern Europe (P11: Henkel 20; 131:131).

Diversity of its workforce brings cultural sensitivity to Henkel and this is very important when the company enters new markets.

\subsection{Multinational team composition and functioning at Henkel CEE}

\subsubsection{Teams size, structure and composition at Henkel CEE}

As already mentioned, the teams consist of team members from different CEE countries who come from the company's subsidiaries or the HQ in Düsseldorf. The marketing teams in the business sector "Laundry and Home Care" at the HQ in Vienna are divided into strategic business units. The strategic business unit 1 (SBU1) is responsible for detergents, powders and gels. This big team is again split into three sub-teams. One team is the value-for money team, the second team is the medium-price brand team and the third is the premium-segment brand team. These sub-teams consist of four members who are either from the HQ or from the 
company's subsidiaries. Three team members report to the senior or the brand manager who is responsible for the sub-team and the senior reports to the SBU 1 leader. $\mathrm{He}$ is the leader of the entire three sub-groups. The members' tasks are congruent and goal interdependent. This creates a positive climate in which they do not only identify with their team and behave in a cooperative way, but are also motivated to exchange their perspectives and different opinions and to manifest creativity and supportive behaviour. When the host country nationals return back to their host country after they have completed their semi-permanent assignment in the HQ in Vienna, they are able to work more effectively within the strategic direction of the company:

"I work in marketing, for detergents in Central and Eastern Europe. And the structure is like this, we have strategic business units. Our SBU strategic business unit is called $S B U 1$. In addition, there are $S B U 2$ and $3 . S B U 1$ is in charge of all the detergents. These are all kinds of detergents. We are active on the markets from Poland to Mongolia. There are 27 countries and the responsibilities for these countries have been subdivided internally. If you imagine, we have this $S B U 1$ business unit, and it is subdivided into three different segments, for example, a premium segment, a medium segment and a value-for-money segment, low price segment. Then I am busy working in the value-for-money segment for 7 countries, Poland, the Czech Republic, Slovakia, Hungary, Slovenia, Croatia, Bosnia and Serbia. 8 countries. I am responsible for these countries and Olena for the rest of them. Hers are actually the Ukraine, Romania, Bulgaria, Mongolia, the Georgia Republic, etc. We are in a team and we have one superior who is responsible for the value-for-money division (P8: Henkel 16; 9:9).

\subsubsection{Diversity within MNTs at Henkel CEE and cultural characteristics of team members from CEE}

Henkel CEE is responsible for operations in CEE. Its workforce consists of employees from this region who work together in MNTs with Austrians and Germans. We could collect numerous norms and values of behaviour of members from CEE. These cultural characteristics and their impact on MNTs functioning will be presented in this chapter.

\section{Individualism in CEE}

Individuals in MNTs serve as entry points for the influences of societal and cultural factors. They bring different cultures to the team. The findings show that 
there is still a lot of improvement potential in terms of teamwork and participation in decision making in CEE countries. There is little understanding of team work and devolved responsibilities among team members in this region. Moreover, there is a preference for individual rather than shared responsibilities in teams and team members seem to be busier using personal contacts with superiors to promote their own interests and strengthen their position in the organizational hierarchy than pursuing common goals and giving support to their team members. The individuals may express pride, loyalty and cohesiveness in their families but not necessarily in their teams and organisations. Their concerns for family or family members will evoke strong collectivist behaviour. In order to serve family interests they will behave in a very individualistic way at the workplace. If somebody or something is opposed to the interest of their family and close friends there will be a strong shift towards individualistic behaviour. This behaviour is intended to serve the in-group interests and may turn out to be very competitive. They have different standards for their family, friends and organisational members and base their treatment of individuals on the specific relationship. In their families they are integrated into strong, cohesive in-groups, yet in their working environment the ties between individuals are looser and they are expected to look after themselves. Consequently, they do not consider themselves dependent on their teams and organisation, pursuing their own goals and interests. This indicates a high degree of context sensitivity in the countries of CEE. In contrast to Austrian team members, who are expected to react in consistent ways in different situations, reactions of employees from this region seem to depend more on the place, time, and person. Behaviour that is judged appropriate for a given place, time, and person may not be appropriate for other times, places and persons. They change the self to meet environmental demands and become highly competitive and individualistic in a business context. It has been reported that they hesitate to share important business-related information with other team members and for Austrian team leaders it is very challenging to complement group or participation-based decision making and to introduce the concept of team work to employees from CEE:

"And what we were able to observe in Russia, with our associates there. They are very self-confident in their appearance, in a very demanding way, they ask for things at very short notice. If they need anything, they cannot really be considered to be team players. From my point of view, I mean you realize it is the culture, that they have grown up to be self-confident. That they know how to make demands, that they are a super power. I think it is noticeable from their behaviour, they are really nice associates, on a human basis really great and you can establish a very good relationship with them, even on a private level, but as I said, they are very demanding on a professional basis, as far as their needs are concerned, they are not really great team players when other people's needs are concerned. If there are matters that are more important to them or more urgent, 
then it is possible you might come up against a brick wall (P4: Henkel 16; $86: 86)$.

"Once, we had to experience (in a local team in Poland) that, for example, within one team, the local team that is, information had not been passed on. How should I put it, it partly due to a game of power where somebody wanted to demonstrate his power by having more information than others. I noticed that quite often, as I said, it is hard to describe, whether it is a cultural thing or whether it has to do with the local unit, with the structure (P4: Henkel 17; 86:86). "

"Teamwork is necessary, basically in most sources, however, you try to beat the other by running him down and that in a manner that sometimes, definitely goes below the waistline, too (P4: Henkel 22; 96:96). "

"No, but you can compare them, what strikes too, I think, was that at the beginning it was said that it has to be somebody's fault if something had gone awry, and then you have to find one culprit, you could not just say that it had been our fault, no, you had to name one person that what was basically punished for that, for example, after we had bought a large ...in production it was even worse and when something had gone wrong, it was said that the person responsible for the mistake had to be punished by, I don't know, deducting $10 \%$ from his wages, a name was demanded, always, always fought for and particularly, again, we win together and we lose together, a name doesn't matter, it is much more important that we understand why and make sure to do it better the next time. It took me one year to make people understand, and still, give me a name, tell me the culprit so I can punish him, I can't punish anybody, I disapprove of a lot of parents beating their children, so why would I lay hands on my employees or take away money? If you try to introduce better regulations, better tools in order to achieve for them to make less mistakes, then that is so much better than keeping $10 \%$ of their income and when we find out that he is not really capable of doing his work the way we want it then we have to fire him. But, it doesn't make sense to punish him three times, instead we say, he has got six months, we monitor him, give him every opportunity, every tool, and if he does not get it by then, we fire him. That simple. It took a while, a lot of convincing had to be done, I think that by now, that by now they do not look for names any more but say, OK, win together, lose together. But in order to develop that kind of team spirit and to teach them what team spirit actually means ... That took a long time (P7: Henkel 41; 251:251). “

Yet, according to the findings obtained from the GLOBE study, the societal culture of the Eastern European cluster is highly group oriented (group collectivism: 5.53) (Bakacsi et al., 2002). We speculate that there may be something unsafe about the validity of the questionnaire items. It has proved difficult to get relevant 
responses to surveys in an East European context due to a general unwillingness to share objective information with outsiders (see, e.g. Birch and Pooley, 1995; Yakovlev and Kokorev, 1995; in Suutari and Riusala, 2001). Consequently, answers to questions such as "employees feel great loyalty towards the organization" or "leaders encourage group loyalty even if individual goals suffer" may be biased. Contrary to GLOBE's study, Trompenaars' (1993) findings showed a high level of individualism in the respondents from CEE - those from Hungary, Czech, Poland, Bulgaria, Romania, and Russia all scoring in the top quartile for individualism. Trompenaars asked his respondents whether they preferred to make decisions alone or in a group, where everybody has a say in the decisions that are made. Respondents showed a marked preference for individual decision-making. Similarly, the response to a second item, whether responsibility for faults and mistakes should be borne by the individual or by the group, showed a strong preference to punish the miscreant as an individual (Trompenaars, 1993). In the same vein as Trompenaars, Smith et al. (1996) reported a preference for individual rather than shared responsibilities in the CEE cultures (Bakacsi et al., 2002). In the majority of the CEE countries, a centrally planned economy existed for 4070 years and the organizations were characterised by high centralization, a wide power gap between top and middle management and command control. The employees tended to experience inefficiency, unfairness, learned helplessness and pessimism (Bakacsi et al., 2002). These circumstances made them value more their self-interests and personal achievements even at the expense of others. This may explain why CEE members were perceived by Austrian team leaders as very competitive, dishonest and self-focused, pursuing their own interests.

\section{Power distance and uncertainty bearing in CEE}

CEE countries are dominated by hierarchical managerial practices. The power differential between management and workers is large and the hierarchy is wellestablished. Employees from this region prefer to build personal connections with their new leaders and with foreigners in the hope of rewards, rather than concentrating on performance and the accomplishment of team goals. Managers from Austria, who are socialized in cultures characterized by low power distance, tend to solicit work-related ideas and suggestions from their employees as part of a democratic leadership style. Yet the preference for hierarchy of employees from CEE countries limits the ability of Western managers to complement group or participation-based decision making:

"For me, Serbia was an example, too, we took over a company there, the majority and when we did that I had to co-operate with the local marketing manager and that's when I realized how strongly people believed in hierarchies there and that they were not used to make decisions on their own, when working with them it was a total surprise how they wanted to have some kind of back-up for every 
single step, wanted to have it re-confirmed, to discuss it with me, and I am not even used to that because everybody has to bear responsibility. They wanted me to make decisions, not we, not the team ... That was a kind of a dramatic experience because I said, well, there seem to be differences in the countries and the corporate cultures. And that was very interesting to observe (P9: Henkel 6; 60:60).

"Thinking in hierarchies is very dominant in these countries, it means that team work is basically introduced by us, whereas I have to mention that I still invite associates to Vienna, for two or three weeks, at the moment Russian associates and associates from Serbia as well, because these are the countries undergoing reorganization right now, I would say. They are thrilled, these young people who come here, they get to know it and suddenly realize that they have to think themselves, that they are able to bring in their ideas, we make decisions together ... that is unbelievable, they are so motivated and when they return home they have to adjust to their hierarchic system again and then you notice, in general, that a major change is on the way. However, as I have mentioned before, we still have to do a few things about that (P1: Henkel 24; 52:52).

According to Fogel (1994), collectivism was the official ideology of the communist party and the welfare of society was very important, yet in practice managers repeatedly used political bargaining and personal contacts to promote their own interests. This should not be so surprising since in practice there was no executive labour market in these countries and career advancement depended on pleasing those at the top of the bureaucracy (Suutari and Riusala, 2001). This is also in accordance with GLOBE findings. The cluster's societal practices are rated as very high on power distance (5.25) (Bakacsi et al., 2002).

A high level of uncertainty bearing among employees from CEE countries has been observed. They are not willing to take responsibility and they tend to ask their superiors or seniors in MNTs for approval of every step they make in order to fulfil a certain task. Moreover, they are characterised as having a low trust culture. Austrian employees report that in order to protect themselves their Polish colleagues have different norms of communication. When they write e-mails, e. g., they tend to copy a large number of recipients on a message to make sure that those people up and down the hierarchy are aware of the content. This way they are protected from criticism. Qualitative evidence collected recently in a large global pharmaceuticals company suggests that this behaviour is linked to low trust environments, and undertaken especially by members of high power distance cultures (Hambrick et al., 1998; in Earley and Gardner, 2005). This result is also in accordance with the findings of the GLOBE study in Eastern Europe which characterise this region as a high uncertainty bearing culture (Bakacsi et al., 2002): 
"That's the only thing. The Polish are even more exhausting in their daily reasoning. But he is already the cool standard. For example, you write an e-mail and want to know: „Aida, what time do we meet?" He writes you an e-mail back with saying "which pigments are used in these colourings". And he does not only write to you, which would be enough, no, he writes to your boss, to the CEO of the business unit and possibly to another three co-workers. He sends it "to" the people addressed and "cc" to all the others. And within an organization like this it is always important that you check, ok, who else knows about the whole thing? So, there is this e-mail with a lot of important people in "cc", and you start thinking that this one must be either really important or a threat. You have not done certain things and now he threatens you with his boss. And that like "not really the right way of doing it". And then you provoke reactions that you did not even want to provoke, originally. The only thing you wanted to know is the name of the colouring in a certain product. But in Poland that seems to be the way to do it (P8: Henkel 8; 54:54).

\section{Criticising behaviour and communication in CEE}

According to my interview partners, employees from CEE countries have been characterised as having a more direct approach of criticising their members. Seniors are more inclined to criticise their subordinates and team members for poor performance. They are said to have a blaming culture and to put more efforts on trying to find the person responsible instead of looking for a solution in order to solve the particular problem. This direct approach leads to critical incidents in MNTs as reported by a Polish and Bosnian employee working in the regional HQ. Unfortunately, there are not many comments on criticising behaviour in CEE in the literature; yet at least Russian managers have been reported as being very active in criticising poor performance on the part of their employees (Suutari and Riusala, 1998). Expatriates in the study conducted by Suutari and Riusala (1998) have reported that host country managers from CEE are more inclined than their Finnish colleagues to criticise their subordinates for poor performance.

One additional problem employees from Henkel have to face when working with their colleagues from CEE countries in multinational virtual teams is their informing behaviour. Team members from this region withhold relevant information. Consequently, the performance of operations in some of these countries is hampered due to poor reporting systems. Communication downwards has not traditionally been very open in CEE and managers usually try to maintain their own strongly centralised power by withholding information from their subordinates. A lack of communication within organisations in CEE has been mentioned by several researchers. Cyr and Schneider (1996) have reported that keeping subordinates informed is not found to be a typical characteristic of managers in CEE countries. Expatriates report that "withholding information is common among 
Hungarian managers", "keeping subordinates informed is not considered important in Poland; they think that information is power and should thus be very selectively given", or "Czech managers give their subordinates hardly any information" (Suutari \& Riusala, 2001).

\section{Relationship management in CEE}

Team members from CEE put great emphasis on personal relations. In certain cases they display a high level of personal involvement with other employees extending even into their personal lives and they are involved in their personal and family matters. They tend to exhibit certain feminine characteristics. The relational aspect is very important. CEE members have very good, instrumental relationships with individuals at the workplace with whom they are interdependent and can form vital relationships for trust building and for exchanging important information. Austrian team leaders who are aware of this phenomenon try to build up long lasting relationships with members from $\mathrm{CEE}$ at a personal level:

"I believe it is the co-operation between the countries, it has more advantages if you bring in your emotional side and not only your head, if you try it from a relationship angle. That's very important, the interpersonal level. This is definitely in our region, very important, in addition, in an industry, anyway, I think in the region, too. This interpersonal level is very important, I think (P4: Henkel 24 ; 108:108).

"OK, I build up this relationship with a person, that is very important, well, you should not underestimate the interpersonal level and then things can get mixed up because, on the one hand, you might have a good personal relationship and you get much more information, information you might not get any other way, shows a lot of trust. It bears certain risks as well, because if there are problems where you have to act tougher than usual, then the situation might change easily and might develop in a completely different direction. What had been an advantage before, might end up being a disadvantage, but I have to say, "risk", you just have to be aware of that. Therefore, you have to try to influence it in a positive way (P4: Henkel 25; 108:108).

"In addition she has a character quality that is quite positive, she is good with people on a personal level. Well, she is not afraid of using a direct way and sends it someplace she considers to be the right one, she really tries to find the person who is responsible, in charge of something in order to get the right input and, by all means, that is quite a positive quality because she is able to get better information or more specific information, and that's important, is great (P4: Henkel $38 ; 148: 148)$. “ 
These findings are in accordance with the literature. Suutari and Riusala (1998) report, that the CEE cultures exhibit certain feminine characteristics such as limited emphasis on performance and advancement and greater emphasis on personal relationships and solidarity (Bollinger, 1994). Fink et al. (in press) have observed that at the workplace individuals in CEE are weaving networks with other individuals with special capabilities. These instrumental friendships, successful transactions, and manipulative actions can be transformed into social capital or into economic resources and are very beneficial for individual employees.

\section{Gender egalitarianism in CEE}

Team members from the countries of former Yugoslavia are characterised as not being gender egalitarian. Applying an equity norm for female and male employees in MNTs consisting of members from these countries is very problematic and leads to critical incidents increasing the conflict potential in MNTs. Team members from cultures characterised as being low on gender egalitarianism tend to harm team effectiveness in the case they don't adjust to the values and norms of behaviour of members from cultures high on gender egalitarianism, e.g. team members from Serbia working together with Austrians:

"Oh well, it doesn't matter, I have only tried to calm things down, to be precise, to make sure nobody is insulted but when, for example, a female associate (Austrian) tells a male co-worker (Serbian) that he has to pay attention about how things are done, then this is quite an unfamiliar situation for him, a "woman" ordering him around ........ That's when you have to make people aware of the fact that teams consist of men as well as of women (P1: Henkel 39; 135:135)."

\subsubsection{Learning processes within the team and the moderating effect of time on cultural standards of MNT members}

In the initial stage of team formation, process losses caused by attitudinal and communication problems and by stress factor, have a negative impact on team effectiveness. MNT members have to put more of their time and effort in creating solidarity and trust. The most challenging task is to understand differences and cope with critical incidents. Every time a new member joins the team, the whole team building process starts again. It is important for both sides to understand the kinds of perceiving, thinking, judging, and acting that are considered as typical by other team members: 
"Of course there are always situations, especially at the beginning, a new associate, a woman, arrives, and you realize the group building process starts all over again, that's the rule, interesting on one hand, on the other hand, of course, you have to try and not intervene too much, sometimes however, words are necessary, because it was, especially, when the team was enlarged by an additional female employee, this was a crucial point, because she is quite different from the rest of the team in her way of thinking and some of her insecurities were expressed in a way that, for other people, were almost a little bit insulting and that's quite a difficult situation, and that needs to be discussed early, because otherwise it might lead to a gap or to a barrier, that would have serious consequences (P4: Henkel 13; 69:69). "

"And then we had a lot of conflicts regarding punctuality. I still tend to be on time a lot and I tend to be annoyed if somebody keeps me waiting, because I think, it's my time as well, there are only 24 hours in a day for me, too, and at the beginning, we had fights over that, when I had to wait for somebody for half an hour. It was an unpleasant situation for both sides, and the situation has improved, they knew relatively soon that being on time was a way of keeping me "quiet". It worked, learning from each and the willingness to get closer together has worked quite well (P7: Henkel 45; 159:159).

When expatriates operate abroad they usually adopt certain aspects of the host country culture and the host country management style. They preserve certain practices and integrate those that they perceive as useful and appropriate. This way they adapt their leadership style to the host country managerial characteristics. This phenomenon has been observed in all three case studies. Yet what happens when those expatriates return to their home country and the HQ? It has been reported that they have to face challenges adapting to the HQ's corporate culture and again to the home country managerial cultures and practices. Their style causes critical incidents when interacting with host country team members, e.g. two Austrian members from one MNT report that they had to face many challenges when a new Austrian team leader joined the MNT. He used to work in Serbia for three years and to lead a team of Serbian employees. When he came back to the HQ he had to learn again to share relevant information with his team, to make group decisions where everybody was involved in the decision process and to share, explore and exploit useful marketing knowledge during discussions and meetings with his employees. The expatriate team leader mentioned that it took him three months to learn how to work in the new team. The first quotation illustrates the experience of the team members and the second quotations shows the challenges for the expatriate team leader in the initial stage:

"At the beginning, when this new senior manager was new, we were aware of a few negative aspects. There was a bad flow of information. It means that he did 
not forward information he had received. It's quite often the case that only the team leader receives some information and not the team as a whole. Or information was not forwarded to us in time. Decisions were made without our knowledge, without our involvement. And we did not like the way discussions were carried out. He asked for our opinions but made the decision all by himself. We addressed this issue, we told him that we wanted this to change. And it did. Our team is quite new. We have only been working together since March, the three of us (P2: Henkel 12; 79:79). "

"Exactly, they were already there. It was also, it was completely different, a whole new experience. It took us three months to find a mutual understanding. I consider that normal, it's a kind of transition period until you get to know each other, until you what's important to the one or the other. What are his abilities, what does he want anyway, where does he come from. In this one case I aim thinking of, everything was fine, the woman who had held my position before me had always worked in Vienna, she had worked in Vienna in this division, and I had come from another country and brought a lot of specific knowledge with me (P7: Henkel 48; 189:189).

These examples show that time has a strong moderating effect on MNT performance. Team members adopt their perspectives and change their ways of perceiving, judging and acting. This adaptation decreases the number of critical incidents in MNTs and increases its effectiveness. The same phenomenon has been observed by Early and Mosakowski (2000). They have found that heterogeneity has a detrimental impact on team functioning but that this disadvantage is not a monotonically decreasing function. The impact is consistent, with both split and heterogeneous teams inferior to a homogeneous team. Over time, however, the impact of heterogeneity on team performance and other team outcome variables becomes curvilinear. After forming ways to interact and communicate, highly heterogeneous teams appear to create a common identity and increase team performance.

\subsubsection{Transfer of knowledge between organisational units through MNTs}

One of the key research questions that has not been answered yet is how MNTs may facilitate the knowledge transfer across geographic and organizational boundaries (Gibson et al., 2003) and consequently reduce the complexity inherent in multinational companies. $80 \%$ of MNTs members at the regional HQ of the company under study are from different CEE subsidiaries and from the HQ in Düsseldorf. These teams facilitate the transfer of knowledge between the Viennese HQ 
and the various subsidiaries and improve the acceptance of knowledge of competitors and consumer behavior in the host country. Moreover, they influence new product development, branding and advertising by supporting the generation and implementation of creative ideas and building upon the ideas of members from CEE. In addition, the intensity of interactions in MNTs develops interpersonal communication skills and creates a unified team culture over time. Through this knowledge-sharing activity the team members promote the effective transfer of knowledge about products, markets, customers, competitors in their home country to the HQ and from the HQ back to the subsidiaries and eventually throughout the entire multinational organization. This experience is very motivating. The company devises its international rotation programs to combat such harmful influences that may emerge from lack of cross-cultural understanding and wasteful distrust and negative stereotyping. The principle behind creating its system of knowledge exploitation and transfer is job rotation. Employees work together in MNTs over a sufficiently long period of time to consolidate close relationships. Members from CEE who work in MNTs at the Viennese HQ on semipermanent assignment increase creativity and prevent situations of groupthink or even myopia. This way, MNTs contribute to the creation and transfer of tacit knowledge that is very important in today's global knowledge-based economy and that contributes to the company's competitive advantage:

"Well, our employees are well aware of the situation, I have to say, that everybody kind of tries to live and let live, and what I do, in any case, before we start, before we start job rotation, I introduce the new people and I like to do that, and I add that we are there to learn. So, if an associate from Serbia or Russia, men or woman, is new, then it has to be clear that we want to learn from him. He does not only come here to learn from us, it's vice versa as well, he has to be aware of that, and then I like to point out that miscommunication happens, it's unwanted and that we have to address problems immediately, discuss everything, and if somebody thinks that he has been treated unfairly, by one statement or the other, then he has to let us know right away (P1: Henkel 31; 151:151). “

"There are several ways I handle situations like that, in no case, however, with my know-how, other people have know-how, too. For me it is important that they put their know-how into proper use, think, in order to achieve our goals. Employees need to find the way to achieve this goal, and I am here to support them. Yes, that's how I would sum it up. (P5: Henkel 31; 68:68).

"I also consider it important that they are here, that we have an exchange and that, when they return home, take with them know-how from Austria. But I think this exchange is very important, because otherwise we would talk about things we know nothing about. Many Austrians work in countries such as Poland, Russia, you can find Austrians everywhere, the bottom line is, 
management etc. might even be local there. And that's the interaction here, too, that you if you walk around in our building here and you can never be sure that, I mean you have to speak English, it happens in the elevator, a co-worker addresses us in English because he is not from Austria and we are quite international here, too, not just abroad. And when communicating as well, I have to pay attention, communication between associates, you have to bear that in mind, not German, you have to use English (P9: Henkel 13; 112:112). “

Such teams are the core performing units in the organisation under study. It accommodates both permanent and temporary teams. Flexibility of structures, systems, and individuals is crucial for adaptability and in order to meet the needs of the work and the environment, the organization must be flexible enough to launch different types of teams quickly (Harris and Beyerlein, 1995). This is also the case in the regional HQ of Henkel. Whenever there is a special project like the launch of a new product, workshops are organized in Vienna where all host country representatives are invited to participate and share their perspectives and knowledge by working together in temporary teams. The new product is introduced and then they are given time to come up with ideas how they would like to execute the launch of the product in the host country market. Everybody is encouraged to come up with ideas and then this valuable information is discussed in detail. There is no monopoly of good ideas. The exhaustive discussions and the feedback from host country representatives lead to the creation of new knowledge and the development of new market entry strategies for CEE. There is always one person who is responsible for summarizing the best ideas at the end of the workshop and to send minutes with the most valuable inputs to the marketing teams of the entire multinational organisation. These workshops are not regular basis meetings. They are just related to projects. If there is a specific project then there is one workshop before the launch of the product. There are no regular meetings regarding these particular projects, but in the case that the launch does not work very well, another workshop may be organised where country representatives are invited to discuss the issue and find new solutions. This way knowledge exploitation takes place and the company creates new knowledge for product improvement and successful market entry strategies in CEE. It shows how the company's ability to launch temporal teams quickly facilitates knowledge creation and transfer:

"I think that these workshops are very important where the countries exchange all their ideas because the thing is here in Vienna we are limited by the amount of work that we have and the number of projects that we deal with but also by the flexibility of our purchasing department and all the suppliers that we have here in Austria. So, we are basically unable to answer every need that a country has. So, I think that it is very important to have a workshop. This is an incentive 
to bring the countries here and exchange ideas. At the beginning it was not a clear success. There were definitively lower expectations. So, we invited all the countries to share their experiences with us. And for example we noticed that in the country where Persil was very successful there were many actions taken which clearly contributed to the success. So, it was very critical and important that the Slovakian team who shared the experience and the mechanisms of the promotions that they introduced in their markets and so that we could excruciate to all the other countries and all the other countries could see it. Now, we started seeing results of it because now the situation of Persil improved in the other countries. This was...very critical (P3: Henkel 7; 61:61)."

"Every once in a while if there is a special project like the launch of a new product and it is important for us we make for example a workshop. So, we invite all the countries where the product will be introduced and we got all them together to exchange ideas. First, we brief them about the product and they have time to come with ideas how they want to execute it. There is no monopoly of good ideas. It is a very profitable process when you bring the people together. They threw their ideas on the table and they exchange it and so they... I do not know. Bulgaria can take its ideas from Slovakia or Russia. They are free to discuss. My job is to summarize the best ideas, to send minutes and the most valuable inputs and ask the countries to say which ideas they want to use and how they want to execute it. And then collect the people for the execution (P3: Henkel 32; 39:39)."

The knowledge-sharing activities lead to the exploitation of very useful marketing knowledge that contributes to the successful implantation of marketing activities in the CEE. The discussions lead to the creation of new knowledge and this knowledge enables the company to stay ahead of the global competition and gain competitive advantage. MNTs consisting of HQ employees and host country representatives (inpatriates) facilitate the exploitation and transfer of knowledge across geographic and organizational boundaries of the company.

\subsubsection{Transfer of the appropriate dimensions of the home organization's culture between organizational units through MNTs}

How to best make use of MNTs can become critical to a company's competitive advantage. Yet to take proper advantage of MNTs requires a good understanding of the impact of such groups on an organisation including its culture. By 
employing inpatriates in MNTs on semi-permanent rotational assignments, the company maintains its cultural consistency between geographically dispersed business units and creates a strong corporate culture characterised by common values and business methods. Team members from CEE spend one or two years in the regional HQ. During this period of time they get familiar with the roles, values and climate of the organisation. When they return back to their home country they are able to work more effectively within the strategic direction and culture of the HQ and to transfer the appropriate dimensions of the HQ's organizational culture. This way they facilitate the creation of a shared company mindset, which supports the willingness of the employees to share marketing knowledge between the host country subsidiaries and the HQs. Again MNTs reduce the complexity in this large multinational company by transferring the appropriate dimensions of the HQ's corporate culture to its subsidiaries in CEE:

"Strictly speaking, our teams work like that, if there is somebody, on a certain level, the one I work for, $80 \%$ are job rotations. It means that people from other countries come to Vienna in order to learn how it works around here and to get to know the corporate culture of Henkel here in Vienna. Then they are able to manage better in their home country, because they know how it works around here. For example, if you are in Hungary and you only get a handbook full of guidelines, you don't have a clue about why. Tomeck is here for 18 months and will then return to Poland. That's the basic idea. That's the way it works for everybody. There are only few exceptions, of people who come here and want to stay and work in Vienna (P8: Henkel 14; 99:99).

"Yes. In principle, they come here in order to get to know Henkel's corporate culture in Vienna because it is quite different from their home countries, local, the corporate culture, in Poland for example. 500 people work there. They come here to learn everything from a professional point of view on the one hand, from a cultural one on the other hand. In addition you then have contacts that make your work life back in Poland much easier. Once you know people in person, whom otherwise you would only know from writing e-mails, that is such a huge advantage (P8: Henkel 17; 105:105).

"There is a team of three, for one part these are employees from other countries who are here on job rotation, who are here in Austria for two or three years or sometimes for one year, where you rather try to maintain the organization and the team spirit, because most of them, at least in those countries, they have a very specific view of their country and we work as a group and there you have to think a little bit differently, more than just saying, OK I am only thinking of Austria right now, a strategy that says, we as the company Henkel always have a common way of thinking, in regard of all the countries together, it means, there has to be an advantage for the whole group and this attitude, I'd call it a 
positive attitude, people here feel it, in order to find out that we, I would say, we do not discriminate against any countries. OK, this apparent disadvantage is actually an advantage for the whole cause and people notice that, more or less and there are teams in these countries that do the same work that we do here, budgeting etc. and the whole operation is managed from here. (P1: Henkel 40; 16:16).

MNTs consisting of HQ employees and host country representatives (inpatriates) facilitate the transfer of the appropriate dimensions of the HQ's corporate culture. They help to maintain an organisation's cultural consistency between geographically dispersed business units.

\subsection{Individual team members at Henkel CEE}

\subsubsection{Team leaders}

In this chapter we will present MNT leader competences that have been identified by team members and team leaders at Henkel CEE. We report findings that incorporate the perspectives of MNT leaders as well as members on MNT leadership together. Identifying and presenting dual perspectives is not the aim of this dissertation and consequently does not play an important role in this context. Selection of team members, goal determination, motivation, communication and monitoring are the most frequently mentioned MNT leader competences. In addition, social competence and the ability to provide virtual MNT leadership have been identified as important factors that enable the effective functioning of MNTs. Expatriate team members face additional challenges in leading teams at subsidiaries in the host countries. They are responsible for transferring knowledge and appropriate dimensions of the home organization's culture within organizational units. Moreover, their major task is to enable the host country team to conduct business in accordance with a HQ company's norms and rules of behaviour. For them, cross-cultural communication competence and the ability to gain the respect and understanding of host country employees are necessary for successful performance. Table 13 shows these functions of team leaders and illustrates them with sample quotations:

MNT leader functions

Communication:

"In terms of head's leadership and also communication which is very important I think that we have very often meetings with him and discuss the pro- 
jects and we have his very constant feedback. He is very clear in setting the directions for developing the process. I think he is pretty efficient. I do not have so much experience to say what he could improve. I am not in a good position to do so (P3: Henkel 24; 109:109)."

\section{Monitoring:}

"Because we always do a monthly review, what each associate has accomplished in a month, and did it contribute to go in that direction. Then we do a short analysis, why yes, why not, if it didn't, why was it done anyway? Did it really deserve the priority it got as something else had to be left aside. Set priorities and check, of course, whether it really was accomplished and if there are discrepancies, and why (P10: Henkel 25; 107:107).

\section{Monitoring:}

"That's how it is in a matrix organization, in a region that is so diverse, with so many different tasks, communication is very, very important for exchange, and what is one of the most essential factors, to check back on the actions we agreed upon. Well, there are, I can remember back then when, legendary examples, where you would sit in a meeting in once country for a whole day, minutes of the meeting, responsibilities, timing and then you come back two weeks later and nothing had happened. In order to have here, you know, together with the countries, that's why mutual things are so important. Procedures are defined and are then monitored together with the respective country manager, in order for it to work or to be adjusted in case there is additional information. This monitoring, the follow up is definitely one of the biggest challenges in order for the system to work. (P11: Henkel 22; 145:145)."

\section{Motivation:}

"The working atmosphere within a team or a department depends, very much so, on its leader. I have had heads of department who asked my why I was still working in my office after $7.30 \mathrm{p} . \mathrm{m}$. and whether I did not have a private life. It's really nice to know your boss is interested in your well-being, and asks you for your wishes, ideas and expectations. This human factor on his part is really motivating and very important. (P15: Henkel 7; 104:104)."

Selection of team members:

"Well, you have to make sure that people feel welcome in this city, in this company, that the team members work well together, because you bring together different characters and different goals and several opinions. I mean, you have to give it some thought, whether one, because you don't hire all of them at once .... As a senior manager you have to consider whether a person 
will work well together with the rest of the team. You sort of have to match your team members. Everybody should be able to feel comfortable within a team, otherwise you are in danger of ruining the work atmosphere. Matching team members is quite essential. As a manager you have to take care of that. When you notice a team member not feeling at ease you have to address him or her. For that you have to know a little something about human nature and you have to find out whether the problem lies with the person or the team. And then you have to try and find a solution that works for all of them. Of course, you should not risk the team spirit for the sake of just one member. In an international team co-operation and understanding between the individual team members have to work (P14: Henkel 22; 136:136).

Goal setting:

"Very important, to give a clear direction, all the team members need to know where they are heading, what's the goal, which direction and that's where they have to focus their energy. Of course, there are always arguments, here and there that need to be dealt with but you must never lose track of the goal. So, what direction do we get and then you need to set standards for it and again and again, what we do, as mentioned before, we have these quarterly meetings or monthly meetings, set standards again and again. (P10: Henkel 24; 107:107)."

Providing virtual team leadership:

"Actually, I am travelling on a weekly basis, right now, almost every week, I visit one of these countries, mostly where reorganization is still in progress, not where everything runs smoothly already. And then I visit headquarters in Düsseldorf quite frequently and have to do the networking there. I guess you can say that I spent $50 \%$ of my time with teams somewhere in Europe (P11: Henkel 26; 111:111). "

Expatriate team leader:

"Most of all, it is important to make oneself familiar with cultural differences and to take the time to get to know the various mentalities ...... I should add that it is my job to make sure that there is no need for other expatriates, once I leave. It's the intention, the goal, to train the local staff in a way, one of them can take over my job (P5: Henkel 22; 44:44).

"The acceptance that a young Austrian can just come to Serbia like that, in order to choose his local team and to be the team leader as well. Simply to see, to convince them, to convince them of one's competence, of one's visions, because Serbs are really sceptical, they believe nobody. That was exciting (P7: Henkel 19; 143:143). 
Social competence:

"So here is this social competence ...., well, without it, it is very difficult to lead teams like that (P1: Henkel 30; 146:146).

"Understanding, but that is a soft skill, in order for this management or team, communications includes soft skills, there are no hard skills one needs to have, that's rather a matter of understanding. ..That's a major factor of success for teams, in my opinion (P7: Henkel 35; 206:206).

Table 13: MNT leader functions and characteristics at Henkel CEE (Source: Author)

These findings are in accordance with the study conducted by Joshi and Lazarova (2005). They identified four core competencies of MNT leaders: communication, direction and goal setting, facilitating teamwork and motivating and inspiring.

One of Henkel's company's values is that it considers itself successful because of its people. Employees are encouraged to make their own decisions and to work independently on interdependent tasks. Trust is highly valued and members act in the best interest of the company. They communicate openly and actively and preserve the tradition of an open family company. Creative and competent employees are a key to Henkel's global success. The company's human resources strategy focuses on attracting the best junior managers, offering them attractive career perspectives and actively developing their skills. This is based on international training programs, systematic knowledge management, and the increasing application of innovative coaching methods. This enables people to work independently and facilitates the work of team leaders. MNT members are familiar with their tasks and have the required skills and abilities to perform well. The HR Department plays an important role in developing their skills and making them understand the values and norms of the corporate organisations that guide them in fulfilling their daily duties and responsibilities. Consequently, team leaders usually have to fulfil just a coaching function:

"It's my business to make sure a goal will be achieved. And I have to add that I see myself as a coach, very much so. I really don't know if coaching is considered a management strategy. I am here for my associates, to help, to achieve the goals. I use different approaches to do that ...It is my job to motivate them, to develop ideas, to encourage team dialogue, to talk to the whole team ... The bottom line is, it's the team that masters a problem, not me (P5: Henkel 30; 68:68). “ 
Researchers should continue identifying core competencies of effective MNT leadership. There is still very little work on leadership in MNTs and empirical work that is not based on student data is still rare (Joshi and Lazarova, 2005). This points to the difficulty in studying these teams in an organizational setting and represents an interesting avenue for future research. However, researchers should be aware that the type of team as well as the organisational and team context do matter. By distinguishing between types of teams in different companies they may find out that the personal capabilities, skills and abilities of MNT leaders will vary for different types of teams and organisations. An effective HRM that focuses on attracting the best people and actively developing their skills will facilitate the role of MNT leaders.

\subsubsection{Team members}

The category team member is characterised by personality, work experience, social competence and open-mindedness. Interview partners have identified the importance of personality traits as a factor influencing MNT interactions. Selecting the right people has been identified as an important MNT leader competence:

"Of course, the biggest challenges are the different people. As people have quite different characters, they need to be led in different ways. Actually, for me, this is the biggest challenge because you have to handle it individually. And then, sometimes, it is difficult, like when you have a jour fix, it is often difficult to handle a discussion on a level that is clear and comprehensible for everyone, because everybody is deeply involved in his own topics, and then to handle it on a level that is an enrichment for everybody not only for the person behind the topic, that is clear, that is, for sure, a challenge as well as a basic executive function. And the personalities as well as the ways of working are completely different from each other. One person is well organized, the other one thinks more globally and has a different goal in mind and does not have to write down every single step and neither has to analyze it but experiences it as a whole. That, of course, is the biggest challenge (P4: Henkel 55; 64:64).

"And I think that the individual team members have to fit together characterwise. That it proves to be difficult to put, I don't know, an introverted person together with a very extroverted, with a totally self-centred person in one team, that is extremely difficult (P7: Henkel 31; 206:206). “

"Cooperation. On the one hand, I would say that it very much depends on the personality of the individual, that's for sure, that's what I have learned during my 5 years with Henkel, that you easily, if there is somebody, where the flow of 
information works out fine, due to personal proximity, I would say, the it works out considerably better. .... (P13: Henkel 6; 62:62).

Interviewees have also reported that social competence and open-mindedness are critical for MNT success. In an MNT there are many perspectives that are represented and team members must be able to appreciate the value that each one has to offer. This includes different technical and cultural views. They must not just tolerate such perspectives, but must also embrace the opportunities for learning that the different views bring. It is through a heavy interaction of perspectives that creativity and innovation occurs. In an international environment enjoying such differences facilitates the interaction of the team. Team members share their perspectives on this point. This finding is in accordance with the literature (e.g., McCrae and Costa, 1997).

Another important issue for an effective team is the work experience of individuals. Past international assignments, as well as work experience in different companies and different countries create additional challenges at the initial stage of team formation. Team members have to get familiar with the rules and norms of behaviour in the company in order to work efficiently with each other. There is a strong socialisation process in the beginning and this improves MNT functioning in the long run, since team members become familiar with their roles and expectations. For team leaders it is often challenging to enhance the development of team members' skills and to communicate goals and procedures during team meetings. New members need more time to understand certain issues. Experienced team members who have experience in MNT work are the ones who are able to facilitate this learning process and increase the level of understanding of their colleagues. Time and learning processes within the team have a moderating effect on its performance:

"Which has to be seen in connection with experience. The associate had just started and never worked in a company like ours before, she had not been able to gain experience and therefore needed to catch up on a lot of things in order to reach a certain level of experience, and I am sure she would look at it differently now compared to three years ago. Naturally, a lot of things have happened since then (P4: Henkel 15; 79:79).

"It's difficult, but this was definitely one of the biggest challenges, the cooperation with these quite different mentalities. Our background as far as experience is concerned is quite different. Language-wise it was no problem. In upper and middle management positions there were only associates with a very good proficiency in English. There was no problem. Still, the mentality and the different levels of experience were the biggest challenge (P5: Henkel 24; 20:20). " 
"And for this reason, the three of us were able to learn from each other, I was taught how it works in Vienna, in the headquarters, what I did not know up to a certain degree and I taught them how problematic headquarters decisions are for the countries and how careful we need to act in order to balance between all our countries. Again, there was a good exchange between different levels of experience and different fields of experience (P7: Henkel 27; 189:189).

In the past studies, on MNTs have tried to assess only one aspect of diversity and have failed to capture the full spectrum of diversity found in MNTs. Obviously, diversity researchers have not yet succeeded in tackling the challenge of empirically assessing multi-dimensional diversity. In future, one should bear in mind that certain personality traits and work experience in different teams, countries and organisations of individual team members will either lead to MNT success or its failure.

\subsection{Summary of empirical findings from Henkel CEE}

Fifteen problem-centred interviews have been conducted at Henkel CEE. The HQ in Vienna is responsible for operations in CEE and it pursues a multinational strategy. MNTs consist of members from this region who are mainly on rotational assignment for a period of one to two years at the HQ in Vienna and who work in MNTs. Eighty percent of the staff at the junior level are inpatriates from the countries where the company operates.

Henkel CEE is a company with a family-like corporate culture that supports team work. The management philosophy of Henkel CEE is one of involvement. The organization is built on the principle that people have the right to be involved in matters that affect them. As a consequence, team members make decisions in the best interest of the organisation. The organisational culture motivates them to do their best in order to achieve the company's goals. Moreover, MNTs add a multicultural perspective to the multinational strategy development and enable the company to act as locally as necessary and as globally as possible.

We could collect numerous norms and values of behaviour of members from CEE. The societal culture of CEE with focus on low collectivism, high power distance, high level of uncertainty avoidance, a preference for a direct approach of criticising team members and subordinates and a tendency to withhold relevant information creates critical incidents in MNTs.

There is still a lot of improvement potential in terms of teamwork and participation in decision making in CEE countries. There is little understanding of team work and devolved responsibilities among team members from this region. More- 
over, there is a preference for individual rather than shared responsibilities in teams and team members seem to be busier using personal contacts with superiors to promote their own interests and strengthen their position in the organizational hierarchy than pursuing common goals and giving support to their team members. The individuals may express pride, loyalty and cohesiveness in their families but not necessarily in their teams and organisations.

Compared to Austrian team members, who are expected to react in consistent ways in different situations, reactions of employees from CEE seem to depend more on the place, time, and person. Behaviour that is judged appropriate for a given place, time, and person may not be appropriate for other times, places and persons. They change the self to meet environmental demands and become highly competitive and individualistic in business contexts. It has been reported that they hesitate to share important business related information with other team members and for Austrian team leaders it is very challenging to complement group or participation-based decision making and to introduce the concept of team work to employees from CEE.

Over time the teams at the regional HQ adopt the values and norms of the organisation and increase the level of mutual understanding and consequently also team performance. They adopt their perspectives and change their kinds of perceiving, judging and acting. This adaptation decreases the number of critical incidents in MNTs and increases its effectiveness.

MNTs at Henkel CEE reduce the complexity of operations of the German multinational company by facilitating the creation and transfer of explicit and tacit knowledge and of appropriate dimensions of the home organisation's culture between geographically dispersed business units. $80 \%$ of the MNTs' members at the regional HQ of the company under study are rotating members from different CEE subsidiaries and from the HQ in Düsseldorf. These teams facilitate the transfer of knowledge between the Vienna HQ and the various subsidiaries and improve the acceptance of knowledge of competitors and consumer behaviour in the host country. Moreover, they influence new product development, branding and advertising by supporting the generation and implementation of creative ideas and building upon the ideas of members from CEE. The intensity of interactions in MNTs develops interpersonal communication skills and creates a unified team culture over time. Through this knowledge-sharing activity the team members promote the effective transfer of knowledge about products, markets, customers, and competitors in their home country to the HQ and from the HQ back to the subsidiaries and eventually throughout the entire multinational organization. Knowledge exploitation takes place when existing knowledge is shared by team members in MNTs. On the other hand, knowledge exploration is triggered by the 
exhaustive discussions during meetings and workshops and leads to the creation of new knowledge and determination of new strategies.

By employing inpatriates in MNTs on semi-permanent rotational assignments, the company maintains its cultural consistency between geographically dispersed business units and creates a strong corporate culture characterised by common values and business methods. MNTs reduce the complexity of operations of the German multinational company by facilitating the transfer of appropriate dimensions of the home organisation's culture between its business units.

Selection of team members, goal determination, motivation, communication and monitoring are the most frequently mentioned MNT leader competences. In addition, social competence and the ability to provide virtual MNT leadership are identified as important factors that enable the effective functioning of MNTs. The category team members' characteristics are personality, work experience, social competence and open-mindedness.

Moreover, this study also shows how the German company exploits marketing knowledge from its vast network of subsidiaries through international rotation of employees and organised workshops, thus reducing the complexity and contributing to the company's competitive advantage. 
Aida Hajro - 978-3-631-75438-2

Downloaded from PubFactory at 01/11/2019 04:52:54AM

via free access 


\section{Empirical findings from $K \& M$ International}

\subsection{Company description: K\&M International}

K\&M International is a small company located in Ohio, Twinsburg. It is the world leader in the production of nature-related toys and operates in the USA, Canada, Australia, Singapore, Hong Kong, Japan, U.K., Denmark, France, Austria, Holland, Italy and Germany and has production facilities in China and India. Around 100 to 120 people work in the HQ in Ohio (approximately $30 \%$ Indians and $70 \%$ Americans). The product development team develops every year approximately 800 to 1000 toys. The company's mission is: "To serve our global community, taking a leadership role in providing innovative nature-related toys that help fulfil our business partners' common mission of education with recreation." (K\&M International, 2007)

K\&M International was founded 1975 by Mr. Pillai who has a strong passion for children and animals and who realized that in the seventies the zoos and aquariums were in a pretty bad shape in the USA:

"I am the president and owner of the company. I founded the company. First, I used to be an engineer. Basically, I was a mechanical engineer. I used to work for a large organisation. This was General Electrics. I had a passion for children and animals. And I wanted to do something for children and animals in combination. I had to make a decision concerning the best way to do this. So, when I was working I used to look at all these toys around and I had to realize that the zoos and aquariums were in a pretty bad shape in the USA 30 years ago. Today, the zoos and aquariums have nice shops with a lot of animal related products. 30 years ago it was not that way. There were many not related products in the zoos. I got the opportunity to start a business in my garage. I used the savings from my job. I used to sell during the weekends to the zoos and aquariums in the USA. I drove to the zoos and aquariums and very soon I managed to find a niche. I bought the toys and started reselling them. At the beginning I did not have the opportunity to start with product development but by buying and reselling these toys the businesses started growing. Then I decided to leave GE. People were telling me that I was taking a great risk but I was very confident with what I was doing and I made a big step in my life. By the way, the first employees were me and my wife. We were packing the toys and then reselling them. Slowly, we started putting more products into the line and we build up good relationships with our customers. I have very good relationships. I was selling the products to zoos, aquariums and museums wherever this was possible. The business started growing. Today, I have sales people. It is not me who is selling the products. So, I 
could concentrate much more on the product development. We have very good people here. As a company, we have different nationalities working here. We have multiple talents. The talent is what we are looking for. The nationality does not matter. Soon, we reached the point where we realized that we were successful. So the question was: "What is our next step?" I did not want to be a toy company. I wanted to be a niche player. A toy company is a big risk since there is a tough competition. We did not have the finance to do it. So; we decided to find a niche and be strong. As soon as I became successful in the USA I decided to expend my business. The question was again if I should go as a toy company or if I should stay a niche play and expend to Canada. After a couple of weeks, I decided to go to Canada. We build up an office there and started selling toys. Then I went to Singapore. There I met a woman who decided to go to Europe after she worked for us in Singapore. So, I asked her if she would like to support us in expending our line to the European market. She decided to do so. She was very capable and she started to expend our business in Denmark. The next step was the U.K. The last market was Austria. We soon built up our own infrastructure to a certain extent by building our own factories in India and in China. We have also suppliers from Hong Kong. I developed these people from zero to this extent. We also went to Austria where we started selling our products in the Vienna zoo six years ago. The next market was Holland. In Vienna and Amsterdam we started with the retail part (P: K\&M 34; 3:3)."

The company pursues a multinational strategy and adopts its marketing activities to national customers' needs. In future it plans to expand its businesses to CEE. We are not allowed to include any financial data about K\&M International in this dissertation.

\subsection{Major findings from $K \& M$ International}

In this following section we will present the findings from the study conducted at K\&M International in Twinsburg, Ohio. The researcher conducted 15 problemcentred interviews with team members and team leaders from India and the USA in August, 2005. The interviews have lasted for approximately one hour. The researcher has spent seventeen days in the corporate HQ conducting interviews, socialising with team members and participating in directors' meetings. This chapter presents the categories of influence on MNT performance identified at $\mathrm{K} \& \mathrm{M}$ International and the relevant codes of each category, which are listed in Table 14. Problem-centred interviews have been conducted in English with Indian and American employees. The section also includes those quotations that present typical arguments for the relevant codes. The most frequently mentioned categories are corporate norms (mentioned by $93 \%$ of interview partners), followed by 
the impact of corporate culture on teams and team leader characteristics (mentioned by $73 \%$ of interview partners) at K\&M International. We could also obtain 51 quotations by $67 \%$ of interview partners that refer to cultural differences between Indians and Americans.

\begin{tabular}{|c|c|c|c|}
\hline Category & Codes & $\begin{array}{l}\text { Number of } \\
\text { quotations }\end{array}$ & $\begin{array}{l}\text { Percentage of } \\
\text { interviews per } \\
\text { code }(100 \%= \\
15 \text { interviews) }\end{array}$ \\
\hline \multirow[t]{6}{*}{$\begin{array}{l}\text { Cultural } \\
\text { differences } \\
\text { between } \\
\text { American and } \\
\text { Indian team } \\
\text { members }\end{array}$} & $\begin{array}{l}\text { Reference to } \\
\text { cultural } \\
\text { differences } \\
\text { between Indians } \\
\text { and Americans }\end{array}$ & 51 & $67 \%$ \\
\hline & $\begin{array}{l}\text { Most frequently } \\
\text { mentioned } \\
\text { differences: } \\
\text { Individualism in } \\
\text { India and } \\
\text { collectivism in the } \\
\text { USA }\end{array}$ & 8 & $40 \%$ \\
\hline & $\begin{array}{l}\text { Power distance in } \\
\text { India versus USA }\end{array}$ & 9 & $40 \%$ \\
\hline & $\begin{array}{l}\text { Context sensitivity } \\
\text { of Indian versus } \\
\text { USA }\end{array}$ & 6 & $33 \%$ \\
\hline & $\begin{array}{l}\text { Gender } \\
\text { egalitarianism in } \\
\text { India versus USA }\end{array}$ & 5 & $20 \%$ \\
\hline & $\begin{array}{l}\text { Perception of time } \\
\text { in India versus } \\
\text { USA }\end{array}$ & 4 & $13 \%$ \\
\hline Industry context & Nature of business & 5 & $20 \%$ \\
\hline $\begin{array}{l}\text { Organisational } \\
\text { context }\end{array}$ & $\begin{array}{l}\text { Organisational } \\
\text { culture }\end{array}$ & 22 & $73 \%$ \\
\hline Corporate norms & Norms & 111 & $93 \%$ \\
\hline MNT dynamics & $\begin{array}{l}\text { Knowledge } \\
\text { exploitation and } \\
\text { exploration in } \\
\text { MNTs }\end{array}$ & 11 & $47 \%$ \\
\hline
\end{tabular}




\begin{tabular}{|c|c|c|c|}
\hline \multirow[t]{12}{*}{ Team leader } & $\begin{array}{l}\text { Team leader } \\
\text { functions }\end{array}$ & 52 & $73 \%$ \\
\hline & Motivation & 12 & $40 \%$ \\
\hline & Communication & 10 & $40 \%$ \\
\hline & Decision making & 6 & $33 \%$ \\
\hline & $\begin{array}{l}\text { Goal } \\
\text { determination }\end{array}$ & 5 & $27 \%$ \\
\hline & Monitoring & 4 & $27 \%$ \\
\hline & $\begin{array}{l}\text { Providing } \\
\text { leadership }\end{array}$ & 3 & $20 \%$ \\
\hline & $\begin{array}{l}\text { Conflict } \\
\text { management }\end{array}$ & 3 & $13 \%$ \\
\hline & Task delegation & 2 & $13 \%$ \\
\hline & $\begin{array}{l}\text { Selection of team } \\
\text { members }\end{array}$ & 3 & $7 \%$ \\
\hline & $\begin{array}{l}\text { Managing the } \\
\text { weaknesses and } \\
\text { improving the } \\
\text { strengths of MNT } \\
\text { members }\end{array}$ & 2 & $7 \%$ \\
\hline & $\begin{array}{l}\text { Team building } \\
\text { function }\end{array}$ & 2 & $7 \%$ \\
\hline \multirow[t]{4}{*}{ Team member } & Personality & 6 & $33 \%$ \\
\hline & Work experience & 5 & $27 \%$ \\
\hline & Social competence & 4 & $27 \%$ \\
\hline & Open-mindedness & 6 & $20 \%$ \\
\hline
\end{tabular}

Table 14: Categories and codes derived from the analysis of interviews conducted at K\&M International (Source: Author)

We start this chapter with a presentation of the influence of macro-variables on MNTs. The results show a strong impact of industry and organisational culture as contextual forces on MNT effectiveness. MNTs at K\&M International consist of American and Indian employees. Different cultural standards of Americans and Indians have a strong impact on team processes and contribute to critical incidents when team members with different cultural backgrounds interact with each other. We will also show how MNT members contribute to company's competitive advantage by sharing valuable tacit knowledge at directors' meetings, international conferences and regular MNT meetings. In addition to the team leader competences required to effectively manage MNTs and individual team members' skills and abilities, we will present data about leadership-cultural specifics of 
India and the USA and the emergence of hybrid cultures in MNTs. Table 15 presents a short summary of major empirical findings from K\&M International.

\begin{tabular}{|c|c|}
\hline \multicolumn{2}{|r|}{ Major empirical findings } \\
\hline Industry & $\begin{array}{l}\text { Industry, among other contexts, affects MNTs and their } \\
\text { members. Consequently, companies operating in different } \\
\text { industries will implement different types of MNTs and the } \\
\text { industrial context will impact MNT performance. }\end{array}$ \\
\hline $\begin{array}{l}\text { Organisational } \\
\text { culture }\end{array}$ & $\begin{array}{l}\text { Organisational culture has a strong impact on team effective- } \\
\text { ness. K\&M International uses teams as the core performing } \\
\text { units. The organization is designed to support teams and the } \\
\text { logic of the organization is team-oriented and not individual- } \\
\text { oriented. The larger organization must give some careful } \\
\text { thought to what is needed to support teams. These reflective } \\
\text { activities must occur regularly. }\end{array}$ \\
\hline $\begin{array}{l}\text { MNT } \\
\text { composition } \\
\text { and cultural } \\
\text { characteristics } \\
\text { of American } \\
\text { and Indian } \\
\text { team members }\end{array}$ & $\begin{array}{l}\text { MNTs at K\&M International consist of American and Indian } \\
\text { members. The finding shows that if two groups with different } \\
\text { values and norms of behaviour have to interact in one team, } \\
\text { then the members will either adopt e.g. American or Indian } \\
\text { norms of behaviour. These different cultural standards also } \\
\text { lead to the emergence of conflicts and are usually the cause } \\
\text { of clashes in team interactions. Demographic diversity } \\
\text { creates faultlines, since demographic characteristics divide } \\
\text { the network into subgroups. } \\
\text { Although we did not seek to determine the level of individu- } \\
\text { alism/collectivism in Indian and the American society, one } \\
\text { of the major findings is the existence of a strong element of } \\
\text { individualism in India and collectivism in the USA. This } \\
\text { finding deviates from prior notions of individual- } \\
\text { ism/collectivism. One would expect that employees who are } \\
\text { high in collectivism will more readily accept the team aspect } \\
\text { than employees who are more individualistic, since cultures } \\
\text { that are collective exhibit more emotional dependence on the } \\
\text { team, and are more conforming, orderly, traditional, team- } \\
\text { oriented and particularistic. Indians are less likely to readily } \\
\text { accept many of the concepts associated with teams and team } \\
\text { work. Collectivism is oriented towards the family but not } \\
\text { necessarily towards the organisation and its members. } \\
\text { A high degree to which Indians accept the uneven distribu- } \\
\text { tion of power among members has been observed. In India, }\end{array}$ \\
\hline
\end{tabular}




\begin{tabular}{|c|c|}
\hline & $\begin{array}{l}\text { they never question decisions made by people above them } \\
\text { and people working for them never question their decisions, } \\
\text { assuming that their power gives them the right to make such } \\
\text { decisions and given their power their decisions had to be cor- } \\
\text { rect. Yet managers from the U.S. tend to solicit work-related } \\
\text { ideas and suggestions from team members as a part of a de- } \\
\text { mocratic leadership style. American members view depend- } \\
\text { ence on the team leader negatively, while Indian members } \\
\text { obtain a sense of security from power coming from their } \\
\text { leaders and view dependence as a positive quality. One could } \\
\text { assume that this might be attributed to the level of uncer- } \\
\text { tainty avoidance in the Indian culture. Yet according to } \\
\text { Hofstede and Bond (1998) the cultural dimension "uncer- } \\
\text { tainty avoidance" is ranged in the mid-range (40) in India } \\
\text { even at a lower level than this is the case in the USA (46). } \\
\text { Indian members are more context sensitive than the Ameri- } \\
\text { can members who work with them in MNTs. Indians are } \\
\text { more willing to change their behaviour in order to cope with } \\
\text { their environment. Americans react in consistent ways in } \\
\text { different situations. In South-India some behaviour that is } \\
\text { judged appropriate for a given place, time, and person may } \\
\text { not be appropriate for other times, places and persons. } \\
\text { Consequently, Indians change their behaviour in order to } \\
\text { meet environmental demands. The ability of Indian team } \\
\text { members to adapt their working and communication style to } \\
\text { the American way decreases communication problems, inac- } \\
\text { curacy, misunderstandings and inefficiency in the MNTs. } \\
\text { The findings also show that team members from cultures } \\
\text { characterised as being low on gender egalitarianism (e.g. } \\
\text { India) may harm team effectiveness in the case they do not } \\
\text { adjust to the values and norms of behaviour of (female) } \\
\text { members from cultures high on gender egalitarianism (e.g. } \\
\text { USA). }\end{array}$ \\
\hline MNT norms & $\begin{array}{l}\text { The results also show that the emergence of norms subse- } \\
\text { quently influences work processes and outcomes. In addition, } \\
\text { they mediate the relationship between team composition and } \\
\text { work outcomes. A broad range of team norms has been iden- } \\
\text { tified in this study. }\end{array}$ \\
\hline $\begin{array}{l}\text { Emergence of } \\
\text { hybrid }\end{array}$ & $\begin{array}{l}\text { Managerial values and attitudes are subject to change in } \\
\text { MNT context and therefore studies aimed to explore the }\end{array}$ \\
\hline
\end{tabular}




\begin{tabular}{|l|l|}
\hline cultures & $\begin{array}{l}\text { effect of cultural dimensions on team effectiveness should be } \\
\text { aware of the fact that culture is not a static variable but is } \\
\text { changing and time has a strong moderating effect on it. } \\
\text { Indian team leaders integrate the American managerial prac- } \\
\text { tices and adopt a different leadership style in MNTs. As a } \\
\text { consequence of this phenomenon, we should rethink accepted } \\
\text { notions of culturally determined managerial identities and go } \\
\text { beyond seeing managerial identities in fixed national terms. } \\
\text { When we study MNTs we must also consider country and } \\
\text { cultural differences other than those provided by culture- } \\
\text { general frameworks. }\end{array}$ \\
\hline MNT leader & $\begin{array}{l}\text { We could identify several team leader competences. These } \\
\text { are the following: motivation, communication, decisions, } \\
\text { goal determination, monitoring, conflict management, ability } \\
\text { to provide leadership, selection of team members, managing } \\
\text { the weaknesses and improving the strengths of team mem- } \\
\text { bers, task delegation, teambuilding and knowledge of the } \\
\text { local language of the country where the team operates. In } \\
\text { addition to these competences, it is critical for an MNT } \\
\text { leader to develop solid relationships with a variety of people } \\
\text { from different countries and to be socially competent and to } \\
\text { have the required interpersonal abilities. He is also expected } \\
\text { to demonstrate real humility that he has only limited } \\
\text { knowledge and skills required to carry out the activities of } \\
\text { the team. }\end{array}$ \\
\hline MNT member & $\begin{array}{l}\text { Persons interviewed highlighted the importance of person- } \\
\text { ality traits, team member social competence and open-mind- } \\
\text { edness as three main factors influencing MNT interactions. }\end{array}$ \\
\hline
\end{tabular}

Table 15: Major empirical findings from K\&M International (Source: Author)

\subsection{Toy industry}

$\mathrm{K} \& \mathrm{M}$ International is the world leader in the production of nature-related toys. The company operates in a very competitive industry. There is intense competition and a constant need for innovation and improvement. Different types of MNTs (e.g., product development teams, customer support teams, sales teams, warehouse teams, customer support teams, IT teams, management teams etc.) are employed. The industry context has a strong influence on team composition, team members' requirements, team tasks and MNT effectiveness. External factors such as weather or changing customer tastes may have a stronger impact on company performance than MNT effectiveness. Therefore, it would be wrong to assess 
team performance solely by measuring a company's profits or sales as has been done in prior studies on MNTs:

"The biggest challenge for me is getting them to make their budget. There are a lot of factors that... Customers have a lot of say what we ship and when we ship it. The zoo business in particular is a division that... There are so many variables that go in to what we ship every month, whether place has major factors, how the ... at the gift shop within the zoo are going, the customers come in the fall in one of our three showrooms that we have in Toronto, San Diego and obviously Cleveland and they place orders which I wished they were concrete orders but they are not. They make usually projections. This is where I think I am going to buy from you. And what happens is the weather will dictate if they will really take the product. Last month my business was down and I am not going to take the order I placed for you to ship in August. What happens we have that inventory and we make it stuck with.... It is the nature of our business and I wish we could change the culture and the way how we are doing it because they just won't take products that they do not need. That does contribute a lot to our inventory problems. One thing that the overall projection for every customer we will always exceed the sales in whatever those projections are. It is the mix of the product. My biggest challenge is to try to make a budget with all these variables that come into play with that (P30: K\&M 3; 22:22)."

MNT researchers cannot afford to continue to ignore factors beyond the organizational level of analysis such as industry context, if they want to explain and predict the behaviour of MNTs and their members. Industry, among other contexts, will affect MNTs and their members (Jelinek and Wilson, 2005). Consequently, companies operating in different industries will implement different types of MNTs and the industrial context will impact MNT performance.

\subsection{Organisational context: K\&M International}

\subsubsection{Organisational culture of $K \& M$ International}

$\mathrm{K} \& \mathrm{M}$ International uses teams as the core performing units. The organization is designed to support teams and the logic of the organization is team-oriented and not individual-oriented. It supports teams and team building processes by introducing different team building activities where all employees are invited to participate. This way people from the company and different teams get the opportunity to know each other and form relationships. By getting familiar with members of different teams in the company, people are more willing to exchange relevant 
information about market trends, product development ideas etc. and contribute to the company's overall success. K\&M International uses teams to perform the core work of the organization and a variety of team types are used to meet the needs of each situation. The type of team varies as the work varies and different types of teams are needed for different types of work. The corporate culture has been characterised as "a family-like culture":

"When you work for $K \& M$ International you are not just a number. You think of you as a member of $K \& M$ family and that has been spread across the staff (P34: $K \& M 35 ; 17: 17)$."

"I know everybody by name. There is not anybody on the whole who passes and I do not know the name. That feels like a family to me as well. Here I know the people at warehouse, at account payable, account receivable. It positively influences the team work because people outside our department are comfortable to come to us and say: 'I have an idea for product development!' They are talking to us and they give us their ideas. It is definitively positive to feel as a family and to know everybody in the company (P35: K\&M 14; 66:66)."

Such a culture is critical to the performance level of the teams. It motivates the employees to go above and beyond the call of duty, to aid fellow workers and contribute to collective success:

"Everybody in the company feels that he should do something; he should contribute to company's success from the warehouse to the upper management and the owner. They promote communication among employees and promote their creativity you actually work in a creative department or not you can still have creative ideas. Things that may.... Everybody from the company contributes to our ideas. Somebody from the sales will call us and say: 'Eh. I have this idea from a customer. What do you think about this?' Sales people work with the customer and we want to make products for the customer and we want to listen what the people in the field are telling us. And if a certain customer says that he needs a certain product it is in our best interest to do something (P35: K\&M 32; 107:107)".

The impact of founder's values on organisational culture

According to Hofstede et al. (1990) the U.S. management literature rarely distinguishes between the values of founders and significant leaders and the values of the organisation's employees. Yet "the values of founders and key leaders undoubtedly shape organisational cultures" (Hofstede et al., 1990: 311). Our findings are in accordance with this conclusion. The founder of $\mathrm{K} \& \mathrm{M}$ International has a strong influence on corporate culture and he creates a sense of mutual obli- 
gation and loyalty, resulting in greater commitment and loyalty from his employees. He has a strong impact on decision making and is very powerful. This phenomenon can be illustrated by the following quotations:

"I am not sure if there is a lot of corporate culture here. It is Mr. P.'s culture. I have worked in a corporate atmosphere and this is the first time that I am working in an owner-based company. The culture is what Mr. P. wants it to be (P32: $K \& M 25$; 93:93)."

"Employees feel like family members when they work in this company. And this is where they turned to be very successful. All the employees are very dedicated to Mr. P., to Mr. P. and Mrs. P. actually. And I think that basically they care very much for the employees and they show that they are always there for their employees. I do not know if this comes from the Indian culture. I have never been anywhere else except in the U.S. so I can not really compare. But this probably makes the teams in this company more successful (P33: $K \& M$ 15; 65:65)."

"Well, again I think being a small company I know several of my employees have had situations where they needed some help and being a smaller company and the owners knowing pretty much everybody who works with the company they are willing to help their employees out in certain situations like for example giving them money that they need but they are always willing to go a step and help you if you have a problem. And I again think that you will not have this in a larger company. The two owners of the company know you by name and you do not feel like you are working for this big corporate entity where you do not know who is on the top or hardly anybody in between (P38: K\&M 3; 21:21)."

"They sometimes work 14 or 15 hours a day or even on weekend and without any complaint. That is because they know and respect Mr. $P$. and they know that they are working together for a common goal. They work as if $K \& M$ would be their own company. That is a tremendous thing that you will see very often in this company. They have targets to achieve, they work very hard for K\&M and as a team they bring in themselves. I think that we have wonderful teams here. Everything is based on good relationships within the team (P31: K\&M 19; 66:66).

According to the literature, the key reference group that influences decisionmaking is likely to be the one that is the most powerful in the organization such as the founder (Schein, 1985) or a group of powerful members (Schneider, 1987). In India the owners' and founding families' authority and influence on the running of the firm is much higher than what was prevalent in firms operating in Western countries (Negandhi, 1973; in Mellahi and Guermat, 2004). We should keep in 
mind that the owner of $\mathrm{K} \& \mathrm{M}$ International is originally from India. In India leaders are urged to create a family-oriented atmosphere in their organisations by cultivating a personalized and nurturant relationship with their subordinates, by participating in community functions, weddings, funerals, etc. (Khandwalla, 1996), so as to create a sense of mutual obligation and loyalty.

\section{Presence of specific practices for managing team work at K\&M International}

In addition to organizational climate and culture, the context of an organisation also includes the presence of specific practices for managing team work and the patterns of social integration (Jackson et al., 2003). Team building activities support teams and team work in the company:

"To be successful I as a head of HR department in this company started a new project called 'bridge the gap'. There are gaps between the teams and different people work in different teams........ So, we thought that we should bridge that gap. We should make these people talk to each other and become friends. Once they become friends, they will improve their relationship and once they have improved their relationship communication will improve. This program started 5 months ago. And we have some activities we do together. Once a month, after work we go to an amusement place and we play e.g. golf. We tie the eyes of one person and the other person has to tell this guy where to hit. So, we tell one team to select any other team from the company. And then these two teams play together. This way, people get to know each other and this facilitates communication and information exchange between the teams in our company. You can even invite friends. This helps us to build a team spirit in our company, to have successful teams and to facilitate the information flow between different departments of the company. Everybody should have a friend in this company. This motivates employees to stay in the company and creates a nice atmosphere. And do not get me wrong here! We are not encouraging dating here. We just encourage our employees to make friends. People are happier to work for us (P31: K\&M 28; 144:144)."

"What we are doing here is ... I asked M. to call the people from the other departments and to let us have a small pizza party here. This forms relationships. What happens is that people get together and they develop some sort of attachment. This forms a real team. People from my company also meet after regular working hours. If my employees spend every day more than 8 hours of their life time here there should be some bonding. There should be some connection between the people (P34: K\&M 24; 44:44).

Lack of information about the context in which many research studies have been conducted impedes our ability to understand the reasons for conflicting results 
found across studies on MNTs. Understanding the corporate culture of K\&M International helps understand why MNTs are so successful in this particular organisation. Creating an environment where teams can thrive does not happen by chance, but comes through time, effort, and commitment. The larger organization must give some careful thought to what is needed to support teams. These reflective activities must occur regularly. The environment the teams work in and the corporate culture are critical to their performance level. Future research should study MNTs in their real organisational context. Only this way we can explain and predict the behaviour of MNTs.

\section{The type of norms and values identified at $K \& M$ International and their impact on MNTs}

According to Hofstede et al. (1990) shared perceptions of daily practices and not so much the shared values represent the core of a corporate culture. Corporate values that define what is important and norms that define appropriate attitudes and behaviours for employees are mostly consistent with team norms and values at K\&M International. Team culture is also partly predetermined by the type of task to be fulfilled.

MNTs at K\&M International adopt corporate norms in order to regulate members' behaviour. These norms have an impact on how team members interact and communicate with one another, make decisions, solve problems and give feedback. Teams have also the freedom to define certain norms that help them better achieve their task. In addition to corporate culture the type of task influences team practices. For example, the product development team emphasizes norms that support innovation, promote creativity and encourage organisational members to develop original and useful products. In addition, members are expected to build upon others' ideas rather than limit their attention to their own ideas:

Innovation-enhancing norm: "In the sense that we are constantly challenging each other with new ideas, new concepts, challenging each other to be really the best that we can be in what we are trying to do. I think this is very important. It creates an environment like a synergy of, you know, we are bringing these separate elements but together we are going to be successful.... (P29: K\&M 14; 73:73)."

They are encouraged and rewarded for information sharing, particularly unique pieces of information, and for emphasizing greater tolerance for intellectual debate. These norms facilitate the generation and expression of creative ideas. Without a combination of diverse perspectives, the product development team may adopt the best individual idea rather than utilize the combined potential of the team: 
Willingness to share information: "Again as far as with product department they go through and request a project. Nick comes to me and I will take it to my team and we will discuss it. Information flows back and forward. I give them the information they need and they give me the information I need. It comes to me and I discuss it with the team. The project request comes to me, I discuss it with my team and we may go to other directors outside of our group to discuss the projects further. And then... As far as they say that they are going to accept the project and so we have to get it completed. It is important that we share information and that everybody is willing to do so. Only this way we can benefit from the combined potential of the team (P39: K\&M 7; 41:41)."

Teams at K\&M International are very cooperative. Cooperative norms, in particular, reflect the degree of importance members place on their personal interests and shared goals, objectives, and mutual interests:

"The nice thing about our team since we are bringing different elements to the table if they are having a bad week or something happens on the IT side that is really you know quite bad hopefully we are doing such a great job and we can kind of smooth out the whole situation as a package.....And if IT is having a crisis hopefully we are having such a phenomenal success on our side. They are more willing to accept whatever shortcomings they may have. If we are not doing well hopefully the IT is providing such a great value to our customer so they are willing to accept some of our shortcomings because of IT.... (P29: $K \& M 12 ; 64: 64)$.

One type of norm that was crucial for team performance is an open communication norm. Open communication norms around task-related differences increase team performance:

Open communication: "What does work very well? I think when we are making a product the most important thing is the communication of the people working on the product and making sure that you are communicating very well. I think that our strength is definitively the communication along the group and the brainstorming, the idea and working it out from a concept to a finished product.... Is an open form. We discuss it openly with each other. The designers are involved in the project and we all sit down at the table and put the drawings at the table and discuss the thing, the price point, the market, the basic look of the product, what the age group should be and things like that. I would say an open form of communication (P35: K\&M 4; 28:28)."

Creating shared goals is not a straightforward task in an MNT. Yet team members having a common goal are more effective than those having inconsistent and fractionated goals. Members who want to work together and who see how their mu- 
tual interests can be served by doing so are more motivated to tolerate and cope with cultural differences in the team:

Common goals: "I have never had to interact with cultures until I started here...... If you take out the nationalities everybody is striving for the same thing. We are similar in a lot of more ways than we are different. In order to be and going back to this whole family thing of $K \& M$ it can be intercultural and it does not matter as long as we all strive to the same direction. And so business is just that a happy family produces and the bottom line is a healthy bottom line (P41: $K \& M 13 ; 70: 70)$."

Moreover, team leaders, who adopt a collaborative and diplomatic approach and who encourage team members to share constructive feedback with each other, increase team effectiveness and improve cooperation among individual members:

"Very constructive! And it is important, sometimes artists take it very personally since they worked on it themselves. You can criticize something with a positive construction or constructive feedback and instant of pointing out what is wrong with it you should point out what can be improved. Making it negative and making it positive. People respond to that better (P35: K\&M 6; 39:39)."

"I am not going to shy away from communicating things. How I will approach it I will not say: 'You suck. What have you done?' If somebody has done something wrong, I am going to try to suggest different ways to go. So, it is something that I keep very private, I do not do it openly, I am not going to openly criticise anyone. But I always try to make it constructive criticism. It is something... It is dealing with something that you want to deal privately. I invite the person to my office and we discuss the issue but it is something that I will try to approach from sort of a constructive criticism point. 'Eh. You did really well on this project. But this one area, maybe try to get it done this way.' You must not put anyone down or hurt any feelings (P39: K\&M 8; 45:45)."

"I give them constant feedback; I try to socialize with them. Giving constant feedback and letting them know when a project is completed and not taking it for granted. They should know that I appreciate their work and that they have performed well. We do it as a department on a weekly basis that we meet and sit doing so we discuss the projects (P39: K\&M 12; 57:57)."

Justice in MNT settings is critical. Team leaders serve as a powerful source of social influence because they have limited amounts of resources and they distribute such resources among their team members selectively. This selective treatment leads to the development of different relationships with different team members. Teams with norms which regulate that these resources are fairly dis- 
tributed among individual members have a higher degree of cohesion and the danger that subgroups consisting of in- and out-group members (those with high quality and lower quality relationships with team leaders) emerge is minimized:

"But at my company I try very hard to be fair to all my employees. There are certain differences between American and Indian working styles but in order to work together my major responsibility is to be fair to all people here at $K \& M . I$ do not distinguish nationalities or anything here at this company. I do not care where you come from. It is not an issue. It is important that you contribute your part to the overall company's success. This is what I am looking for. I do my best in order to treat my employees fairly. People know this. They say to each other: "If you do your job well, then he will be the person who will appreciate your effort (P34: K\&M 15; 26:26)."

"Fairness is very important. As long as every team member is treated fairly the team will function effectively...... (P34: K\&M 28; 50:50)."

The empirical findings show the impact of corporate culture on team norms and how these norms influence work processes and outcomes. A broad range of corporate norms has been identified in this study. Most of them are consistent with the corporate culture. Sometimes, team culture is partly predetermined by the type of task to be fulfilled, e.g. product development teams. Successfully enacted team norms can predict whether a diverse team will be more or less effective. The negative effects of demographic heterogeneity diminish when corporate norms encourage a focus on interdependent objectives and teams enact this type of norm.

\subsubsection{Organisational strategy of K\&M International}

In the beginning, K\&M International used to be a small company located in Ohio, USA producing toys only for the American market. Today it is the world leader in the production of nature-related toys and operates in the USA, Canada, Australia, U.K., Denmark, France, Austria, Holland, Italy and Germany and has production facilities in China and India. The company used to pursue a global strategy. Yet today it follows a multinational strategy and tries to adopt its products to local market consumer tastes and needs:

"The biggest challenge that we have now on the design aspect... In the USA graphic design is more aggressive, brighter colours, big statement, because it is so competitive on the shelf so that your products have to really stand out and catch your eye on the shelf. Where I found in England, England design is very clear and we have sometimes troubles switching gears because in the United 
States we have been designing like this ever since I have started. So you have to start thinking in a different direction when you start doing things for Europe because they require something different. They do not like very loud design. It is very settled, very clear, and very simple where in the United States it is just the opposite. And then the translation, because translation for us is a big issue.... we are reselling these products in different markets and we are having a very hard time making all the changes that every country needs. We can not translate everything on a packaging. We have to kind of...(P37: K\&M 6; 25:25)."

The diversity within the teams is positively related to their performance. Having people from India working in the HQ facilitates the interaction and information exchange with the company's representatives and employees in the production facilities in India. In future, $\mathrm{K} \& \mathrm{M}$ International is even considering employing European designers in its product development and marketing team in the HQ in Ohio in order to benefit more from their knowledge about different markets, customer needs and desires. At the moment they are still working virtually with the artists, local sales people and market experts in Europe. This cooperation and virtual teamwork are very beneficial and have definitively increased the company's competitive advantage.

The findings presented are in accordance with the literature. According to Richard (2000), higher racial diversity will be positively related to firm performance when the firm pursued a growth strategy. Companies that are involved in expansion and focus on 'consumer to consumer marketing' can benefit from market-related advantages obtained from cultural diversity. Diversity brings cultural sensitivity that is very important if the company enters new markets and tries to reach different market segments (Cox, 1993).

\subsection{Different team tasks and their impact on MNTs at K\&M International}

By distinguishing among different types of teams, we have found that certain variables have a stronger impact on MNT's functioning and the findings vary for different types of team. Consequently, the type of team matters for the determinants of effectiveness. At K\&M International, interviews have been conducted with members of different teams, e.g. product development team, sales force team, IT team, customer support team, management team and virtual teams. Different teams are responsible for accomplishing different tasks and depending on the task the team members work more independently or interdependently. Consequently, task and goal interdependence have a strong moderating effect on team effectiveness. In MNTs with congruent task and goal interdependence, the 
team leader's task of increasing the level of motivation, cooperation and identification is less challenging compared to teams with high goal but low task interdependence. It is much easier e.g. to motivate the customer support team members to work together and help each other than to increase the cooperation between individual sales people who are forming the sales force team and have one common goal but individual tasks. Each member is responsible for the sales in his own territory and consequently there is less cooperation and information exchange between individual team members:

"Yes, there are challenges but most of them have been here... The youngest person in the division has been here for four years. They range from 4 to about 8 years. So, they have been working together for many years. But each person has his own challenges as well. They each have a territory dealing with their customers as well. So, it is almost... I have to work with them individually to make their challenges and their budgets and their goals and if each one can do that we come together as a team on the sales side. It is much easier to get the customer service people to work together as a team which they do very well in covering for one another if somebody is busy jumping in and helping them, take the orders and things like that but from the sales side it is like baseball if you know American baseball. It is individual. Each one of my sales people has his individual challenges but if they do well they come together as a team (P30: $K \& M$ 4; 28:28)."

The tasks of the IT team are congruent and interdependent. This creates a positive climate in which Indian and American team members not only identify with their team and behave in a cooperative way, but are also motivated to exchange their perspectives and different opinions, to manifest creativity and supportive behaviour and to help each other:

"We are very interdependent. There are... Yes, we are very interdependent, dependent on one another. They are really.... They are the back on and without them we would not exist. Really without the support the things that we bring to the table if we stop offering that they would stop to exist as well. The nice thing about our team since we are bringing different elements to the table if they are having a bad week or something happens on the IT side that is really you know quite bad hopefully we are doing such a great job and we can kind of smooth out the whole situation as a package. K\&M International is bringing to services this whole package. Part of it is computer, part of it is merchandising, and part of it is customer support and all of these other things. And if IT is having a crisis hopefully we are having such a phenomenal success on our side. They are more willing to accept whatever shortcomings they may have. If we are not doing well hopefully the IT is providing such a great value to our customer so they are willing to accept some of our shortcomings because of IT. Really as a 
package we come to our customer with so much value. And so again that just creates tremendous dependency on one another. It encourages them to be so good and then when we do have... How to smooth it over because the other one is so good? There is no competition. I do not feel any sort of competition and I think part of that is because we bring such unique things such unique elements to this project. And I think we are recognized that we are bringing a great value. We need the other part in order to be as successful as we are (P29: K\&M 11; 64:64)."

In addition to task and goal interdependence, also the nature of the product to be designed, e.g., the degree of innovation expected, is an MNT's feature that should be described in order to understand team functioning and study results. Probably, the most successful team at K\&M International is the product development team. This team consisting of six members is developing around 800 to 1000 toys each year. The individual members are interdependent in their tasks, share responsibility for outcomes and see themselves and are seen by others as a social identity in the organisation. When decisions have to be made, all designers are asked to sit down, put the drawings on the table and discuss the thing, the price point, the market, the basic look of the product, what the age group should be etc. A high degree of innovation is expected and achieved. This team enjoys a high position and recognition for its success within the organisation and from the company's owner. This has a positive impact on its effectiveness:

"I am the product development manager and my responsibilities are to take the product development process from concept all the way to the finished product with packaging and making it ready for the market.... I manage the staff of designers. These are about six designers and in addition to that I also design products myself. I started as a project designer and I still enjoy the creative process and I design products myself. So, I make sure that I am managing the department. The majority (4 members) of them are Americans in the product development team. Two are Indians. In marketing department we have an Indian woman working for us (P35: K\&M 1; 10:10)."

"Everybody from the company contributes to our ideas. Somebody from the sales will call us and say: 'Eh. I have this idea from a customer. What do you think about this?' (P35: K\&M 32; 107:107)"

"Then, the whole atmosphere in the company is motivating. We all are pretty much friend and we work closely together with each other. So, it is very easy to come up with new ideas. Somebody gives you suggestions and it is a day to day interaction between the team members. Then, Mr. P. also contributes to our ideas. He is very hands on. I mean he is part of the process in every step from coming up with the ideas and concepts to making sure that everything that we 
do... I am not sure how he manages sales and other departments but with us he is very approachable. He is one of us and he just sits down on the table and he starts talking and telling us his ideas or he brings samples from places he has been to make our products better. He is just very approachable with everybody in our department and he treats everybody..... It does not matter if I am the manager. He speaks to everybody and tells everybody his ideas and gets their feedback (P35: K\&M 21; 84:84)."

In order to draw the best expertise regardless of where it resides, $K \& M$ International also benefits from virtual teams whose members are located in India and the USA:

"The team I am working with the computer component we have a division which develops and manages the software that $K \& M$ has developed. There are three people who are working in the USA and who are managing the customer support side. And there are four to six people working in India on the development of that product. I work pretty closely with this team helping to develop a better, stronger software program that is better suited for this niche of the zoo we are so successful in. I do not work directly with the people in India. People that are here in the USA I work with them very frequently and they are kind of contact point for the people back in India...... That team is in a process of growing because they are developing two sides to the computer system. And they are totally developing the back office side of the system and they are looking to hire more people for that development process. (P29: K\&M 2; 29:29)."

Consequently, the company uses different types of MNTs as the core performing units and basic units of accountability and work. The findings indicate that the type of team matters for the determinants of effectiveness. Yet most research (with only few exceptions, e.g. Van Der Vegt et al., 2003) conducted in this filled does not indicate the type of MNT and the types of tasks being performed. Lack of this information impedes our ability to understand study results.

Congruent task and goal interdependence create a positive climate in which dissimilar team members from K\&M International not only identify with their team, and behave in a loyal and cooperative way, but are also stimulated to explore and exchange their different perspectives and opinions and to manifest creativity and innovative behaviour. This finding is in accordance with the literature. Interdependence, whether based on task inputs and processes or on shared goals and rewards, establishes connections and increases the need for cooperation between team members (Saavedra et al., 1993; Thompson, 1967). Members must interact to diagnose, analyze, and complete a task. Task interdependence requires and results in more cooperative behaviour and information sharing than does individual-based work (Colquitt and Noe, 1997). Strong ties between members should 
therefore develop in interdependent work environments (Kozlowski and Klein, 2000). This cohesion may facilitate the exchange of information among team members by providing the opportunity for all members to discuss organizational policies and practices and to jointly interpret the team's experiences (Roberson and Colquitt, 2005). The study conducted by Van Der Vegt et al. (2003) shows that under congruent high-high combinations of task and goal interdependence, members are more willing to exchange relevant data and to go above the call of duty to aid fellow workers and contribute to team success, whereas for team members working under congruent conditions of low task and low goal interdependence, little interaction is required and members pursue their personal interests.

\subsection{Multinational team composition and functioning at $K \& M$ International}

\subsubsection{Team composition at K\&M International and occurrence of bilateral conflicts}

Around 100 to 120 people work in the HQ in Ohio (approximately $30 \%$ Indians and $70 \%$ Americans). Consequently, teams at K\&M International consist of individuals from two different cultural backgrounds. In this section we will present the cultural differences between American and Indian team members and explain how these differences impact MNT performance.

\section{Power distance and individualism/collectivism in India and the USA}

A high extent to which Indians accept or reject the uneven distribution of power among members has been observed by Americans working in teams with employees in the production facilities in India as illustrated by the following quotation:

"It is very hierarchical. I think that there are many people who do not do much. They sit on their desk and just make few decisions. They are very lax in their work attitude in India. They are not real hard working, take a lot of breaks, work slowly... The lower people are very submissive. They will do anything that they are told to do like: 'Do not speak until spoken to.' You know and that type of thing (P40: K\&M 13; 128:128)."

In India, they never question decisions made by people above them and people working for them never question their decisions, assuming that their power gives them the right to make such decisions and given their power their decisions have 
to be correct. On the other hand, managers from the U.S. tend to solicit workrelated ideas and suggestions from team members as a part of a democratic leadership style. American members view dependence on the team leader negatively, while Indian members obtain a sense of security from power coming from their leaders and view dependence as a positive quality. This dependence and hierarchy of Indian employees limits the ability of American team leaders to make team decisions and build effective teams. In addition, Indians have to face many challenges when they start working in teams at $\mathrm{K} \& \mathrm{M}$ International:

"American employees and this is true, American employees are very settled. You can not be direct with them. ... I know that I am his boss but this has to be a little bit indirect. They do not like authority. They do not like being told. This is a cultural difference. And this is very different as when you have to cope with Indian salesmen because in India boss, manager..... It is very formal, hierarchical, rigid... You are the one who makes decisions whereas here you are expected to make decisions with the others in the team... (P28: K\&M8; 65:65)."

"You stand up when your boss comes to your office. And this happened to me first. My first job here..... My managing director was only 29 years old making millions of dollars. Whenever he would come to my office I would stand up. It was just a reflex. He told me: 'Stop it!'... So, I had to get used to it. Moreover, he expected me to make own decisions. I was not used to this. So, there were many challenges at the beginning. (P28: K\&M 9; 65:65)"

This hierarchical emphasis of Indians is also identified by Hofstede and Bond (1998). According to their findings, India scores very high on power distance, as can be seen in the table below.

\begin{tabular}{|l|l|l|}
\hline Cultural dimensions & India & USA \\
\hline Power distance & 77 & 40 \\
\hline Uncertainty avoidance & 40 & 46 \\
\hline Individualism (Collectivism) & 48 & 91 \\
\hline Masculinity (Femininity) & 56 & 62 \\
\hline
\end{tabular}

Table 16: Cultural dimensions of India and USA (Source: Hofstede and Bond, 1998)

Table 17 shows the societal cultural practices and values scales for India and the USA from the GLOBE project (Source: House et al., 2004).

\begin{tabular}{|l|l|l|l|l|}
\hline \multicolumn{4}{|c|}{ Scores for Societal Cultural Values Scales (India and USA) } \\
\hline Country & Assertiveness & $\begin{array}{l}\text { Institutional } \\
\text { Collectivism }\end{array}$ & $\begin{array}{l}\text { In-Group } \\
\text { Collectivism }\end{array}$ & $\begin{array}{l}\text { Future } \\
\text { Orientation }\end{array}$ \\
\hline
\end{tabular}




\begin{tabular}{|l|c|c|c|c|}
\hline India & 4.65 & 4.59 & 5.22 & 5.43 \\
\hline USA & 4.36 & 4.20 & 5.79 & 5.34 \\
\hline India & Gender & $\begin{array}{l}\text { Power } \\
\text { Distance }\end{array}$ & \multicolumn{2}{|c|}{$\begin{array}{c}\text { Uncertainty } \\
\text { Avoidance }\end{array}$} \\
\hline USA & 4.40 & 2.58 & \multicolumn{2}{|c|}{4.58} \\
\hline India & 5.03 & 2.88 & \multicolumn{2}{|c|}{3.99} \\
\hline \multicolumn{2}{|c|}{ Scores for Societal Cultural Practices Scales (India and USA) } \\
\hline Country & Assertiveness & $\begin{array}{l}\text { Institutional } \\
\text { Collectivism }\end{array}$ & $\begin{array}{l}\text { In-Group } \\
\text { Collectivism }\end{array}$ & $\begin{array}{l}\text { Future } \\
\text { Orientation }\end{array}$ \\
\hline India & 3.70 & 4.25 & 5.81 & 4.04 \\
\hline USA & 4.50 & 4.21 & 4.22 & 4.13 \\
\hline India & Gender & $\begin{array}{l}\text { Power } \\
\text { Distance }\end{array}$ & \multicolumn{3}{|c|}{$\begin{array}{c}\text { Uncertainty } \\
\text { Avoidance }\end{array}$} \\
\hline USA & 2.89 & 5.29 & \multicolumn{3}{|c|}{4.02} \\
\hline India & 3.36 & 4.92 & \multicolumn{2}{c|}{4.15} \\
\hline
\end{tabular}

Table 17: Scores for Societal Cultural Values and Practices Scales in India and the USA (Source: House et al., 2004)

The GLOBE project identifies India as part of the Southern Asian cluster. The cluster's societal practices are rated high on group collectivism, power distance, and human orientation and low on gender egalitarianism. The other cultural dimensions are rated in the mid-range, around an average of 4 . These findings are partly in accordance with my results and describe India as highly humane, male dominated, and hierarchical.

As far as group collectivism is concerned, our data shows contradictory results. According to House et al. (2004: 30) In-Group Collectivism can be defined as "the degree to which individuals express pride, loyalty, and cohesiveness in their organisations or families." Yet we recommend distinguishing family from ingroup collectivism. This is what we have done in this study. Our results show a big difference between family collectivism at the societal level and in-group collectivism at the organisational level. In our study Indian members have reported that they behave more individualistically in India than this is the case in the USA. Their concerns for family or family members evoke strong collectivist behaviour but in order to serve family interests they usually behave in a very individualistic way at work place. If their working colleagues' needs and goals are opposed to the interest of their family there is a strong shift towards individualistic behaviour. This behaviour is intended to serve the family interests and turns out to be very competitive. Indians report that the working atmosphere at $\mathrm{K} \& \mathrm{M}$ International is very cooperative and supportive for teamwork, while the highly competitive 
atmosphere in Indian companies limits team effectiveness and forces employees to behave in an extremely competitive and individualistic manner. Only in the case that they can find an opportunity to beat their colleague they will go ahead. Climbing up in the corporate hierarchy is important in order to serve the interests of the family:

"In India, it is usually more difficult to have well performing teams. People try to compete with each other in order to be promoted. There are not so many challenging jobs in a company and at the same time the competition might be very strong. This is very true for India. I speak from my own experience since I used to work in India. People are not team players. Each one is trying to reach a certain goal on a competitive level. That destroys the cohesiveness of the team. It is not the team that works. Even despite the fact that India is a more collectivist society........ You know people from India and China are collectivists when it comes to their role in the families but when it comes to their functioning in the company they are individuals. This is a very important point (P34: K\&M 30; 60:60)."

One would expect that employees who are high in collectivism will more readily accept the team aspect than employees who are more individualistic, since cultures that are collective exhibit more emotional dependence on the team, and are more conforming, team-oriented and particularistic. Individualistically oriented cultures, such as the United States, Germany and Hungary, value autonomy, self-interest and performance. In contrast, collective cultures, such as Japan, Sweden and Russia, value group harmony, cooperation and satisfaction. Multicultural teams whose members differ in orientation between individualism and collectivism are likely to face challenges in developing team roles and norms because of different senses of organizational and individual responsibility (Bantz, 1993; in Matveev and Nelson, 2004). Yet Indians have reported that they learnt how to work effectively in a team when they started working for K\&M International. Team leaders with prior experience in leading teams in India have been surprised by the level of cooperation in teams consisting mainly of American employees. Indians are less likely to readily accept many of the concepts associated with teams and team work:

"When you find an opportunity to beat the other person then you can go ahead. That is the work culture in India. That is because there are so many people in India and there are just a few jobs. Everybody is trying to beat you to a job. It is all about... If you slack a little bit somebody overtakes you. You are always watching people around you and watching what the people around you are doing. That is the Indian mentality. But here I find it a little different. People do not care about my job. They understand that this is my job and they will concen- 
trate on their job. If they want to support you then they will come to you and will tell you: 'Eh. I have got an idea. What do you think about this?' In India it is all about trying to do everybody's job and trying to prove yourself one better than the other. So, it gets very hard to motivate people in India. It is very hard to do team building in India. The mindset is not as open as it is over here. It is a very competitive work atmosphere in India (P32: K\&M 24; 87:87)."

We assume that those high in individualism view team membership as taskspecific and transitory, whereas those low in individualism view team membership as more long term. When in-group collectivism at the organisational level is high, team membership is highly integrated into a person's life. Despite the fact that India is rated high on group collectivism (see Hofstede and Bond, 1998), our data shows contradictory results. Indians describe the level of competition in teams consisting of primarily Indian members as much tougher. It is always necessary to be one step ahead of the other member in order to stay competitive. Individuals will even stay longer and work until late in the evening in order to achieve better results than their team-mates during the regular working hours. This puts them one step ahead and makes them more competitive:

"There is probably one big difference. In India, if you want to achieve something in a company, you have to act as an individual. There is not enough room for team work. Only in the case that you perform better than your colleague you will be promoted. The atmosphere is very competitive. This prevents you from being a team player. There are not so many opportunities for each individual employee to be successful. And if there are not enough opportunities for all only the best and most successful will be promoted. You want to survive and in order to survive you will even betray your colleagues. In the USA you have plenty of opportunities. In India good jobs are limited. You will try to convince your boss that you are the one who deserves to be promoted (P42: K\&M 25; 92:92).'

According to Kirkman and Shapiro (2001), employee acceptance of teams and self-management is related to deeply held cultural values. Employees who are high in collectivism more readily accept the team aspect of SMWTs than do employees who are more individualistic. In addition, a tendency for higher levels of collectivism is associated with greater job satisfaction and organizational commitment.

Yet the data obtained in this study raise doubts about Indians' unequivocal nature of collectivism. In the classical study by Hofstede (1980), India's score of 48 on a 100-point scale of collectivism-individualism indicates only a slight tilt towards collectivism. Verna and Triandis (1998) present a number of scenarios to samples of college students in Patna (Bihar, India) and Urbana (Illinois, USA). The findings indicate that Indian students opt for a higher percentage of collectivist (53\%) 
and a lower percentage of individualist alternatives (47\%) than the Urbana students who opt for $39 \%$ collectivist and 615 individualist alternatives. However, the finding that $47 \%$ of the Patna students endorse individualist options, along with other studies referred to above, raise doubts about the sweeping generalization that Indians are collectivists (Sinha et al., 2001).

According to the results obtained from a study conducted by Kappor et al. (2003), the hypothesis predicting that the US sample will score lower than the Indian sample on collectivistic values and score higher than the Indian sample on individualistic values is partially supported. The Indian sample reports significantly higher scores on collectivism than the USA sample. However, the Indian sample also reports significantly higher scores on individualism than the United States (Kapoor et al., 2003).

There is indeed evidence of the presence of individualist orientation in India. Paranjpe (1998) has observed that in the intellectual and cultural tradition of India it is the individual, rather than the group, that has been the focus for moral responsibility. Furthermore, Indians are found to maintain an inner private psychological space that is central to their individuality (Roland, 1988, in Sinha et al., 2001).

Sinha et al. (2001) has examined the effect of eighteen situations on the choice of collectivist and individualist behaviour and intentions, or their combinations. A sample of 292 respondents, drawn from three locations in India, has participated in the study. The findings indicate that concerns for family or family members evoke purely collectivistic behaviour. Compelling and urgent personal needs and goals in conflict with the interests of the family lead to a mix of individualist and collectivist behaviour and intentions. Individualist behaviour intends to serve collectivist interests is the third most frequently opted choice.

This shows that the simplistic notions of individualism/collectivism are not enough to describe the Indian culture. According to GLOBE, organizational individualism and collectivism is distinct from societal individualism and collectivism (House et al., 2004). However, the two levels are expected to be interrelated, since societal level culture affects organizational work culture by shaping shared managerial assumptions about the nature of employees and how the organization needs to be structured for such employees (Kanungo and Jaeger, 1990). Yet, our results indicate that Indians are integrated into strong, cohesive in-groups which protect them in exchange for unquestioning loyalty outside of the organization at the societal level in their family surrounding, while in the organizations at the corporate level the ties between individuals are loose and everybody is expected to look after himself or herself. 
Sinha et al. (2001) have found that a relatively impersonal place such as an organization or a market, compared to a family, facilitates exchange behaviour aiming at maximising one's utility. The in-group setting, on the contrary, enhances the salience of social norms regarding reciprocal expectations and appropriate codes of conduct. These in-groups also vary in their salience. A more proximate in-group such as the family induces stronger collectivist orientation than a distant group such as the community. Yet in an impersonal setting, individuals will feel free to pursue their individualist needs and goals. In addition, the person with whom people interact is another important determinant of either their collectivist, individualist behaviour or intention or a combination of both types. Family members cause pro-social, while others cause utilitarian responses (Sinha et al., 2001). According to Sinha (1990a), Indian employees extend cooperation and exhibit feelings of affective reciprocity primarily to family members and individuals who are perceived to be members of the same in-group. Behavioural patterns are strikingly different towards members who are considered to belong to non-family members. Relationships with these people are fraught with distrust, friction, and conflict (Saha, 1993).

We agree with Kirkman and Shapiro (2001) that employee acceptance of teams and self-management is related to deeply held cultural values. Yet when we study MNTs we must also consider country and cultural differences other than those provided by culture-general frameworks. These frameworks will never cover all information we need to know about people in different contexts. Each society has at least some qualitatively distinctive values that are not found in other cultures and that may have a stronger influence on team functioning than e.g. the notion of individualism/collectivism. Moreover, researchers should have a closer look at different constructs designed to measure "collectivism/individualism" before drawing any conclusions on expected behaviours. The literature review shows that there are mixed results as far as this cultural dimension is concerned. This represents an interesting avenue for future research.

\section{Context sensitivity of Indian team members}

Our findings also indicate that Indian members are more context sensitive than American members who work with them in MNTs. They are more willing to adapt their behaviour in order to cope with their environment. Indian team leaders report how they adapt their authoritarian leadership style and become more cooperative and participative. They have the potential to integrate, blend and accommodate their traditional values and western management practices in order to lead their teams more effectively. They change themselves by adapting their behaviours to the demands of the ever-changing context in their environment. In this way they create a hybrid managerial culture. They neither fully accept nor reject American values and norms of behaviour but they integrate them into their 
cultural standards. They seem interested in adopting certain parts of it which they find useful and appropriate. The strong influence of situational factors strengthens the adaptive nature of an idea or behaviour of Indian members, while Americans react in consistent ways in different situations, as has been reported by several Indian interview partners:

"Similarly, five other Indians joined the company the same year when I joined the company. So, I know how they behave too. We all actually adjusted and learnt their system. I do not think that they came down to our level to try to study and understand our way of thinking or our culture. We had to adjust to their level and we are pretty much well coping with that now. So, obviously it is a big adjustment on our side and not their side. If something happens to an Indian and we culturally deal with such situations very differently from Americans. I do not think that they would do any research in order to try to find out how to cope with such a situation, but we definitively do. Otherwise, we could not create such a positive atmosphere in our teams and in our company. I am happy that I studied the American working style and their culture because now I feel very comfortable when somebody comes to the company. I know the system and I know how things are working here. It was a big step for us at the beginning (P31: K\&M 11; 56:56)."

"My working style has changed so much since I have been working here. In India, it is all about being to the point and cut and dry. But then when you come here you start working with your team members in a way which is not so cut and dry. You try to be more diplomatic. I try to be more diplomatic but I am direct without being negative. I am direct but you know... It is always welcome. I have adopted my approach and style. The way I am talking now to my team members has changed. In India I had a different style of working with employees. The way people are talking and the way they approach a problem is different. People are more sensitive over here so you have to keep this in mind and you can not be that direct and rude. You have to credit somebody for what he has done and at the same time be objective and try to give feedback whether his job achieves the goals or if you have to do something different. You are constantly trying new methods. The communication style in the USA and in India is totally different (P32: K\&M 42; 123:123)."

"We try to be.... How do you call it? You know stay back, watch, study and then move. We have that. However, I did not see Americans doing that to us. Obviously, they think everybody is like them. They do not try to adjust to the level we try to adjust (P31: K\&M 11; 56:56)."

These findings are in accordance with the literature. In India, a large body of literature suggests that managerial behaviours are determined to a very large 
extent by the situation rather than internal attributes (Miller, 1984; Sinha and Kanungo, 1997). Sinha and Kanungo (1997: 96) attribute the strong influence of situational factors to the high "context sensitivity" of the Indian culture. Their framework proposes two overarching dimensions characterising Indian culture: context sensitivity and balancing. Context sensitivity is "a thinking principle or a mind-set that is cognitive in nature and determines the adaptive nature of an idea or behavioural context." This cultural dimension is under-researched in crosscultural management literature. However, a number of recent studies have demonstrated that whereas the cultures of various countries differ on context sensitivity, many Eastern countries including India are high on this dimension (Gudykunst et al., 1985; Triandis, 1994).

Trompenaars (1993) reported that North Americans and most North Europeans behave in a rule-governed manner, whereas people from Eastern countries such as South Korea, China, and India behave in a context-dependent fashion. Sinha and Kanungo (1997: 49) noted that "some of the top men in Indian organizations are not quite consistent in their behaviour patterns and values." In India some behaviour that is judged appropriate for a given place, time, and person may not be appropriate for other times, places and persons. Consequently, they adjust their behaviour in order to meet environmental demands (Mellahi and Guermat, 2004).

\section{Differences in communication style between Indian and American team members}

Indians have reported that they have a very direct communication style that they had to change when they started working in MNTs in the USA. Their style has become more indirect. They acknowledge differences in the communicative and interactional styles of American members and demonstrate a very high level of cultural empathy by showing understanding for these differences and working in a more flexible manner by becoming more indirect in giving feedback and criticising others in the team. They demonstrate more flexibility in resolving misunderstandings and are able to better understand and communicate team goals, roles and norm to others than their American colleagues. High level of forbearance in intercultural situations is displayed and they use this forbearance to work in a more flexible manner in the team. They adapt their communication style and integrate certain cultural American characteristics, whereas the opposite is true for American team members:

"When I criticize the American salesmen I do it in an indirect way as well. But Indians may perceive you as weak. If you say: 'Can I meet with you at 7 o'clock?' This is weak. You say: 'I want you at four o'clock. What are you doing? Are you busy?' Then they will come. The indirect style sometimes does not work with Indian employees. When you start criticizing here, then you may 
say: 'Everybody has development needs. Mine are that I work too much. But, by the way I think that you could improve there and there. What do you think about this?'(P28: K\&M 12; 70:70)."

"The Indian style of working is very different from the American style. Also, the way Indian managers criticise their employees is very different. It is mostly all about being very direct. 'This is not good. I do not like this. Do it in a different way.' It is not about: 'You know what you have done is quite good but how could we explore something a little bit different.' (P32: K\&M 28; 97:97)."

"One observation I made is that the American society is very inter driven or self driven. They are not really aware about what is happening around the world. They are not much aware of different cultures. They do not understand how people from different nations speak and react. There is one incident that we had. There was this senior person in our company and we had a Chinese team that came to meet us here. It is very hard to understand Chinese people. You have to speak very slowly and you have to understand what they are saying. So, I was talking to the Chinese people very slowly and I was trying to avoid long sentences because they do not understand the terminology... So, we had a conversation and there was this other person who tried to speak with them and he started talking in totally American English. They did not understand him. They replied back to him but they did not know what he was talking about. I had to explain to him that he could not talk to them like this. ........They are pretty much culture blind. I do not believe that they are as open to cultures as they claim to be. Indians are much more open to foreign cultures and much more willing to adjust...... (P32: $K \& M 46$; 135:135)."

"But when we talk about this indirect form.... You know even feedback is very settled. 'Hey. Brad, you are an outstanding person and I love taking calls from you but you know what ..' You know I have one American salesperson. She is good but she is a big talker. She will constantly repeat herself, she will not listen to you, and she will say the same thing that she speaks with you to other five people. How to tell her that she has to improve this? You have to say: 'Hey, you know last time I was getting my review done I had this useful framework. It is called. Stop, Start, Continue. It is a good way to receive good feedback. You just ask five people to do it for you. It is really great. Would you do it for me?' If I do that all the five people will say to her: 'Stop talking too much.' Than I can tell her: 'What did you get out of that?' Then she will say people tell her that she speaks too much or communication improvement. Then you can say: 'You know I agree with that. You could do a much better job. You are a smart person but this is how people get it. Don't repeat yourself.' This is very, very subtle and indirect. You have to be professional. 
When I speak with an Indian salesman then I can say: 'Stop it. You talk too much.' And he is going to keep it. Communication is much more indirect here (P28: K\&M 11; 65:65)."

These findings contribute to the research on cross-cultural communication by exploring the relationship between cross-cultural communication competence and MNT performance. According to the results obtained in this study, the level of cross-cultural competence facilitates team work and improves the overall team effectiveness.

The literature says (e.g., Gudykunst, 1998; Spiess, 1996, 1998) that cross-cultural communication competence entails not only knowledge of the culture and language, but also affective and behavioural skills such as empathy, human warmth, charisma, and the ability to manage anxiety and uncertainty. The Cross Cultural Communication Competence Model (Matveev, 2002; Matveev et al., 2001) identifies four dimensions of this competence: interpersonal skills, team effectiveness, cultural uncertainty, and cultural empathy. According to this model, Indians working at K\&M International are effective cross-cultural communicators. The study conducted by Matveev and Nelson (2004) has identified a positive relationship between the level of cross cultural communication competence of a multicultural team member and the performance of a multicultural team. The ability of Indian team members to adopt their working and communication style to the American way decreases communication problems, inaccuracy, misunderstandings and inefficiency in the MNTs and consequently the cultural diversity doesn't diminish effective team functioning.

\section{Gender egalitarianism in the USA and India}

American team members have reported a low level of gender egalitarianism, which has a negative impact on team functioning. Women don't seem to have the same rights and many of them are discouraged from telling their opinion since this can be damaging to their career. It is a challenging task to work together with male Indian members of the team and to effectively communicate with them. The fact that some female employees feel as second-class citizens and are discouraged from giving feedback and expressing their opinion has a harming effect on MNT functioning. To overcome these difficulties a huge adjustment is required on their side:

"Women do not have the same opportunities. They have a clear picture in their heads what women have to do and what they are not supposed to do. So, it is difficult to work with male Indian employees. There are also no women on management positions. Jennifer is the only one and I am surprised why. I wonder how she manages to effectively communicate with them. I have to be very careful when 
giving feedback to my Indian co-workers. I had difficulties with one particular manager who is Indian. So I have to be very careful how I say things and how I work. That is probably one of the biggest challenges I have to deal with in the team. I have to adjust to their culture as well. As a woman you sometimes feel as a second-class citizen. And I am not the only one in this company who has this feeling. ......This has definitively been a challenge and an adjustment since I am used to being treated equally. And our American culture says that we should be equal, and diversity... Telling your point of view could be sometimes damaging to your career.... This is what I found out.... This is probably the biggest cultural difference (P33: K\&M 17; 73:73)."

"There is something that does not impact me directly but I do see that the owner of the company and many other Indian people they do tend to put more of validity at something that male say and are maybe.... more with the male who works with them than the female. That is something that I noticed. I mean just say ... just an incident ... the owner of the company will walk down the hall and you see a female worker he may not even acknowledge her and if there is a male worker he will start a conversation with him. It is just something that I noticed and I do not know how to elaborate on it. I think that just the culture is ... I think that they try to do it and I think that is probably better here as in many other places I have seen but it is still there (P40: K\&M 6; 76:76)."

According to the GLOBE project, the societal practices in India are rated as low on gender egalitarianism (2.90). In the private sector, most woman-managers rely on family connections or long professional experience, while in the public sector they often need higher education attainments to break through the "glass ceiling" than their male counterparts (Wright and Tellei, 1993; in Gupta et al., 2002).

None of the studies on MNT effectiveness has examined the effect of gender egalitarianism on team functioning. Our findings show that team members from cultures characterised as being low on gender egalitarianism harm team effectiveness in the case they do not adjust to the values and norms of behaviour of (female) members from cultures high on gender egalitarianism.

Activity orientation: "being" versus "doing" orientation in India and the USA

We have found a fundamental difference between Indian and American activity orientation. Americans are much more focused on achieving results and they expect to be rewarded according to their achievements. They take a more thoughtful and rational approach and things are done only after some reflection. The following quotations illustrate the importance of achievement and the accumulation of 
material wealth for American team members from a perspective of Indian employees:

"The first thing that comes to my mind is that in this country the main thing is results. I used to work very hard. 19 hours a day and I did everything. And I could not achieve my results. That works but you must have a very good story. This is so much result focused and it was very difficult for me initially because usually there are issues that I do not really have under control. It was o.k. in my culture but it was not o.k. here and actions have consequences. These are jobs where you are under huge pressure to perform. If you do not perform you are in troubles. This is one thing (P28: K\&M 2; 42:42).

"In the USA... It is money. This is another thing. I worked also for some European companies and it is not all about money. It is more about job satisfaction, happiness etc. Here you want money, you want promotion, you want raise. What is my commission on this? So those are the primary drivers. If you are not on track, if you are of your budget then you have 16 days to improve or we will fire you. Those things work. Where, when you deal with Indians it is more about job satisfaction. Job satisfaction is also important here but this is an easier way. You can hire and fire people. What motivates them most is either money or promotion or the threat to lose their job. Here, you have control over your variables. Whereas in some other countries like India you can not fire them, you can not give somebody 5\% raise and somebody else only $2 \%$ raise. This is what I can do in my team here. I can give somebody 5\% raise and somebody else $10 \%$ and no one will complain. Management is easier here. Goals are clear and there are not 15 goals that you are trying to maximize. Goals are much clearer and much more realistic, objective, defined. I find it very easy to be a manager in the USA compared to India. Indian salesmen are different. They like more recognition. Rewards, certificates... American salesmen want money. Indians want more this public recognition (P28: K\&M 13; 76:76)."

These findings are in accordance with the literature. The basic orientation of the American culture is one of doing whereas Indians are more focused on being. The Indian work ethic, influenced by the Hindu religion, encourages people to work primarily for satisfying family needs and wants. Work in an American context (referred to as the doing orientation) is based on the Protestant ethic and is considered to be lifelong, and a calling from God (Kanungo, 1983). Societies characterised by the doing orientation give importance to achievement, accomplishment, accumulation of material wealth and economic activity, objectives that are not found in societies with a being orientation (Cavanagh, 1990; Stewart, 1972; in Gopalan and Rivera, 1997). 


\section{Time orientation of Indian and American team members}

Indian team members have reported to be more oriented towards the past. The preference for planning, compartmentalizing, scheduling time and a sense of urgency tend to be less emphasized in India due to their time orientation. They are impressed by the way American members are coping with time issues. In addition, being punctual is a big challenge for many Indians:

"The second thing is that you have to be very professional. When I say I meet you at 1:45 then we will meet at 1:45. This means not one minute earlier, not one minute later. And people are very professional. When I worked in India for seven years you had to remind the people to come to the meeting and everybody is late. It is just a very social atmosphere at the work. The people here are very friendly but business alike friendly. It is very professional and you can trust people. If somebody tells you: 'I will send you an e-mail before the end of the day.' This means that before 5 p.m. it is in my inbox. This is unbelievable for me. I have a lot of respect for this (P28: K\&M 3; 46:46)."

In a study, in which the importance of the past, the present and the future has been measured, Americans have regarded the future as most important and the past as least important (Trompenaars and Hampden-Turner, 1997). The preference for planning, compartmentalizing, scheduling time, and a sense of urgency that are characteristic of future-oriented societies such as the USA tend to be underemphasized in India due to a different time orientation (Gopalan and Rivera, 1997).

\section{Heterogeneity of values and norms of behaviour of Indian employees}

Finally, we would like to question the homogeneity of values and norms of behaviour of team members from India. Interviewees stress the fact that India can not be studied as one country due the heterogeneity of religions, practices, values and norms of behaviour etc. of people living in different regions of this country. Results in Bihar could be quite different from those obtained in Tamil Nadu. Therefore, studying the specifics of single cultures, in addition to the "culturegeneral" knowledge offered by etic frameworks, could be more useful in the case of India. The following two quotations show the subtleties of difference that can be found in the country:

"I was born in a small city called $K$. that is located in the Southern part of India. After my graduation I moved to a Metropolitan city called $V$. The culture, the language, the religion was very different from what I experienced in $K$., my hometown. So, that was an experience for me because all of a sudden I had to face a different culture, different people, and different language. Everything was different. I kept moving from one place to the other place and I have seen 
different cultures, different people, and different religions. Consequently coming to the USA was not such a big challenge for me. I knew how to cope with cultural differences (P42: K\&M 5; 37:37)".

"You can not compare the USA and India. In the USA you have one language whereas back in India people from different parts of the country will speak different languages, different religions. If you go to a Metropolitan city the managers will not have this authoritarian working style whereas if you go to South India they will have an authoritarian style of leadership. The majority of my Indian colleagues at $K \& M$ International are from the Southern part of India. In metropolitan cities everything is totally different. We have much more freedom. In Southern part if you are late to work for 10 minutes you will be punished in a certain way whereas in Bombay you can be 30 minutes late and you will not have to face any negative consequences since your managers are going to trust you that you will fulfil your duties even if you have to work until late in the evening. In South people are rigid and punctuality will be very important. If you work from 8 to 5 you have to be in the company during these areas. The working environment in metropolitan cities is totally different from the working atmosphere in smaller cities in India (P42: K\&M 13; 49:49). "

These findings are in line with the growing body of research on national subculture heterogeneity (see for example: McSweeney, 2002). The basic contention of this body of research is that the assumption of homogeneity of values within countries and the notion of national culture sharedness are false (Bock, 1999; McSweeney, 2002) because they do not take into consideration the heterogeneity of managerial values within a country (Mellahi and Guermat, 2004). Given the diverse cultural, linguistic, racial and ethnic diversity in India, it would be impossible to explore the impact of a certain Indian cultural dimension on team effectiveness. As one of the employees at K\&M International mentioned, the level of power distance in India will vary within the country, being high in the southern part of India and low in its Metropolitan cities.

\section{Occurrence of bilateral conflicts in team composed of Indian and American employees}

The differences in cultural characteristics of Indian and American team members lead to critical incidents in MNTs. In order to avoid the occurrence of bilateral conflicts, Indians adapt the working values and norms of behaviour of American employees and they make great efforts to assimilate with U.S. culture at least for the time they spend working in the company. Sometimes, this is challenging and hard to realize. The findings show that if two groups with different values and norms of behaviour have to interact in one team, then the members will either adopt e.g. American or Indian norms of behaviour. Yet these different cultural 
standards also lead to the emergence of conflicts and are usually the cause of clashes in team interactions:

"You know, we have only Indians and Americans in our teams. If you have more nationalities in a group then you adopt much easier and then your level of patience, your level of understanding is much better. In a bi-cultural team it is either my way or your way. If there are more people from different national backgrounds then you try to blend all nationalities and do one common language. You try to adopt one way of working. You are much more willing to compromise and not just to compromise but also to bend yourself and to make everybody a part of the team because you know that you need everybody as part of your team (P32: K\&M 47; 139:139)."

According to Fink et al. (2004), the larger the team and the more culturally different the members are, the less easily bilateral conflicts will occur since the likelihood to succeed with the establishment of new team norms increases with the level of diversity. If two groups with different values and norms have to interact in one team, then the adaptation of either norms A or B as team norms will take place or become a stalemate confrontation. This complies with our observations and it would be interesting to test the validity of these findings in different contexts in different teams in different companies.

\subsubsection{Team identification and subgroup formation}

A successful MNT at K\&M International is characterized as having an integrated and synergistic culture. After mutual interactions, team members adopt a simplified set of rules and actions for how team members relate to one another, distribute finite resources, and interact socially. This creates a positive social environment within the team. Cultural diversity has negative consequences for the teams at the initial stage, since team members are more likely to experience ineffective team processes (e.g. poorer communication and decision making and greater conflict) that, in turn, result in lower levels of team performance (e.g. lower productivity and quality) and lower levels of team member satisfaction. Yet in the longer term these teams become more efficient and they develop clear rules of interaction. Time has a strong moderating effect on trust building and the development of team cohesion:

"The good thing here is that people have worked with each other for a long time and there is a way they respond to each other. This is great. People know who is good at what and they kind of balance each other. They have complimentary skills. 
People trust each other and there is a long working relationship (P28: K\&M 16; 82:82)."

Over time teams develop, share and enact a set of rules for how team members relate to one another, work capability expectations, and member perceptions. These factors create a positive environment within the team and have a positive impact on team identification and team performance.

When a new member joins the team, there is high conflict potential and high level of resistance to new ideas. The whole team building process starts again. Over time members learn to interact with each other and their different perspectives help them to generate innovative and creative solutions to resolve organizational problems and satisfy customers:

"It is sometimes just the way you talk and you use phrases which most Americans do not understand. They are not used to it. They criticize what you are saying and then you are upset and you retaliate by saying: 'This is the right way. 'Initially, it was just the way I spoke English and just the way I was thinking because I had an advertising background. Consequently, there is a lot of strategic thinking that you are doing and that I found that team members here do not have. When you try to explain this to them they do not agree with you even if it is the right thing to do. So initially, there was a lot of conflict potential. But we learnt to understand each other and today we work fine (P32: K\&M 18; 65:65). "

"The initial challenge I had to get these people work for me because I had a totally different background and nationality. There is the challenge of getting everybody understand my point of view. I have an advertising background. I used to work for an advertising agency for about 7 years. There are some modern things that you come with and some modern brand building ideas. There is a certain amount, a certain strategic thinking that you have in advertising and that you finally bring to the table and do marketing for a company. The challenge was to get the team understand your point of view, to understand branding, to understand strategy. Communication was another challenge. It was a challenge to make them understand consistency in communication and design and to finally motivate them to work for you. Today, everybody is pretty much on the same level now. We understand each other. It is getting better now (P32: K\&M 2; 18:18)."

"The thing is that every new member who joins the team comes with some new way of thinking and you have your own previous background and your own experience and you want to bring it on the table. So there is resistance when a new person comes in. The question is how much more value you can add to us, how much better do you know my job than myself. There are all these chal- 
lenges that everybody has to face. This is also pretty much what I had to face at the beginning but things are much better now (P32: K\&M 3; 24:24)."

"What is not so good is that they get set in their ways. I had to fight with this whole history. I have been here for 9 years and I have been here for 5 years. The downside is that teams are solid here. You come in and you have no option but to be part of the team. If you say something that the team is not comfortable with, or that the team does not know, or that the team disagrees with you have a conflict situation. For example, how do they do catalogue as a process. ... I met a lot of resistance in the teams at the beginning because my way was different. .... It is hard to get accepted as a new team member. You have to adapt to this value system. The team part is good but it definitively has some interesting conflicts. But it is good. Conflict is sometimes good. The key is a good balance between the existing and the fresh.... (P28: K\&M 17; 82:82)."

The literature says that before being able to work together efficiently, culturally diverse group members need to share their perceptions, definitions and frames of reference so that they can later predict how, and explain why, other members react in a certain way (Larkey's 1996; in Vallaster, 2005). This way they create a hybrid team culture (Adler, 1991; Earley and Mosakowski, 2000). A hybrid team culture refers to an emergent set of values and norms of behaviour that individuals within a team develop and share after mutual interactions (Earley and Gibson, 2002; Earley and Mosakowski, 2000; Earley and Gardner, 2005). Given team members' diversity of values and assumptions about appropriate interaction, developing clear rules can be highly complex in MNTs (Earley and Gardner, 2005). Strategies for managing diversity in MNTs are based on the team's stage of development. The initial team formation is characterised through trust building and the development of cohesion. Studies show that members of multicultural teams put more of their time and effort in creating cohesion and solidarity than do members of homogeneous groups. Diversity makes this stage of development more difficult and therefore the process should be based on using similarities and understanding cultural differences (Adler, 1991).

Another phenomenon that has been described is subgroup formation. Workgroup composition and particularly, diversity among members create barriers to effective group interaction. Demographic diversity creates faultlines, since demographic characteristics divide the network into subgroups. In contrast, similarities among group members tend to cue the formation of interpersonal relations and cohesiveness within the group and lead to the creation of nationally homogeneous subgroups consisting of either Indian or American members. One major reason for subgroup formation is the language barrier. It appears to be an even higher problem than functional and cultural differences: 
"Today, my team is well organized. We work fine and I speak the same language. There are other Indians in the company who do not speak English as well as I do. So, then they definitively feel the divide. Some Indians who do not speak English well do not really mix with the Americans. They build their own group. Because I can speak very well English, I have no problem. I can speak with everybody (P32: K\&M 45; 135:135)."

"However, I have to mention that sometimes you can observe that my Indian colleagues prefer working together. There is sometimes a light split between American and Indian employees (P42: K\&M 21; 76:76)."

Theory and research have suggested that individuals are motivated to interact most with members of their own social categories (McPherson et al., 2001) and to emphasize the positive aspects of their categories in relation to other categories (which end up suffering by comparison) (Tajfel and Turner, 1979). The natural tendency may be to stereotype the other members of one's team, to assume that they "just do not understand", and to argue and defend rather than seek conciliation and integration (Van Der Vegt and Bunderson, 2005). Consequently, demographic diversity creates "faultlines" (Lau and Murnighan, 1998). This theme is also present in social network research, which suggests that similarity between members of networks affects the interpersonal ties or relationships in the network, since similarity positively influences interaction and communication between members (see Brass, 1995; in Roberson and Colquitt, 2005). In addition, language can be a big source of problems in MNTs and may be an even higher potential problem than functional differences and culture per se (Schweiger et al., 2003).

After mutual interactions team members at $\mathrm{K} \& \mathrm{M}$ International adopt a simplified set of rules and actions for how team members relate to one another, distribute finite resources, and interact socially. Similarities among MNT members facilitate the formation of interpersonal relations and cohesiveness within the group and lead to the creation of nationally homogeneous subgroups consisting of either Indian or American members.

\subsubsection{Knowledge exploitation and exploration through MNTs}

An interesting research questions is how MNTs can facilitate knowledge exploitation and exploration and its transfer across geographic and organizational boundaries. Teams at $\mathrm{K} \& \mathrm{M}$ International reduce the complexity of operations by facilitating this knowledge exploitation and exploration during directors' meetings and international conferences where all chief representatives from the host country subsidiaries are present. The management team consists of eight members 
(Indians and Americans) who are the heads of the different departments in the company. They meet on a regular basis to discuss the current situation, strategic choices and future plans. Everybody contributes to the discussions and everybody is welcome to express his/her opinion. The team consists of 7 male members and only one female director. By exchanging important information, brainstorming and leading discussions new ideas arise and new strategic and marking plans are developed. Knowledge exploitation takes place when existing knowledge is shared within the management team during directors' meetings. On the other hand, knowledge exploration is triggered by the exhaustive discussions and by the feedback from the heads of different departments of $\mathrm{K} \& \mathrm{M}$ International. This leads to the creation of new knowledge for future product development and marketing plans:

"Once a week we have the directors' meeting and there are 8 to 9 of us going over what we did, where we are going and him hearing all these short presentations from each one of us. And he discusses the issues with us... (P30: K\&M 22; 65:65)."

"We have sales people, we have marketing people in there, we have product development people in there and every major division in the company is represented. Mr. P. says: 'Why is the zoo/museum job not doing well?' I have to explain that. 'Did we do a good job ordering products?' We have open communication and open criticism that is good criticism. We are not there to embarrass anybody. O.k.! We did not do a good job marketing our products. It could be anything. What are we going to do? Tell us what your plans are. And everybody in that room interacts with one another. Everybody in this management room contributes and interacts. Everybody has to say his point of view and add solutions. It is constructive criticism more than negativity.... After exhaustive discussions we come up with new ideas and new future plans (P30: K\&M 33; 87:87)."

In addition to management team meetings, an international conference is organized every year. Employees with various cultural backgrounds from the different host country subsidiaries of $K \& M$ International come to Ohio in order to attend this conference. All chief representatives are invited to the company's HQ. They spend one week getting to know each other, developing relationships, exchanging market relevant information, discussing problems and finding common solutions. They share their perspectives and knowledge and work together in temporary teams. They are asked to come up with new ideas about product launches, marketing strategies, new product development and product adaptation and to share their knowledge and develop new ideas. The exhaustive discussions lead to the creation of new knowledge for product improvement and adaptation: 
"When we fail to communicate internationally, globally that is when we run into problems. So, that is a challenge. And we need to understand and feel that they are part of the global team. Every year they come. We do an international conference when all the directors from our subsidiaries come and we discuss all the important issues and show them the new products from the coming year. So, they come to our showroom. And they talk about their communication issues, inventory issues, sales issues, purchasing issues, customer preferences, local competitors .... These meetings are very effective. We come up with new ideas, new products and new marketing plans ( $P 30: K \& M 25$; 73:73)."

"We invite all our offices around the world to come in and the product development, packaging and marketing puts on a big meeting. We show all the new items that we are doing, make it look like as if it is the actual piece, show it to the sales people so that they can start pre-selling. .... We try to bring everybody together for that one week and discuss all the issues that we have. We try to fix all the problems, if it is shipping issues or product issues or packaging issues. We try to talk about that and together we develop new strategies (P37: $K \& M 5 ; 21: 21)$.

These knowledge sharing activities lead to the exploitation of very useful marketing knowledge that contributes to the development of new products and the successful implementation of marketing activities. Knowledge exploitation and exploration also take place during intensive interactions between members of different teams in the company. They all have one common goal and are consequently highly motivated to exchange their ideas and contribute to the product development. Without this cooperative approach it would not be possible for the product development team, consisting of only six members, to come up with 800 to 1000 new items every year and sustain the company's position of being the world leading company in the production of nature related toys:

"Everybody in the company feels that he should do something. He should contribute to company's success from the warehouse to the upper management and the owner. They promote communication among employees and promote their creativity you actually work in a creative department or not you can still have creative ideas. Things that may.... Everybody from the company contributes to our ideas (P35: K\&M 32; 107:107)."

"Yes. I work closely with product development. I kind of float in between marketing and product development. The way the process works....... Then I work with product development manager and discuss how we are going to package it. We work hand in hand. Even tough I am in a separate division technically in the company I work very closely with the product development. I am involved with the initial development stages of the product. I need to know what 
we are doing and what is coming up in the next months. So, we work really very closely. We have to. It is almost like we are one department. And also there is the marketing department. .... So, there is like three steps that I work through to get the packaging done. It is a lot of meetings, a lot of talking and a lot of communication and we all work together, people from the product development, marketing, sales or graphic design department. This is what makes us so successful (P37: K\&M 3; 13:13)."

K\&M International shows how MNTs may facilitate knowledge exploitation and exploration. According to Ichijo (2002), knowledge exploitation and knowledge exploration are indispensable for a company to increase its competitive advantage. Kyriakopoulos and Moorman (2004) found that market-oriented firms can gain important bottom-line benefits from pursuing high levels of both strategies in product development.

\subsection{Individual team members at K\&M International}

\subsubsection{Team leaders}

Researchers and practitioners alike have endeavoured to understand the factors that enable the effective functioning of MNTs. One such factor is leadership, and especially, the competencies that managers must possess to be able to effectively lead such teams (Kayworth and Leidner, 2002). K\&M International is a company that was founded by an Indian entrepreneur. Consequently, in addition to the team leader competences needed to effectively manage MNTs, information has been obtained about leadership cultural-specifics of India and the USA and the emergence of hybrid cultures that we would like to present in this section of the dissertation. We report findings that incorporate the perspectives of MNT leaders as well as members on MNT leadership together. Identifying and presenting dual perspectives is not the aim of this dissertation and consequently does not play an important role in this context.

\section{Indian versus American leadership style and the emergence of hybrid cultures}

Indian leaders have been characterised as having a very authoritarian leadership style and their managerial practices have been described as obedience to authority and centralization of power. Social relations tend to be hierarchical and Indian team members are more status conscious. The majority has reported that they find it easier to work in superior-subordinate relationships. Team members who manage to meet organizational goals are rewarded by warmth, affection, and close 
relationship with their leaders and those who consistently fail are shunned and ostracized:

"The leadership style in India is more authoritarian. They have this praise for power probably not all of them but definitively the majority. Leaders are more ambitious and they are striving for power. They would probably not criticize a worker for the job he has not done the way he was expected to do it but just fire him. They are stricter to their co-workers. If a leader in India does not like a person for some reason then this person is really in troubles. They also usually make drastic decisions and they do not take the time to tell their employees about the expectations they have and so on. They are very tough and very direct. They tell their employees straight ahead what they think and what they do not agree with. However, there is a lot of Western influence in India and many Indian companies are becoming more and more westernized. So, Indian managing style is changing as well. There is so much diversity in India and it is hard to say that there is only one style of leadership in India (P36: K\&M 24; 85:85)."

They have reported to develop personal relationships with those members who accept their higher status and appear to seek their affection, guidance and direction. Team members who are reliable, trustworthy and loyal to the team leader have a high quality relationship with them and can benefit from this status by accessing higher levels of the organizational hierarchy. Indian team leaders serve as a powerful source of social influence. They have personal and organizational resources and they distribute such resources among team members selectively. Those who are close to the superior are bestowed with favours, while those who are not, tend to be distanced.

Team leaders and managers guide and direct their employees, not only in job related matters but also in family matters. They help the subordinates even at the expense of their inconveniences. As a consequence, they enjoy respect and team members' loyalty. Team leaders delegate power and authority only to their own personally loyal subordinates and show affection, take personal interest in their well being and are committed to their growth. The majority pays great attention to employee welfare:

"All the employees are very dedicated to Mr. P., to Mr. P. and Mrs. P. actually. And I think that basically they care very much for the employees and they show that they are always there for their employees. I do not know if this comes from the Indian culture. I have never been anywhere else except in the U.S. so I can not really compare. But this probably makes the teams in this company more successful (P33: K\&M 15; 65:65)."

"Honestly, I think that he has got good qualities from both sides. From what I can 
see, he frequently comes to our $R \& D$ department, he visits us, and he asks questions about our progress. He has some good qualities of an American manager and some good qualities of an Indian manager. Good qualities from an Indian manager in the sense that if there is a new person coming to the USA and to our company he understands how challenging this can be. Then this is a totally new culture for this person. Mr. P. is very helpful and he even provides accommodation to this person. So, this is more the Indian way. This is part of his culture and tradition. If he would be just an American manager, I am not sure how much he would bother about the difficulties his employees are facing. He has also qualities of an American manager. He is more professional. He knows what to expect and what not to expect from his employees. Definitively, in this company it is very hard to keep both sides and to act as an American and as an Indian manager (P36: K\&M 13; 61:61)".

"So, there is a difference in the sense that if it is a complete American culture they stick to what is professional they do not really go to the personal side of anything. In Indian companies leaders and this is also a characteristic of the Indian culture... there is a tendency that they get more involved in your personal life and do not just stick on the professional. They show interest for your personal life .... (P36: $K \& M 8 ; 51: 51)$."

Interview partners have reported that American team leaders tend to solicit workrelated ideas and suggestions from their employees. However, such an invitation is viewed by several Indian leaders and team members as a sign of weakness and incompetence:

"It is usually the boss who decides. Indian leaders have the feeling that they are superior and they do not want somebody to give them an idea or suggestion which actually overrules their decision. The Indian style is very different even though I do not agree with the way it works and I prefer the way it works here. Your opinion is important and subordinates have the right to say what they think (P31: K\&M 24; 126:126)."

"When I started working for K\&M International I have already been well prepared. American people are friendlier than people in India. And American leaders are even more approachable for their employees than Indian leaders. They have a different leadership style. Indians have a more authoritarian style and the only thing they want to know is if you managed to reach your target. Your effort does not play an important role. The accomplishment of the final goal is the only thing that does matter. Whereas here managers will ask you: 'Are you going to achieve the goal?' If this is not the case they will support us in reaching the target. So, it is more of a cooperative approach. One example: 'By the end of August you should reach the following figure.' At the end of the month they will 
come to you and ask you: 'Did you manage to reach the target?' Whereas here we will define the target for the month of August and in the very first week we will have a meeting and discuss how far we managed to achieve our target in the first week of the month. If I e.g. was not so successful they will ask me why and we will try to find a solution and ways how to increase our sales..... So, I will get support in overcoming this struggle (P42: K\&M 11; 41:41)."

Indian members had to face many challenges when they started working for $\mathrm{K} \& \mathrm{M}$ International, since the managerial practices in the USA are totally different. They don't reject them but they also don't simply accept them. What they do is to integrate them into their management culture. They change the way they lead teams in India by adopting certain parts of it and improving the effectiveness of their leadership style and at the same time they preserve their managerial cultures and practices. By integrating local managerial cultural characteristics into their own, they produce new hybrid cultures. They adopt the most effective local managerial practices and at the same time improve their leadership skills and abilities. Indian team leaders learnt how to provide leadership when they started working at K\&M International. In India nobody ever questions their decisions. They favour an authoritarian management style, whereas in the USA they adopt a more participative style. They learn how to provide leadership, and to cope with many different issues simultaneously, whether it is formulating clear goals, resolving conflicts, making good decisions, providing resources, or solving problems. Acting as a team leader in the USA is a much more challenging task. There is much more pressure on them to provide leadership:

"Team members are looking for leadership, so what does this mean. They are looking for direction. It does not matter if I am 18 years old or 25 years I am the leader here and team members who are working for me are looking for leadership. So, you have to provide leadership. Whether it is formulating clear goals, whether it is resolving conflicts, whether it is making good decisions, whether it is providing resources, or whether it is sometimes solving problems. There are many issues. In all these issues you have to provide leadership, take action, everything. People look at you as a team leader and you have to provide some kind of leadership. Being a team leader here is much more difficult than in India. You have to honour that. Every day. They are scrutinizing you and you are scrutinizing them. There is much more pressure on you to provide leadership. People have high expectations and they are looking for leadership (P28: $K \& M 21 ; 90: 90)$."

"You rely on your people here. You do not make the decisions by yourself. But when you are in a conference and we are tackling an important issue and people throw a bunch of problems at you they expect me to push back. And I am a smart boss and a better team leader if I say that there is one way to go. I 
should not just ask my members what they think and they say: 'O.k. Let us do this because three out of four want to do A.' That is perceived as weak by the American employees. If you do that three or four times you lose that informal thing and it will not last. There is a lot of more aggressiveness. That is the common word that is used. Here, a leader has to be aggressive, whereas in India leaders do not have to be aggressive (P28: $K \& M$ 27; 94:94)."

All findings presented in this section are in accordance with the literature. In India, social relations tend to be hierarchical and people are status conscious, finding it easier to work in superior-subordinate relationships. Sinha and Sinha (1990) listed caring for subordinates, showing affection, taking personal interest in the well being of employees and commitment to their growth as the key characteristic of Indian managers. England's (1987; in Mellahi and Guermat, 2004) seminal study found that Indian managers put more emphasis on organizational stability than their counterparts from other countries, pay more attention to employee welfare than to the goal of profit maximization and value obedience and conformity. They display a high level of personal involvement with their subordinates, extending even into their personal lives. Leaders provide nurturance contingent upon the subordinate's task accomplishment (Sinha and Kanungo, 1997).

After reviewing over forty field and experimental studies of Indian organizations, Sinha (1988) considers the "nurturant-task (NT)" leadership style as highly suitable for an Indian work environment. A nurturant-task leader is one who "cares for his subordinates, shows affection, takes personal interests in their well being and above all is committed to their growth" (Sinha, 1990b:252). Subordinates who meet organizational goals are rewarded by close relationship with their leaders (Gopalan and Rivera, 1997).

Superiors tend to develop personalized relationships with their superiors (Sinha, 1980), while subordinates seem to have a moral obligation to accept the higher status of their superiors and to seek their affection. They feel insecure if their superiors tend to maintain only contractual relationship (Dayal, 1976; Kakar, 1978). The superiors, too, have a moral responsibility to nurture the subordinates and to guide and direct them, not only in job related matters but also in career and family matters. As patrons, they are expected to help the subordinates even at the expense of their inconvenience. The superiors still enjoy familial respect and the subordinates' loyalty (Sinha and Kanungo, 1997).

In addition, the powerful play in Indian organizations tends to be very personal, wherein those who are close to the superior are bestowed with all kinds of favours, while those who are not, tend to be distanced (Sahay and Walsham, 1997). Roland (1988) described the relationship towards powerful people in Indian organizations as submissive and accommodating to avoid conflicts. In a 
similar vain, Jain and Dwivedi (1990; in Mellahi and Guermat, 2004) noted that rules of paternalism and powerful superiors govern Indian organizations.

This study has shown that managerial values and attitudes are subject to change in an MNT context and therefore studies aimed to explore the effect of cultural dimensions on team effectiveness should be aware of the fact that culture is not a static variable but is changing and time has a strong moderating effect on it. Indian team leaders have integrated American managerial practices and adopted a different leadership style in MNTs. As a consequence of this phenomenon, we should rethink accepted notions of culturally determined managerial identities and go beyond seeing managerial identities in fixed national terms.

\section{Team leader functions and characteristics}

One key factor that enables the effective functioning of MNTs is leadership. In the course of the study several competencies that leaders must possess and functions they should fulfil in order to effectively lead such teams have been identified. Table 18 shows the most frequently mentioned team leader functions and the number of quotations per function.

\begin{tabular}{|l|l|}
\hline $\begin{array}{l}\text { MNT leader } \\
\text { functions }\end{array}$ & Sample quotation \\
\hline Motivation & $\begin{array}{l}\text { "He shows a lot of appreciation and he motivates people. } \\
\text { area is contributing to the big or to the whole and I think } \\
\text { this would be motivating for everyone regardless of what it } \\
\text { is that you are doing in the company. It is important to } \\
\text { know how your product is contributing to the overall suc- } \\
\text { cess. This is motivating. The team leader should stress the } \\
\text { importance of your individual work (P 29: K\&M 27; } \\
90: 90) . "\end{array}$ \\
\hline Communication & $\begin{array}{l}\text { "You know I still think I will go back to my communica- } \\
\text { tion thing I really think that a team leader needs to fre- } \\
\text { quently communicate with those who needs to be his sub- } \\
\text { ordinates and other people honour him and to frequently } \\
\text { remind and make it a priority to let team members know } \\
\text { what they are contributing is really valuable to the whole } \\
\text { process (P29: K\&M 24; 90:90)." }\end{array}$ \\
\hline $\begin{array}{l}\text { Decision } \\
\text { making }\end{array}$ & $\begin{array}{l}\text { "Daily there are decisions... and if I am not able to come } \\
\text { to a decision at a certain point than we will go to Jason, } \\
\text { the manager of the product development, and ask for his }\end{array}$ \\
\hline
\end{tabular}




\begin{tabular}{|c|c|}
\hline & $\begin{array}{l}\text { input. He will then help as to make the final decision that } \\
\text { is important and that will affect the whole team (P40: } \\
\text { K\&M 5; 49:49)." } \\
\text { "When decisions have to be made, then I use to bring all the } \\
\text { members here together. I ask them to raise their hands if } \\
\text { they think that this is the right direction where we should } \\
\text { go. ... Sometimes there are no answers and then you need } \\
\text { to make leadership and decisions. It does not always func- } \\
\text { tion the democratic way. You can have democratic proc- } \\
\text { esses. Good. But sometimes there must be somebody to } \\
\text { make the final decision. Other ways things do not run the } \\
\text { way they should (P34: K\&M } 20 ; 38: 38) . "\end{array}$ \\
\hline $\begin{array}{l}\text { Goal } \\
\text { Determination }\end{array}$ & $\begin{array}{l}\text { "A good team leader must formulate clear goals and give } \\
\text { a clear direction (P28: } K \& M 22 ; 90: 90) \text {." }\end{array}$ \\
\hline Monitoring & $\begin{array}{l}\text { "From what I can see, he frequently comes to our } R \& D \\
\text { department, he visits us, and he asks questions about our } \\
\text { progress (P36:K\&M 10; 61:61)." }\end{array}$ \\
\hline $\begin{array}{l}\text { Conflict } \\
\text { Management }\end{array}$ & $\begin{array}{l}\text { "There is sometimes conflict between designers arguing } \\
\text { about a certain product or about the price. Sometimes } \\
\text { people do get frustrated and they take it personally. I think } \\
\text { that everybody in our group has been. You try to work } \\
\text { through it as quickly as possible. I make sure that both } \\
\text { sides express their opinions and then we let the group de- } \\
\text { cide what the right direction to go with that product is. } \\
\text { Everybody does get along and we work very well together. } \\
\text { Occasionally it happens. Sometimes during the discus- } \\
\text { sions we had more intense with certain people and this is } \\
\text { why I try to work through that and to see both sides and to } \\
\text { hear what is happening and to understand the situation } \\
\text { (P35: K\&M 12; 56:56)." }\end{array}$ \\
\hline $\begin{array}{l}\text { Providing lead- } \\
\text { ership }\end{array}$ & $\begin{array}{l}\text { "If you are the one who has to lead a team and give clear } \\
\text { directions to a team then you first have to have your fun- } \\
\text { damentals and your knowledge at place to be able to lead } \\
\text { your team in a certain direction and then take valuable } \\
\text { insights from your team. This is important in order to } \\
\text { help achieve a goal. If you are not knowledgeable about } \\
\text { where you want to go how can you lead a team? } \\
\text { A team leader must have the ability to lead his team (P32: } \\
K \& M 33 ; 110: 110) . "\end{array}$ \\
\hline
\end{tabular}




\begin{tabular}{|c|c|}
\hline $\begin{array}{l}\text { Selection of } \\
\text { team members }\end{array}$ & $\begin{array}{l}\text { "The challenges for me are to put the right people to- } \\
\text { gether and create the right product. However, if I do not } \\
\text { have the right people I will also not succeed with the best } \\
\text { product. This is my major challenge (P34:K\&M 4; } \\
\text { 14:14)." }\end{array}$ \\
\hline $\begin{array}{l}\text { Managing the } \\
\text { weaknesses and } \\
\text { improving the } \\
\text { strengths of } \\
\text { team members }\end{array}$ & $\begin{array}{l}\text { "I have to ask them: 'What is your strength?' At the next } \\
\text { management meeting I am planning to ask: 'You are man- } \\
\text { aging so many people. What are you looking at?' I strongly } \\
\text { believe in managing the weakness and improving the } \\
\text { strengths and not the other way around. I do not want the } \\
\text { people to work on their weaknesses (P34: K\&M } 6 ; 14: 14) \text {." }\end{array}$ \\
\hline Task Delegation & $\begin{array}{l}\text { "It is very important to know the talents of your team } \\
\text { members. It is my job to assign the projects to the design- } \\
\text { ers and it is based on what they could do best, based on the } \\
\text { skills that a particular designer has that is who finally gets } \\
\text { that type of product to work on it. We have really talented } \\
\text { people in this company. It is very important to recognize } \\
\text { talents of the employees for the benefit of the team and for } \\
\text { the benefit of the company and use them for what they can } \\
\text { do best (P35: K\&M } 28 ; 89: 89) . "\end{array}$ \\
\hline $\begin{array}{l}\text { Team building } \\
\text { function }\end{array}$ & $\begin{array}{l}\text { "I want my employees to be in that situation. I have to de- } \\
\text { velop my people to the degree that they feel like a big team } \\
\text { here. Team work is essential. ... And my task is to } \\
\text { strengthen the cohesiveness of my team (P34: K\&M 14; } \\
20: 20) . "\end{array}$ \\
\hline $\begin{array}{l}\text { Knowledge of } \\
\text { local language }\end{array}$ & $\begin{array}{l}\text { Working with the gift shop in Vienna, one of the biggest } \\
\text { barriers and challenges, is just the language barrier and } \\
\text { certainly that has applications for me and for M. And how } \\
\text { are we going to best communicate with one another? I do } \\
\text { not have frustration I guess just concern that what it is } \\
\text { that I am communicating has being completely communi- } \\
\text { cated to her. Since we are always going through somebody } \\
\text { is translating for us you know I am spelling out this para- } \\
\text { graph of information and somebody needs to translate that } \\
\text { to her and I have no idea what is it that is being communi- } \\
\text { cated to her. And I just hope that they grab the entire } \\
\text { essence of what I am saying and not just kind of filtering } \\
\text { what they consider the most important part. I am particu- } \\
\text { lar about what it is that I want to communicate. And I am } \\
\text { sure she is M. has the same concern. She has many years } \\
\text { of experience working in this gift shop and managing this } \\
\text { gift shop. Things that she is sharing back to me that are }\end{array}$ \\
\hline
\end{tabular}




\begin{tabular}{|l|l|}
\hline valuable and that are important and I am sure that at time \\
that she must consider: 'I hope that he is getting the whole \\
story and not just bits and pieces of what the translator is \\
communicating.' That has been a challenge. It is always... \\
We depend on the trust of the translators that he is \\
sharing everything because I know from my end that \\
everything that I am saying is what I want to be passed on \\
to her. I think there is that barrier to overcome. I mean...I \\
am the leader of the team in Vienna and everything would \\
be much easier if I could speak German (P29: K\&M $30 ;$ \\
$114: 114) . "$
\end{tabular}

Table 18: MNT leader functions at K\&M International (Source: Author)

Motivation is the most important leadership function. By showing appreciation for the work done by individual team members and giving constructive and instant feedback, team members are more motivated to contribute to the team's success. Team leader communication is also essential for effective team leader performance. Leaders who share information with team members, to let them know what they are contributing is really valuable to the whole process and who enforce the creation of norms that encourage team members to communicate among themselves frequently and openly, are more successful in leading teams. Sometimes it is necessary to make the final decisions and team members expect their leaders to fulfil this task. It does not always function the democratic way and therefore it is important to have somebody who will take the responsibility and make the final decision. Another two team leader competences that have been identified and considered as important by MNT leaders and members at K\&M International are goal determination and monitoring. Sometimes there is a high conflict potential in MNTs. Members get frustrated and took it too personally. They expect the team leader to make sure that both sides express their opinions, to let the team choose the right direction and to finally resolve the conflict. A team leader also has to have the fundamentals in order to be able to lead a MNT. Without being knowledgeable about where to go he is not able to lead his members. Consequently, the ability to lead a team is also identified as an important MNT leader competence. To select the right people and to manage their weaknesses and help improve their strengths is essential for team effectiveness and a team leader function. He is responsible for assigning the tasks to members based on what they can do best and the skills they have. It is very important to recognize talents of the employees for the benefit of the team and for the benefit of the company and use them for what they can do best. Two interview partners also mentioned team building and the knowledge of local language as important team leader competences. 
In addition to the functions mentioned and described above, for a MNT leader it is critical to develop solid relationships with a variety of people from different countries and therefore it is necessary to be socially competent and to have the required interpersonal abilities. A successful team leader has the ability to build relationships and to bind people together for common purposes. Social competence is critical for effective team leadership. He is also expected to demonstrate real humility that he has only limited knowledge and skills required to carry out the activities of the team:

"I think that first of all it is very important to be very open-minded and look within yourself for your own weaknesses. It is important that you work on your own weaknesses, improve yourself and that you are able to lead your team on. You can grow from your weaknesses and your team's strengths. You can not grow from your team's strengths. If you have soothing weak, then you look for strengths in your team. But you have to have the ability to look within yourself and to see: ' $O . k$. This is what I like. This is how I can do better and this is how I can motivate my team' (P32: K\&M 36; 110:110)."

These MNT leadership competences, functions and abilities have been identified as necessary requirements by other researchers too. The literature seems to suggest that team leader competencies comprise certain personality factors (e.g. openness), have a cognitive component (e.g., knowledge about foreign cultures), and include a behavioural component (e.g., ability to change behaviour according to cultural cues, cf. Earley and Ang, 2003; Thomas and Inkson, 2004). Joshi and Lazarova (2005) have identified 5 competences that are considered as important by MNT leaders and members across multiple locations. The same competences have been identified to have a strong impact on team effectiveness in the course of this explorative study.

\subsubsection{Team members}

Individual team members react to socialization attempts in MNTs in different ways. Interviewed persons have highlighted the importance of personality traits, team member social competence and open-mindedness as three main factors influencing MNT interactions.

The personality of individual team members has a strong influence on MNT performance. The right fit of personalities in a team contributes to its success or failure to achieve certain goals. The role of personality in MNTs is highlighted in the literature analysis. In analogy to the expatriate adjustment literature (Ward et al., 2001), it can be assumed that specific personality traits are supportive for 
MNT work. Therefore, it is important to choose the 'right people'. Psychological tests, handpicking of experts and assessment centers are management tools right at hand (Neyer, 2004):

"First of all, you have to recognize that people have different personalities and that you have to work with them as personalities. Probably the biggest issue in a team is that most people are honest and they try to be honest with other people. If there is a slack and some people try to take over, and within a team you have a person who wants to be the leader, a person who wants to be... and a person who just wants to sit back and not really have much priority and is too shy and maybe this quiet person has a lot of ideas and is just too shy to express them. All of us are different personalities and we should create an environment where everybody feels comfortable and free and there should not be a person who tries to dominate another. This may not be their attempt but their personality. Some do very well and some do not (P33: K\&M 6; 43:43)."

"With artists, it is a different breed of people. There are a lot of egos involved. Personality that goes into the work! You have to find the right people in order to work together because we put so many hours in work together. Things are stressful and if you do not have the right mix of people you become selfdestructive. And I have been in art departments before where these people just do not get along and I think with graphics you really have to be involved, you have to be friends; you have to be able to handle the stress. You might not agree with somebody on what is going on but you will have to agree with this person. And this can happen. I think this is the toughest part of the work. It is like American baseball. You have a series of people who all do the same thing if you do not work together the team loses. It is the same thing (P37: K\&M 8; 29:29)."

Socially competent team members who have the required interpersonal abilities and the ability to appreciate the value of different perspectives represented in MNTs increase team effectiveness. They are able to display patience in intercultural situations, to be tolerant of ambiguity and uncertainty due to cultural differences, and to work in a flexible manner with others on a MNT. They show appreciation for a variety of working styles, and have the ability to view the ways things are done in other cultures not as bad but simply as different. These findings are in analogy with literature on cross-cultural communication (Matveev and Nelson, 2004).

In addition, cultural distance between team members has a strong influence on team effectiveness. Members from India had difficulties at the beginning finding the right ways of interaction and showing understanding for different cultural values and norms of behaviour. As soon as they became familiar with the cultural differences, they knew how to react in different situations and could show more 
understanding and tolerance for different norms of communication, decision making and criticizing. Again, time has a strong moderating effect on team effectiveness.

\subsection{Summary of empirical findings from K\&M International}

The study has been conducted at the HQ of K\&M International. The researcher has spent seventeen days at K\&M International and during this period of time she could conduct fifteen problem-centred interviews with members and leaders of different MNTs, e.g. product development team, sales force team, IT team, customer support team, management team and virtual teams.

The industry context has a strong influence on team composition, team members' requirements, team tasks and MNT effectiveness at K\&M International. Industry, among other contexts, affects MNTs and their members. Consequently, companies operating in different industries implement different kinds of MNTs and the industrial context impacts MNT performance.

Organisational culture has a strong impact on team effectiveness. K\&M International uses teams as the core performing units. The organization is designed to support teams and the logic of the organization is team-oriented and not individual-oriented. Such a culture is critical to the performance level of the teams. It motivates the employees to go above and beyond the call of duty, to aid fellow workers and contribute to collective success. The larger organization must give some careful thought to what is needed to support teams. These reflective activities must occur regularly. The environment the teams work in and the corporate culture are critical to their performance level.

K\&M International pursues a multinational strategy. Companies that are involved in expansion and focus on 'consumer to consumer marketing' can benefit from market-related advantages obtained from cultural diversity in their teams.

Congruent and interdependent tasks create a positive climate in which Indian and American team members not only identify with their team and behave in a cooperative way, but are also motivated to exchange their perspectives and different opinions, to manifest creativity and supportive behaviour and to help each other. Consequently, the type of task has a strong influence on team cohesion and collective team identification.

Seventy percent of the employees working at the HQ are Americans and thirty percent are Indians. MNTs at K\&M International consist of American and Indian 
members. By studying these MNTs, we could obtain valuable information about cultural specifics of India. Although we did not seek to determine the level of individualism/collectivism in Indian and the American society, one of the major findings is the existence of a strong element of individualism in Indian and collectivism in the USA. This finding challenges prior notions of individualism/collectivism. One would expect that employees who are high in collectivism will more readily accept the team aspect than employees who are more individualistic, since cultures that are collective exhibit more emotional dependence on the team, and are more conforming, orderly, traditional, team-oriented and particularistic. Yet Indians are less likely to readily accept many of the concepts associated with teams and team work. Compelling and urgent personal needs and goals in conflict with the interests of the family lead to a mix of individualist and collectivist behaviour and intentions.

A high extent to which Indians accept or reject the uneven distribution of power among members has been observed. In India, they never question decisions made by people above them and people working for them never question their decisions, assuming that their power gives them the right to make such decisions and given their power their decisions have to be correct. Yet managers from the U.S. tend to solicit work-related ideas and suggestions from team members as a part of a democratic leadership style. American members view dependence on the team leader negatively, while Indian members obtain a sense of security from power coming from their leaders and view dependence as a positive quality.

The empirical findings also indicate that Indian members are more contextsensitive than the American members who work with them in MNTs. They are more willing to change their behaviour in order to cope with their environment. Americans react in consistent ways in different situations. In South-India some behaviour that is judged appropriate for a given place, time, and person may not be appropriate for other times, places and persons. Consequently, they change their behaviour to meet environmental demands. The ability of Indian team members to adapt their working and communication style to the American way has decreased communication problems, inaccuracy, misunderstandings and inefficiency in the MNTs.

None of the studies on MNT effectiveness reviewed has examined the effect of gender egalitarianism on team functioning. The findings show that team members from cultures characterised as being low on gender egalitarianism (e.g. the USA) may harm team effectiveness in the case they do not adjust to the values and norms of behaviour of (female) members from cultures high on gender egalitarianism (e.g. India). 
A fundamental difference between the Indian and American activity orientation has been observed. Americans are much more focused on achieving results and they expect to be rewarded according to their achievements. They take a more thoughtful and rational approach and things are done only after some reflection. In addition, Indian team members report to be more oriented towards the past. The preference for planning, compartmentalizing, scheduling time and a sense of urgency tend to be less emphasized in India due to their time orientation. They are impressed by the way American members are coping with time issues.

The finding shows that if two groups with different values and norms of behaviour have to interact in one team, then the members will either adopt e.g. American or Indian norms of behaviour. These different cultural standards also lead to the emergence of conflicts and are usually the cause of clashes in team interactions. Workgroup composition and particularly, diversity among members creates barriers to effective group interaction. Demographic diversity creates faultlines, since demographic characteristics divide the network into subgroups.

Time has a strong moderating effect on trust building and the development of team cohesion. By the time teams develop, share and enact a set of rules for how team members relate to one another, work capability expectations, and member perceptions. These factors create a positive environment within the team and have a positive impact on team identification and team performance.

In the case of $K \& M$ International, knowledge exploitation takes place when existing knowledge is shared commonly in MNTs at directors' meetings and international conferences. On the other hand, knowledge exploration is triggered by the exhaustive discussions and by the feedback from the subsidiaries' staff and leads to the creation of new knowledge for future product development.

We could identify several team leader competences that are needed to effectively manage MNTs. These are the following: motivation, communication, decisions, goal determination, monitoring, conflict management, ability to provide leadership, selection of team members, managing the weaknesses and improving the strengths of team members, task delegation, teambuilding and knowledge of local language of the country where the team operates. In addition to these competences, it is critical for an MNT leader to develop solid relationships with a variety of people from different countries and to be socially competent and to have the required interpersonal abilities. $\mathrm{He}$ is also expected to demonstrate real humility that he has only limited knowledge and skills required to carry out the activities of the team.

Individual team members react to socialization attempts in MNTs in different ways. Interviewed persons have highlighted the importance of personality traits, 
team member social competence and open-mindedness as three main factors influencing MNT interactions.

Indian members face many challenges when they start working for K\&M International, since managerial practices in the USA are totally different. They don't reject them but they also don't simply accept them. What they do is to integrate them into their management culture. They change the way they lead teams in India by adopting certain parts of it and improving the effectiveness of their leadership style and at the same time they preserve their managerial cultures and practices. By integrating local managerial cultural characteristics into their own they produce new hybrid cultures. They adopt the most effective local managerial practices and at the same time improve their leadership skills and abilities.

Managerial values and attitudes are subject to change in an MNT context and therefore studies aimed to explore the effect of cultural dimensions on team effectiveness should be aware of the fact that culture is not a static variable, but is changing and time has a strong moderating effect on it. Indian team leaders integrate the American managerial practices and adopt a different leadership style in MNTs. As a consequence of this phenomenon, we should rethink accepted notions of culturally determined managerial identities and go beyond seeing managerial identities in fixed national terms. 
Aida Hajro - 978-3-631-75438-2

Downloaded from PubFactory at 01/11/2019 04:52:54AM

via free access 


\section{Summary and the conceptual framework for MNTs in business organisations}

The purpose of this dissertation is to explore the influence of categories on MNTs in business organisations and to develop a more comprehensive framework connecting the internal dynamics with contextual aspects of MNTs functioning in companies operating in the high-tech and consumer good industries in Europe and the USA. In this chapter we will present the conceptual framework derived from data collection and data analysis. But first of all, we would like to provide a short summary and present the main categories of influence on MNTs by focusing on the relevant codes of each category.

Rich data has been collected in the context and, consequently, a detailed understanding of organisational processes is required. The context is part of the design and the research study aims to examine research questions and issues by setting these in a contextual and often causal context. In order to meet the criterion of generalization, the theory is developed on the basis of a three cases research design. This approach increases confidence in the findings, by enabling cross checking and comparison. A clear link between theory and data collection is created and the researcher has worked closely with a variety of informants in their organizational settings. The study has been conducted at VA TECH, an Austrian multinational company that operates in the high-tech industry, Henkel, one of the most internationally aligned of German consumer goods companies and $\mathrm{K} \& \mathrm{M}$ International, the American world-leader in the production of nature related toys. Forty-two problem-centred interviews have been conducted with 22 team members and 20 team leaders and considerable time has been given to writing up notes of observation. The interviews have lasted for approximately one hour and all of them have been recorded. Finally, a 565 page long transcript has been produced and data analysis and interpretation are based on the findings of this interview transcript and notes of observation. By spending time at the HQ of VA TECH in Vienna and K\&M International HQ in Ohio the researcher could gain a deeper understanding for the dynamics of the social setting, MNT processes and its functioning. At K\&M International she has participated at directors' meetings. Through actual participation in the organisations being studied an ongoing extensive interaction between researcher and subject could take place. The interviews at Henkel CEE were conducted from July to September 2005. In addition to the data obtained from interview partners the researcher has spent time observing team members' interactions and meetings with representatives from subsidiaries. Valuable information could be obtained during lunch time or numerous coffee breaks with company's employees. The interviews have been analysed by applying a qualitative content analysis (Mayring, 2000). Through inductive category de- 
velopment and deductive category application 205 codes have been formulated. The most relevant codes are presented in this chapter. The basic idea of qualitative content analysis is to preserve the advantages of quantitative content analysis for a more qualitative text interpretation (Mayring, 2000). Table 19 (follows on pages 187-190) shows the categories of influence on MNT performance in a business context, focusing on the relevant codes of each category. It also includes the number of quotations for each code and the percentage of interviews per most frequently coded variables, enabling the researcher to indicate the perceived salience of matters.

Industry characteristics, nature of business, levels of uncertainty and stress and present turbulence have an impact on organisations and MNTs, since teams and organisations react to them in order to shape their strategies. MNT researchers cannot afford to continue to ignore these factors, if they want to explain and predict the behaviour of MNTs and their members. Companies operating in different industries implement different types of MNTs and industry context has a strong impact on team composition, team members' requirements, team tasks and MNT effectiveness. External factors may even have a stronger influence on company performance than MNT effectiveness. Therefore, it would be wrong to assess team performance by only measuring a company's profits. MNT information that should be relayed must also include the type of company and the local and global situation in the industry at the time when research is conducted. We could obtain data about industry context and its impact on team functioning from 14 quotations mentioned by $83 \%$ of interview partners from VA TECH and from 5 quotations mentioned by $20 \%$ of interview partners from K\&M International. It is interesting that interviewed persons have not addressed issues related to the impact of the consumer-good industry on MNT performance at Henkel CEE. One reason might be the strong, no-blame corporate culture of Henkel CEE that protects its members from external forces and limits the level of perceived stress. The opposite has been observed at VA TECH, a company with a weak corporate culture. Eightythree percent of interview partners have mentioned the negative impact of industry turbulence and stress on MNT functioning.

The context of an organisation includes organisational culture, competitive strategy and corporate structure. Organisational culture has a strong impact on team effectiveness. The corporate culture of Henkel CEE and K\&M International have been described as family-like corporate cultures. This type of culture supports team work and the management philosophy is one of involvement and the organization is built on the principle that people have the right to be involved in matters that affect them. As a consequence, team members make decisions in the best interest of the organisation and the organisational culture motivates them to do their best in order to achieve company's goals. K\&M International and Henkel 
CEE use teams as the core performing units. The organizations are designed to support teams and the logic of the organization is team-oriented and not individual-oriented. Both companies give some careful though to what is needed to support teams. These reflective activities occur regularly. The environment the teams work in and the corporate culture are critical to MNT performance.

MNTs at VA TECH perform well and contribute to the reduction of complexity inherent in the multinational company. The corporate culture has been described as a task achievement culture. The company doesn't have a strong organisational culture and consequently MNTs have more opportunity to develop their own unique cultures, which have the potential to deviate from the values and norms set by the organisation, ultimately influencing the organisational culture.

This is not the case at Henkel CEE and K\&M International. Both companies had strong corporate cultures. In both cases corporate values (that define what is important) and norms that define appropriate attitudes and behaviours for employees (how to feel and behave) are consistent with team norms and values.

Diversity turns out to be beneficial in all three companies. At Henkel CEE MNTs add a multicultural perspective to the multinational strategy development and enable the company to act as locally as necessary and as globally as possible. Despite the fact that VA TECH focuses on cost savings and follows a global strategy, diversity turns out to be beneficial, since important knowledge about different markets, customers, and distribution partners, local competitors etc. is shared within MNTs and then applied in order to successfully enter new markets.

HRM is one important component that helps an organisation with a matrix structure to improve team effectiveness by delegating the right people to projects where their skills are immediately needed and by developing their skills and knowledge. The matrix-structure at VA TECH is not well established and the HRM is not effective. The failure of the HRM to delegate the right people to projects where their skills are needed has harmed MNT effectiveness at VA TECH. This is not the case at Henkel CEE where HRM system contributes to team performance. Team members from VA TECH also report that the repeated withdrawal of employees due to the need to apply specialised expertise to next projects harms team cohesiveness. The findings show that the strength and performance of HRM has a positive impact on MNT performance in companies with a matrix structure, where human resource successfully delegates the right people to projects where their skills are immediately needed.

Interviews have been conducted with members of different teams, e.g. product development team, project teams, sales force team, IT team, customer support team, management team, virtual teams etc. By distinguishing between different 
types of teams, we found that certain variables have stronger impact on MNT's functioning and the findings captured vary for different types of team. Consequently, the type of team matters for the determinants of effectiveness. Different teams are responsible for accomplishing different tasks and depending on the task the team members work more independently or interdependently. Consequently, task and goal interdependence have a strong moderating effect on team effectiveness. In MNTs with congruent task and goal interdependence the team leader's task of increasing the level of motivation, cooperation and identification is less challenging compared to teams with high goal but low task interdependence.

We could identify 177 quotations mentioned by $62 \%$ of the interview partners that describe the impact of different cultural norms of behaviour of team members on MNT functioning. Our findings show that when we study MNTs we must also consider cultural differences other than those provided by culture-general frameworks. Those frameworks will never cover all information we need to know about people in different context. Each society has at least some qualitatively distinctive values that are not found in other cultures and that may have a strong influence on MNTs.

Effective team leadership is one of the most important factors that enable the effective functioning of MNTs. This study illustrates its impact on MNT performance and it presents the functions and competences team leaders should possess in order to effectively lead such teams (see Table 19). The three most frequently mentioned team leader competences that are considered to be important aspects of a MNT leader's role are communication, motivation and goal setting. For a leader, it is also necessary to be socially competent and to have the required interpersonal abilities. Moreover, he/she should be a competent cross-cultural communicator in order to work effectively with people with different cultural backgrounds. Our findings also show that competences or minimum requirements of effective MNT leadership vary in different organisational and team contexts. It is interesting that we could obtain only 22 quotations that illustrate the role of MNT leader in enabling the effective functioning of MNTs at Henkel, compared to 87 quotations at VA TECH. One possible reason for this is Henkel's corporate culture and the effective role of the HRD in supporting MNTs. The company's human resources strategy focuses on attracting the best junior managers, offering them attractive career perspectives and actively developing their skills. The HRD plays an important role in developing their skills and making them understand the values and norms of the corporate organisations that guide them in fulfilling their daily duties and responsibilities. The fact that human resource managers at VA TECH, who are responsible for delegating the right people to projects where their skills and abilities are immediately needed, don't perform well creates additional chal- 
lenges for MNT leaders. This may explain why the importance of team leadership has been stressed most in this company.

The category team member comprises 11 codes. Interviewed persons highlight the importance of personality, social competence, open-mindedness and work experience as four main factors influencing MNT interactions. In an MNT there are many perspectives that are represented and team members must be able to appreciate the value that each one has to offer. This includes different technical and cultural views. They must not tolerate such perspectives, but must also embrace the opportunities for learning that the different views bring. It is through a heavy interaction of perspectives that creativity and innovation occurs. In an international environment, enjoying such differences facilitates the interaction of the team. Another important issue for an effective team is the work experience of individuals. Experienced team members who have experience in MNT work are the ones who are able to facilitate the learning process in teams and to increase the level of understanding of team members.

Several types of norms that increase MNT performance and influence how team members interact and communicate with one another, make decisions, solve problems and give feedback have been identified. Values (that define what is important) and norms that define appropriate attitudes and behaviours for MNT members (how to feel and behave) are consistent with the organisational culture at Henkel CEE and K\&M International. The larger organizational culture within which teams operate is supportive. Certain strong norms such as a cooperative approach, constructive and instant feedback, open communication and innovation enhancing norms facilitate the generation and expression of creative ideas. MNTs at VA TECH have the freedom to define their norms and values of behaviour. These are not necessarily consistent with the organisational culture. Consequently, the impact of a norm on effectiveness is shown to depend both on its content and its context. The context of the corporate culture is not so strong at VA TECH and team norms are more dependent on team context. A broad range of team norms has been identified in this study.

MNT size, composition, structure, time and technology have a strong moderating effect on MNT performance. Splitting into three or more subgroups facilitates the creation of a positive motivational climate in MNTs through greater information sharing about personal traits, backgrounds, and interests. In MNTs consisting of two major partners on the other hand, demographic diversity creates faultlines, since demographic characteristics divide the network into two subgroups. Time has a strong moderating effect on societal influences on MNT members. This study captures complex interactions of individual team members with differences in language, interpersonal styles, and a host of other factors. Our findings show that over time team members reconstruct their identities and adopt new perspec- 
tives, new sets of rules and norms of behaviour, expectations and perceptions. Time has a moderating effect on the societal and national influences on MNT members. The learning processes within the team help to overcome insufficiencies in the performance of individuals and they change their prior rules, procedures, norms of behaviour and communication. Team members' cultural standards are subject to change over time due to an intense interaction with employees from different countries. Individuals improve their performance through an on-going integration of different cultural values and norms of behaviour that they find useful and appropriate. Prior studies that have used such measures as collectivism or individualism or have tried to assess the influence of the relative cultural distance between team members on team effectiveness have ignored the effect that mutual and intense interaction of team members over a certain period of time may have on their identities, societal values and norms of behaviour. Moreover, seventeen percent of interview partners have reported that technology and the equipment used facilitates the information exchange and contributes to MNT effectiveness.

Our findings also show how MNTs can contribute to the reduction of complexity inherent in large multinational companies. They reduce the complexity of operations by facilitating the creation and transfer of explicit and tacit knowledge between geographically dispersed business units. For example, $80 \%$ of the MNTs members at Henkel CEE are rotating members from different CEE subsidiaries and from the HQ in Düsseldorf. By supporting the generation and implementation of creative ideas and building upon the ideas of members from CEE, they contribute to new product development, branding and advertising. Inpatriates from CEE promote the effective transfer of knowledge about products, markets, customers, and competitors in their home country to the HQ and from the HQ back to the subsidiaries and eventually throughout the entire multinational organization. The principle behind creating this system of knowledge exploitation and transfer is job rotation. Employees work together in MNTs over a sufficiently long period of time to consolidate close relationships. This way, MNTs contribute to the creation and transfer of tacit knowledge that is very important in today's global knowledge-based economy. Unfortunately, many companies underestimate the positive impact of MNTs on organisational culture, knowledge creation and consequently performance. Just recently IBM has reduced the number of rotational assignments in its HQ in Vienna due to the need to cut costs (Repitz, 2006). Yet in the long run, this decision may decrease a company's performance. By employing inpatriates in MNTs on semi-permanent rotational assignments, Henkel CEE also maintains its cultural consistency between geographically dispersed business units and creates a strong corporate culture characterised by common values and business methods. Again, MNTs reduce the complexity of operations of the German multinational company by facilitating the transfer of appropriate dimensions of the home organisation's culture between its business units. 
Table 19 shows the categories of influence on MNT performance.

\begin{tabular}{|c|c|c|c|}
\hline Category & Sub-category & $\begin{array}{l}\text { Number of } \\
\text { quotations }\end{array}$ & $\begin{array}{l}\text { Percentage } \\
\text { of } \\
\text { interviews } \\
\end{array}$ \\
\hline $\begin{array}{l}\text { Cultural } \\
\text { differences } \\
\text { between team } \\
\text { members } \\
\end{array}$ & $\begin{array}{l}\text { Cultural differences between } \\
\text { team members (inductive } \\
\text { reasoning) }\end{array}$ & 177 & $62 \%$ \\
\hline \multirow[t]{3}{*}{ Industry } & $\begin{array}{l}\text { Industry turbulence (inductive } \\
\text { reasoning) }\end{array}$ & 14 & $21 \%$ \\
\hline & $\begin{array}{l}\text { Stress factor (inductive } \\
\text { reasoning) }\end{array}$ & 10 & $17 \%$ \\
\hline & $\begin{array}{l}\text { Nature of business (inductive } \\
\text { reasoning) }\end{array}$ & 5 & $7 \%$ \\
\hline \multirow[t]{3}{*}{$\begin{array}{l}\text { Organisation } \\
\text { as a set of } \\
\text { contextual } \\
\text { factors }\end{array}$} & $\begin{array}{l}\text { Organisational culture: task } \\
\text { achievement versus "family- } \\
\text { like" corporate culture } \\
\text { (inductive reasoning) }\end{array}$ & 53 & $50 \%$ \\
\hline & $\begin{array}{l}\text { Organisational strategy: } \\
\text { global versus multinational } \\
\text { (deductive reasoning) }\end{array}$ & 23 & $24 \%$ \\
\hline & $\begin{array}{l}\text { Organisational structure: } \\
\text { matrix structure and the role } \\
\text { of HR (inductive reasoning) }\end{array}$ & 33 & $21 \%$ \\
\hline \multirow[t]{3}{*}{$\begin{array}{l}\text { Team context } \\
\text { and internal } \\
\text { processes }\end{array}$} & $\begin{array}{l}\text { Team size (deductive } \\
\text { reasoning) } \\
\text { Team composition: bi-cultural } \\
\text { versus MNTs (deductive } \\
\text { reasoning) } \\
\text { Team structure (inductive } \\
\text { reasoning) }\end{array}$ & & \\
\hline & $\begin{array}{l}\text { Team task: task } \\
\text { interdependence (deductive } \\
\text { reasoning) }\end{array}$ & 11 & $21 \%$ \\
\hline & $\begin{array}{l}\text { Team processes and time } \\
\text { factor (inductive reasoning) }\end{array}$ & 9 & $14 \%$ \\
\hline \multirow[t]{2}{*}{ Team leader } & Team leader characteristics & 52 & $41 \%$ \\
\hline & $\begin{array}{l}\text { Social competence (deductive } \\
\text { reasoning) }\end{array}$ & 18 & $24 \%$ \\
\hline
\end{tabular}




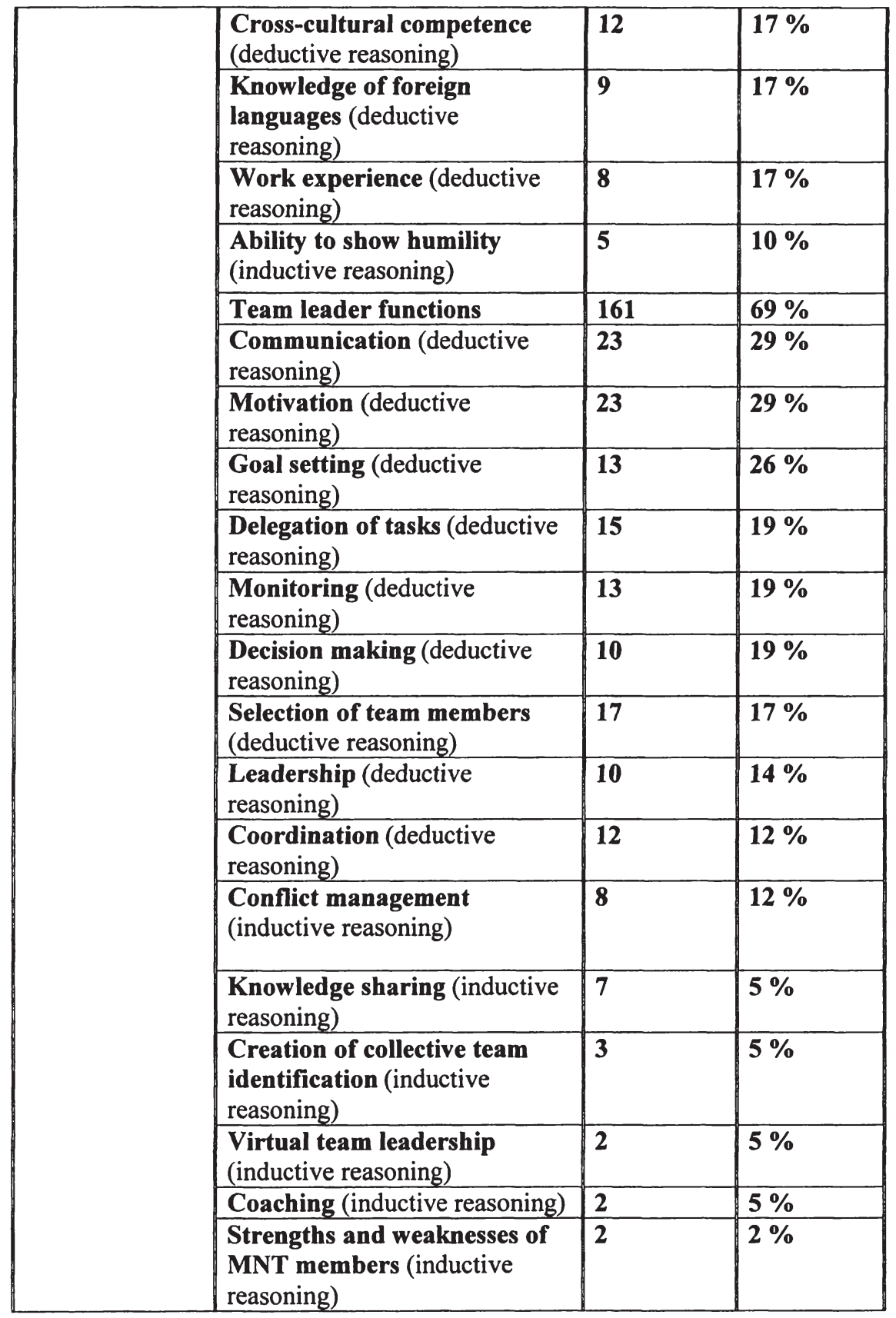




\begin{tabular}{|c|c|c|c|}
\hline & $\begin{array}{l}\text { Teambuilding function } \\
\text { (inductive reasoning) }\end{array}$ & 1 & $2 \%$ \\
\hline \multirow[t]{12}{*}{ Team member } & Team member & 143 & $79 \%$ \\
\hline & \begin{tabular}{|l|}
$\begin{array}{l}\text { Personality (deductive } \\
\text { reasoning) }\end{array}$ \\
\end{tabular} & 25 & $41 \%$ \\
\hline & $\begin{array}{l}\text { Work experience (inductive } \\
\text { reasoning) }\end{array}$ & 31 & $38 \%$ \\
\hline & \begin{tabular}{|l|}
$\begin{array}{l}\text { Social competence (deductive } \\
\text { reasoning) }\end{array}$ \\
\end{tabular} & 23 & $36 \%$ \\
\hline & \begin{tabular}{|l|}
$\begin{array}{l}\text { Open-mindedness (deductive } \\
\text { reasoning) }\end{array}$ \\
\end{tabular} & 24 & $33 \%$ \\
\hline & $\begin{array}{l}\text { Knowledge transfer between } \\
\text { HQ and local subsidiaries: } \\
\text { expatriate versus inpatriate } \\
\text { team member (inductive } \\
\text { reasoning) }\end{array}$ & 18 & $33 \%$ \\
\hline & $\begin{array}{l}\text { Multi-lingual (deductive } \\
\text { reasoning) }\end{array}$ & 7 & $12 \%$ \\
\hline & $\begin{array}{l}\text { Coordination function } \\
\text { (inductive reasoning) }\end{array}$ & 5 & $7 \%$ \\
\hline & $\begin{array}{l}\text { Adaptability and flexibility } \\
\text { (inductive reasoning) }\end{array}$ & 4 & $7 \%$ \\
\hline & Age (inductive reasoning) & 2 & $5 \%$ \\
\hline & Gender (inductive reasoning) & 2 & $5 \%$ \\
\hline & $\begin{array}{l}\text { Free lancer (inductive } \\
\text { reasoning) }\end{array}$ & 2 & $5 \%$ \\
\hline \multirow[t]{6}{*}{$\begin{array}{l}\text { Team norms } \\
\text { and values }\end{array}$} & $\begin{array}{l}\text { MNT norms (deductive } \\
\text { reasoning) }\end{array}$ & 223 & $100 \%$ \\
\hline & \begin{tabular}{|l|} 
Cooperative approach \\
(deductive reasoning)
\end{tabular} & 49 & $55 \%$ \\
\hline & \begin{tabular}{|l|} 
Constructive and instant \\
feedback (inductive reasoning)
\end{tabular} & 41 & $50 \%$ \\
\hline & $\begin{array}{l}\text { Open communication } \\
\text { (inductive reasoning) }\end{array}$ & 24 & $41 \%$ \\
\hline & $\begin{array}{l}\text { Clear direction and common } \\
\text { goals (inductive reasoning) }\end{array}$ & 26 & $38 \%$ \\
\hline & $\begin{array}{l}\text { Willingness to share } \\
\text { knowledge (inductive } \\
\text { reasoning) }\end{array}$ & 19 & $38 \%$ \\
\hline
\end{tabular}




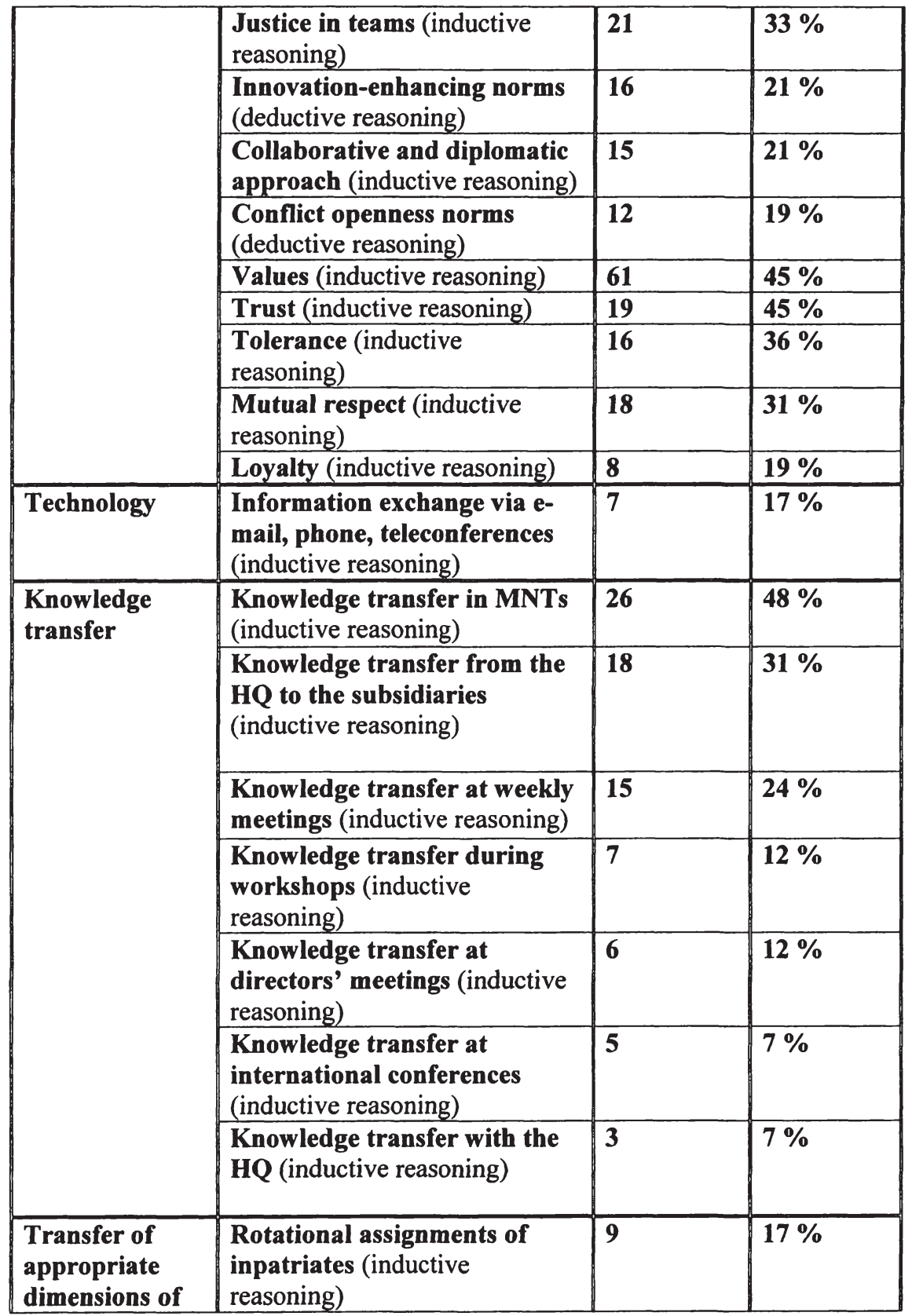




\begin{tabular}{|l|l|l|l|}
\hline $\begin{array}{l}\text { the } \\
\text { organisational } \\
\text { culture }\end{array}$ & $\begin{array}{l}\text { Function of expatriates team } \\
\text { members (inductive reasoning) }\end{array}$ & 7 & $17 \%$ \\
\hline
\end{tabular}

Table 19: Categories and sub-categories derived from data analysis (Source: Author)

Figure 1 presents the conceptual framework for MNT functioning in business organisations. Industry has an impact on the organisational strategy, structure and culture. This is illustrated by the white triangle. It shows the relationship between these two categories. The black arrows connect the internal MNT dynamics with the organisational context and the black triangles illustrate the reciprocal relationships between the organisation and MNTs. MNTs impact the organisation through the transfer of the appropriate dimensions of the home organisation's culture and of knowledge between geographically dispersed organisational units of the company through MNTs. MNT task is specified as an important driver of team processes in our framework. Team size, technology and time present important moderating variables that have a strong impact on MNT performance and on societal-level cultures of individual team members as can be seen from the two white arrows in the left and right corner of figure 1. MNT norms are a powerful form of social control over employees (see the four white triangles). They may either be consistent with the organisational culture or deviate from the values and norms set by the organization, ultimately influencing the corporate culture. 
Organization:

Organizational strategy: global versus multinational strategy

Organizational structure : matrix structure and human resource department (HRD) effective/non effective

Organizational culture : task/achievement vs. family-like corporate culture

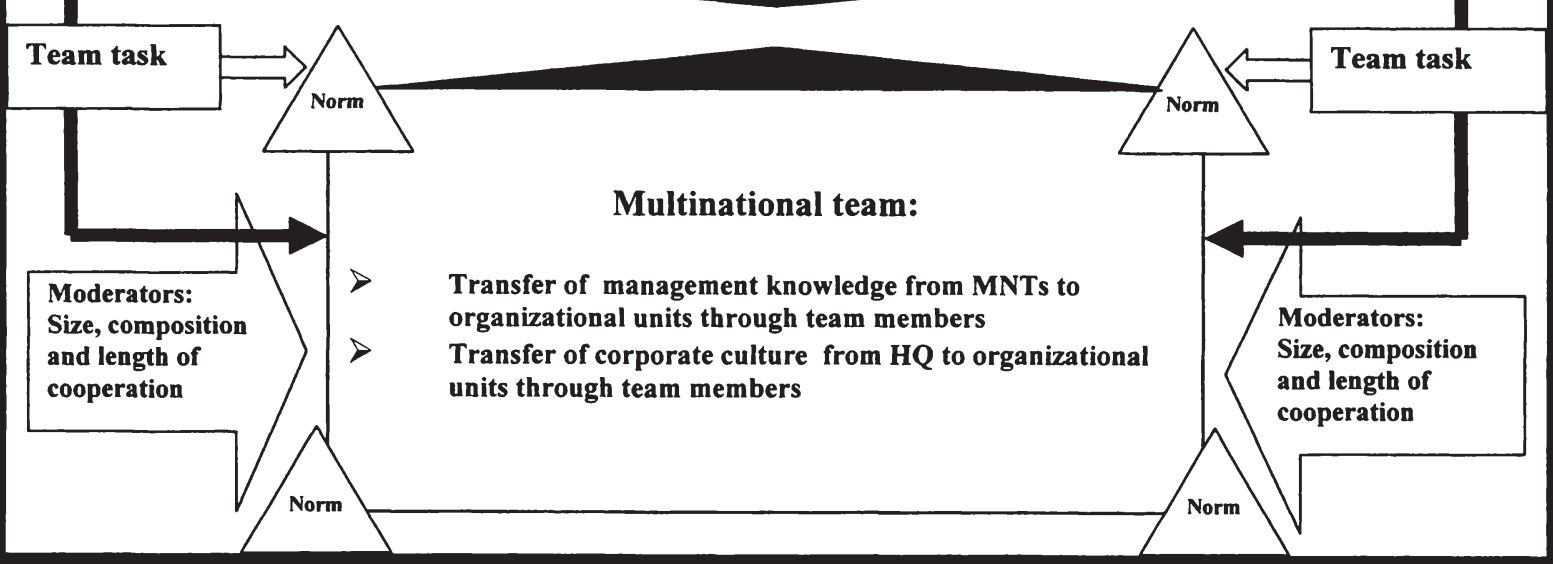

Figure 1: Conceptual framework for MNT in business organisations (Source: Author) 


\section{General conclusions}

\subsection{Discussion: limitations and future research implications}

\subsubsection{Limitations of this dissertation}

Taking proper advantage of MNTs requires a good understanding of the impact of various factors at the environmental, organizational, team and individual levels of analysis on their performance. The aim of this study is to identify categories of influence on MNTs in business organisations and to develop a conceptual framework connecting internal dynamics with contextual aspects of MNT functioning.

Research has been conducted in an Austrian, a German and an American company. In order to test the validity of the results derived from the data collection and analysis, a more systematic investigation of this phenomenon is needed and requires that MNTs in multiple organisations located in multiple cultural contexts and operating in different industries are included in the sample. Interviews should be conducted by researchers with different national backgrounds in order to avoid construct and interview bias. A shift in theoretical framing to a culturally general framework is necessary (Gibson et al., 2003). Time and manpower have limited the results of this dissertation and forty interviews have been conducted by one researcher in German, English and Bosnian. Foreign languages can have a negative impact on trust building, the current flow of the interview and on the content of the interview. Consequently, interviewers who are from the same culture as the interview partners achieve better results (Fink et al., 2004b). At this point, we would like to mention that this is a part of a more comprehensive empirical study on MNTs in business organisations in a cross-cultural context which has been conducted in Austria and the USA (see Repitz, 2006; Rubesch, in press). The study includes 190 qualitative interviews with team leaders and team members in different companies (e.g., VA TECH, Henkel CEE, K\&M International, Siemens, IBM, Pöyry, OMV, Bombardier etc.) operating in the high-tech and consumer good industry. It has been conducted over a period of more than three years at the Vienna University of Economics and Business Administration. 


\subsubsection{Implications for future research}

This dissertation makes an important contribution to the existing MNT research. It presents a model that includes reciprocal relationships between context and individuals and teams. It is necessary to be aware of the internal dynamics and external aspects of MNT functioning and their reciprocal relationships. Otherwise, we will continue to find relationships within identified set of variables that seem to be causal due to the existence of other variables that moderate the discovered relations and lead to contradictory results.

Our findings show that MNT norms in companies with a strong corporate culture (e.g., K\&M International and Henkel CEE) are reflective of the organizational culture. Consequently, the corporate culture has a strong impact on teams and its members. MNTs at companies with a weak corporate culture develop their own unique cultures and deviate from the values and norms set by the organization (e.g., VA TECH). It would be interesting to investigate this issue in different organisations with different types of corporate culture.

In future, we may continue identifying core competences of effective MNT leadership. Yet, the type of team will matter. By distinguishing among types of teams we may find out that the personal capabilities, skills and abilities of MNT leaders will vary for different types of teams.

When assessing MNT performance, it is interesting to study the specifics of single cultures, in addition to the culture-general knowledge offered by etic frameworks. Cultures can be studies from a perspective that provides deeper specific understandings of cultural differences. For example cultural standards are more specific and they provide more specific knowledge about cultural differences than cultural dimensions (Fink et al., 2006). Our findings show that different norms of behaviour of team members from different cultures impact MNT effectiveness.

Different levels of gender egalitarianism of members from different cultures who work in MNTs may impact team effectiveness and cause critical incidents. Our findings show that team members from cultures characterised as low on gender egalitarianism may harm team effectiveness in case they do not adjust to the values and norms of behaviour of (female) members from cultures high on gender egalitarianism (see chapter: 6.6.1 Team composition at K\&M International and occurrence of bilateral conflicts). It would be interesting to conduct additional studies that incorporate the potential impact of this cultural dimension on MNT effectiveness. 
Future research may test the validity of the questionnaire items aimed at assessing the level of collectivism and individualism in CEE and India. Our data raise doubts about Central Eastern Europeans' and Indians' unequivocal nature of collectivism as reported in the GLOBE project. Contrary to GLOBE's study, also Trompenaars' (1993) findings show a surprising level of individualism in the respondents from CEE - those from Hungary, Czech, Poland, Bulgaria, Romania, and Russia all scoring in the top quartile for individualism. In the same vein, Smith et al. (1996) reported a preference for individual rather than shared responsibilities in the CEE cultures (Bakacsi et al., 2002).

\subsection{Managerial implications}

In the following section we will present important managerial implications:

Companies that pursue a global strategy should be aware of the importance and necessity to implement MNTs. Cultural diversity within project teams of companies with a global strategy will be positively related to a firm's performance. MNT members will have the necessary pool of resource-net works and through the intensity of mutual interactions based on trust and respect they will secure vital tacit knowledge about different niche markets. By facilitating knowledge exploitation and knowledge exploration they will increase a company's competitive advantage.

Firms that are involved in expansion and focus more on 'business to consumer marketing' will benefit from the implementation of MNTs. They will benefit from market-related advantages obtained from cultural diversity and this cultural diversity of the workforce will bring cultural sensitivity that is very important when the company enters new markets and tries to reach different market segments. MNTs will add a multicultural perspective to the strategy development of such companies and enable them to act as locally as necessary and as globally as possible.

MNTs play an important role in today's global knowledge-based economy. MNTs consisting of HQ employees and host country representatives (inpatriates) will facilitate the exploitation and transfer of knowledge across geographically dispersed business units of the company.

In order to take proper advantage of MNTs, it is necessary to have a good understanding of the impact of such groups on an organisation including its culture. By employing inpatriates in MNTs on semi-permanent rotational assignments, companies will maintain their cultural consistency between geographically dispersed business units and create a strong corporate culture characterised by common 
values and norms. MNTs will reduce the complexity of operations by transferring the appropriate dimensions of the HQ's corporate culture to its subsidiaries.

Our findings show that the HRD contributes to MNT effectiveness. An effective HRD helps to quickly mobilize employees with diverse capabilities into well functioning teams in order to respond to new challenges and contribute to a company's success. By delegating the right employees to projects were their skills are immediately needed and by developing their skills and knowledge and increasing their motivation HRD improves a company's success and increases its MNT performance.

MNTs that consist of one core team whose members are involved in pursuing team goals from the beginning of a project until its end will easier develop team cohesiveness and members will identify with the team. A sense of collective team identification is critical for MNT performance. If team members are repeatedly being withdrawn from the team, they may not be able to develop this sense of collective team identification.

Our findings show that Indian team leaders integrate American managerial practices into their management culture. They change the way they lead teams in India by adapting certain parts of American leadership style. This way they are able to improve their personal leadership style. By integrating American local managerial cultural characteristics into their own they produce new hybrid cultures and become more successful.

At this point, we would like to mention once more that this study has been conducted in three different companies. In order to test the validity of the results derived from the data collection and analysis, a more systematic investigation of this phenomenon is needed. This represents the major limitation of the dissertation. Thus, it provides a value-added contribution to existing research and important implications for managers. 


\section{Bibliography}

Abbey, A., and Dickson J.W. (1983). R\&D work climate and innovation in semiconductors. Academy of Management Journal, Vol. 26, No. 2: 362-368.

Adler, N.J. (1991). International dimensions of organizational behaviour. $2^{\text {nd }}$ ed., Boston: PWS-Kent.

Adler, N. J., and Boyacigiller, N. A. (1991). The Parochial Dinosaur: Organizational Science in a Global Context. The Academy of Management Review, Vol. 16, No. 2: 262-290.

Adler, N. J., and Jelinek, M. (1986). Is organizational culture culture bound? Human Resource Management, Vol. 25, No. 1.

Allport, G.W. (1937). Personality: A Psychological Interpretation. New York: Holt, Rinehard and Winston, p. 48.

Apgar, M. (1998). The alternative workplace: Changing where and how people work. Harvard Business Review, May-June: 121-139.

Atteslander, P. (2000). Methoden der empirischen Sozialforschung. $9^{\text {th }}$ ed., Berlin.

Bakacsi, G., Sandor, T., Andras, K., and Viktor, I. (2002). Eastern European Cluster: Tradition and Transition. Journal of World Business, Vol. 37, No. 1.

Bantz, C.R. (1993). Cultural Diversity and Group Cross-cultural Team Research. Journal of Applied Communication Research, February: 1-20.

Barney, J. (1991). Firm Ressources and Sustained Competitive Advantage. Journal of Management, Vol. 17, No. 1: 99-120.

Beersma, B., Hollenbeck, J.R., Humphrey, S.E., Moon, H., Conlon, D.E., and Ilgen, D.R. (2003). Cooperation, competition, and team performance: towards a contingency approach. Academy of Management Journal, Vol. 46, No. 5: 572590 .

Begley, T. M., and Boyd, D. P. (2003). Organizing U.S. Business Practices To Manage Culture Clash. Organizational Dynamics, Vol. 32, No. 4. 
Bettenhausen, K.L., and Murnighan, J.K. (1985). The emergence of norms in competitive decision making groups. Administrative Science Quarterly. Vol. 30: 350-372.

Birch, N., and Pooley, J. (1995). Changes in Russian quality management practices from 1989 to 1992. Management International Review. Vol. 35: 219239.

Bock, P.K. (1999). Rethinking psychological anthropology. $2^{\text {nd }}$ ed., Prospect Heights, IL: Waveland.

Boeije, H. (2002). A Purposeful Approach to the Constant Comparative Method in the Analysis of Qualitative Interviews. Quality \& Quantity, Vol. 36: 391-409.

Bollinger, D. (1994). The four cornerstones and three pillars in the "House of Russia" management system. Journal of Management Development, Vol. 34: 4954.

Bortz, J., and Döring, N. (2002). Forschungsmethoden und Evaluation für Human- und Sozialwissenschaftler. $3^{\text {rd }}$ ed., Berlin.

Brannen, M.Y., Gómez, C., Peterson, M.F., Romani, L., Sagiv, L., and Wu, P-C. (2004). People in organizations: culture, personality and social dynamics, in: Lane, H.W., Maznewski, M., Mendenhall, M.E., McNett, J. (2004). The Blackwell Handbook of global management: a guide to managing complexity, pp. 26-54. Oxford: Blackwell Publishing Ltd

Brass, D.J. (1995). A social network perspective on human resources management. In G.R. Ferris (Ed.), Research in personnel and human resources management. Vol. 13: 39-79. Greenwich, CT:JAI Press.

Brass, D.J. (1981). Structural relationships, job characteristics, and worker satisfaction and performance. Administrative Science Quarterly. Vol. 22: 331348.

Brytting, T. (1995). Organizing in the small growing firm: a grounded theory approach, in B. Glaser (ed.), Grounded Theory 1984-1994, Mill Valley, CA: Sociology Press, 517-38.

Butler, C.L., and Earley, P.C. (2001). Multinational Groups and the Structuration of Organizational Culture: a Sociological Perspective; in Cooper, C.L., Cartwright, S., Earley, P.C. (2001), Organizational Culture and Climate, 53-85. New York: John Wiley \& Sons Ltd. 
Caligiuri, P., Jacobs, R., and Farr, J. (2000). The attitudinal and behavioural openness scale: scale development and construct validation, International Journal of Intercultural Relations, Vol. 24, No. 1:27-46.

Campion, M. A., Papper, E. M., and Medsker, G. J. (1996). Relations between work team characteristics and effectiveness: A replication and extension. Personnel Psychology, Vol. 49: 429-452.

Campion, M. A., Medsker, G. J., and Higgs, C. A. (1993). Relations between work group characteristics and effectiveness: Implications for designing effective work groups. Personnel Psychology, 46: 823-850.

Canney Davison, S.F. (1995). Intercultural processes in multinational teams. Unpublished Doctoral Dissertation, London Business School.

Cappelli, P., and Sherer, P.D. (1991). The missing level of context in OB: the need for a mesolevel approach. Research in Organizational Behaviour, Vol. 13: 55-110.

Carpenter, M. (2002). The implications of strategy and social context for the relationship between top management team heterogeneity and firm performance. Strategic Management Journal, Vol. 23: 275-284.

Carrero, V., Peiro, J.M. and Salanova, M. (2000). Studying radical organizational innovation through grounded theory. European Journal of Work and Organisational Psychology, Vol. 9: 489-514.

Cavanagh, G.F. (1990). American business values. Englewood Cliffs, NJ: Prentice Hall.

Chatman, J. A., and Flynn, F. J. (2001). The influence of demographic heterogeneity on the emergence and consequences of cooperative norms in work teams. Academy of Management Journal, Vol. 44, No. 5.

Chatman J.A., Polzer J., Barsade S., and Neale M. (1998). Being different yet feeling similar: the influence of demographic composition and organizational culture on work processes and outcomes. Administrative Science Quarterly, Vol. 43, No. 4: 749-780.

Collins, J. C., and Porras, J. I. (1994). Built to Last: Successful Habits of Visionary Companies. New York: HarperCollins. 
Colquitt, J.A., Noe, R.A., and Jackson, C.L. (2002). Justice in teams: Antecedents and consequences of procedural justice climate. Personnel Psychology, Vol. 55: 83-109.

Cox, T., and Tung, R. L. (1997). The multicultural organization revisited. In C.L. Cooper \& S.E. Jackson (Eds.), Creating tomorrow's organizations. New York: Wiley.

Cox, T. (1993). Cultural diversity in organizations: theory, research \& practice. San Francisco: Berrett-Koehler.

Cox T., Lobel S., and McLeod P. (1991). Effects of ethnic group cultural differences on cooperative and competitive behaviour on a group task. Academy of Management Journal, Vol. 34, No. 4: 827-847.

Cummings, J.N. Leading group from a distance: How to mitigate consequences of geographic dispersion. In: S. Weisband and L. Atwater (Eds.), Leadership at a distance (in press).

Dayal, I. (1976). Cultural factors in designing performance appraisal system. New Delhi: Shri Ram Centre for Industrial relations and Human Resources.

Den Hartog (2005). Emics and etics of culturally-endorsed implicit leadership theories: Are attributes of charismatic/transformational leadership universally endorsed? Leadership Quarterly, will be published in 2005.

Diekmann, A. (1995). Empirische Sozialforschung: Grundlagen, Methoden, Anwendungen. Rororo, Reinbek bei Hamburg.

DiMaggio, D.J., and W.W. Powell (1983). The iron cage revisited: institutional isomorphism and collective rationality in organizational fields. American Sociological Review, Vol. 48: 147-160.

Earley, C., and Gardner, H.K. (2005). Internal dynamics and cultural intelligence in multinational teams. in Shapiro, D. L. (2005). Managing Multinational Teams: Global Perspectives. Amsterdam: Elsevier.

Earley, P.C., and Ang, S. (2003). Cultural intelligence: Individual interactions across cultures. Stanford, CA: Stanford University Press.

Earley, P.C., and Gibson, C.B. (2002). Multinational Work Teams: A New Perspective. Lawrence Erlbaum Associates, Inc., Publishers. 
Earley, P.C., and Mosakowski, E.M. (2000). Creating hybrid team cultures: An empirical test of international team functioning. Academy of Management Journal, Vol. 43: 26-49.

Elron, E. (1997). Top management teams within multinational corporations: Effects of cultural heterogeneity. Leadership Quarterly, Vol. 8: 393-412.

Ely, R. D., and Thomas, D. A. (2001). Cultural diversity at work: The effects of diversity perspectives on work group processes and outcomes. Administrative Science Quarterly, Vol. 46: 229-273.

England, G.W. (1983) Japanese and American management: theory $Z$ and beyond. Journal of International Business Studies, Vol. 14: 131-141.

England, G.W (1978). Managers and their value systems: A five country comparative study. Columbia Journal of World Business, Vol. 13: 35-44.

Erez, M., and Earley, P.C. (1993). Culture, self-identity and work. New York: Oxford University Press.

Ferris, G.R., and Wagner, J.A. (1985). Quality circles in the United States: a conceptual reevaluation. Journal of Applied Behavioural Science, Vol. 21: 155167.

Fink, G., Holden, N., and Lehmann, M. (in press). Survival by Subversion in Former Socialist Economies: Tacit Knowledge Exchange at the Workplace, in: Kate Hutchings/Kavoos Mohannak (Eds.), Knowledge Management in Developing Economies: A Cross-Cultural and Institutional Approach. Australian Institute of Management/Edward Elgar Publishing (forthcoming).

Fink, G., and Lehmann, M. (in press). People's Twist: The Cultural Standard of 'Loyalty' and Performance in Former 'Socialist Economies'. Ed. Pauleen, D.J., Contribution to Cross Cultural Perspectives on Knowledge Management, to be published by Libraries Unlimited.

Fink, G., Neyer, A.K., and Kölling, M. (2006). Understanding Cross-Cultural Management Interaction: Research into Cultural Standards to Complement Cultural Value Dimensions and Personality Traits. International Studies of Management and Organisation, Vol. 36: 38-60.

Fink, G., and Holden, N. (2005a). Introduction: The Global Transfer of Management Knowledge. The Academy of Management Executive, Vol. 19, No. 2: 5-8. 
Fink, G., and Holden, N. (2005b). Guest editorial: Absorption and application of management knowledge. Journal of Managerial Psychology, Vol. 20, No. 7: 560565 .

Fink, G., Neyer, A. K., Kölling, M., and Meierewert, S. (2004a). An Integrative Model of Multinational Team Performance. EI Working Paper Nr. 60.

Fink, G., Neyer, A. K., Kölling, M., and Meierewert, S. (2004b). Research on intercultural management interaction: the cultural standard method. Paper presented at the First International Co-Sponsored Conference, Research Methods Division Academy of Management, in Lyon, France.

Fink, G., and Holden, N. (2002). Collective culture shock: contrastive reactions to radical systemic change, IEF Working Paper 45, October 2002.

Fink, G., and Feichtinger, C. (1998). The collective culture shock in transition countries - theoretical and empirical implications. Leadership and Organization Development Journal, Vol. 19, No. 6: 302-309.

Flick, U., Karlsdorff von, E., and Steinke, I. (2000). Qualitative Forschung - Ein Handbuch. Hamburg.

Flynn F.J., and Chatmann J.A. (2001). Strong cultures and innovation: oxymoron or opportunity? In Cooper C. L., Cartwright S., and Earley P.C. (Eds.), The International handbook of organizational culture and climate. John Wiley \& Sons, Ltd.

Fogel, D.S. (1994). Managing in emerging market economies: Cases from the Czech and Slovak Republics. Boulder: Westview Press.

Francesco, A. M., and Gold, B. A. (1998). International Organizational Behaviour: Text, Readings, Cases, and Skills. Prentice Hall, Inc., New Jersey.

Friel, D. (2005). Transferring a Lean Production Concept from Germany to the USA: the Impact of Labour Laws and Training Systems. The Academy of Management Executive, Vol. No. 19: 5-8.

Gerben, S., Van Der Vegt, and Bunderson, J. S. (2005). Learning and performance in multidisciplinary teams: The importance of collective team identification. Academy of Management Journal, Vol. 48, No. 3: 532-547.

Gersick, C.J.G. (1988). Time and transition in work teams: toward a new model of group development. Academy of Management Journal, Vol. 31: 9-41. 
Gibson, C.B., Zellmer-Bruhn, M.E., and Schwab, D.P. (2003). Team Effectiveness in multinational organizations: evaluation across contexts. Group and Organization Management, Vol. 28, No. 4: 444-474.

Gibson, C.B., and Zellmer-Bruhn, M.E. (2001). Metaphors and meaning: An intercultural analysis of the concept of teamwork. Administrative Science Quarterly, Vol. 46: 274-303.

Gibson, C.B. (1999) Do they do what they believe they can? Group efficacy and group effectiveness across tasks and cultures. Academy of Management Journal, Vol. 42, No. 2: 138-152.

Glaser, B., and Strauss, A. (1999). The discovery for grounded theory: strategies for qualitative research. 2nd ed., De Gruyter, New York.

Glaser, B.G. (1998). Doing grounded theory: issues and discussions. Mill Valley, CA: Sociology Press.

Glaser, B.G. (1995). Grounded theory: 1984-1994. Mill Valley, CA: Sociology Press.

Glaser, B., and Strauss, A. (1967). The discovery for grounded theory: strategies for qualitative research. $1^{\text {st }}$ ed., De Gruyter, New York.

Gomez, C., Kirkman, B. L., and Shapiro, D. L. (2000). The impact of collectivism and in-group/out-group membership on the evaluation generosity of team members. Academy of Management Journal, Vol. 43, No. 6: 1097-1106.

Goodall, K., and Roberts, J. (2003). Only connect: teamwork in the multinational. Journal of World Business, Vol. 38: 150-164.

Gopalan, S., and Rivera, J.B. (1997). Gaining a perspective on Indian value orientations: Implications for expatriate managers. The International Journal of Organizational analysis, Vol. 5, No. 2: 156-179.

Gudykunst, W.B. (1998). Applying Anxiety/Uncertainty Management (AUM) Theory of Intercultural Adjustment Training. International Journal of Intercultural Relations, Vol. 22: 227-50.

Gudykunst, W.B., Stewart, L.P., and Ting-Toomey, S. (1985). Communication, culture and organizational processes. Beverly Hills, CA: Sage. 
Gupta, V., Surie, G., Javidan, M., and Chhokar, J. (2002). Southern Asia cluster: where the old meets the new? Journal of World Business, Vol. 37: 16-27.

Gupta, V., Hanges, P.J., and Dorfman, P. (2002). Cultural clusters: Methodology and findings. Journal of World Business, Vol. 37: 11-15.

Hackman, J.R. (1999). Thinking differently about context. In R. Wageman (Ed.), Research on managing groups and teams: groups in context. 233-247. Stamford, CT: JAI Press.

Hackman, J.R. (1991). Groups that work (and those that don't). San Francisco: Jossey Bass.

Hackman, J.R. (1987). The design of work teams, in: Lorsch, J.W. (ed.). Handbook of organizational behaviour. London: Prentice-Hall.

Hackman J.R. (1976). The design of self-managing work groups. Technical Report, No. 11, School of Organization and Management, Yale University.

Hall, E.T. (1959). The silent language. New York: Anchor Press.

Hambrick, D.C., Davison, S.C., Snell, S.A., and Snow, C.C. (1998). When groups consist of multiple nationalities: Toward a new understanding of the implications. Organizational Studies, Vol. 27.

Harris, P.R., and Moran, R.T. (1997). Managing cultural differences. $4^{\text {th }}$ ed., Houston, TX:Gulf.

Harris, C. L., and Beyerlein M. M. (1995). Team-based organization: Creating an environment for team success; in West, M. A., Tjosvold, D., and Smith, K. G. The Essentials of Teamworking: International Perspective. Chichester: Wiley.

Harrison, D. A., Price, K. H., and Bell, M. P. (1998). Beyond relational demography: Time and the effects of surface- and deep-level diversity on work group cohesion. Academy of Management Journal, Vol. 41: 96-107.

Harrison, R., and Stroles, H. (1990). Diagnosing Your Organization's Culture. Berkley, CA: Harrison \& Assoc. Inc.

Harrison, R. (1987). Organisational culture and quality of service, Association for Management Education and Development, London. 
Harrison, R. (1972) How to describe your organization's culture. Harvard Business Review, May-June, Vol. 5, No. 1.

Henkel (2007a):

www.henkel.com last access $31^{\text {st }}$ of Jannuary, 2007.

Henkel, (2007b):

http://www.henkel.com/int-

henkel/ourcompany_at/channel/index.cfm?pageid $=144$. last access $31^{\text {st }}$ of Jannuary, 2007.

Henkel, (2007c):

http://origin.henkel.com/int_henkel/ourcompany_cee/channel/index.cfm?pageid= 211 last access $31^{\text {st }}$ of Jannuary, 2007.

Hirokawa, R. Y. (1980). A comparative analysis of communication patterns within effective and ineffective decision-making groups. Communication Monographs, Vol. 47: 312-321.

Holden, N. J. (2004). Why marketers need a new concept of culture for the global knowledge economy. International Marketing Review, Vol. 6, No. 21: 563-572.

Hofstede, G. and McCrae, R.R. (2004). Personality and culture revisited: Linking traits and dimensions of culture, Cross-Cultural Research, Vol. 38, No. 1: 52-88.

Hofstede, G. (2001). Culture's Consequences: Comparing Values, Behaviours, Institutions, and Organisations across Nations. $2^{\text {nd }}$ ed., Thousand Oaks, CA: Sage.

Hofstede, G., and Bond, M.H. (1998). The Confucius connection: from cultural roots to economic growth. Organizational Dynamism, Vol. 16, No. 4: 4-18.

Hofstede, G. (1991). Culture and organization: Software of the mind. London: McGraw-Hill.

Hofstede, G., Neuijen, B., Ohavy, D.D. and Sanders, G. (1990). Measuring Organisational Culture: A Qualitative and Quantitative Study across Twenty Cases. Administrative Science Quarterly, Volume 35: 286-316.

Hofstede, G. (1980). Culture's consequences: International differences in work related values. Beverly Hills, CA: Sage. 
House, R., Javidan, M., Hanges, P., and Dorfman, P. (2004). Culture, Leadership, and Organizations: The GLOBE Study of 62 Societies. Sage Publications, Inc., Thousand Oaks, California.

Hurt, M., and Hurt, S. (2005). Transfer of managerial practices by French food retailers to operations in Poland. The Academy of Management Executive, Vol. 19, No. 2: 36-49.

Ichijo, K. (2002). Knowledge exploitation and knowledge exploration: Two strategies for knowledge creating companies. In C. W. Choo and N. Bontis (Eds.), The strategic management of intellectual capital and organizational knowledge, 477-483. New York: Oxford University Press.

Jackson, S. E., Joshi, A., and Erhardt, N. L. (2003). Recent Research on Teams and Organizational Diversity: SWOT Analysis and Implications. Journal of Management, Vol. 29, No. 6.

Jackson, S. E. (1992a). Consequences of group composition for the interpersonal dynamics of strategic issue processing. In P. Shrivastava, A. Huff \& J. Dutton (Eds.), Advances in Strategic Management, Vol. 8: 345-382.

Jackson, S. E. (1992b). Team composition in organizational settings: Issues in managing an increasingly diverse work force. In S. Worchel, W. Wood, \& J. A. Simpson (Eds.), Group process and productivity, 138-141. Newbury Park, CA: Sage.

Jain, R., and Dwivedi, O. (1990). Administrative culture and bureaucratic values in India. Indian Journal of Public Administration, Vol. 36: 435-450.

Janz, B. D., Colquitt, J. A., and Noe, R. A. (1997). Knowledge worker team effectiveness: The role of autonomy, interdependence, team development, and contextual support variables. Personnel Psychology, Vol. 50: 877-904.

Javidan, M., Stahl, G. K., Brodbeck, F., and Wilderom, C. P.M. (2005). Crossborder transfer of knowledge: Cultural lessons from Project GLOBE. The Academy of Management Executive, Vol. 19, No. 2: 59-76.

Jehn, K. A., and Bezrukova, K. (2003). A field study of group diversity, group context, and performance. Unpublished manuscript, The Wharton School, University of Pennsylvania, Philadelphia.

Jehn K.A. (1997) A multi-method examination of the benefits and detriments of intragroup conflict. Administrative Science Quarterly, Vol. 42, No. 3: 530-557. 
Jelinek M., and Wilson J. (2005). Macro influences on multicultural teams: A multi-level view. In Shapiro D.L. (Eds.) Managing Multinational Teams: Global Perspectives. Amsterdam: Elsevier.

Joshi, A., and Lazarova, M. (2005). Do Global teams need global leaders? Identifying leadership competences in multinational teams. In Shapiro, D. L., Managing Multinational Teams: Global Perspectives. Amsterdam: Elsevier.

K\&M International (2007):

http://www.kmtoys.com

Kakar, S. (1978). The inner world: A psychoanalytic study of childhood and society in India. New Delhi: Oxford University Press.

Kanungo, R.N., and Jaeger, A.M. (1990). Management in developing countries. London: Routledge.

Kanungo, R.N. (1983). Work Alienation: A pancultural perspective. International Studies of Management and Organization, Vol. 13: 119-138.

Kapoor, S., Hughes, P. C., Baldwin, J. R., and Blue, J. (2003). The relationship of individualism-collectivism and self-construals to communication styles in India and the United States. International Journal of Intercultural Relations, Vol. 27, No. 6: 683-700.

Kayworth, T.R., and Leidner, D.E. (2002). Leadership effectiveness in global virtual teams. Journal of Management Information System, Vol. 18, No. 3: 7-40.

Kelle, U. (1995). Computer-aided Qualitative Data Analysis: Theory, Methods and Practice. SAGE Publications. Guildford.

Khandwalla, P. (1996). Effective corporate response to liberalization: The Indian case. Social Engineer, Vol. 5, No. 2: 5-33.

Kirchmeyer C., and Cohen A. (1992). Multicultural groups: Their performance and reactions with constructive conflict. Group and Organisation Management, Vol. 17, No. 2: 153-170.

Kirkman, B.L., and Shapiro, D.L. (2005). The impact of cultural value diversity on multicultural team performance; In Shapiro, D. L. (2005). Managing Multinational Teams: Global Perspectives. Amsterdam: Elsevier. 
Kirkman, B.L., Rosen, B., Tesluk, P.E., and Gibson, C.B. (2004). The impact of team empowerment on virtual team performance: The moderating role of face-toface interaction. Academy of Management Journal, Vol. 47.

Kirkman, B.L., Rosen, B., Gibson, C.B., Tesluk, P.E., and McPherson, S.O. (2002). Five challenges to virtual team success: Lessons from Sabre, Inc. The Academy of Management Executive, Vol. 16: 67-79.

Kirkman, B. L., and Shapiro, D. L. (2001). The Impact of Cultural Values on Job Satisfaction and Organizational Commitment in Self-Managing Work Teams: The Mediating Role of Employee Resistance. Academy of Management Journal, Vol. 44, No. 3: 557-569.

Kluckkohn, C. (1951). Values and Value-Orientation in the Theory of Action: An Exploration in Definition and Classification. In Toward a General Theory of Action, ed. T. Parsons and E. Shils: 388-433. Cambridge: Harvard University Press.

Kotter, J. P., and Heskett, J. L. (1992). Corporate culture and performance. The Free Press: A Division of Macmillan, Inc., New York.

Kozlowski, S.W.J., and Klein, K.J. (2000). A multilevel approach to theory and research in organizations: Contextual, temporal and emergent processes. In K.J. Klein \& S.W.J.

Kozlowski (Eds.). Multilevel theory, research, and methods in organizations. San Francisco: Jossey-Bass.

Kyriakopoulos, K., and Moorman, C. (2004). Tradeoffs in marketing exploitation and exploration strategies: The overlooked role of market orientation. International Journal of Research in Marketing, Vol. 21, No. 3: 219-240.

Lagerstroem, K., and Andersson, M. (2003). Creating and sharing knowledge within a transnational team - the development of a global business system. Journal of World Business, Vol. 38: 84-95.

Lamnek, S. (1995). Qualitative Sozialforschung. Band 1: Methodologie. München, Psychologie Verlags Union.

Lansisalmi, H., Peiro, J.M., and Kivimaki, M. (2004). Grounded theory in organisational research, in Cassell, C., and Symon, G. (ed.), Essential Guide to qualitative methods in organizational research. Sage. 
Lansisalmi, H., Peiro, J.M., and Kivimaki, M. (2000). Collective stress and coping in the context of organisational culture. European Journal of work and Organizational Psychology, Vol. 9: 527-59.

Larkey, K.L. (1996). Toward a Theory of Communicative Interactions in Culturally Diverse Workgroups. Academy of Management Review, Vol. 21, No. 2: 463-491.

Lau, D. C., and Murnighan, J. K. (1998). Demographic diversity and faultlines: The compositional dynamics of organizational groups. Academy of Management Review, Vol. 23: 325-340.

Leung, K., and Bond, M. (1984). The impact of cultural collectivism on reward allocation. Journal of Personality and Social Psychology, Vol. 47: 793-804.

Lincoln, J.R., Hanada, Mr.R., and Olson, J. (1981). Cultural orientation and individual reactions to organizations: a study of employees of Japanese armed forces, Administrative Science Quarterly, Vol. 26: 93-115.

Locke, K. (2001). Grounded theory in management research. Sage

Lowe, A. (1995). Small hotel survival, in B. Glaser (ed.), Grounded theory 19841994, Mill Valley, CA: Sociology Press.

Lunnan, R., Lervik, J.E.B., Traavik, L.E.M., Nilsen, S.M., Amdam, R.P.. and Hennestad, B.W. (2005). Cultural Counterpoints, Global transfer of management practices across nations and MNC subcultures. The Academy of Management Executive, Vol. 19, No. 2: 77-80.

Lunnan, R., and Barth, T. (2003). Managing the exploration versus exploitation dilemma in transnational "bridging teams". Journal of World Business, Vol. 38: $110-126$.

Mannix E.A., Thatcher S., and Jehn K.A. (2001). Does culture always flow downstream? Linking group consensus and organizational culture. In Cooper C.L., Cartwright S. \& Earley P.C. (Eds.), The International handbook of organizational culture and climate. John Wiley \& Sons, Ltd.

Matveev, A. V., and Nelson, P. E. (2004). Cross cultural communication competence and multicultural team performance: Perceptions of Americans and Russian Managers. International Journal of Cross Cultural Management, Vol. 4, No. 2: 253-270. 
Matveev, A.V. (2002) The Perception of Intercultural Communication Competence by American and Russian Managers with Experience on Multicultural Teams. Dissertation, Ohio University. Ann Arbor, MI: UMI Dissertation Services.

Matveev, A.V., Rao, N., and Milter, R.G. (2001). Developing a scale to measure intercultural communication competence: A Pilot Study in Multicultural Organizations, paper submitted to the International and Intercultural Communication Division of the National Communication Association, Atlanta, November.

May, R.C., Puffer, S.M., and McCarthy, D.J. (2005). Transferring management knowledge to Russia: A culturally based approach, The Academy of Management Executive, Vol. 19, No. 2: 24-35.

Mayring, P. (2002). Qualitative Sozialforschung. Weinheim \& Basel: Beltz Verlag.

Mayring P. (2000). Qualitative Content Analysis. Forum: Qualitative Social Research. Vol. 1, No. 2.

Mayring, P. (1999). Einführung in die qualitative Sozialforschung: Eine Anleitung zu qualitativem Denken. Weinheim, Basel.

Maxwell, J.A. (1997). Designing a qualitative study. in Bickman, L., and Rog, D.J. (Eds), Handbook of Applied Social Research Methods. Sage Publications, London, 69-100.

Maznevski M.L., and Chudoba K.M. (2000). Bridging space over time: Global virtual team dynamics and effectiveness. Organization Science, Vol. 11, No. 5: 473-492.

Maznevski, M., and DiStefano, J. (2000). Global leaders are team players: Developing global leaders through membership on global teams. Human Resource Management, Vol. 39, No. 3: 195-208.

McCrae, R. R., and Costa, P. T. Jr. (1997). Personality trait structure as a human universal. American Psychologist, Vol. 52: 509-516.

McGrath, J.E., Berdahl, J.L., and Arrow, H. (1995). Traits, expectations, culture, and clout: the dynamics of diversity in work groups. In S. Jackson and M. Ruderman (eds.), Diversity in work teams: Research paradigms for a changing workplace, 17-45. Washington, DC: American Psychological Association. 
McGrath, J.E. (1991). Time, interaction, and performance (TIP): a theory of groups. Small Group Research, Vol. 22, No. 2: 147-174.

McPherson, M., Smith-Lovin, L., and Cook, K.M. (2001). Birds of a feather: Homophily in social networks. In K.S. cook and J. Hagan (Eds.). Annual Review of Sociology, Vol. 27: 415-444. Palo Alto, CA: Annual Review.

McSweeney, B. (2002). Hofstede's model of national cultural differences and their consequences: A triumph of faith - A failure of analysis. Human Relations, Vol. 55, No. 1: 89-118.

Mellahi, K., and Guermat, C. (2004). Does age matter? An empirical examination of the effect of age on managerial values and practices in India. Journal of World Business, Vol. 39: 199-215.

Mendez, A. (2003). The coordination of globalized R\&D activities through project teams organization: an exploratory empirical study. Journal of World Business, Vol. 38: 96-109.

Miles, M.B. (1979). Qualitative data as an attractive nuisance: the problem of analysis. Administrative Science Quarterly, Vol. 24, No. 4: 590-601.

Millar, J. G. (1984). Culture and the development of everyday social explanation. Journal of Personality and Social Psychology, Vol. 46: 961-078.

Mruck, K., and Mey, G. (2000). Qualitative Sozialforschung in Deutschland. Forum Qualitative Sozialforschung/ Forum: Qualitative Social Research (Online Journal), Nr. 1/2000. Verfügbar über: http://qualitative-research.net.: Paragraph 30.

Nadler D.A., and Tushman M. (1988). Strategic Organizational Design: Concepts, Tools, and Processes. Glenview, IL: Scott Foresman.

Napier, N. K. (2005). Knowledge transfer in Vietnam: starts, stops, and loops. Journal of Managerial Psychology, Vol. 20, No. 7: 621-636.

National Association of Manufacturers (1998). The Skills Gap: The shortage of qualified workers. Washington D.C: Department of Labour.

Negandhi, A.R.T. (1973). Modern organizational behaviour. Ohio: Kent University Press. 
Neumann, G.A., Wagner, S.H. and Christiansen, N.D. (1999). The relationship between work-team personality composition and the job performance of teams. Group and Organisational Management, Vol. 24, No. 1: 28-45.

Neyer, A. K. (2004). Multinational Teams in the European Commission and the European Parliament. Unpublished Dissertation at the Vienna University of Economics and Business Administration.

Nonaka, I., and Takeuchi, H. (1995). The knowledge-creating company, how Japanese companies create the dynamics of innovation. New York, Oxford: Oxford University Press.

Ongwuegbuzie, A.J. (2003). Effect Sizes in Qualitative Research: A Prolegomenon. Quality and Quantity, Vol. 37: 393-409.

O'Reilly C.A., and Chatman J. (1996). Culture as social control: corporations, cults, and commitment. In Staw B.M. and Cummings L.L. (Eds.). Research in Organizational Behaviour, Vol. 18: 157-200. Greenwich, CT: JAI Press.

O'Toole, J. (1993). The executive's compass: Business and the good society. New York: Oxford University Press.

Paranjpe, A. C. (1998). Self and identity in modern psychology and Indian thought. New York: Plennum Press.

Patton, M.Q. (1997). Utilization-focused evaluation: the new century text. Thousand Oaks, CA.

Pauleen, D. (2003). An Inductively Derived Model of Leader-Initiated Relationship Building with Virtual Team Members. Journal of Management Information Systems, Vol. 20, No. 3.

Peters T.J., and Waterman R.H. (1982). Search of excellence. London: Harper and Row.

Pfeffer, J. (1991). Organizational theory and structural perspectives on management. Journal of Management, Vol. 17: 789-803.

Pichler, R. J. (2003). The Impact of Culture on Leadership and Communication: Comparing Austrian and US American Corporate Leadership. Unpublished Dissertation at the Vienna University of Economics and Business Administration. 
Randal, A. E. (2002). Identity salience: A moderator of the relationship between group gender composition and work group conflict. Journal of Organizational behaviour, Vol. 23: 749-766.

Repitz, B. (2006). Multinationale Teams im unternehmerischen Kontext: Eine empirische Analyse der Teamprozesse in zwei Unternehmen der Hightechindustrie. Unpublished Master Thesis at the Vienna University of Economics and Business Administration.

Richard, O. C. (2000). Racial diversity, business strategy, and firm performance: A resource-based view. Academy of Management Journal, Vol. 43: 164-177.

Roberson Q. M., and Colquitt J. A. (2005). Shared and configural justice: a social network model of justice in teams. Academy of Management Review, Vol. 30, No. 3: 595-607.

Roland, A. (1988). In search of self in India and Japan: Towards a cross-cultural psychology. Princeton, NJ: Princeton University Press.

Rubesch, A. (in press). Multinational Teams: Empirical Evidence from Siemens and Pöyry. Unpublished Master Thesis at the Vienna University of Economics and Business Administration.

Saavedra, R., Earley, P. C., and Van Dyne, L. (1993). Complex interdependence in task-performing groups. Journal of Applied Psychology, Vol. 78: 61-72.

Saha, A. (1993). The cast system in India and its consequences. International Journal of Sociology and Social Policy, Vol. 13: 1-76.

Sahay, S., and Walsham, G. (1997). Social structure and managerial agency in India. Organization Studies, Vol. 18, No. 3: 415-444.

Schein, E.H. (1985). Organizational culture and leadership. San Francisco, CA: Jossey-Bass.

Schlegelmilch, B.B., and Ambos, B. (2004). The use of international R\&D teams: An empirical investigation of selected contingency factors. Journal of World Business, Vol. 39: 37-48.

Schneider, B. (1987). The people make the place. Personnel Psychology, Vol. 40: 437-453. 
Schoonhoven, C.B., and Woolley, J.L. (2005). Top management team in an international context: an assessment and review; In Shapiro, D. L. (2005). Managing Multinational Teams: Global Perspectives. Amsterdam: Elsevier.

Schweiger, D. M., Atamer, T., and Calori, R. (2003). Transnational project teams and networks: making the multinational organization more effective. Journal of World Business, Vol. 38: 127-140.

Schwer, S. (2004). Salsa Cultures. Unpublished Master Thesis at the Vienna University of Economics and Business Administration

Scott. W.R., and Meyer, J.W. (1994). Institutional Environments and Organizations: Structural Complexity and Individualism. Thousand Oaks, CA: Sage.

Shen-Wei Hwong (2001). Kulturstandardvergleich zwischen Österreichern und Chinesen. In Fink, G. and Meierewert, S (Edt.) Interkulturelles Management: Österreichische Perspektive, Springer Verlag, Wien.

Snow, C.C., Snell, S.A., Canney Davison, S., and Hambrick, D.C. (1996). Use transnational teams to globalize your company. Organizational Dynamics, Vol. 24, No. 4.

Sinha, J. B. P., Sinha, T. N., Verma, J., and Sinha, R. B. N. (2001). Collectivism coexisting with individualism: an Indian scenario. Asian Journal of Social Psychology, Vol. 4: 133-145.

Sinha, J.B.P., and Kanungo, R.N. (1997). Context sensitivity and balancing in Indian organizational behaviour. International Journal of Psychology, Vol. 32: 93-105.

Sinha, J.B.P., and Sinha, D. (1990). Role of social values in Indian organizations. International Journal of Psychology, Vol. 25: 705-714.

Sinha, J. B. P. (1990a). Work culture in an Indian context. New Delhi: Sage.

Sinha, J.B.P. (1990b). A model of effective leadership styles in India. In A.M. Jaeger \& K.N. Kanungo (Eds.), Management in developing countries, 252-263. New York. Routledge.

Sinha, J.B.P. (1980). The nurturant task leader. New Delhi: Concept. 
Smith, P.B., Dugan, S., and Trompenaars, F. (1996). National culture and the values of organisational employees. A dimensional analysis across 43 nations. Journal of Cross-Cultural Psychology, Vol. 27: 231-264.

Spiess, E. (1998). Das konzept der empathie, in E. Spiess (ed.). Formen der cooperation: Bedingungen und perspektiven. Göttingen: Hofrefe.

Spiess, E. (1996). Kooperatives Handeln in Organisationen. Münich: Peter Hampp.

Stalk, G., Jr., and Hout, T.M. (1990). Competing against time: How time-based competition is reshaping global markets. New York: The Free Press.

Stern, E. (1997). Crisis and learning: a conceptual balance sheet. Journal of Contingencies and Crisis Management. Vol. 5, No. 2: 69-86.

Stewart, E. (1972). American cultural patterns: A cross-cultural perspective. Pittsburgh, PA: Intercultural Communications Network.

Strauss, A.L., and Corbin, J.M. (1998a). Basics of Qualitative Research: Grounded Theory Procedures and Techniques, Sage Publications, Thousand Oaks, CA.

Strauss, A.L., and Corbin, J.M. (1998b), Basics of Qualitative Research: Techniques and Procedures for Developing Ground Theory, $2^{\text {nd }}$ ed., Sage Publications, Thousand Oaks, CA.

Suutari, V., and Riusala, K. (1998). Leadership behaviour in Eastern Europe: Finish expatriates' experiences in Russia and Estonia. The international Journal of Human Resource Management. Vol. 9: 235-258.

Sutton R.I., and Hargadon A. (1996). Brainstorming groups in context: effectiveness in a product design firm. Administrative Science Quarterly, Vol. 41, No. 4: 685-718.

Szabo, E., Brodbeck, F. C., Hartog, D. N. D., Reber, G., Weibler, J., and Wunderer, R. (2002). The Germanic Europe cluster: where employees have a voice. Journal of World Business, Vol. 37: 55-68.

Tajfel, H., and Turner, J.C. (1979). An integrative theory of intergroup conflict. In W.G. Austin and S. Worchel (Eds.), The social psychology of intergroup relations, 33-47. Montery, CA: Brooks/Cole. 
Thomas, A.(1993). Kulturvergleichende Psychologie: Eine Einführung, Hofgrefe Verlag für Psychologie, Göttingen, Bern, Toronto, Seattle.

Thomas, D.C., and Inkson, K. (2004). Cultural intelligence: People skills for global business. San Francisco, CA: Berrett-Koehler.

Thomas, D.C. (1999). Cultural diversity and work group effectiveness. Journal of Cross-cultural Psychology, Vol. 30, No. 2.

Thompson, J.D. (1967). Organizations in action. New York: McGraw-Hill.

Triandis, H.C. (1995). Individualismand collectivism. Bolder, CO: Westview.

Triandis, H.C. (1994). Culture and Social Behaviour. McGraw-Hill, New York.

Trompenaars, F., and Hampden-Turner, C. (1998). Riding the Waves of Culture: Understanding Cultural Diversity in Busines, $2^{\text {nd }}$ ed., New York: McGraw-Hill.

Trompenaars, F. (1993). Riding the waves of culture: understanding culture diversity in business. London: Nicolas Brealey Publishing.

Turner, J.C., Oakes, P.J., Haslam, S.A., and McGarthy, C. (1994). Self and collective: Cognition and social context. Personality and Social Psychology Bulletin, Vol. 20: 454-463.

Ulrich, D., Hausser, K., Mayring, Ph., Strehmel, P, Kandler, M., and Degenhardt, B. (1995). Psychologie der Krisenbewältigung. Eine Längsschnittuntersuchung mit arbeitslosen Lehrern. Weinheim: Belz.

Vallaster C. (2005). Cultural diversity and its impact on social interactive processes: Implications from an empirical study. International Journal of CrossCultural Management, Vol. 5, No. 2: 139-163.

Valtingojer, T. (2001). Internationales Management im Schnittpunkt zw. Kulturen: Italien und Österreich. In Fink, G. and Meierewert, S (Edt.) Interkulturelles Management: Österreichische Perspektive, Springer Verlag, Wien.

Van Der Vegt G. S., Van De Vliert, E., and Osterhof A. (2005) Informational dissimilarity and organizational citizenship behaviour: The role of intrateam interdependence and team identification. Academy of Management Journal, Vol. 46, No. 6: 715-727. 
Van Der Vegt, G.S., and Bunderson, J.S. (2005). Learning and performance in multidisciplinary teams: The importance of collective team identification. Academy of Management Journal, Vol. 48, No. 3: 532-547.

Van Der Vegt, G. S., Van Der Vliert, E., and Oosterhof, A. (2003). Informational Dissimilarity and Organizational Citizenship Behavior: The Role of Intrateam Interdependence and Team Identification. Academy of Management Journal, Vol. 46, No. 6: 715-727.

Van Der Vegt, G. S., Emans, B. J. M., and Van Der Vliert, E. (2001). Patterns of interdependence in work teams: A two-level investigation of the relations with job and team satisfaction. Personal Psychology, Vol. 17, No. 1: 50-68.

VA TECH (2007a):

http://ar2004.vatech.at/ereport.asp?fCompanyID=7\&fAction=SHOWREPORT\&f LangID=1\&freportid=78\&fpageid=1891 last access $31^{\text {st }}$ January, 2007.

VA TECH (2007b):

http://ar2004.vatech.at/ereport.asp?fCompanyID=7\&fAction=SHOWREPORT\&f LangID=1\&freportid=78\&fpageid=2178 last access $31^{\text {st }}$ of January, 2007.

Verma, J., and Triandis, H.C. (1998). The measurement of collectivism in India. Paper presented at the meeting of International Association of Cross Cultural Psychology, Bellingham, WA, August.

Wagner, S. (2004). Grounded theory in human resource management studies: A literature analysis of grounded theory methodology in human resource management studies and the conformity of implementation and methodology. Unpublished Master's Thesis at the Vienna University of Economics and Business Administration.

Wagner, J.A. (1995). Studies of individualism-collectivism: effects on cooperation in-groups. Academy of Management Journal, Vol. 38: 152-172.

Wang, C., Bochner, St., and Furnham, A. (2001). The psychology of the culture shock. Hove UK.

Watson, W.E., Johnson, L., and Merritt, D. (1998). Team orientation, selforientation and diversity in task groups: their connection to team performance over time. Group and Organizational Management, Vol. 23: 161-189. 
Watson, W.E., Kumar, K., and Michaelsen, L.K. (1993). Cultural diversity's impact on interaction process and performance: Comparing homogeneous and diverse task groups, Academy of Management, Vol. 36, No. 3: 590-602.

Weinstein, M., and Thomas, K. (1995). The limits of diffusion: recent developments in industrial relations and human resource practices in the United States. In Employment Relations in a Changing World Economy. Ed. Richard Locke, Thomas Kochan, and Michael Piore, Cambridge Massachusetts: MIT Press.

West, M.A. (2002). Sparkling fountains or stagnant ponds: An integrative model of creativity and innovative implementation in work groups. Applied Psychology: An International Review, Vol. 51: 355-424.

Wiedemann, P. M. (1986). Erzählte Wirklichkeit: Zur Theorie und Auswertung narrativer Interviews. Weinheim, Basel.

Williams, K. Y., and O'Reilly, C. A. (1998). Demography and diversity in organizations: A review of 40 years of research. In B. M. Staw, and L. L. Cummings (Eds.). Research in Organizational Behaviour, Vol. 20: 77-140. Greenwich, CT: JAI Press.

Yakovlev, A., and Kokorev, R. (1995). State wholesale firms in Russia amid economic reform. International Studies of Management and Organisation, Vol. 25: 59-76.

Yin, R. (1994). Case Study Research: Design and Methods. $2^{\text {nd }}$ ed., Thousand Oaks, CA: Sage.

Yin, R. (1993). Case Study Research: Design and Methods. Beverly Hills, CA: Sage.

Yoo, Y., and Alavi, M. (2004). Emergent leadership in virtual teams: What do emergent leaders do? Information and Organization, Vol. 14: 27-58.

Zaccaro, S. J., Rittman, A. L., and Marks, M. A. (2001). Team Leadership. The Leadership Quarterly, Vol. 12: 451-483. 


\section{Forschungsergebnisse der Wirtschaftsuniversität Wien}

Herausgeber: Wirtschaftsuniversität Wien vertreten durch a.o. Univ. Prof. Dr. Barbara Sporn

Band 1 Stefan Felder: Frequenzallokation in der Telekommunikation. Ökonomische Analyse der Vergabe von Frequenzen unter besonderer Berücksichtigung der UMTS-Auktionen. 2004.

Band 2 Thomas Haller: Marketing im liberalisierten Strommarkt. Kommunikation und Produktplanung im Privatkundenmarkt. 2005.

Band 3 Alexander Stremitzer: Agency Theory: Methodology, Analysis. A Structured Approach to Writing Contracts. 2005.

Band 4 Günther Sedlacek: Analyse der Studiendauer und des Studienabbruch-Risikos. Unter Verwendung der statistischen Methoden der Ereignisanalyse. 2004.

Band 5 Monika Knassmüller: Unternehmensleitbilder im Vergleich. Sinn- und Bedeutungsrahmen deutschsprachiger Unternehmensleitbilder - Versuch einer empirischen (Re-)Konstruktion. 2005.

Band 6 Matthias Fink: Erfolgsfaktor Selbstverpflichtung bei vertrauensbasierten Kooperationen. Mit einem empirischen Befund. 2005.

Band 7 Michael Gerhard Kraft: Ökonomie zwischen Wissenschaft und Ethik. Eine dogmenhistorische Untersuchung von Léon M.E. Walras bis Milton Friedman. 2005.

Band 8 Ingrid Zechmeister: Mental Health Care Financing in the Process of Change. Challenges and Approaches for Austria. 2005.

Band 9 Sarah Meisenberger: Strukturierte Organisationen und Wissen. 2005.

Band 10 Anne-Katrin Neyer: Multinational teams in the European Commission and the European Parliament. 2005.

Band 11 Birgit Trukeschitz: Im Dienst Sozialer Dienste. Ökonomische Analyse der Beschäftigung in sozialen Dienstleistungseinrichtungen des Nonprofit Sektors. 2006

Band 12 Marcus Kölling: Interkulturelles Wissensmanagement. Deutschland Ost und West. 2006.

Band 13 Ulirich Berger: The Economics of Two-way Interconnection. 2006.

Band 14 Susanne Guth: Interoperability of DRM Systems. Exchanging and Processing XML-based Rights Expressions. 2006.

Band 15 Bernhard Klement: Ökonomische Kriterien und Anreizmechanismen für eine effiziente Förderung von industrieller Forschung und Innovation. Mit einer empirischen Quantifizierung der Hebeleffekte von F\&E-Förderinstrumenten in Österreich. 2006.

Band 16 Markus Imgrund: Wege aus der Insolvenz. Eine Analyse der Fortführung und Sanierung insolventer Klein- und Mittelbetriebe unter besonderer Berücksichtigung des Konfigurationsansatzes. 2007.

Band 17 Nicolas Knotzer: Product Recommendations in E-Commerce Retailing Applications. 2008.

Band 18 Astrid Dickinger: Perceived Quality of Mobile Services. A Segment-Specific Analysis. 2007.

Band 19 Nadine Wiedermann-Ondrej: Hybride Finanzierungsinstrumente in der nationalen und internationalen Besteuerung der USA. 2008.

Band 20 Helmut Sorger: Entscheidungsorientiertes Risikomanagement in der Industrieunternehmung. 2008.

Band 21 Martin Rietsch: Messung und Analyse des ökonomischen Wechselkursrisikos aus Unternehmenssicht: Ein stochastischer Simulationsansatz. 2008. 
Band 22 Hans Christian Mantler: Makroökonomische Effizienz des Finanzsektors. Herleitung eines theoretischen Modells und Schätzung der Wachstumsimplikationen für die Marktwirtschaften und Transformationsökonomien Europas. 2008.

Band 23 Youri Tacoun: La théorie de la valeur de Christian von Ehrenfels. 2008.

Band 24 Monika Koller: Longitudinale Betrachtung der Kognitiven Dissonanz. Eine Tagebuchstudie zur Reiseentscheidung. 2008.

Band 25 Marcus Scheiblecker: The Austrian Business Cycle in the European Context. 2008.

Band 26 Aida Numic: Multinational Teams in European and American Companies. 2008.

Band 27 Ulrike Bauernfeind: User Satisfaction with Personalised Internet Applications. 2008.

Band 28 Reinhold Schodl: Systematische Analyse und Bewertung komplexer Supply Chain Prozesse bei dynamischer Festlegung des Auftragsentkopplungspunkts. 2008.

www.peterlang.de 